\title{
BASILIO CALDERÓN CALDERÓN
}

\section{El valle de Campóo \\ Estudio geográfico}

Tesis doctoral realizada bajo la dirección del Dr. D. Jesús García Fernández, Catedrático de Geografía de la Universidad de Valladolid

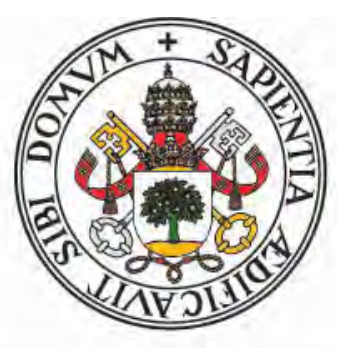

\section{Universidad deValladolid}

Facultad de Filosofía y Letras. Departamento de Geografía Año 1982 
B A S I I I O C A I D E R O N C A L D I R $O N$

EL VALLE DE C C I O : : R I C O

Tesis doctoral realizada bajo la dirección del Dr. D. JESUS GARCIA FERNANDEZ, Catedrático de Geografla de la Universidad de Valladolid.

Facultad de Filosofla y Ietras

Universidad de Valladolid

1982. 
INDICE GENERAL

Página

INTRODUCCION

I PARTE. - LAS CONDICIONES ECOLJOGICAS DEI, VALLE DE CAMPOO

CAPITULO I\& LA ESTRUCTURA MORFOLOGICA

1.- Un sector de la cuenca tríásica cantábrica..

2.- El sinclinal de Abiada: una estructura compleja

3.- La Intensa tectónica de fractura del sector oriental: Campoo de Enmedio y Yuso ..........

4.- El modelado glaciar: un mero retoque ........

5.- Un relieve de montana caracteristico .......

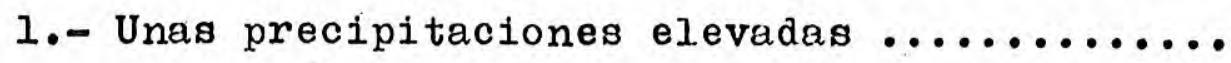

a) Importancia y significado de las precipi-

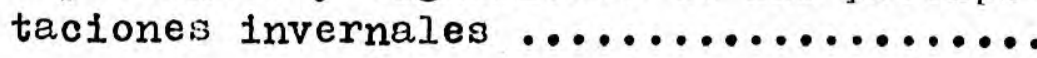

b/ El declive estival de las precipitaciones:

un fenómeno de enorme significado, en par te atenuado por las precipitaciones secun

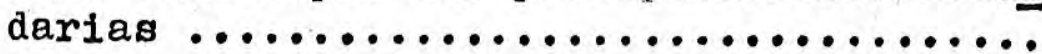

c/ La presencia y regularidad de la nieve en

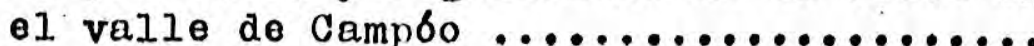

2. Un régimen térmico de montaña

a/ Un invierno frlo y de larga duración ....

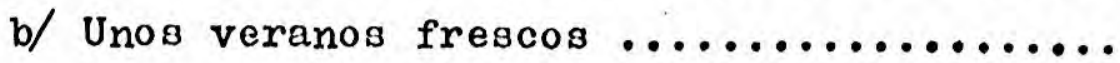

CAPITULO III. - UN PAISAJE VEGETAI, FROFUNUAMENTE TRANSFORMADO.

1.- El carácter residual de las masas foresto,les

2.- El predominio de las formaciones subseriales: un resultado de la práctica destrucción de la climax arborea 
Página

II PARTE. - LA ORGANIZACION TRADICIONAI DEL ESTACIO:

SOCIEDAD Y ECONOMIA DE UN VALLEE DE MON'TANA ......

CAPITULO IV. - UNA ECONOMIA DE SUBSISTENCIA $\ldots \ldots \ldots \ldots \ldots$

1.- La dualidad en el aprovechamiento del espa-

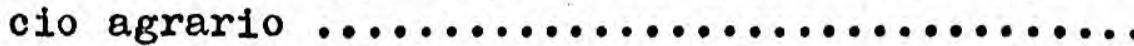

2.- La organización colectiva del terrazgo: una respuesta a las insuficiencia estructurales del valje de Campó

3.- El predominio de las tierras de pan llevar: un aprovechamiento del potencinl ecológico de cara al autoabastecimiento ...............

a/ Unas técnicas y sistemas de cultivo adap tados al medio, pero inadecuados ........ 87

b/ La debilidad e irregularidad de los rendimientos: una constante en la actividad agraria tradicional ................. 93

c/ El carácter subsidiario de los prados .... 97

4.- El aprovechamiento del monte: una actividad complementaria, sometida a numerosas res-

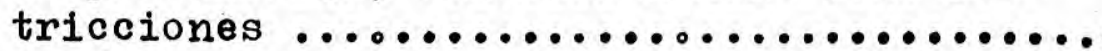

a/ El artesanado de la madera: una actividad tradicional destinada al intercambio .............................. 100

b/ los obstáculos a la explotación del monte

CAPITULO V.- UNA ECONOMIA AGRARIA BASADA EN LA EXIILUTACION GANADERA EXTEN'SIVA

1.- La complejidad de la composición y significado de la explotación ganadera .......... 107

2.- El predominto de sistemas extensivos para el aprovechamionto de los pastos ........... 1.14

a/ Las comunidades de pastos: el aprovecha miento extensivo de los pastos de monta ña

CAPITULO VI. - ILA BUSQUEDA DE UN COMYLEMENTO A INS BAJUS RENDIMIEN'TOS AGRICOIJAS

1.- El carácter tradicional del intercambio con el interior del pals 
Página

2. - El desarrollo de la carretería en el siglo XVIII: una actividad de marcado carácter estacional

a/ La construcción de la carretera de Reino sa: el ocaso del aislamiento tradicional del valle de Campoo

b/ E1 auge de la industria harinera en Reinosa: una consecuencia del tráfico de trigo con destino al puerto de Santander..

CAPITULO VII. - LOS OBSTACULOS Y CONDICIONANTES EN TAA ORGANIZACION TRADICIONAL DEL ESPACIO .......... 140

1.- Una población exigua en un regimen demográfico tradicional.

a/ Ell recurso a ja emigración: una constante en la evolución demográfioa de la comarca

2.- Una sociedad campesina de pequeños propietarios: el escaso significado de la gran propiedad tradicional

CAPITULO VIII.- LA ECONOMIA RURAL TRADICIONAL

1.- Una economía generadora de escasas rentas: la miseria de gran parte de la población campesina

2.- La entidad y significado de las rentas no agrarias

III PARTE.- CAMBIOS Y I ERMANINCIAS EN LA SOCIEDAD Y ECONOMIA TRADICIONALES

CAF ITULO IX. - LA PROGRESIVA TRANSFORMACION DE JAS EITTRUCTURAS AGRARIAS TRADICIONALES: UN , ROCL'SO LEN'LO Y PLAGADO DE DIFICULTADES

1.- Una estructura agraria heredada: el escaso impacto del proceso desamortizador ..........

a/ Los resultados del proceso desamortizador: una estructura de la propiedad inalterada.

b/ La pervivencia del carácter comunal en el aprovechamiento del monte.

2. - La construcción del ferrocarril Alar-Santan der: la crisis de los sistemas de transporte tradicionales. 
rágina.

3.- De una economía autárquica a una economía de intercambio: la progresiva consolidación de la opción ganadere ............... 174

CAPITULO X.- LAS IIFICUJTADES PRESENTES EN El, MUMI'NTO

DEL CAMBIO.

1.- El lastre del pasado: una estructura de la

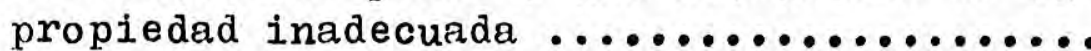

2.- La construcción del limbalse del Ebro: In dislocación de las estructuras tradiciona-

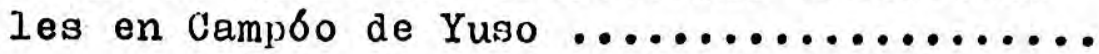

CAFITUL,O XI.- EL CONTRAYUNTO A J,OS :SI.SLEMAS DE VIDA TRA DICIONALES: INS IRIMLROS' INTENIUS INUU,TIRIAJIZA

DORE, DEJ, VAJLE DES CAMPOO ..............

1.- El carácter tradicional. de las primereis industrias de Campbo ...................... 190

2. - El nacimiento de 1a industria moderna: La Sociedad Española de Construcción Naval ....

193

CAPITULO XII.- IA IRREGULAR EVJIUCION DEMUGRAFICA DE

CAMPOO: UI LENTO CRECIMIENTY DE LA JOBLACIUN PU

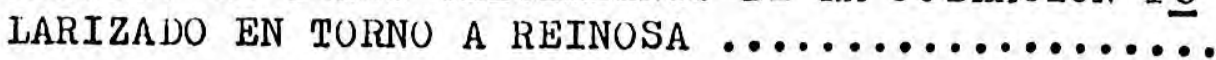

1.- Una población en irregular y débil, pero conatante crecimiento ............... 201

a/ La contención del bxodo rural y el estun camiento de la poblaclón en el últim. tếr clo del siglo XIX .................. 201

b/ De una población estancada a una pobla ciśn en crecimiento: un resultado de la expansion economica de lieinosa ......... 203

c/ Ia vuelta al estancamiento: un fenómeno reciente, de significado contradictorio... 205

2.- Una dinámica demográfica irregular presidida por el éxodo rural.

a/ La desigual trayectoria de la natalidad y mortalidad hacia la consecución de un bajo crecimiento vegetativo

b/ El éxodo rural: una constante en la evolu ción demográfica de la comarca ......... 213 
3.- Un tipo de envejeoimiento complefos dimensiones y contrastes espaciales............

4.- La despoblacion: una consecuencia de la concentración en el núcleo de Reinosa........

TRANSFORMACION

1.- Una estructura de la propiedad arcaica básico en la sociedad rural ..............

b/ La gran propiedad colectiva: el contra punto a la exigüedad y fragmentacion de la pequeña propiedad

2. - Los cambios en el tamaño y estructura de las explotaciones: un proceso complejo ......

3.- Un e jemplo de transformación planificada: Ia conoentración parcelaria en Campóo de Yuso

CAPITULO XIV . - LA PROGRESICA CONSOLIDACIUN DE LA OPCION GANADERA: UN YROCE.JO RECIENTE

1.- El carácter marginal del espacio cultiva do

2.- Hacia una simplificación en la estructura de la explotación ganadera.

264

a) El retroceso de la ganadería extensiva.... 265

b/ La ambivalencia del rebaño campurriano: ganado de leche y de aptitud mixta .......

c/ Bl carácter subsidiario del ganado equino y menor

3.- Ja mecanizacion: una constante en la nueva.

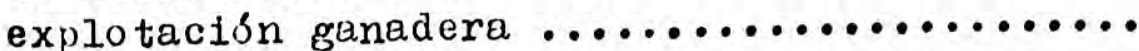

4. - Una actividad en retroceso: el aprovechamiento del monte

CAPITULO XV.- LA RECIENTE EXIPANSION DE REINUSA: UN PEQUEÑO NUCLEO INDUSTRIAL, CENTRO COMARCAL

1.- La preeminencia de la industria siderúrgica: una actividad con escaso efecto multiplicador 
2. Ia consolidación de Reinosa como centro

légina

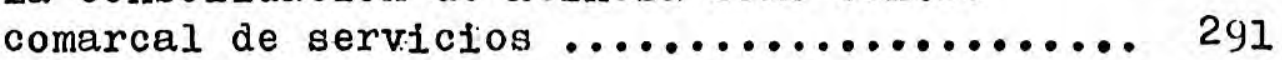

3.- La intensidad de las recientes transfor maciones en el núcleo urbano de Reinosa

CAPITULO XVI.- SIGNIFICADO DE LOS CAMBIOS RECIENTES EN LA ECONOMIA Y ORGANIZACION DEL ENPACIO .........

1.- El resultado de las recientes transforma ciones: un nuevo paisaje agrarto ......... 302

a/ El Impacto de Reinosa: el desarrollo de una agricultura a tiempo parcial ..... 303

b/ Ia explotación ganadera moderna: una inacabada especialización en la produccion de leche.....................

c/ Un paiaje agrario nuevo y totalmente subordinado a la explotación ganadera

2. - La escasa renovación del poblamiento tra dicional: un mero retoque a una estructura heredada.........................

a/ Un poblamiento concentrado, constituido por pequeñas unidades agrupadas en

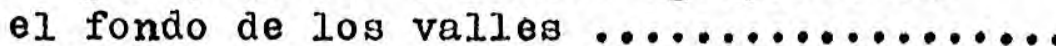

b/ un tipo de vivienda esencialmente funcional: la casa-bloque de piedra ....... 319

3.- Hacia la consecución de un nivel de vida más elevado........................

CONCLUSIONES

FUENTES $\times$ BIBLIOGRAFIA......................... 334

INDICES...................................... 349

-Indice de cuadros...................... 350

-Indice de figuras ...................... 353

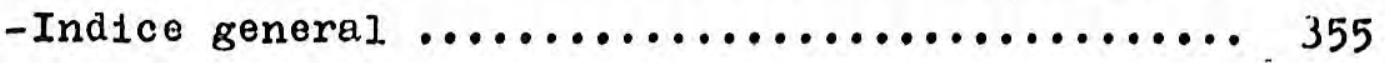


INTRODUCCION

Si diffcil resulta, por lo general, precisar los limites de un espacio concreto, más lo es, al menos "a priori", en es te caso en el que tal espacio ha seguido una desigual trayectoria administrativa, en la que no obstante no se han logrado desdibujar sus rasgos bésicos, adquiridos en un dilatado y co tidiano quehacer sobre 61 ; y es que, y no vamos a abundar en este aspecto, la realidad administrativa se aviene mal, frecuentemente con la realidad geográfica, con la realidad espacial en suma.

Con idéntica dificultad se tropieza llegados al punto de englobar, bajo una denominación espectfica el espacio que se trata de singularizar, o mejor que, pese a todo, se ha man tenido singular en el tiempo. Frecuentemente un mismo topónimo abarca espacios que, aunque próximos, son dispares en lo esen cial, tanto desde el punto de vista flsico como humano.

Precisamente el sector objeto de este estudio reune en apariencia todas estas dificultades; la realidad es muy otra, porque por encima de cualquier denominación historica, y sobre los complejos problemas que dieron lugar a una dependencia administrativa cambiante se encuentra la indudable realidad de su individualidad como espacio montafés dentro de la vertiente meridional de la Cordillera Cantébrica. Y es precianmente este atributo el que ha impuesto, en una dilatada tra yectoria historica formas de aprovechar $y$ aun de ocupar f1sicamentie el espacio, homogeneas, constantes en el tiempo y acordes con unas condictones naturales que se presentan con 


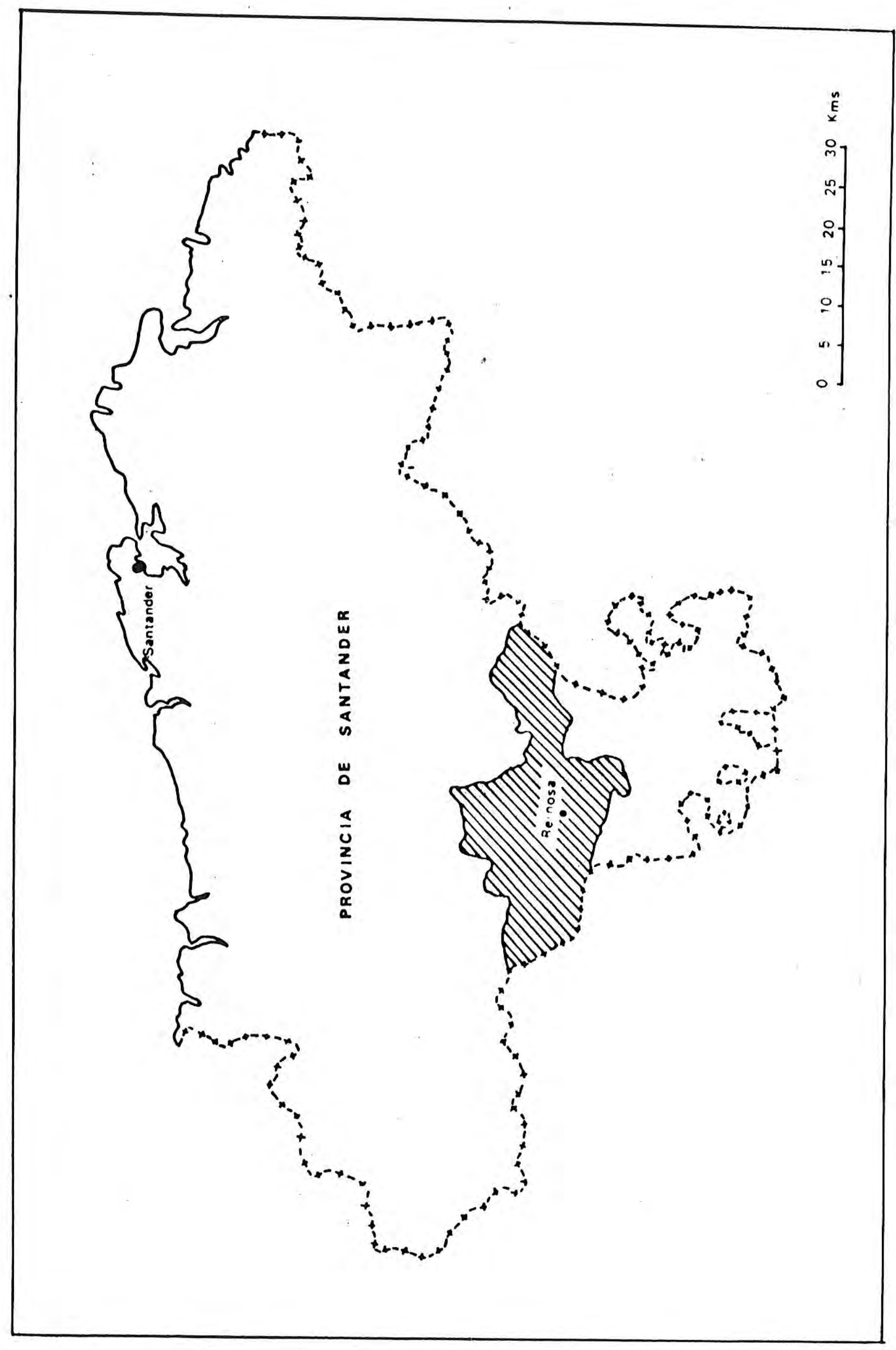

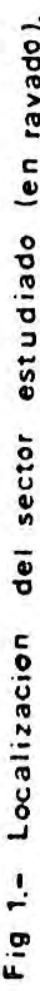


caracteres singulares, especfficos.

Cierto es, por otra parte, que este espacio se encuentra en un sector de influencias contrastadas desde el punto devis ta ecológico, atlánticas y mediterraneas, pero no es menos cierto que, si las primeras todavla se dejan sentir en forma compleja y contradictoria por efecto de la altitud, las segun das apenas se reciben de modo atenuado; y de esa reducción, de esa préctica carencia, es en buena medida responsable la altitud.

El Valle de Campó, entendiendo por tal aquél sector que de modo especffico conserva tal denominación, dentro de la pro vincia de Santander, puede ser definido como un espracto plena mente de montaña; práoticamente todo 61 se encuentra a máa de 850 metros de altitud, alcanzando alguna de las culminaciones del borde montañoso que individualiza a la comarca más de los 2.000 metros, sin que por ello, y pese a esta elevada altitud tales sectores hayan dejado de tener significado en la organi zacion trädicional del espacio. Su aprovechamiento era, en cierto modo obligado ante la exiguedad del terrazgo de que se disponfa, y ello dib lugar a formas especlfiaas de organizacibn; cuya singujaridad nos pernite constreñix la tradictonal denominación de Campoo al espacio del que, por otra parte es originaria ( 1 ).

Ciertamente, esta exigüedad del terrazgo corfigurb, en su momento, y ha permanecido durante largo tiempc, una fórma de aprovechar el espacio en la que, la subordinación de lo in dividual a lo colectivo es la nota dominante. Y esta preeminencla del aprovechamiento en común, tenfa su propia justifi cación en un rasgo propio de gran parte de las sociedades agxarias tradicionales, y más aún de aquellas asentadas en un

(1) J. CALDERON ESCAJADA - Panorama histórico y etnográfico de un valle. Instituto de Etnografia y Folklore "Hoyos Sainz" Institución cultural de Cantabria. Diputación Provincial de Santander, 2971. pág. 13 y sig. 


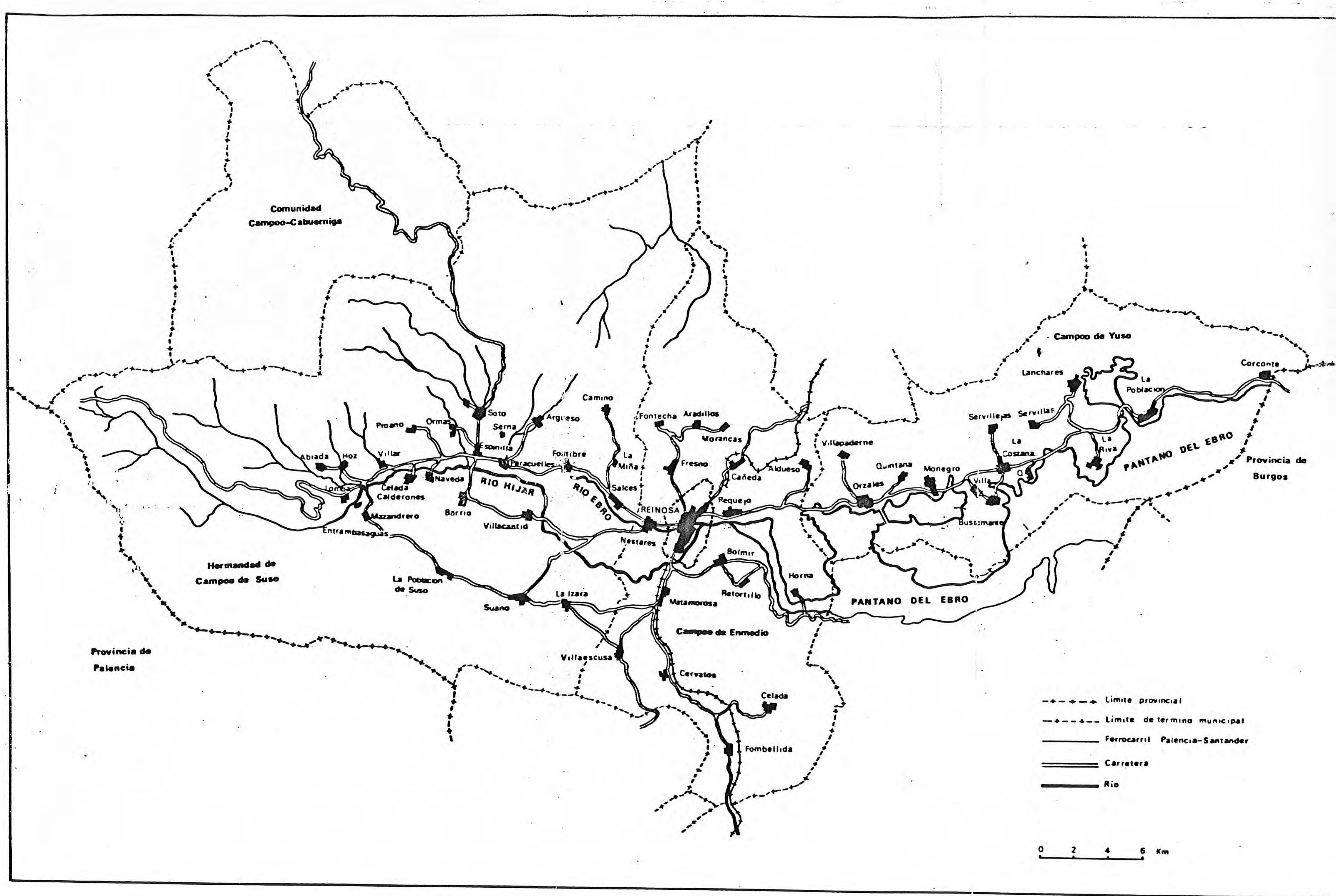


espacio de montaña una agricultura de subsistencia que, en éste, como en otros aspectos, estaba subordinada a una econo mia basada en la ganaderfa ( 2 ). Este aspecto, no exclusivo del valle de Campó, adquiere aqul caracteres relevantes, de enorme arraigo $y$ permanencia en la comarca; de su observación, de su análisis resaltará la singularidad de un espacio, que he denominado en sentido genérico el Valle de Campbo, englobado tradicionalmente en la Merindad de Camp6o, de dependencia adminiatrativa cambiante hasta el siglo XIX, en que quedará adscrito a la provincia de Santander ( 3 ).

Pese a estar acogidos a una misma denominación historica, la Merindad de Campóo agrupaba distintos sectores, suficientemente diferenciados, tanto desde el punto de vista flafco como en el modo de organizar el espacio. Abordaremos aque el estudio de uno de ellos, uniforme en sus caracteres geográfí cos, en su evolución $y$ en sus recientes transformaciones sociales, econbmicas y espaciales, en suma : el que denomino va lle de Camporo, y que se corresponde con los tres términos mu nicipales que conservan tal nombre, Campóo de Suso, Campóo de Enmedio y Campóo de Yuso, a los que, centro de todos ellos, hay que añadir el núcleo de Reinosa.

Constituye un espacio de dimensión reducida $-409 \mathrm{~km} \mathrm{-,}$ pero de rasgos aingulares. En primer lugar se trata de un eg

(2) J. GARCIA FERNANDEZ - Organizacion del espacio y economia rural en la España Atléntica. Siglo XXI.Mádrid 1975 p.38. (3) Hasta el alglo XV, la Merindad de Campbo estuvo bajo la jurisdiccion de Palencia, pero al perder esta ciudad su voto en cortes en ese mismo siglo, pas6 a depender de la jurisdicción de Toro, dependencia que se confirma en el siglo XVIII con la creación de las Intendencias y Partidos. Junto a la Merindad constituirá el Partido de Reinosa también, el Real valle de Valderredible,pertenecientes todos a la provincia de Toro. No acabará aquí el tránsito o la disputa por abarcar bajo su jurisdicción a la Merindad de Campóo; a principios del siglo XIX, Palenctia recupera nuevamente el l'artido de Reinoaa, finalizando este singular y secular pleito en 1833, año en el que, y por decreto del 30 de noviembre se fijaron los limites de las actuales provincias de Santander, Oviedo, Burgos y palencia. El partido de Reinosa pasará a depender de la provincia de Santander desde esa fecha. 
pacio de montaña; la mayor parte de su superficie se encuentra por encima de los 850 metros, alcanzando alguna de sus culminaciones más de los 2.000 metros; es asimismo un espacio de montaña por sus condiciones climáticas, en especial por la larga duración y rigurosas temperaturas del invierno y el carácter fresco de los veranos; y es un espacio de la montaña cantábrica por la elevada humedad y sin duda por su paisaje vegetal.

Pero los rasgos caracteristicos, propios de un espacio de montaña no se circunscriben al medio flsico; aparecen tam bién y son componentes esenciales de aquél, en lo humano. En efecto, las formas de organizar el espacio, tanto en el pasa do como en la actualidad dejan entrever con nitidez su perte nencia a la montaña; en el pasado porque, en el contexto de una economia de subsistencia se llevará a cabo un aprovechamiento del potencial ecolbgico en condiciones limite, que se traducirá en una organización del espacio en la que la preeminencla de sistemas colectivos es una constante. Pese a ello, un exiguo terrazgo y unas condiciones ecológicas adversas se resuelven en frecuentes crlsis de subsistencia que obligarán a emigrar, periodicamente, a parte de la población.

Para evitar en parte tales crísis, y para obtener el $1 \underline{6}$ gico complemento a una "dieta"de susbsistencia desequilibra da, se consolidará un tipo de actividad marginal a la explotación agraria, pero esencial en la economia rural, por cuan to era la unica forma de obtener algún ingreso en metálico, consistente en el temporal desplazamiento a Castilla en bus ca de "pan" y "vino", productos de los que la comarca era de ficitaria -en el primer caso- o no producla -en el segundo-; para poder adquirir estos productos se desarrolla un peculiar artesanado de la madera, aprovechando la madera de los montes comunales, si bien en forma limitada. Se Jogra de este modo 
completar 10 s escasos excedentes de la explotación agraria, reducidos a alguna crla de ganado vacuno o equino.

Este sistema se mantiene invariado hasta que, en el siglo XIX, la actividad del transporte estacional se generaliza, casi podrlamos decir que se profesionaliza, merced al in tenso tráfico de trigo y harinas con destino al puerto de San tander, facilitado por la construcción del Camino Real de Rei nosa. A consecuencia de ello, el Valle de Campóo logrará una cierta, pero pasajera prosperidad, que finaliza al inagurarse el ferrocarril Alar-Santander y desaparecer la carreterfa.

Tras este acontecimiento, la comarca de lampóo retorna al sistema de vida tradicional -que por otra parte tampoco se habla perdido-, $y$ en él se mantiene, con independencia incluso de las espectativas creadas a rala de la incipiente industria lización de Reinosa, hasta, prácticamente la década de 1960. De aqui en adelante, el sistema de vida, la organización y aprovechamiento del espacio agrario, y en suma el paisaje agra rio sufre una completa mutación; decaen o desaparecen ciertas prácticas colectivas, se reduce la superficie cultivada, se incrementan los prados y praderas artificiales y se generali. $z a$, en suma, un tipo de explotación ganadera radicalmente opuesto al tradicional. En ella se abandona un tipo de "rebario" que podemos denominar de subsistencia, en el que coexistian diversas especies, para iniciar una especialización hacia la produccion lechera, al menos en dos de los tres municipios de la comarca.

No acaban aqui todas las transformaciones que en los úl timos años se han sucedido en la comarca; en efecto, el núcle - de Reinosa reforzará su protagonismo dentro de ella de modo bastante intenso, hasta tal punto que concentra más del 60 por 100 de la población comarcal. De los 20.511 habitantes que te nla el valle de Campó en 1981, un total de 13.296, es decir 
el 64,82 por 100 corresponden al núcleo de Reinosa; este pro ceso no resulta de un desmesurado crecimiento de su población, sino del progresivo despoblamiento del resto de los mu nicipios de la comarca, fenómeno especialmente perceptible desde el año 1960.

Asimismo, Reinosa consolidará e incrementará su tradicio. nal funcion de centro comarcal de servicios, merced a una in tensa demanda, tanto del propio núcleo como de la comarca en general.

Pese a todo, algunos de los condicionantes de la organizacion tradicional del espacio, por su mayor resistenciaal cambio todavia persisten; una estmactura de la propiedad de signo marcadamente arcalco, en la que se opone un gran número de pequeños propietarios, a una propiedad comunal a pesar de que gran parte de sus atributos están en desuso, obsoletos a causa del cambio de estructura de las explotaciones agrarias. Persiate igualmente un tipo de poblamiento concentrado, caracteristico de otros sectores de la montaría cantébrica, en el que se aprecian raggos de incipiente dispersión por lo extendido de su caserfo, en el que las modificacjones han sido poco destacadas en la mayor parte de los casos.

Pese a todo, el resultado de esta reciente evolucion ha sido la aparición de un nuevo palsaje agrario, en el que se entremezclan hechos heredados y nuevas aportaciones que, en sfintesis responden a la búsqueda de una mejor adaptación a las condiciones ecolbgicas, tradicional y serts obstáculo en el quehacer de la población campesina. Por ello, la primacla en su consideración está plenamente justificada. 
I IARTE

LAS CONDICIONES ECOLOGICAS DEL VALLE DE CAMPOO 
Si algún rasgo define, identifica a la conarca de Campobo este es sin duda el atributo montaffés; la pertenencia a un e $\underline{3}$ pacio de montaña se refleja en la regularidad con que se dejan sentir ciertos atributos del mismo, es decir, una reducida dis ponibilidad de espacio que, servidumbre de la altitud, queda limitado al fondo de los valles y arranque de las laderas, y unos caracteres climáticos especificos, que dejan entrever no sblo el influjo de la altitud, sino también de la peculiar con figuración morfologica e incluso de la localización de la comarca en la vertiente de sotavento de la cordillera Cantábrlca.

Todos estos caracteres hablan de tener una respuesta, y la tuvieron, en una organización del espacio especifica, en la que los condicionantes apuntados intervinieron de modo decisi vo.

Desde el punto de vista morfologico, la comarca de Campóo está constitulda por dos conjuntos bien diferenciados; el que constituye el sector más accidental de la misma, el valle de Campbo de Suso -o de arriba-, rodeado por la especie de anfiteatro montañoso que forman las Montañas de Reinosa, con altitudes superiores a los 2.000 metros y profundas diferencias 
respecto al fondo del valle, dado que éste se encuentra a tan s610 950-1.000 metros. Tiene este sector un carácter cerrado, salvo por el Este del mismo, donde se enlaza, sin solución de continuidad con el segundo conjunto: los Campos de Reinosa, es decir el Campoo de Einmedio y la depresión de la Virga -el Campbo de Yuso o de abajo-.

Esta segunda unidad, de reducidas dimensiones-menos de 200 Kilometros cuadrados dentro de la comarca-, se encuentra todavia a una altitud superior a los 850 metros, y aparece delimitada por el Norte por otra alineacion que, en cierto modo sirve de solución de continuidad entre los Montes de Reinosa y los energicos relieves de los Montes del las; esta alineación introduce desniveles de más de 450 metros respecto a los sectores más deprimidos del Campóo de Yuso, hoy en buena parte cubiertos por las aguas del Pantano de]. Ebro.

Pero si existen considerables diferencias de altitud en los bordes montañosos que individualizan los citados conjuntos, éstas se reducen considerablemente en las depresiones que contribuyen a singularizar; en efecto, el fondo del valle de Campóo de Suso -la tierra baja- se encuentra prácticamente a la misma altitua, entre 850 y 950 metros que la conocida como 11a nura o "páramo" de la Virga, es decir el Campbo de Yuso. Por ello, la práctica isoaltitud del espacio aprovechablo, unida a unas condiciones ecolbgicas que, con pequeños matices, refle jan sin ningún género de dudas su pertenencia a un sector de montaria, dará como resultado unas formas de organizar el espaclo similares en el pasado y aun en el presente, lo cual permite contemplar ambos conjuntos en forma homogenea, bien enten dido, no obstante, que tal homogeneidad no implica una absolu ta similitud, y que las diferencias morfolbgicas e incluso ecolbgicas, pequer̃as en entidad, han sido y son suficientes para dotar a los mismos de cierta personalidad. 


\section{CAPITULO I}

IA ESTRUCTURA MORFOLOGICA

La morfologia de la comarca se caracteriza por el niti do contraste, en un espacio esencialmente reducido, entre forma deprimidas -el fondo de los valies, a una altitud su perior a los 850 metros-, y formas erguidas, que cierran por el Norte y por parte del Sur la comarca. Este anfiteatro mon tañoso no presenta una isoaltitud, sino que ésta desciende de forma gradual en dirección Oeste-Este y 0este-Sudeste, desde Campóo de Suso o de arriba, a Camp6o de Yuso o de abajo, y ha cia el Sudeste -Puerto de Pozazal-, cerrando en esta dirección el Valle de Campó.

En camblo, la perdida de altitud es muy ráplda, incluso brusca, entre los bordes montañosos y el fondo de los valles, hecho que acentúa aún más el carácter de auténtica muralla de los primeros respecto a los sectores deprimidos.

Sin menospreciar la importancia y significado que tienen las formas de relieve, todas ellas se adaptan, en la comarca de modo más o menos fiel a las estructuras; El relieve de Camp6o es pues esencialmente estructural. Y en esta estructú 
ra se reflejan de manera inmediata las deformaciones del zbca10, que en el limite occidental de la comarca comienza a hundirse de forma progresiva. La tectónica de fractura adquiere por ello cierta importancia en Campbo, hasta tal punto que en alguno de sus sectores se forma un compliejo entramado de fallas de descompresión de dirección Este-0este y Noreste-Sureg te, que si bien no constituyen más que un accidente de detalle, contribuyen a individualizar a los mismos.

En estrecha dependencia con esta tectónica de fractura, que traduce sin duda accidentes más profundos, del zócalo, hay que situar los fenbmenos de intrusión, los afloramientos diap 1 ricos de la comarca, de reducida extensión en ajgún caso, pero de enorme significado, no sólo en el orden geológico, sino también desde el punto de vista humano; no en vano, sobre las mar gas $\mathrm{y}$ arcillas del Keuper se extendlan tradicionalmente las me jores tierras de labor, hoy convertidas en prados.

Se encuentra perfectamente caracterizada esta tectónica en las proximidades del pueblo de la población y de Reinosa; en ambos casos están constituidos estos diapiros por un núcleo bastante considerable de ofitas, rodeadas por margas del Keuper $y$, en una segunda y discontínua aureala por las calizas acarnioladas hetangienses y por el Lias -complejo margoso Plieng bachiense-Bajociense- ( 4 ).

La misma tectónica de fractura se deja sentir en el sector occidental de la comarca, en el que el Trísico, representado especialmente por lus grandes espesores de conglomerados del Buntsandstein, forma un sinclinorio inclinado axialmente hacia el Este-Sureste, y fallado longitudinalmente ( 5 ).

(4) Mapa Geológico de España, E. I/50.000. Explicación de la ho ja no 83, 18-6, REINOSA. I.G.M.E. Madrid 1978. P. 20 y sig. ( 5 ) $\mathrm{F}$. HERNANDEZ PACHECO.- Fisiografía, geologla y glaciarismo cuaternario de las Montañas de Reinosa. Memorias de la Real Academia de Ciencias flsicas y naturales de Madrid.Tomo $X$. Pág. 78 y sig. 


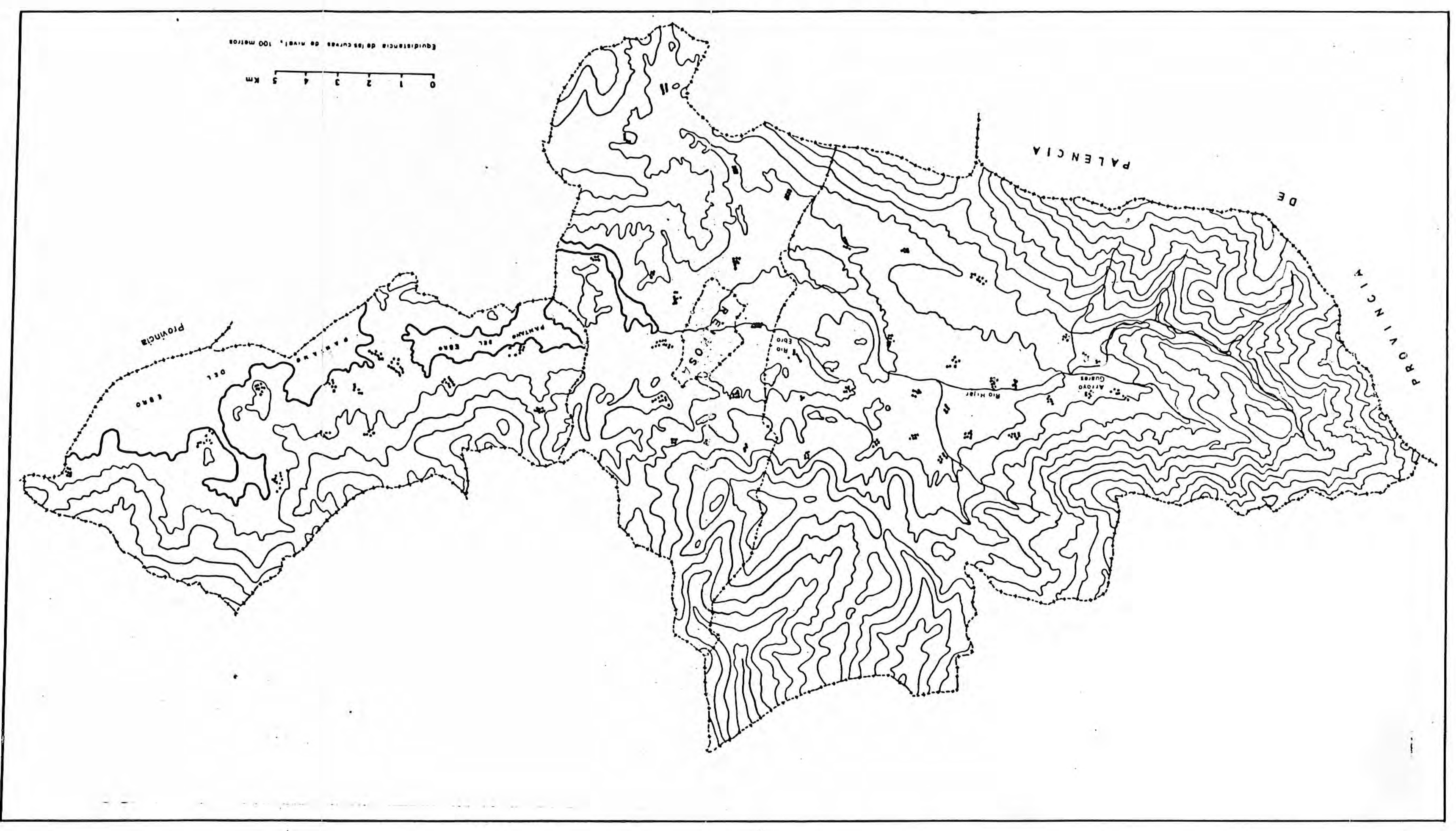


1.- UN SECTOR DE IAA CUENCA TRIASICA CANTABRICA.

Por la proximidad a los sectores del zócalo, con los que se llega a entrar en contacto en el extremo occidental de la comarca, se dejaron sentir con fuerza los efectos de una tecto nica de fractura que, afectando a los materiales más profundos, se dejo sentir en forma compleja en la cobertera mesozoica. Tal cobertera está compuesta, en gran parte, por un notable espesor de sedimentos triásicos, dado que esta región se hundio muy poco con posterioridad a los movimientos post-Kimericos, por Io cual, la zona de mayor potencia sedimentaria emigró, paso a paso, hacia el Noreste ( 6 ). Por esta causa, y porque sin dy da la región formaba parte del talud continental durante el me sozoico, los espesores de los materiales triásicos son importantes; en Valdecebollas y en la Sierra del Pico Cordel éstos llegan a alcanzar los 800 metros.

No es de estrañar por ello que sean los conglomerados del tríácico inferior -Buntsandstein- los que proporcionen un auténtico carácter al relieve e incluso al paisaje de las Mon tañas de Reinosa; estos conglomerados, bien representados en los sectores más elevados, están compuestos por cantos muy ro dados, de gran tamaío en ocasiones y, casi sin excepción de cuarcitas, han estado sometidos a grandes presiones, como 10 prueban las señales de penetración de los cantos y el hecho de que muchos de ellos estén estallados; pese a que el cemento siliceo que los une es muy resistente, la prolongada acción erosiva contribuye a que se desprendan con cierta facilidad, formando caracterlsticos canturriales y rellenando, en parte, el lecho del rio Hijar hasta su desembocadura en el Ebro, en las proximidades de Reinosa.( 7 ). Se encuentran estos conglo

(6) H. KARRENBERG.- La evolución jostvariscica de la cordillera cántabro-astúrica. Iublicaciones extranjeras sobre Geologia de Espan̆a. Vol III. Consejo Superior de Investigaciones cient1ficas Madrid 1946. C\&r.pág 217.

( 7 ) F. HERNANDEZ PACHECO.- op. cit. pág. 73. 
merados en fuerte discordancia con el paleozolco -Carbonffero-, que se hunde bajo el sinclinal de Campoo de suso ( 8 ).

La existencia de una facies caliza - Muschelkalk- entre el Buntsandstein y el trísico superior -Keuper- ha sido pue $\underline{\text { s }}$ ta en tela de juicio; parece no obstante que los pequerios aflo ramientos en los alrededores de Reinosa, corresponden a masas que han sufrido fuertes desplazamientos al estar sumergidas en sedimentos plásticos -arcillas y margas del Keuper-y apoyadas sobre las margas blandas, de color rojizo, de la parte superior del Buntsandstein. Pero el problema no está resuelto aún, a fal ta de dataciones más precisas ( 9 ).

Con menor entidad en Campoo de Suso, pero alcanzando una extensión considerable en el resto de la comarca, las arcillas y margas del Keuper, de fuerte coloración rojiza - hez de vinoentre las que son bien visibles los cuarzos bipiramidales -Ja cintos de Compostela- caracterizan en forma suficiente el Triá sico superior. Acompañando a estos materiales plástioos so oncuentran pequer̃os afloramientos de"ofitas" en las proximidades de los núcleo de población de La población, Reinosa y Cervatos, adoptando, en este último lugar una disposición radial, denunciando sin duda el carácter intrusivo -diapírico-perforando las calizas tableteadas Hettangienses y ell complejo Pliensba chiense-Bajociense (10).

Esta facies blanda, margo-arcillosa, intercalada entre los conglomerados del Buntsandstein, calizas Hettangienses y las calizas liásicas, ha jugado un papel fundamental en la con figuración de una parte sustancial del relieve de la comarca; por su plasticidad no ha podido transmitir los movimientos tec

(8) Es muy probable que el Westfaliense productivo, hundido bajo la potente serie triásica de Campó de Suso, sea el mismo que el de la Cuenca de Barruelo. F. HERNANJEZ PACHECU.- Up. cit, pág. 78.

( 9 ) J. SAIZ DE OME JACA.- Nota previa sobre el medio sedimentario en la cuenca triásica cantábrica. Real sociedad Española de Historia natual. Tomo $72 \mathrm{n}^{0}$ 1-4 Madrid 1974. (10 ) K. KARRENBERG.- Op. cit. pág.120. 
tónicos a las capas suprayacentes, y se han producido fuertes migraciones de la misma acompañada de desplazamientos de parte de las calizas del Jurásico e incluso del Muschelkalk, formando cerros con estructura de pequeños anticlinales, levantados todos ellos en yacimientos de irregular distribucion (11). Los materiales más modernos -Cretaceos- y hasta la base del Cenomanense, aparecen al Este de la comarca, formando pequeińos cerros alomados en los que la tectónica de fractura ha jugado un papel decisivo; los "campos de fallas" adquieren aqu1 -llanura o"páramo de la Virga"- una extensión considerable, facilitando la acción exosiva de pequerios, pero numerosos arroyos que, antes de ser sumergidas parte de estas tierras por las aguas del pantano del t́bro, excavaron minúsculos valles a favo de tales accidentes; pero, éstos, recubiertos por las aguas, hacen muy dificil reconstruir las estructuras.

En cambio, donde éstas pueden ser apreciadas con una cierta claridad, pese a que la tectónica de fractura sea también una constante, es en el sector occidental de la comarca, en Campóo de Suso.

\section{2.- EL SINCLINAI DE ABIADA: UNA RETRUCTURA COMPL,EJA}

De modo sintético, la estructura del valle de Campó de Suso queda reducida a un sinclinal triásico, fracturado en su charnela por una falla de dirección Noreste-Suroente, apoyado todo el oonjunto sobre ol finjoozoleo con fuorto diucordinota ansular; pero los hechos no son tan sencilloos. En efecto, de trata de un sinclinal disimetrico; su flanco Norte, constitui do por conglomerados del Buntsandstein se levanta casi hasta

(11) K. KARRENBERG.- Op. cit. pág. 192. 
la vertical buzando de 50 a 70 grados hacia el Sur-Soroeste y formando la alineación de la Sierra del pico Cordel desde el Pico Tresmares hasta la Garma de los ladrones sobre el pueblo de Villar. Por el contrario, su flanco Sur es mucho más tendi do, buzando 25 o 30 grados hacia el Norte-Noroeste, y mucho menos monótono.

En forma oblicua al sinclinal, y cerca del pueblo de Hoz de Abiada, arranca un pequeño anticlinal -la loma de Piedrafita-, que separa las cuencas del rio Hijar y del arroyo Guares $y$ divide en dos el citado sinclinal (12). Este antiolinal se prolonga, paralelo al flanco meridional del sinclinal de Abiada, hasta el pueblo de Suano, aislando ente él y el permotrias del flanoo sur una estreche banda sinclinal triásica sobre la que se encuentran pequeños islotes de calizas jurásicas, sin duda desplazados sobre las arcillas y margas del Keuper. El anticlinal que podemos denominar de la loma de Piedrafita se ha ido también estrechando, quedando reducido en ese mismo pun to -Suano- a un pliege-falla en los conglomerados del Buntsands tein. ( 13 ).

La irregularidad o mejor la singularidad del sinclinal de Abiada se acentúa por el hecho de que, en dirección leste y particularmente en direción Norte-Noroeste, se estrecha progresivamente, pasando a ser un "sinclinal pinzado"; en efecto, en la cltada dirección el sinclinal de Ablada desaparece hacia los sectores más elevados de la cuenca del río Hijar, siendo sustituido por una falla que fractura todo el conjunto de con glomerados y arentiscas del Triásico Inferior, alterando la es tructura considerablemente, puesto que estará constitu1da por dos grandes conjuntos o "paquetes" del Buntsandstein separados por una falla, gracias a la cual ambos ofrecen unos buzamien-

(12) R. CIRY.- Etude géologique d'une partie des provinces de Burgos, Palencia, León et Santander. Bulletin de la Societé d'Historie Naturelle de Touluose, tome 74 Toulouse 1939. Cfr. p. 321 .

(13) R. CIRY.- Ibid. id. 
tos contrarios, hacia el Noreste y Suroeste ( 14 ).

En sintesis, el desigual comportamiento, la desigual res puesta de los materiales de la cobertera mesozoica -trlasica sustancialmente en el valle de Campbo- ha dado lugar a comple jas estructuras, cuya reconstrucción se hace las más de las ve ces diffcil, al haber sido transportados gran parte de ellos, por la plasticidad de algunos de los que componen la serie su perior al Buntsandstein -arcillas y margas del Keuper en especial. Ello ha dado lugar a la formación de pequeños islotes rocosos distribuidos de forma inorgánica por el centro y sobre todo en los margenes del valle. Se trata de elementos albctonos constituídos por las calizas jurásicas y en algún caso por las calizas del Muschelkalk, desgajados del conjunto del que hablan de formar parte y replegados posteriormente en forma compleja, siendo perceptibles con claridad entre Abiada y Espinilla y en el sector Este, en Fontibre, all1 donde el vallie comienza a abrirse a la lanura de Reinosa.

Todo ello contribuye a dar variedad al fondo del valie, que lejos de ser una llanura monbtona, uniforme se encuentra salpicada por estos pequefios cerros, fmprestón que ne acentún desde el extremo más oriental. del mismo porque tales asomos ro cosos pueden llegar a alcanzar clerte ajtura impidiendo la con templación del anfiteatro montañoso que cierra el valle por el 0este. Constituyen tales cerros la solución de continuidad, en cierto modo para el otro gran conjunto de la comarca, en el que la tectónica de fractura se ha dejado sentir con más inten sidad, y a la que se ha acompañado una tectónica intrusiva, dia plrica, sin duda relacionada con ella.

3.- LA INTENSA TECTONICA DE FRACTURA DEI SECTCR URIENTAL: CAMPOO DE ENMEDIO Y DE YUSO.

Conforme se progresa hacia el Este, se produce, dentro

(14) F. HERNANDEZ PACHECO.- op. cit. pág 92. 
de la comarca un tránsito hacia materiales más modernos -Jurá sicos y del Cretácico Inferior, en particular las facies Purbek y Weald-, especialmente bien representadas en Campoo de Yuso (15)

Todos estos materiales han estado sometidos a una intensa tectónica de fractura, siendo muy abundantes las fallas con direccion Este-0este y Noroeste-ijureste, originadas en las pro ximidades de dos áreas diaplricas bien caracterizadas, el diapiro de Reinosa y el. de La Población.

Los contactos anormales y los pequeños cabalgamientos, de diffcil reconstrucción son componentes habituales en una eg tructura complefa; y esta complefidad se acentúa si tenemos en cuenta que, parte de esos elementos se han ordenado -o mejor desordenado- en torno a unos sectores on los que la tectónica intrusiva es un componente esencial. Pero ambos responden sin duda a los movimientos del zócalo, que en la comarca, y proba blemente por constituir un unbral durante el Mesozoico, está recubierto por una cobertera de poco espesor, que habría reci bido con intensidad tales movimientos; y éstos se vieron acen tuados por la plasticidad de una parte de los materiales triá sicos, que facilitaron el desplazamiento de las calizas y calizas margosas suprayacentes, salpicando parte de la comarca de elementos albctonos que forman pequeños cerros poco destacados sobre la llanura domiante en el paisaje.

El Keuper intrusivo tiene en Campó una cierta extension, si bien aparece concentrado en los núcleos diapíricos de Reino sa y La Población, el primero. de mayores dimensiones que el segundo, pero ambos con una estructura similar. Se trata, en efecto, de dos afloramientos de margas y arcillas, en cuyo cen tro aparecen, elemento consustancial, las ofitas. Como consecuencia de la presión del Keuper, las calizas Hettangienses

(15) J. RAMIREZ del POZO y Ma J. AGUIl,AR.- Consideraciones sedimentologicas y paleogeográficas en las facies Purbeck $y$ Weald de la cubeta de Santander-Burgos, Estudios Geolbgicos Vo1. XXVIII no 2-3 1972, pág. 173-193. 
y el complejo margoso liásico-jurásico aparecen ligeramente le e vantados rodeando a este núcleo, si bien es cierto que la erosion posterior ha arrasado todo el conjunto contribuyendo a acentuar la planitud de la Vega de Reinosa y de Campóo de Yuso. En ambos sectores tan sólo quedan en resalte pequeños cerros, suavemente alomados, que introducen unos desniveles de escasa entidad, Insuficlentes para alterar la práctica isoaltitud del conjunto. Frente a 6sta, y constituyendo una de las caracterís ticas del relieve de la comarca, se encuentran los sectores de mayor altitud, en los que se dejaron sentir con alguna intensi dad los efectos del glaciarismo cuaternario.

4.- EL MODEJ,ADO G],ACIAR: UN MERO RETOQUE.

Por la elevada altitud sin duda, pero también por su lo calización y pertenencia a la Cordillera Cantábrica, el glacia rismo cuaternario se dejo sentir con cierta intensidad en el sector más occidental de la comarca.

Se trata empero de un glaciarismo de escasa entidad; los circos glaciares apenas están insinuados en los niveles más alevados y de ellos -no en todos los casos-sallan pequeñas lenguas, alcanzando la de mayor recorrido,6 kilómetros ( 16 ). Sin duda, la uniformidad litológica, y el hecho de localizarse en pendientes muy acusadas -entre e]. 17 y el 20 por 100- expli ca, entre otras causas, el escaso desarrollo de estos circos.

Apenas existen rupturas de pendiente, y por ello, los distintos campos morrénicos enlazan entre sí sin apenas discon tinuidades; el más bajo de ellos -1250 metros-y el de mayor entidad sin duda corresponde al Mindel. Por encima de ella, se

(16) F. HERNANDEZ-PACHECO.- Op. cit. pág. 166. 
reconocen otros, aproximadamenta a 1530 metros, sin duda originados durante el estadio Rissiense; por último, hacia los 1640 metros se encuentran otros arcos morrénicos, de reducidas dimensiones, prácticamente en el limite de los circos glaciares y que se corresponden al estadio Würmiense ( 17 ).

La mayor parte de los depósitos morrénicos se encuentran bastante destruldos, siendo sólo identificables por la presen cia de grandes bloques erráticos de conflomerados; de esta deㅡ trucción es sin duda responsable la intensa erosión fluvial de los periodos interglaciares, durante los que, una gran parte de los materiales de pequeño tamaino fueron arrastrados por los nu merosos cursos de agua tributarios del H1jar o por éste mismo.

En cambio, y en los sectores más ellevados tienen gran sig nificado los procesos de alteración debidos al frio; la gelifracción actual o subactual es, en efecto, bastante intensa, pu diéndose apreciar con cierta nitidez en aquellos espacios desprovistos de cobertera vegetal. Pese a todo, apenas se altera una estructura que, en lo general seguirá caracterizándose por la oposicion entre los sectores elevados, en los quo predominan los prooesoss erosivos, y aquelion situsidos a monor altitud y en los que tienen mayor importancia los procesos de acumulación.

5.- UN RELIEVE DE MONTANA CARAC'LERISTICO.

Pese a la reducida extensión de la comarca, ej. contraste, a veces brusco entre los sectores elevados y los espacios abier tos, todavía a una altitud elevada -más de 800 metros-, constituye un rasgo dominante del paisaje campurriano.

Es en esta oposicion en donde se encuentra la original1dad del relieve montañes, porque si los primeros ofrecen una topografia accidentada, compleja, los segundos se caracterizan por la simplicidad morfologica, por el predominio de la llanura

(17) F. HISRNANDEZ-PACHECU.- Up. cit. pág. 166. 
tan s6lo salpicada por suaves ondulaciones que introducen cier ta variedad en un conjunto en el que, la planitud es la nota dominante. Y ésta, que sin duda responde a la propia configuración estructural, se verá reforzada por la intervención de los agentes erosivos sobre tales estructuras, esencialmente plegadas, pero fuertemente tectonizadas, hecho que facilitará au ac tuacion.

Como consecuencia de ésta se modificó someramente la topografla de 103 valles, on la que destacan los fondos planos, más cuanto más hacia el Este. Por el contrario, en dirección Oeste y Norte, las formas de relleve son abruptar, y en ellas se ha encajado una red hidrográfica compuesta por numerosos cursos tributarios de dos principales, el Ebro y el Hijar. El primero, desde la surgencia en la que tiene origen, discurrirá por un fondo plano hasta lo que hoy constituye su embalse regulador; en cambio, el rlo Hijar se caracteriza por un acusado regimen torrencial, puesto que en un corto espacio-menos de 20 kil6metros- desciende más de 750 metros-. Por esta causa su capacidad erosiva ha sido mayor, suponiendosele encajado aprowlmadamente 150 metros en los sectores medios de su cuenca alta (18). Sin duda, tal incisión fue debida, pese a la re sistencia de los conglomerados triásicos, al elevado volumen de su caudal; recibe, en efecto, las aguas de las zonas más ele vadas, que, durante los periodos interglaciares, procedian do los glaciares de éstos elevados sectores. En su cuenca alta, y desde su nacimiento hasta la confluencia con el arroyo de Pledrahita, recorre 8 kilbmetros, salvando un desnivel de más de 400 metros.

Pero en la intensidad de esta acción erosiva intervino también el basculamiento que, en las últimas fases del plegamiento Alpino afectb a todo el conjunto, inclinándolo de veste a Este y de Suroeste a Noreste. Este movimiento modifico el ni

( 18 ) F. HERNANDEZ-PACHECO.- Op. cit. pág 98. 
vel de base local, y desencadenó una muy intensa acción erosiva (19). Esta es además remontante, capturando para si lo que en otro momento fue la alta cuenca del arroyo Guares. No es por ello extraño que éste haya realizado una acción erosiva de menor entidad -una incisión aproximada de 70 a 80 metros-, suficlente, no obstante, para dejar en resalte el asomo rocoso de la llamada loma de Pledrafita, uno de 100 muchos, st bien el de mayor entidad, de los que sobresalen en el fondo plano del Valle de Campbo de Suso; Este está en parte recubierto por 10 aluviones aportados por el rlo Hijar y arroyo Guares, y entre ellos afloran algunas manchas de arcillas y margas del Keuper.

En estas condiciones se forman unos suelos jovenes, con escaso desarrollo de sus horizontes, neutros o débilmente ácidos, pero que por su estructura y textura, han sido sobre los que tuvieron agiento las tierras de "pan llevar" tradicionales, hoy convertidas en praderas permanentes o destinados al cultivo de forrajeras. En contraste con éstos, no sollo por e] apro vechamiento que de ellos se realiza, sino también porque se lo calizan en los sectores más elevados, se encuentran otros, t1picamente forestalea, Terra l'usce. y Tierra Parda Húmeda, muy pobres en elementos nutrientes, por lo que, cuando se encuentran ocupados por prados de guadaria -ceso muy frecuente-, tan s6lo permiten un corte anual. ( 20 ).

Estos mismos caracteres edáficos se repiten en Campóo de Enmedio y Campbo de Yuso, sectores que se caracterizan por la acusada planitud y altitud igualmente elevada -más de 850 me tros-. Se trata en efecto, de una superficie plana o suavemente alomada, en la que el encajamiento de la red hidrogáfica es menos pronunciado, pese a la entidad que adquieren las formaciones blandas y pese a estar todo el conjunto sumamente frac turado. Tan sólo los arroyos Proncio y Vilga discurrían somera (19) F. HERNANDEZ-PACHECO.- op. cit. pág 99. ( 20 ) A. GUERRA DELGADU.- Mana de suelos de Espaila E. 1/1.000.000 Descripción de las asociaciones y tipos vrincipales de suelos. 
mente encajados, antes de desaparecer bajo las aguas del Panto.no del Ebro, sustrayendose al terrazgo de Campoo de Yuso uno de sus sectores más fertiles. Este valle se encuentra cerrado por el Norte por un conjunto de modestas culminaciones -entre 1100 y 1300 metros-, que en realidad coresponden a una serje de plie gue monoclinales fallados y buzando suavemente hacia el Sur. El desnivel respecto al fondo del valle es por lo tanto de escasa entidad -entre 300 y 400 metros-y no se realiza en forma brusca, sino a traves de suaves pendientes, por lo general. Pese a ello, la incidencia en las condictones climáticas no es nada despreciable, puesto que actúan a modo de pantalla que preserva a éste del influjo de los húmedos vientos del Nor te, llegando no sólo aqul, sino a toda la comarca en general, desprovistos de parte de la citada hunedad.

En sintesis, gran parte del valle de Campó, y con mayor - menor continuidad, se encuentra rodeado por un anfiteatro mon tañoso que aisla, que individualiza unas zonas deprimidas, pero a una altitud todavia considerable, hecho que tiene una incidencia inmediata e indudable en las condiciones climáticas comarcales. 


\section{'CAPITULO II}

\section{LAS CONDICIONES CLIMATICAS}

Las condiciones climáticas, que vamos a analizar aqui en modo descriptivo, interpretando hasta donde sea posible los mecanismos en $10 s$ que estas tienen fundamento, constitu yen uno de los aspectos singulares de la comarca. Merced a ellas resalta aún más su individualidad como un sector de la montana cantábrica en el que, se han llevado a cabo formas especificas de organización del espacio.

Dos son los condicionantes básicos en los que se enmarca el clima de la comarcas la localización en la vertiente meridional de la Oordillera dantábrica y la altitud. Ambas, pero especialmente la segunda, constituyen la base, el telón de fondo de unas condiciones climáticas en las que el rasgo más sobresaliente es el acusado déficit térmico anual. El frio es en efecto una de las constantes del clima campurriano acen tuado por la elevada nebulosidad e incluso por la frecuencia $y$ persistencia de la niebla; una muestra de estas condiciones térmicas extremas puede ser el hecho de que la estación libre de heladas sea en general muy corta -3 meses en Reinosa-, y que la temperatura media anual no supere $10 s 10^{\circ} \mathrm{C}$ en este $\mathrm{ni}$ en otros observatorios, dentro o fuera de la comarca, pero pró xima a ella.

Un carácter regular tiene también en toda la comarca el volumen anual de las precipitaciones y la distribución mensual de las mismas. Todas las estaciones metereologicas superan los $900 \mathrm{~mm}$. de precipitación anual, siendo la componente otoro-in vernal la que aparece dominante en las mismas. Pero con ser 
expresivo este umbral, no es suficiente para definir, para ca racterizar los rasgos especificos del clima comarcal. La ate nuación sensible de las precipitaciones mensuales durante la estación estival, constituye un atributo claramente mediterra neo, trasunto inmediato de la peculiar localización de la comarca en un espacio de influencias encontradas, atlánticas y mediterraneas, sensiblemente modificadas por la altitud.

La presencia de la nieve, la frecuencia con la que se produce, su aparición regular, invariable todos los inviernos, as1 como su permanencia, es otro de los aspectos claves para un adecuado entendimiento del clima del Valle de Campó; un promedio de más de 8 dias de nieve durante los meses de Enero y Febrero es habitual, sin que sean desconooldos affos de más de 15 dias de nieve en los mismos meses. Tan solo los meses de Junio, Julio, Agosto y Septiembre aparecen constantemente libres de nieve en los 30 años sometidos a observación. Las nevadas tempranas y tardfas, aunque paco frecuentes, tampoco son desconocidas en la comarca.

No obstante, dentro de estas constantes generales se pueden apreciar pequeñas diferencias de matiz, que afectan, no ya a la presencia o ausencia de los distintos fenomenos, sino a su intensidad. Por la carencia de información no podemos precisar más este aspecto, pero todo parece apuntar on esa direccion. La discontinuidad de las observaciones tan só lo deja entrever una atenuación de los valores térmicos y pluviométrioos en dirección Sur y Este; Arija, observatorio perteneciente a la provincia de Burgos, pero en el mismo l1mite de la comarca, tiene un promedio de d las de nieve inferior al de Reinosa -4 dias-, siendo el resto de los velores prácticamente similares, es decir, una temperatura media anual baja -9,4 grados- J unas precipitaciones elevadas -915 mm.-. En cambio, en direccion Sur las temperaturas se dulci- 
flcan, sin que por ello sean elevadas, y las preciptitaciones se reducen aproximadamente en un tercio respecto a las de Re1 nosa; tal es lo que sucede en el observatorio de Aguilar de Campó, en el Norte de la provincia de Palencia. Evidentemente la localización de esta núcleo en una situación meridional, dentro del sector de sotavento de la unidad cantábrica, expli ca tal degradación de las precipitaciones, en particular de las estuvales, hecho que en el Valle de Campó se deja sentir con menor intensidad como consecuencia de su postción más sep tentrional, y pese a encontrarse igualmente en el sector de so tavento de la citada unidad.

Son pues factores geográficos los que dan lugar a estos contrastes que, por otra parte, no hacen más que resaltar la propia singularidad del clima de la comarca. La altitud permite comprender la duración y rigor de los inviernos, la suavidad térmica de los veranos, acentuada por una elevada amplitud diurna, y las abundantes precipitaciones, que a la vez refleja claramente su pertenencia a la unidad cantábrica.

1.- UNAS PRECIPITACIONES ELEVADAS

Las elevadas precipitaciones connstituye uno de los rasgos más sobresalientes del valle de campó (21). Todas las es-

(21) Para el análisis del clima de este sector tropezamos con no pocas dificultades, relacionadas con la irregulariad e insuficiencia de gran parte de las observaciones. Tan sólo la estación termopluviométrica de Reinosa ofrece observaciones continuadas durante un periodo superior a los treinta anos. La otra estación con registros térmicos y pluviométricos, Espinilla, $\tan s$ ślo ofrece 9 anos de observación térmica -no completos muchos de ellos- y 25 años on el caso de las precitaciones, en las mismas condiciones de irregularidad. Las restantes, Soto de Campठo y Arija -ésta, fuera de la comarca- son exclusivamente pluviométricas y adolecen de los mismos defectos sefalados anteriormente. Otras estaciones pluviombtricas, Cervatos, Corconte, Servillejas, Suano y Villasuso remiten sus datos a Iberduero, pero la absoluta irregularridad de ellos nos ha obligado a no tenerlas en consideración. 

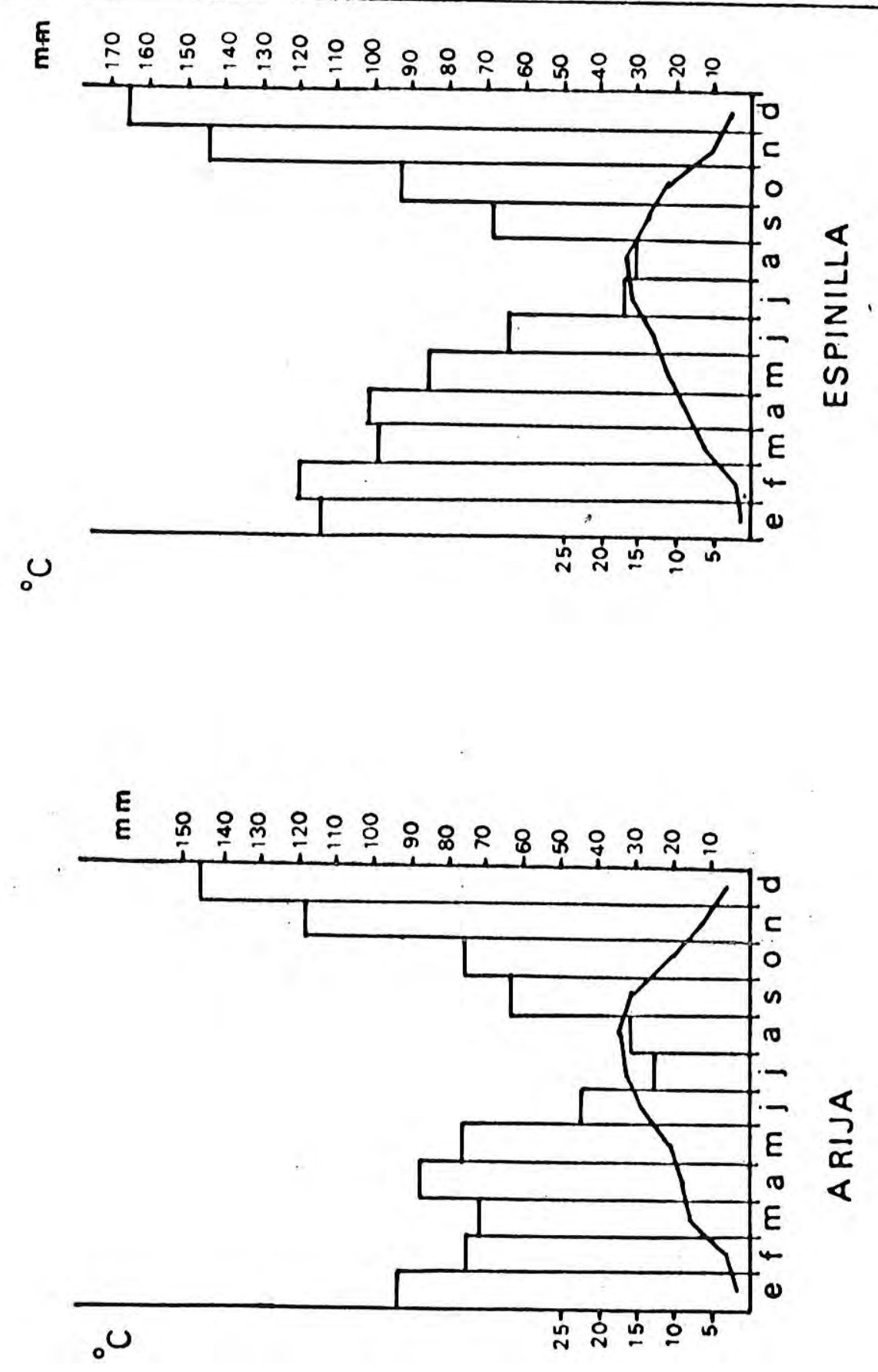

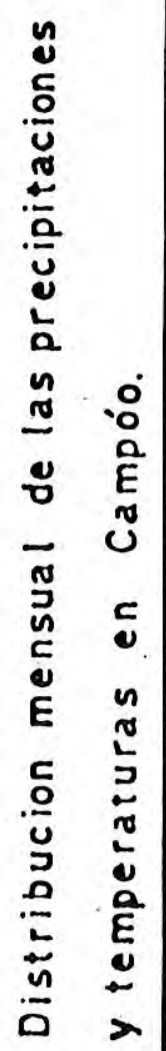

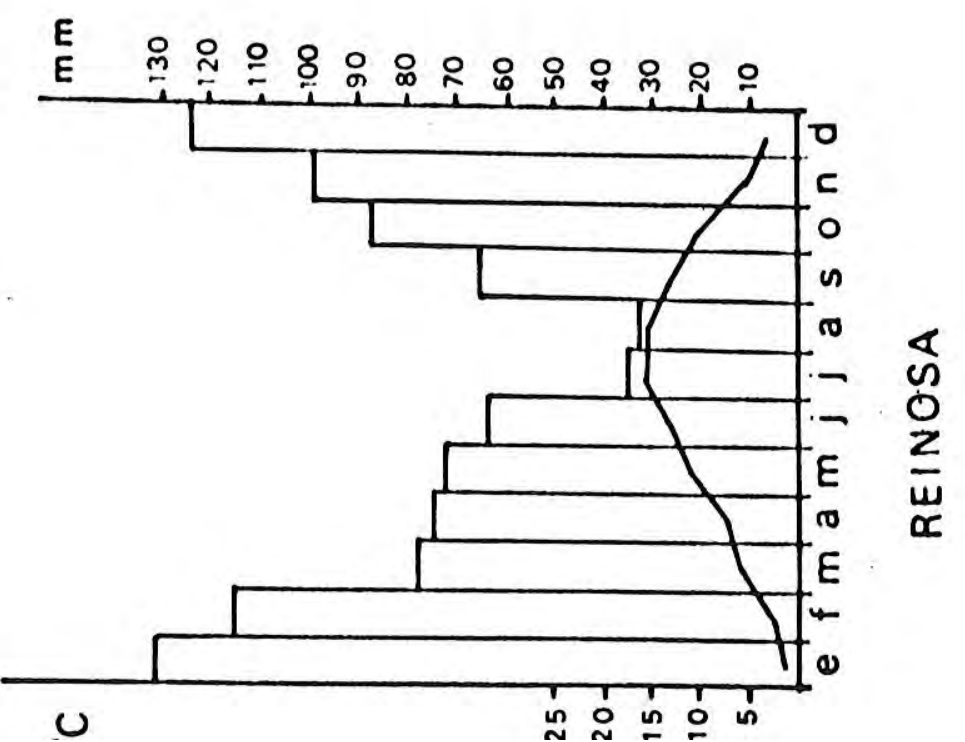

$\dot{0}$
$\dot{0}$ 
taciones superan $108900 \mathrm{~mm}$. anuales, y aun en algun caso se alcanzan 10 s $1100 \mathrm{~mm}$. Estos elevados valores anuales esconden, no obstante gxandes desequilibrios intermensuales. Domi nan las precipitaciones durante el semestre invernal-otofal, en el que se superan siempre $10 s 80 \mathrm{~mm}$. mensuales, existiendo al menos tres meses en los que éstas son superiores a los $100 \mathrm{~mm}$.

Pero junto a las elevadas precipitaciones, el elevado número de dias de lluvia y nieve en los meses otofales e in vernales determina, con una precision aún mayor, los caracteres climáticos de la comarca. Más de la mitad de los das de cada mes, en los anteriormente citados, son dias en 108 que hace su aparición, invariablemente, la lluvia o la nieve, al menos en Reinosa, puesto que en Arija, en el extremo Este de la comarca, pero fuera de ella, el número de dias se redú ce Iigeramente, tanto de aquellos en los que llueve, como en los que nieva.

Durante el resto del afro, y particularmente en 108 tres meses de verano, las precipitaciones descienden de modo apre clable, manteniendose por encima de $10 s 30 \mathrm{~mm}$, o descendien do por debajo de este umbral 11geramente. Asimiamo, el número de das de precipitación, bastante reducido, nos lleva a suponer la especial conoentración de ésta dentro del mes, 10 que acentuarla la insuficiencia del citado umbral. En efecto, el empleo exhaustivo de Indices medios que comunmente se hace, esconde grandes errores. Si 108 meses de verano aparecen, on una primera aproximación como meses secos, o con escasas pre cipitaciones, no son desconocidos anos on 108 que alguno de estos meses recibe una precipitación superior a $108100 \mathrm{~mm}$, particularmente en el mes de Septiembre (22). Igualmente

(22) En el mes de Septiembre de 1947 se recogieron en Reinosa $142 \mathrm{~mm}$. $y$ en el mismo més del ano 1962 el volumen recibido fue de $193 \mathrm{~mm}$., siendo estos dos años los que mayor precipitación tuvieron, on el mes citado. Iogica.

Reinosa, Estación Metereo- 


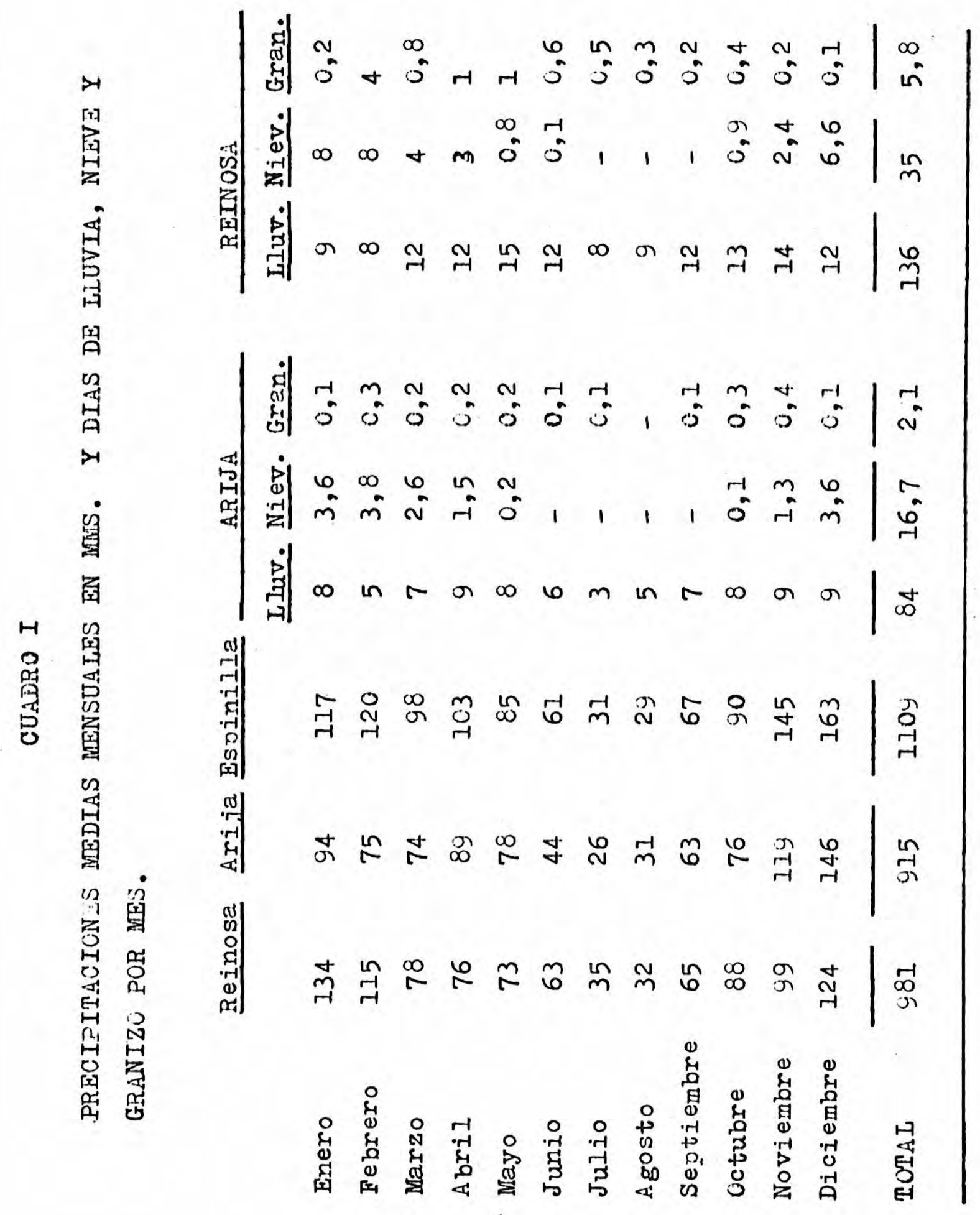


en el resto de los meses. de verano se alternan afos muy 1 luviosos con otros en los que las precipitaciones recogidas son insignificantes. Y Gsta es sin duda otra de las caracterfstí car de la comarca, reflejo de la encontrada influencia atlán tica y mediterranea; esta ultima se deja sentir con mayor $r \underline{i}$ gor precisamente durante el est1o e introduce unos condicionantes ecologicos de especial significado. Por ello, el convencional Indice de 10 s $30 \mathrm{~mm}$. como unbral de la Iberia Húmeda carece en la comarca de olgnificado y deberla oer muy matizado mediante el empleo de otras observaciones más detaIladas.

Empero, la irregular presencia de la lluvia durante el verano no es el único rasgo sobresaliente del clima de la co marca. En efecto, la variabilidad del número de dias de 11 via on cada estación del afo, la importanoia de la precipita ción estival en Campbo de Sugo frente a la menor cuantla del resto, y aun la gradación de la precipitación invernal en las tres valles -Campoo de Suso, Enmedio y Yuso- son otros tantos rasgos de variabilidad del clima de la comarca, dentro de la regularidad impuesta por su pertenencia a un espacio de montafa. Dentro de este contexto, las precipitaciones, y en particular las invermales, eon un elemento definidor del clima campurriano.

a/ Importancia y significado de las precipitaciones Invernales.

Como anteriormento apuntabamos, las elevadas precipitaclones anuales, aunque son un elemento excluyente no es en ab soluto definidor del clima de la comarca. Un total anual elevado no implica en absoluto una regularidad; más bien habrla que indicar que es la irregularidad anual el rasgo dominante. Dentro de esta irregularidad, el predominio de la precipitación invernal es, sin lugar a dudas, un elemento fundamental. 
En efecto, durante 10 meses de Octubre a Febrero, que en rigor deben considerarse como plenamente invernales, se re coge un volumen de precipitación superior al 60 por 100 del total anual; son 108 meses de Diciembre, Enero y Pebrero 10s que reciben ésta en mayor cuant1a, más de $100 \mathrm{~mm}$. por término medio, sin que sea posible, por la insuficiencia de 108 regie tros, discernir lo que corresponde a precipitación llquida o solida. No obstante esta última debe ser abundante por el ele vado numero de dlas de nieve on los citados meses.

\section{CUADRO II}

DISTRIBUCION DE LAS PRECIPITACIUNES ANUALES

\begin{tabular}{l|c|c|c|c|c|c|c|c}
\cline { 2 - 8 } & \multicolumn{2}{c|}{ OtoNo } & \multicolumn{2}{c|}{ INVIEIRO } & \multicolumn{2}{c|}{ PRIMAVERA } & \multicolumn{2}{c}{ VELANO } \\
\hline & Total & $\%$ & Total & $\%$ & Total & $\%$ & Total & $\%$ \\
\hline Reinosa & 311 & 31,7 & 327 & 33,3 & 211 & 21,5 & 132 & 13,5 \\
Espinilla & 470 & 38,4 & 362 & 29,6 & 240 & 19,6 & 150 & 12,4 \\
Arija & 341 & 37,2 & 243 & 26,5 & 211 & 23 & 120 & 13,3 \\
Aguilar & 200 & 31,8 & 183 & 29,1 & 154 & 24,5 & 91 & 14,6 \\
\hline
\end{tabular}

Se trata, en suma de un régimen de precipitación de mar cado caracter invernal, sin que por ello sea despreciable la precipitación equinocial, y dentro de ella, la primaveral. Prácticamente en todos los observatorios las lluvias comienzan a producirse con cierta regularidad en el mes de Septiembre, y se prolongan, sin solución de continuidad, $y$ 
olempre dentro de valores elevados, hasta el mes de Febrero. A partir de este mes, las precipitaciones inician un sensible descenso, acentuado en $10 s$ meses centrales del est1o.

Pero junto a la elevada cuantla, destaca la regularidad con que se producen; durante el periodo otoño-invernal, 108 dlas en los que se recoge algún tipo de precipitación, ya sea de Iluvia o de nieve, son superiores al 50 por 100 .

Frente al predominio de la precipitacion invernal, 108 bajos porcentajes, sobre el total anual, de la que corresponde a la primavera y verano, constituyen otro rageo distintivo, sin que ello suponga inexistencia de la misma. En ambas estaciones, los porcentajes de precipitación son, en el conjunto de los observatorios de la comarca, de 23,4 por 100 en la prí mavera, y de 13,4 por 100 en el verano. La parquedad de estos porcentajes no se puede interpretar en términos de escasa cuan tia de las mismas, puesto que en el primer caso, durante la primavera, ; se recoge un promedio de más de $220 \mathrm{~mm}$., y en el segundo, más de $130 \mathrm{~mm}$; del mismo modo, prácticamente en todos los meses la lluvia recogida es superior a $10830 \mathrm{~mm}$, si bien es cierto que, en algunos casos este umbral se rebasa en muy poco: (23).

Es precisamente este rasgo, el declive de la precipitacion durante el periodo estival, el que posee un mayor significado desde el punto de vista ecológico y aun geográfico. La organización del espacio agrario tradicional estará, como veremos, en gran parte condicionada tanto por la entidad y continuidad de la nieve durante $10 s$ inviernos, como por la escasa cuantia de la precipitación estival. Dos aspectos en ciertomodo contradictorios que explican la propia contradicción de la organización del espacio.

(23) El mes de Agosto es en el que un menor volumen de precipi tación se recoge on toda la comarca. En reinosa $32 \mathrm{~mm}$., Arija afos en los que la cuantia es muy superior. En 1959 se recogie ron en Reinosa $76,9 \mathrm{~mm}$. y $60,4 \mathrm{~mm}$. on Espinilia. 
b/ El declive estival de las precipitaciones: un fenómeno de enorme significado, en parte atenuado por las precipitaciones secundarias.

De acuerdo con los Indices medios se aprecia en la comarca una estación durante la cual las precipitaciones recogidas son muy inferiores a las del resto del ano, proximas a los $30 \mathrm{~mm}$. al menos durante 2 meses del verano. De acuerdo con ello, y empleando ten sblo lndices medios, la comarca estarla situada fuera de 10 e limites de la aridez mediterranea, y por ende, en una consideración estrictamente pluviométrica, dentro de la Espafia atlántica.

No obstante, tales Indices esconden numerosas irregularidades. En efecto, son numerosos los años en los que los meses de Julio y Agosto al menos, reciben un total de precipita ciones sensiblemente inferior a los $30 \mathrm{~mm}$. en cada mes. En Reinosa, de 30 años sometidos a observación fueron 20 los que estuvieron por debajo del umbral citado, en el mes de Agosto, y 21 en el mes de Julio. Ello nos lleva a suponer que, ni los Indices medios, ni siquiera los dias de lluvia mensuales son suficlentes para interpretar el alcance de la aridez. La suma de las precipitaciones recogidas a lo larko de cada mes, encubre el modo según el cual. estas se han producido, es deoir, ei de modo concentrado o regular.

Tan solo un Indioe puede servirnos para descubrir el aig nificado de la precipitación estival e incluso anual, y este no es otro que el de la lluvia máxima recogida on un oblo da. De acuerdo con 61 podemos afirmar que la mayor concentración de la precipltacion tiene lugar en el verano, $y$ en particular en el mes de Agosto, durante el cual más del 50 por 100 se recoge en un sólo dia (24). En el resto del año el grado

(24) Conviene hacer notar que tan sollo contamos con esta observación en la estación de Reinosa, y para un periodo de tiempo breve: 12 anos. Pese a todo, los resultados pueden servir de "apunte" sobre una posible tendencia de la distribución de las precipitaciones. 


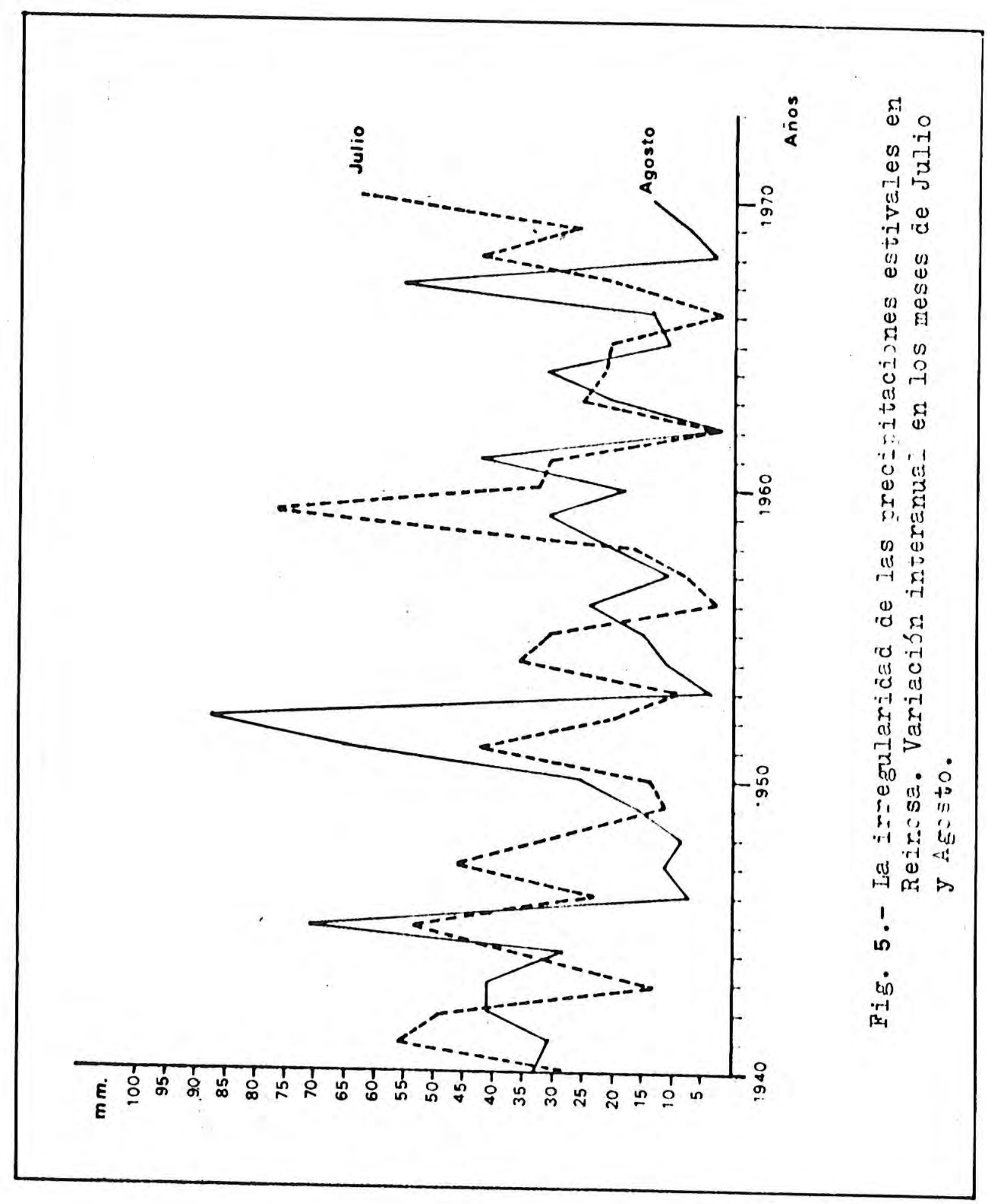


de concentración es menor, sin que por ello deje de ser expre siva la cuantla de la precipitación recogida en un sólo dia.

$$
\text { CUADRO III }
$$

ILUN:IA MAXIMA EN UN DIA EN LOS DIFERENTES MESES

\begin{tabular}{lrrl} 
& Total mensual & $\begin{array}{c}\text { Total un dia } \\
\text { mms. }\end{array}$ & $\%$ \\
\hline Enero & 120,5 & 25,9 & 21,4 \\
Febrero & 118,5 & 29,6 & 24,9 \\
Marzo & 67,9 & 20,8 & 30,6 \\
Abril & 74,8 & 17,4 & 23,2 \\
Mayo & 72,4 & 21,7 & 29,9 \\
Junio & 61,8 & 22,7 & 36,7 \\
Julio & 36,4 & 15,7 & 43,1 \\
Agosto & 38,4 & 19,5 & 50,7 \\
Septiembre & 49,1 & 18,6 & 37,8 \\
Octubre & 95,3 & 32,1 & 33,6 \\
Noviembre & 100,7 & 27,7 & 27,5 \\
Diciembre & 110,4 & 29,3 & 26,9 \\
\hline
\end{tabular}

Entre el 20 y el 30 por 100 de la precipitación media mensual se recoge en un sólo dla, durante la mayor parte de los meses; ello supone que, en términos generales prácticamen te el 30 por 100 de la precipitación anual corresponde a los 12 dlas de máxima precipitación mensual.

Por esta causa, el alcance del declive estival de las precipitaciones es mucho mayor del que revelan los indices medios, y merece una consideración más detenida. En efecto, tan sólo la mitad de la precipitación media mensual es la que se distribuye a lo largo de los 6 o 7 dias restantes del mes en los que llueve, durante el verano campurriano. Pero, lo 
cierto es que el grado de concentración es mucho mayor por la proximidad de los dias lluviosos, to cual acentua aún más la insuftclencia de agua en gran parte del verano. Una insuficien cia relativa, en parte corregida por las precipitaciones secun darias, de enorme significado ecológico, cuya presencia atenúa sensiblemente la aridez.

Son, en efecto, las precipitaciones "invisibles" o inapreclables, en forma de llovizna, las nieblas muy húmedas que se asientan $y$ permanecen en el fondo de los valles durante una parte del dia, las que mantienen condiciones ambientales y edá ficas capaces de retrasar o reducir el agostamiento de los pra dos. Pero el alcance de tales formas de condensación es, cabe suponer,insuficiente, en particular en aquellos años en los que la precipitación liquida de los meses de verano no alcanza siquiera $10 \mathrm{~s} 30 \mathrm{~mm}$.

El número medio de dias de roclo y niebla puede, pese a ello, se un Indice expresivo, no tanto desde el punto de vista climático como ecológioo. En Reinosa los dias de roolo son supertores a 15 en cada mes durante la primavera y verano, e Incluso a 20 en, al menos, dos de los meses, Agosto y Septiem bre. Por contra durante el otofo e invierno el número de dias con roclo es inaprectable. Lo mismo cabrla dectr de la niebla, sin que, como en ol caso anterior, nos sea posiblo conocer la intensidad de ambas formas de condensacion.

En gran parte la causa de estas formas de condensacion menores, y de las precipitaciones liquidas, es geográfica; la elevada altitud a la que se encuentra la comarca y su localización, en la vertiente meridional de la cordillera Cantábrica permite explicar gran parte de los tipos de tiempo que la afectan a lo largo del afio. En efecto, los enérgicos relieves de la Cordillera actúan de pantalla condensadora para las masas de aire cargadas humedad arrastradas hacia el interior 
por flujos de componente Oeste a Norte, dando lugar a que las mayores precipitaciones se registren en la vertiente septentrional; traspasado el unbral cantábrico, el aire enfriado desciende ocupando todos los valles, causa por la cual no se producen precipitaciones en la comarca, sino en una posición más meridional, cuando este aire frfo vuelva a desplazar maeas de alre cálido.

En cambio, cuando el frente cálido procede del Sudoeste las precipitaciones tienen lugar en la vertiente meridional, afectando al Valle de Campó en ou totalidad. En esta situación se recogen en la comarca las mayores precipitaciones, en particular durante la primavera y otono (25).

Durante el verano las mayores precipitaciones, o al me nos buena parte de llas tienen un origen tormentoso; los dias en los que dominan flujos del Este y del Sudeste, el suelo se calienta con rapidez, originéndose un fuerte gradiente térmico, favorecido por la peculiar configuración morfologica de la co marca, que da lugar no sólo a que las precipitaciones sean más - menos frecuentes, sino también a un incremento apreciable de su intensidad; la nebulosidad es habitualmente muy elevada, has ta un punto tal que,Reinosa, en el centro de la comarca tiene, durante el verano, más de un 80 por 100 de los dlas nubosos: o cubiertos en cada uno de los meses.

A esta precipitacion de origen tormentoso hay que anadix la que tiene lugar, también durante el verano, con tipos de tiempo anticiclonicos y que con menor intensidad, pero con ma yor continuidad, aportan un volumen, cuando menos apreciable, de la precipitación eatival. Son las denominadas "situaciones cantábricas", cuya génesis, cuya explicación en suma,es esen -

(25) G. MORENO MURAL.- Notas preliminares para una climatologia de Cantabria. Anales del Instituto de Estudios Agropecuarios. Vol. IV. Pág. 59-81. Santander 1979-1980. Cfr, pág 6y. 
cialmente geográfica (26). Se originan cuando el borde oriental del anticiclón subtropical coincide sobre la Penf́nsula, po sieión durante la que dominan vientos flojos de componente Nor te que arragtran hacia el interior masas de aire cálidas' y húmedas. Estas masas nubosas avanzan hacia el interior sin producir apenas efectos, envolviendo los valles de la vertiente septentrional en una persistente "morrina", hasta llegar a la Cordillera, donde a causa del ascenso y consigutente enfriamien to llegan a producir alguna precipitacion que, empero, apenas sobrepasa la divisoria. Su penetración hacia el interior es muy reducida, llegando a las vertientes de sotavento tan solo restos de aquelia nubosidad que trasponen la cordillera por colla dos o altitudes más modestas; su llegada tan solo es apreciable por las nieblas que resbalan por las laderas dejando caer un imperceptible goteo, un "sirimiri" inapreciable, al menos desde el punto de vista pluviométrico.

Pero si estas situaciones no llegan a producir apenas precipitaciones, si contribuyen a mantener unas condiciones de humedad ambiental de enorme aignificado ecológico. Gracias a ellas se puede pallar en parte el déficit de precipitaciones, no tanto por su intensidad, como por la frecuencia con que se suceden. Y este efecto, que se deja sentir en toda la comarca, es más acusado on ou extremo oriental. Aqui la altitud os més reducida y los restos de la nubosidad del sector de barlovento trasponen con mayor facilidad las cumbres, siendo la niebla un fenómeno habitual no sólo por esta causa, sino también por la que deriva de la fuerte irradiación nocturna en las proximidades del Pantano del Ebro. El volumen de agua embalsada y las bajas temperaturas nocturnas, incluso durante el verano, dan lugar a que en el contacto del aire cálido próximo a la superficie del agua con el aire frio de las primeras horas del dia, se produzca una intensa condensacion que llega cubrix

(26) J. ORTEGA VALCARCEL. - Ia transformación de un espacio rural. Ias Montañas de Burgos. Universidad de Valladolid. Departamento de Geografia. 1974. Cfr. pág. 95 y sig. 
parte de los valles de Campó de Enmmedio y de Camp6o de Yuso, permaneciendo, próxima al suelo hasta las horas centrales del dia.

La evaluación de este factor - la niebla- no puede reali zarse en tórminos rigurosos por causa de la falta de registros en este sentido, pero no dudamos de su importancia atendiendo al elevado numero de das en los que aparece en las proximidades del embalse del Ebro. En Reinosa el numero de dias con niebla durante el verano llega a representar casi el 50 por 100 en cada mes, siendo la permanencia de la misma otro aspecto nada despreciable, dado que se mantiene, y la propia expe riencia as1 lo confirma, durante gran parte de la mañana.

Con todo, es la localización y la altitud la que permite comprender el alcance y significado no sólo de estas formas de condensacion, sino también de otros tipos de precipitación que, como en el caso de la nieve caracterizan, por su: volumen, regularidad y permanencia el clima campurriano.

of La presencia y regularidad de la nieve en el Valle de Campoo.

La nieve es, en la comarca cempurriana, uno de los elementos de mayor significado, no sólo por la elevada cuantia, presumible, pero diffcil de evaluar, sino, y sobre todo, por la regularidad con que hace su aparicion. El periodo durante ol cual se pueden producir netradas comienza en el mes de 0ctú bre y se prolonga hasta Mayo, mes en el que se registró precipitación de nieve en 13 de 10830 años observados; es cierto sin embargo que en este mes son pocos los dias en los que nieva, y la cuantla y permanencia en el suelo, salvo en los sectores más elevados, prácticamente despreciable.

El fenomeno se concentra de modo bastante acusado durante los meses centrales del invierno, no sólo porque en ellos 
el número de dlas es mayor -entre 6 y 9 dias-, sino por la frecuencia con la que aparece -más del 90 por 100 de $10 s$ me8อ8.

\section{CUADRO IV}

FRECUENCIA DE IA NIEVE EN CAMPO

\begin{tabular}{llll} 
& $\begin{array}{l}\text { Afros con } \\
\text { Nieve }\end{array}$ & $\begin{array}{c}\text { Frecuencia } \\
\%\end{array}$ & $\begin{array}{c}\text { Media de dias } \\
\text { de nieve }\end{array}$ \\
\hline Enero & 29 & 96,6 & 8,6 \\
Febrero & 27 & 90 & 8,5 \\
Marzo & 24 & 80 & 3,9 \\
Abril & 15 & 50 & 3,2 \\
Mayo & 13 & 43,3 & 0,8 \\
Octubre & 7 & 23,3 & 0,9 \\
Noviembre & 21 & 70 & 2,4 \\
Diciembre & 28 & 93,3 & 6,6 \\
& & & \\
\hline Reinosa. Estacion metereol6gica. &
\end{tabular}

Los meses de Noviembre y Marzo constituyen la solución de continuidad entre aquellos en los que la nieve es una cong tante y aquellos en $10 s$ que ésta aparece de modo esporádico. En efecto, ambos meses, y con una frecuencia todavia muy acu sada, más del 70 por 100, registran nieve en una cuantla que desconocemos, durante al menos dos dias.

Pero si los valores medios son suficientemente expresivos conviene indicar que no son desconooldos afos con un número de dias de nieve muy elevado, más de 30 e incluso de 40 . La expl 1 cación de esta frecuencia hay que buscarla no sblo on la presencia de tipos de tiempo especificos, sino también en las con diciones morfologicas de la comarca. Son estas las que, dentro del periodo de nevadas abierto por las condiciones metereológi cas, permiten comprender la frecuencia y aun la intensidad de las mismas. Los más de $850 \mathrm{~m}$. de altitud a los que se encuentra 
toda la comarca constituyen un elemento clave para el entendimiento, no sólo de la presencia de este elemento, sino también de los caracteres térmicos que, aún mejor que las precipitacio nes, singularizan el clima comarcal.

2.- UN REGIMEN TERMICU DE MONTANA

El Valle de Campoo puede, como ya hemos apuntado, ser definido, desde el punto de vista climático, como un sector de acusado déficit térmico. El atributo montañés se refleja de modo inmediato en unos caracteres térmicos que, en si mismos, singularizan el clima campurriano.

El frlo es, en efecto, uno de los rasgos más destacados del clima del Valle de Campbo; la media del mes más frlo no su pera, en ninguno de los observatorios, 2,5 grados, mientras

\section{CUADRO V}

TEMPLRATURAS MEDIAS MENSUALES

\begin{tabular}{lcccc} 
& Reinosa & Arifa & Aguilar & Espinilla \\
\hline Enero & 2,2 & 2,3 & 2,3 & 2,2 \\
Pebrero & 3 & 3,4 & 3 & 2,8 \\
Marzo & 6 & 6,4 & 6,4 & 5,6 \\
Abril & 7,8 & 8,3 & 8,6 & 7 \\
Mayo & 10,3 & 10,9 & 11,7 & 10,4 \\
Junio & 13,8 & 13,1 & 15,2 & 13,4 \\
Julio & 15,7 & 16,7 & 17,8 & 15,8 \\
Agosto & 15,9 & 16,7 & 17,9 & 15,7 \\
Septiembre & 14,1 & 15,1 & 15,4 & 13,9 \\
Octubre & 10 & 10,6 & 11 & 10,3 \\
Noviembre & 6 & 6,3 & 5,7 & 5,5 \\
Diciembre & 3,1 & 3,6 & 2,8 & 3 \\
D & & & & \\
\hline
\end{tabular}




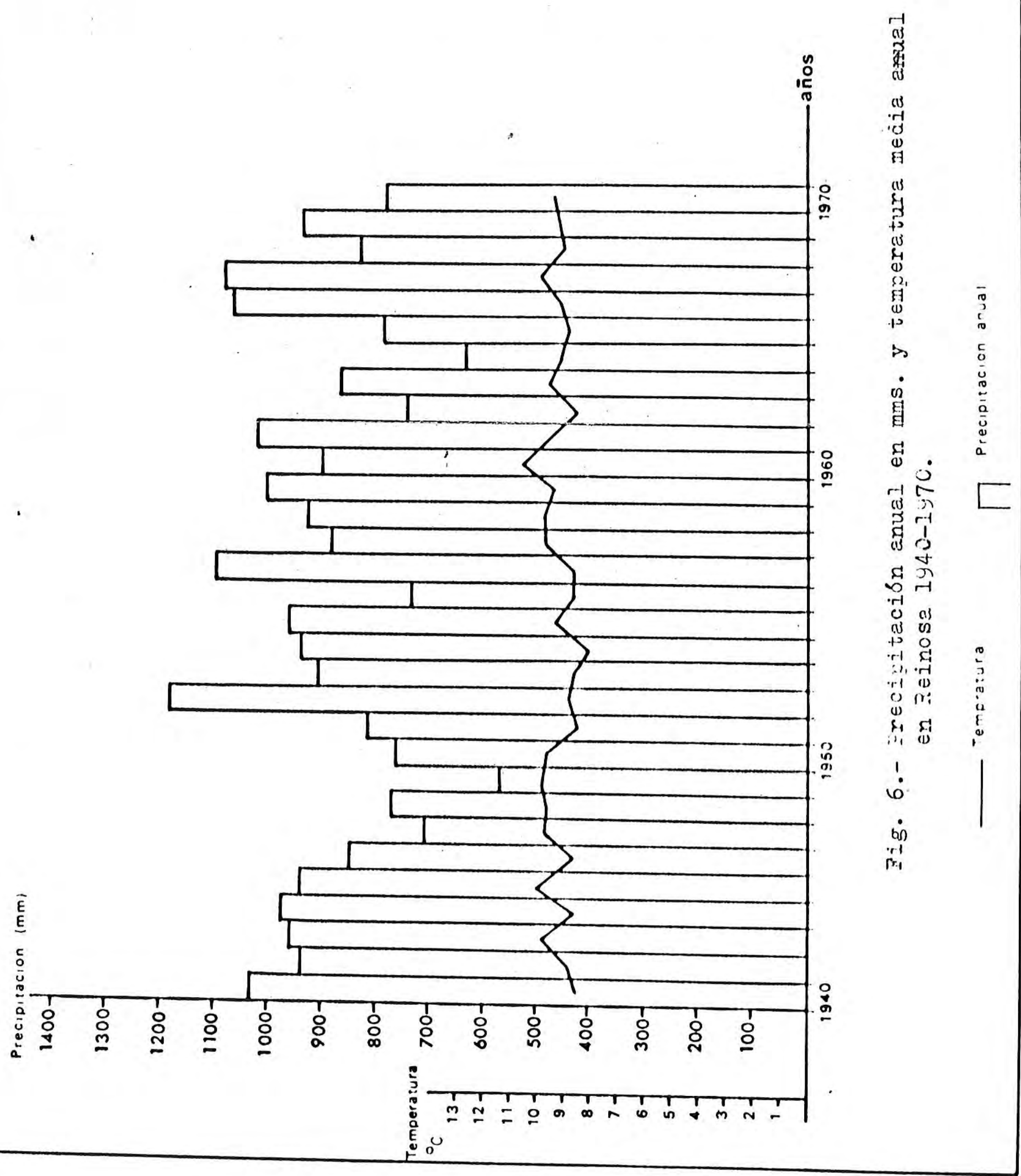


que el mes más caluroso apenas alcanza los 16 grados. Entre tres y cinco meses estan por debajo de los 6 grados, y tan soblo cinco meses en Reinosa y seis en Arija superan los 10 grados. Por último, ningún mes tiene una temperatura media superior a los 18 grados, 10 cual hace más patente la regula ridad, dentro de valores bajos, de las temperaturas en la comarca.

Pero, mayor significado que los valores medios mensuales tiene la consideración de las temperaturas extremas, es decir, la media de las temperaturas máximas y minimas. La temperatura minima media del mes más frío es, en todos los casos, negativa, mientras que la máxima media del mes más caluroso no sobrepasa los 22 grados. Igualmente, la media de las temperaturas $\mathrm{m} 1$ nimas absolutas es negativa desde octubre a Mayo, ambos inclusive, en Reinosa, desde Octubre a Abril en Arija y desde Noviembre a Abril en Espinilla, (27).

\section{a) Un Invierno frlo y de larga duración.}

La rigurosidad y duración de los inviernos es, como atributo de montaña, un rasgo especffico del clima de la comarca. Afectada por situaciónes atmosféricas y tipos de tiempo propios del invierno peninsular, los efectos de éstos se ven incrementados por la estructura morfologica, que contribuye a estancar masas de aire frlo, favoreciendo con ello inversiones térmicas muy acusadas (28): Ello explicarla los bajos valores que alcanzan las temperaturas invernales; son frecuentes valores

(27) El reducido número de años completos de que dispone la estación metereológica de Espinilla, obliga a considerar los valores expuestos con cierta prevención. Bien es cierto que los resultados, de haber contado con más años de observación, no serlan muy diferentes, por la regularidad que muestran tan

(28) Desde el Pico "Tres Mares", vértice occidental de la comar ca, en Campó de Suso, parten dos alinaciones. Una -la sierra de Hijar, con dirección Sureste, cierra el Valle por el Sur hasta el Puerto de Pozazal -989 m.-, y otra -la sierra del Pico cordel, que en dirección Este cierra el Valle por el Norte, si bien es cierto que en Campoo de Yuso la attitud desciende consi- 
extremos inferiores a 15 grados bajo cero, e incluso a 20 grados. Asimismo, entre los meses de Noviembre y Abril, son absolutamente habituales valores extremos negativos.

CUADRO VI

TEMPERATURAS MINIMAS MEDIAS Y MINIMAS ABSOLUTAS

\begin{tabular}{|c|c|c|c|c|c|c|}
\hline & \multicolumn{3}{|c|}{ Minimas medias } & \multicolumn{3}{|c|}{ Minimas absolutas } \\
\hline & Reinosa & Arija & Espinilla & $\overline{\text { Reinosa }}$ & Arija & Espinilla \\
\hline Enero & $-2,2$ & $-1,6$ & $-0,6$ & $-10,4$ & $-9,7$ & $-13,3$ \\
\hline Pebrero & $-1,7$ & $-0,9$ & $-0,2$ & $-10,3$ & $-7,8$ & $-6,5$ \\
\hline Marzo & 0,9 & 1,5 & $-0,1$ & $-5,5$ & $-4,6$ & $-5,5$ \\
\hline Abril & 2,7 & 3,1 & 0,9 & $-2,6$ & $-1,2$ & $-0,9$ \\
\hline Mayo & 4,9 & 5,1 & 6,4 & $-0,8$ & 0,1 & 1,6 \\
\hline Junio & 8,2 & 6 & 8,4 & 3 & 3,9 & 1,7 \\
\hline Julio & 9,6 & 10,2 & 10,2 & 3,9 & 5,4 & 3,1 \\
\hline Agosto & 9,6 & 10 & 9,1 & 4,2 & 5,2 & 3,1 \\
\hline Septiem. & 8 & 9,1 & 7,1 & 2,1 & 3,3 & 0,3 \\
\hline Oatubre & 4,6 & 5,4 & 6,1 & $-1,4$ & $-0,5$ & $-0,3$ \\
\hline Noviembre & 1,4 & 1,8 & 2,7 & -5 & $-4,4$ & -3 \\
\hline Diciembre & 0,9 & $-0,2$ & $-1,5$ & $-7,9$ & -6 & $-6,1$ \\
\hline
\end{tabular}

Pero si como hemos apuntado el invierno es largo y muy orudo, son los meses de Enero y Febrero los que destacan en el conjunto, sin que por ello sean desconocidas fuertes oleadas de frio a finales del otofo y principios de la primavera. La media de las temperaturas minimas es, en todos los casos negativa en Enero y Febrero, $y$ si en Noviembre y Marzo es positiva, $20 s$ valores extremos son negativos.

El frlo es, en la mayor parte del invierno una constante; la temperatura minima es habitualmente negativa, y las $\mathrm{m} 1$ nimas medias mensuales lo son también como resultado de absolutas negativas, durante bastantes dlas. $¥$ este carácter se en 


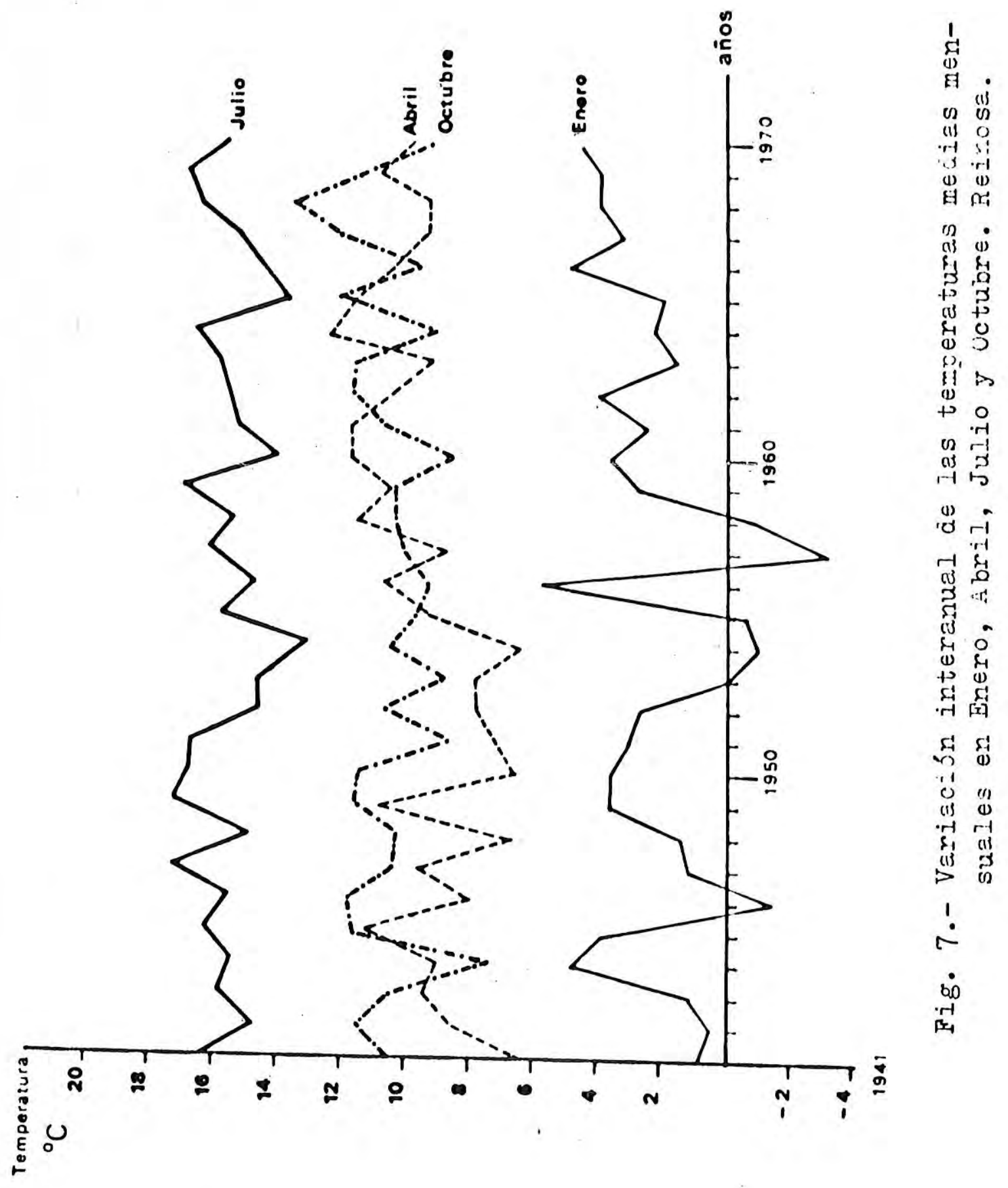


cuentra reforzado por la escasa entidad de las temperaturas positivas; la media de las máximas rara vez alcanza los 10 gra dos, si bien es ciexto que excepcionalmente, las máximas absolu tas, dentro del periodo invernal, pueden alcanzar los 18 grados. Una temperatura elevada, que no empequerece el rigor del frlo, cuya presencia se deja sentir durante una parte sustancial del año.

Son muchos 10s meses, desde Votubre a Mayo, durante 108 que las temperaturas minimas pueden ser negativas, y ello con carácter habitual, si bien es cierto que en los márgenes de la primavera y del otofo, se suceden tipos de tiempo menos riguro sos que, empero, no som suficientes para enjugar lo que todavia conotituye el rasgo dominuntes el frio.

Los rigores invernales se prolongan durante gran parte de la primavera y otono, periodos en los que la temperatura me dia de las minimas es positiva, pero raramente excede de los 6 grados; aún en estos meses, las minimas absolutas son por 10 general negativas, las heladas extemporaneas son frecuentes, so adelantan en el otofio $y$ se prolongan en la primavera, al me nos hasta Mayo. Su origen hay que buscarlo en la presencia de situaciones atmosféricas de estabilidad, anticiclónicas, duran te las que la irradiación nocturna es muy fuerte, acentuada por la altitud $y$ por el carácter cexrado del valle. Una muestra de la presencia de esta situaciones y su frecuencia en la comarca es, sin duda, el elevado número de dís en los que la escarcha hace ou aparición en el suelo, entre 5 y 15 dias durante la prí mavera y otono.

Al igual que las precipitaciones, las temperaturas de am bas estaciones son una práctica continuidad de las invernales. Bien pueden oer consideradas como estaciones sin personalidad, como un mero tránsito durante el que las primeras inician una inexorable marcha hacia los minimos estivales, y las segundas 
se van suavizando, sin que ello suponga una desaparición del frio. Ios tipos de tiempo son también una continuidad de 108 que predominan durante el invierno, si bien entre ellos se in tercalan breves periodos de buen tiempo cuya frecuencia se $1 \underline{n}$ orementa en las proximidades del verano, que, pese a todo, $y$ como una muestra más del carácter montańes de la comarca, es esencialmente fresco.

\title{
b/ unos veranos frescos
}

En el Valle de Campbo, y salvando los breves periodos on los que el calor es la nota dominante, durante los que se pueden alcanzar máximas extremas superiores a los 30 grados, las temperaturas medias en 108 meses de verano apenas sobrepasan 10810 grados. Del mismo modo, y a pesar de que durante la mi-

\author{
CUADRO VII
}

TEMPERATURA MAXIMAS MEDIAS Y MAXIMAS ABSOLUTAS

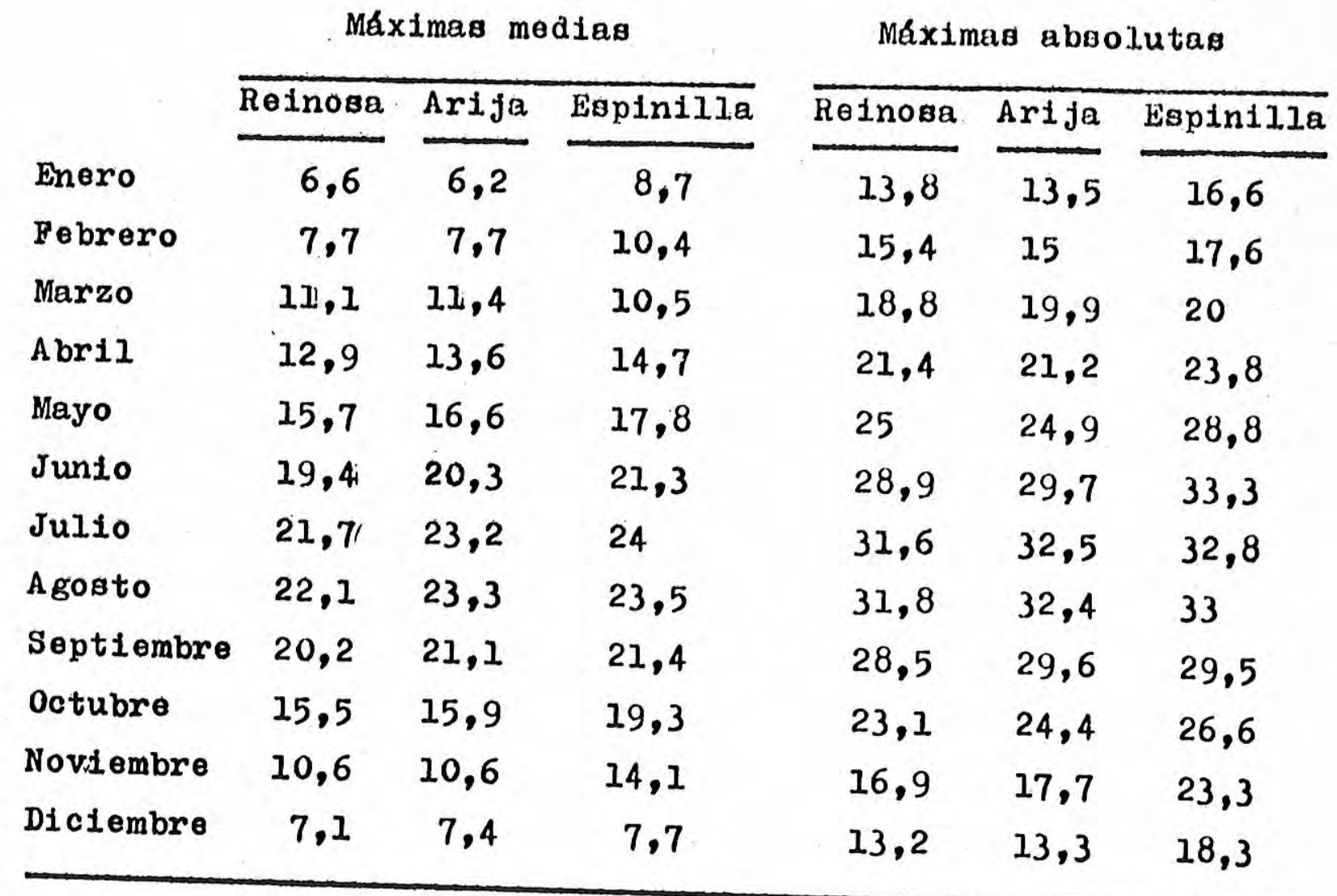


tad del affo - de Mayo a Octubre- las temperaturas medias mensuales son iguales o superiores a los 10 gxados, no se puede considerar este largo periodo como verano propiamente dicho. La delimitación del mismo, aun partiendo de los valores medio, máximos y mínimos, no deja de ser aleatoria desde el mismo momento en que es preciso establecer unos umbrales excluyentes. Pese a esta dificultad, podemos reducir la estación estival a aquelios meses en los que las temperaturas minimas medias supexan 10s 8 grados, y las máximas medias los 20 grados, es decir, a 108 meses en $10 s$ que la amplitud térmica supera 108 12 grados.

De acuerdo con ello el perlodo estival queda reducido a Iов meses de Julio, Agosto y Septiembre, si bien en este últi mo caso las temperaturas minimas medias son ya sensiblemente bajas. El carécter fresco es, como de los valores apuntados se puede deducir, el rasgo dominante del verano campurriano. En ninguno de los tres observatorios, Reinosa, Arija y Espini 1la, que pese a la parquedad de las observaciones en algún caso, pueden ser perfectamente representativos de los tres Valles, las temperaturas medias mensuales superan $10 s 18$ grados, sien do incluso en Septiembre francamente bajas $-14,1$ grados en Reinosa, 14,2 en Espinilla y 15,1. en Arija.

No son desconocidos en cambio tipos de tiempo, coinciden tes con situaciones de componente meridional, en 108 que las altas temperaturas son un elemento habitual; durante su perma nencia la sequedad se acentúa y la humedad relativa puede descender a la mitad de sus valores habituales. Se trata de das en los que se alcanzan las temperaturas más elevadas del año, 10 mismo que en gran parte de la costa cantábrica (30).

La presencia de estas situaciones es, empero, poco frecuente. Más constante es la presencia de tipos de tiempo t1pi-

(30) G. MURLNO MURAL.- Notas... Op. cit. pág. 72 
canentie estivales, que mantienen las temperaturas máximas pró ximas a los 30 grados. Gracias a ellos, y puesto que no son desconocidos tipos de tiempo frios e inestables, la media de los valores máximos oscila durante el verano entre los $20 \mathrm{y}$ 24 grados. En efecto, como ya habiamos apuntado, la situacion septentrional de la comarca, permite que ésta participe de tí pos de tiempo, de situaciones atmosféricas, de escasa influen cia en el conjunto de la Penfnsula, pero de decisiva acción sobre la costa cantábrica. Tal es 10 que sucede con $10 s$ extremos de frentes frlos, que ven acentuada su incidencia, en par te por la elevada altitud de la Cordillera Cantábrica y cuya presencia se deja sentir con cierta frecuencia, incrementándo se la nubosidad, suavizándose las temperaturas y reduciéndose apreciablemente el número de horas de sol (31). Y esta es una de las notas dominantes del verano en Campbo. En efecto, es el carácter fresco de gran parte del verano lo que distingue y diferencia este sector de montaña de otros relativamente pr's ximos; un frescor que se acentúa por la fuerte irradiaction noc turna, $y^{\prime}$ que puede hacer descender el termometro hasta valores próximos a los 0 grados en las primeras horas del dla (32). Nuevamentio hemos de atribuir a la morfologla de la co marca un papel fundamental, deciaivo, en la reducción de las temperaturas eativales. Menced a ella, el aire frio permanece en el fondo de los valles, por su mayor densidad, durante gran parte del dia. Tras el calentamiento diurno, la consiguiente irradiación nocturna hace descender considerablemente el ter-

(31) El número de dias nubosos o cubiertos es elevado en el estlo campurriano. En conjunto, la nebulosidad -suma de los dfas nubosos y cubiertos- es considerable: en Julio más del 85 por 100 de los dlas del mes, en Agosto el 83 por $100 \mathrm{y}$ en Septiembre,el 86 por 100 . (132) En la estación metereológica de Reinosa, y de modo más acusado en la de Espinilla -Campbo de Suso-, la media de las minimas absolutas no supera los 3 grados, ni siquiera en el centro del verano. 
mómetro, generándose una intensa condensación -niebla o rocioen las proximidad del suelo. Por esta causa, entre otras, las temperaturas se mantienen uniformemente moderadas durante gran parte del verano.

Todo ello nos lleva a considerar el verano de la comara como una estación poco definida; ni las elevedus o bajas tempe raturas, ni la presencia o ausencia de la lluvia son "per se" rasgos distintivos. Mas bien habrla que indicar que es la irre gular sucesión de todos ellos el aspecto más sobresaliente del verano en Campठo. Y esta Irregularidad está presente en el con junto del año, con un carácter, con una constancia tal que ha actuado, a nuestro entender, como elemento clave en la organización del espacio agrario tradicional.

En efecto, estas condiciones climáticas, en las que son constantes la elevada humedad, irregularmente repartida a lo largo del año, y la larga duración y rigurosidad de los invien nos, unidas a la altitud y, obviamente a la localización de comarca en un sector de la cordillera Cantábrica, constituyen los ejes sobre los que se vertebran los rasgos esenciales del paisaje vegetal, un paisaje que no por estar profundamente transformado ha perdido los caracteres básicos de su atributo montañés y de la montaña cantábrica en particular. 


\section{CAPITULO III}

UN PAISAJE VEGETAL PROFUNDAMENTE TRANSFORMADO

La altitud -toda la comarca se encuentra por encima de los $800 \mathrm{~m}$. - y unos rasgos climáticos en los que sobresale la elevada humedad y el intenso frio invernal, confieren a este sector unos caracteres peculiares cuyo reflejo inmediato es un paisaje vegetal variado, pero constituldo por un número no muy elevedo de especies, precisamente la que mejor se adaptan a los condicionantes apuntados, y cuyo valor fisionómico, geo gráfico es indudable.

La superficie ocupada por formaciones vegetales en la comarca es superior al 50 por 100 del total -20246 Has.-, pe ro esto no quiere decir, ni mucho menos que toda ella corresponda a una superficie arbolada. Muy al contrario, y al menos en la actualidad, la mayor parte de la cobertera vegetal está compuesta por formaciones inferiores, herbaceas y arbustivas; y este estrato es la nota dominante en un paisaje que tan solo esporádicamente en los niveles bajos, y algo más en continuidad en los sectores más elevados -por encima de los $1000 \mathrm{mo-}$ aparece salpicado por pequeños rodales de monte muy degradados a causa de la continua explotación de que han sido objeto. Los limites de estos son en todos los casos muy precisos; no existe apenas solución de continuidad entre los prados y ellos, muestra evidente de que su retroceso obedece al dilatado queha cer de una población asentada en un terrazgo exiguo, cuyos 11 mites periódicamente se vela obligada a ampliar.

No ha de sorprender por lo tanto que el resultado de to do ello sea la reducida extensión que tienen en la actualidad los montes arbolados; éstos no alcanzan a cubrir el 19 por 100 
de la superficie forestal total de la comarca, con la particu laridad de que la mayor parte de ellos se localizan en los sec tores más elevados, en enclaves-refugio que les han permitido eludir la acción humana.

Por ello el paisaje natural actual es tanto el resultado de la adaptación de las distintas especies a las condiciones ecolbgioas del medio, como de las sucestvas modificaciones Impuestas por el hombre, que ha transformado los rasgos esenciales del primitivo manto vegetal; éte, de estar constituido por formaciones arbóreas ha pasado a estar dominado por la om nipresencia de los prados y matorrales, que ocupan más del 80 por 100 de la superficie total de la comarca.

La perturbadora acción humana aparece por lo tanto como la principal responsable de los caracteres que la cobertera vegetal presenta en la actualidad. Una acción a la que se tra to de poner limtaciones desde fecha muy temprana, pero que sin embargo fueron insuficientes pare contener el proceso sis temático de destrucción de la superficie arbolada. La pobreza, la extremada penuria de gran parte de la población durante mu chos siglos permite comprender, en parte, las dimensiones del citado proceso,por el cual gran parte de las extensas superfí cies arboladas han quedado reducidas a meros rodales de monte bafo, afln en cuanto a sus caracteres y su génesis con los matorrales y con $10 s$ que se confunde y entra en contacto en numerosas ocasiones sin transicion aparente (33).

De este modo, si desde los orlgenes del poblamiento prác ticamente todos los pueblos contaban con una superficie de monte más o menos amplia, actualmente, y el resultado era ya evidente en el siglo XIX, estas superficies están ocupadas

( 33 ) J. CALDERON ESCALADA,- Campóo... Op. cit. p. 145. 
por el matorraj. y los pastog. Tal ha stdo la intensidad del proceso roturador, tanto individual como colectivo que ni si quiera las sectores vedados de los montes, las "conclas" se libraron del hacha y del fuego, quedando finalmente converti das en un monte bajo, y éste muy aclarado para facilitar el aprovechamiento de los escasos pastos que podia proporcionar.

Pero no fue sólo la ampliación del terrazgo la causa por la que las primitivas masas forestales desaparecieron o se vie ron reducidas en su extensión; en la economla rural tradicional, el aprovechampento de la madera para la elaboración de productos artesanales constituia un capltulo esencial, el úni co a veces, para los que no tenian otros recursos, en la subsistencia de la población campesina.

La suma de tales acciones en un proceso secular, habría dado lugar no sólo a la reducción de la superficie arbolada, sino incluso a una profunda degradación de la misma, provocan do cambios decisivos en el paisaje.

1.- EI CARACTER RESIDUA], DE JAi MASAi FORESTAJES.

La superficie arbolada representa ton sblo un 19 por 100 de la cobertera vegetal, con una superficie de 3.833 hectáreas. Pal extensión no se presenta en forma continua, sino que muy al contrario aparece fragmentada en varios montes, alguno de los cuales tienen una superficie muy reducida, 20 o 30 hectáreas. En gran medida la existencia de gran parte de estos montes se debe a que están localizados en enclaves de diffcil. acceso, muy alejados de los núcleos de población y: poco atractivos pa ra su transformación en pastizales, práctica habitual en el pasado y causa de la destrucción de no pocos de ellos; por otra 
parte no hay que olvidar que en muchos de ellos el aprovechamiento de Ja madera ha estado tradicionalmete limitado, lo cual ha sido un factor esencial en su conservación.

Salvo en Campóo de Enmedio, donde aún se encuentran super ficies arboladas de cierta entidad, la mayor parte de éstas se localizan en Campbo de Suso; es aqui, en efecto, donde se con servan los montes de mayor superficie, bien poblados, constitu yendo autenticas reservas forestales.

No obstante, y pese a que su situación es marginal dentro del valle, su explotación ha sido también intensa, tanto de la madera, como de los pastos que de modo fragmentario se encuentran en ellos. El aprovechamiento de estos pastos en el verano por los ganados de la Comunidad Campó-Cabuérniga constituyo, en efecto, uno de los fundamentos de la economia tradicional.

pero tanto en éstos como en otros, con independencia de su extensión, el proceso de degradación ha sido -lo es menos en la actualidad-continuo, y sus consecuencias no se han dejado sentir en el orden económico -al fín y al cabo de ha dila pidado un extraordinario capital-, sino también en el orden ecológico, toda vez que las superficies ocupadas otrora por montes blen desarrollados, densos, se han degradado hasta con vertirse en monte bajo o matorral de "brezos" y "argomas", con algún pasto y "algunos árboles afslados ( 34 ).

Los testimonios de esta sistemática destrucción de las masas forestales en Campbo son bastante numerosos. Aparecen recogidos desde fecha muy temprana en las ordennazas de los diferentes concejos, en ocasiones junto a estrictas disposiciones destinadas a su fomento, tales como la obligación de plantar determinadas especies por parte de los vecinos anual

(34) Descripción de los montes Pastiza y Picales. Lugar de Argüeso. En Relación comprensiva de los bienes comunales exig tentes en este término municipal, con expresion de su clase, nombre, cabida, producción linderos y pueblo al que pertenecen, que se forma en cumplimiento de lo ordenado por el Exmo. Gobernador Civil de la provincia en circular no 112, inserta en el Boletín Oficial n 90 del Viernes 12 de Junio de 1931. Archivo del Ayuntamiento de la Hermandad de Campóo de Suso. S.C. 


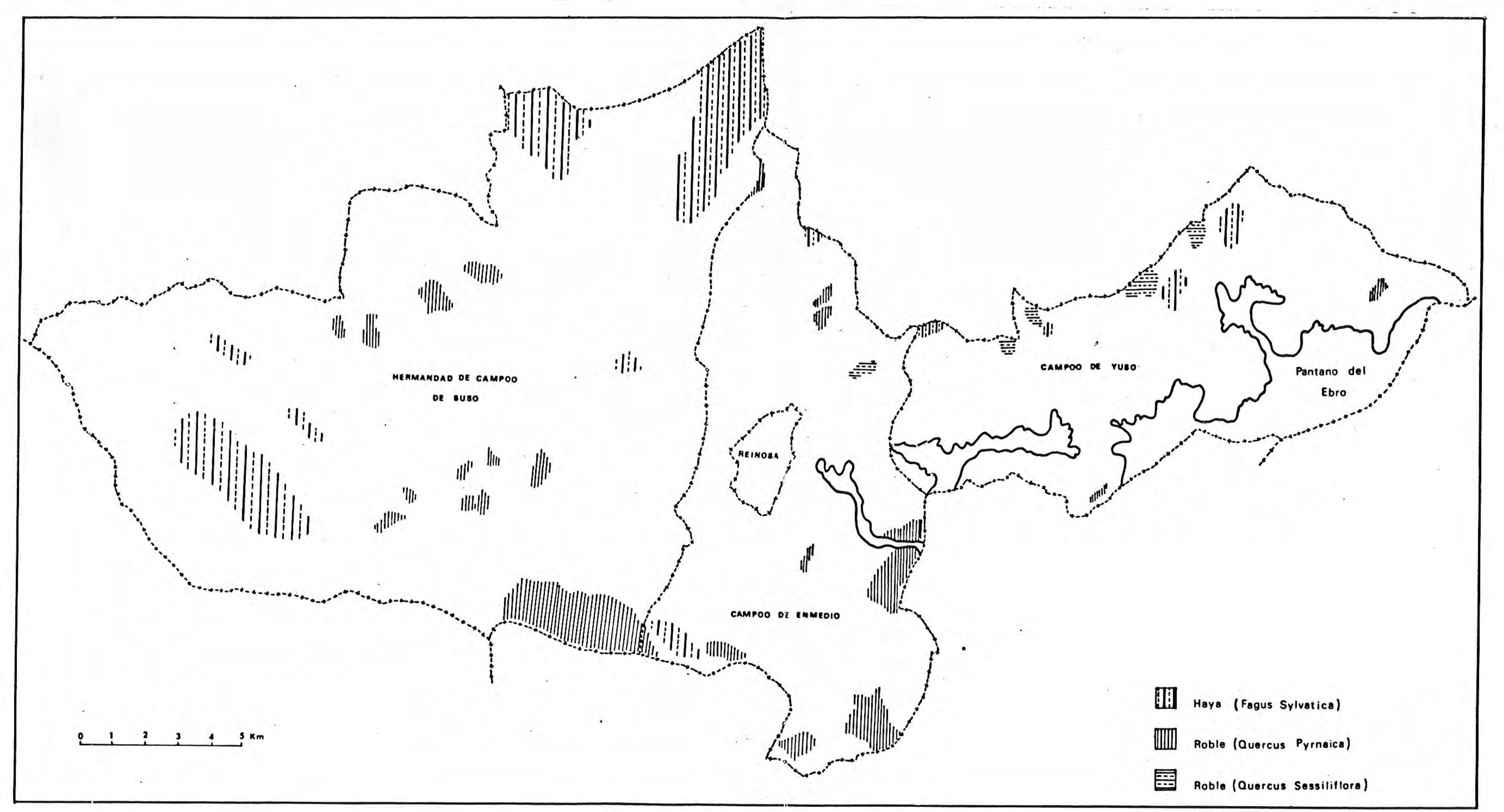

Fig. 9- Distribucion de las masestorestales 
mente o respetar 10 s sectores acotados (35).

A mediados del aiglo XVIII, la superficte arbolada, cuya extension nos es imposible precisar, parece encontrarse bastante mermada, especialmente en 10 que se refiere a los montes de roble, especie muy codiciada, tanto para la ejaboración de carbón con destino a las ferrerlas, como para la construcción naval; no en vano parte de los montes de roble estaban bajo jurisdicción de la Intendencia de Marina de Guarnizo. Un cál culo prudencial hecho en 1779, estimaba en más de 40.000 los carros de lef̃a que anualmente se hacían con destino a las ferrerlas " sin que se hubiese plantado ni uno sólo para su reem plazo, ni menos para el de tantos miles yue se han sacado para la construcción real"( 36 ).

No ha sido solo la formación vegetal la cue se ha transformado; en el mismo proceso de degradación en el que se inter fieren factores humanos, edáficos y aun climáticos se ha producido una variación de los caracteres de determinadas asocia ciones vegetales, cuya presencia en la actualidad tiene tan $s \underline{6}$ lo el carácter de testigo de los que en un pasado lueron forma ciones vegetales más densas, y asociaciones climácicas mucho más desarrolladas. De entre estas sobresalen, por su mayor ex tensión actual los hayedos, pero sin duda la mayor destrucción se ha realizado sobre los robledales.

En efecto, el roble propiamente dicho, "Quercus seusiliflora" y Q. Pyrenaica", se encuentra dentro de la comarca formando pequeñas masas aisladas que alcanzan casi hasta los 1100 metros de altura, en contacto con el sptimo climático de los hayedos. Tales masas se encuentra en la actualidad muy degra( 35 )." que entre dos vecinos planten cada un año un "cajigo" y le cierren ocho pies de alto" urdenanzas del Concejo de la Loma y Entrambasaguas. Año 1716. Citadas por J. CAJDERON EiCALADA. - Campóo... Op. cit. pág. 227. En el mismo sentido abundan las ordenanzas de la Hermandad de Campbo de Suso " Utrosi ordenaron que ninguno corte ningún pie de aya (sic) roble ni aceba ni espina, ningún arbol en ningún sel de vacas ebceto para hacer cabaña". Ibid. pág. 215.

(36) Geografía Moderna del Doctor Josef Jordan y Fargo. Miadrid 1779. Citado en Fontibre no 33 Mayo de 1959 pág 2. 
dadas, las copas de lps distintos individuos se encuentran se paradas, imponiendo un sotobosque de heliffilas no propiamente nemorales ( 37 ). Gan parte de estos montes -más bien peque ños tallares- se encuentran rodeados de fincas particulares, lo cual. habrla facilitado su tala furtiva, reduciendo la densidad progresivamente de lo que otrora fue sin duda un bosque denso; hoy gran parte de éstos están compuestos por "árboles de roble, escasos, de mala clase, en su mayoría inmaderables", descripcion que se repite en la mayor parte de ellos (38).

El último y casi definitivo impulso para su destrucción tiene lugar en el siglo XVIII, y está relacionado con el carboneo, actividad orientada a abastecer de este combustible a las ferrerlas; pese a estar limitada en todas las ordenanzas, tal forma de proceder díb al traste con gran parte de los "robles bravos y hayas de los bosque reinosanos" ( 39 ).

La adaptación a las condiciones climáticas y edáficas de esta especie -el roble-, tanto en su variedad "sessil" como en te "tozo" es bptima; por sus exigencias edáficas -se trata de une especie silicicola- se localiza, dentro de la comarca, en los afloramientos arcillo-arenosos de la facies Wealdense, as 1 como sobre las margas del Keuper. En uno y otro caso, los suelos son ácidos, profundos y muy lavados por el agua de lluvia, con un horizonte A rico en humus, en especial en su capa más superficial, en la que se acumula una gran cantidad de hojarasca seudo-humificada.

A lo largo de toda la comarca aparecen mezclados el $Q$. Sessiliflora y el Q. Pyrenaica -Rebollo-, predominando,

\footnotetext{
(37) E. GUINEA IOFEZ.- Geografía botánica de Santander. Santander 1953. Pág. 199.

( 38 ) Relación comprensiva... op. cit. Lugar de Soto. ( 39 ) G. BuWLEs. - Introducción a la Hist.ria Natural y a la Geografla de España. Madrid 1782. En F. BARREDA.- Prosperidad de Santander y desarrollo industrial desde el siglo XVIII. A portación al estudio de la Historia económica de la Montaña. Santander 1957. pág. 537.
} 


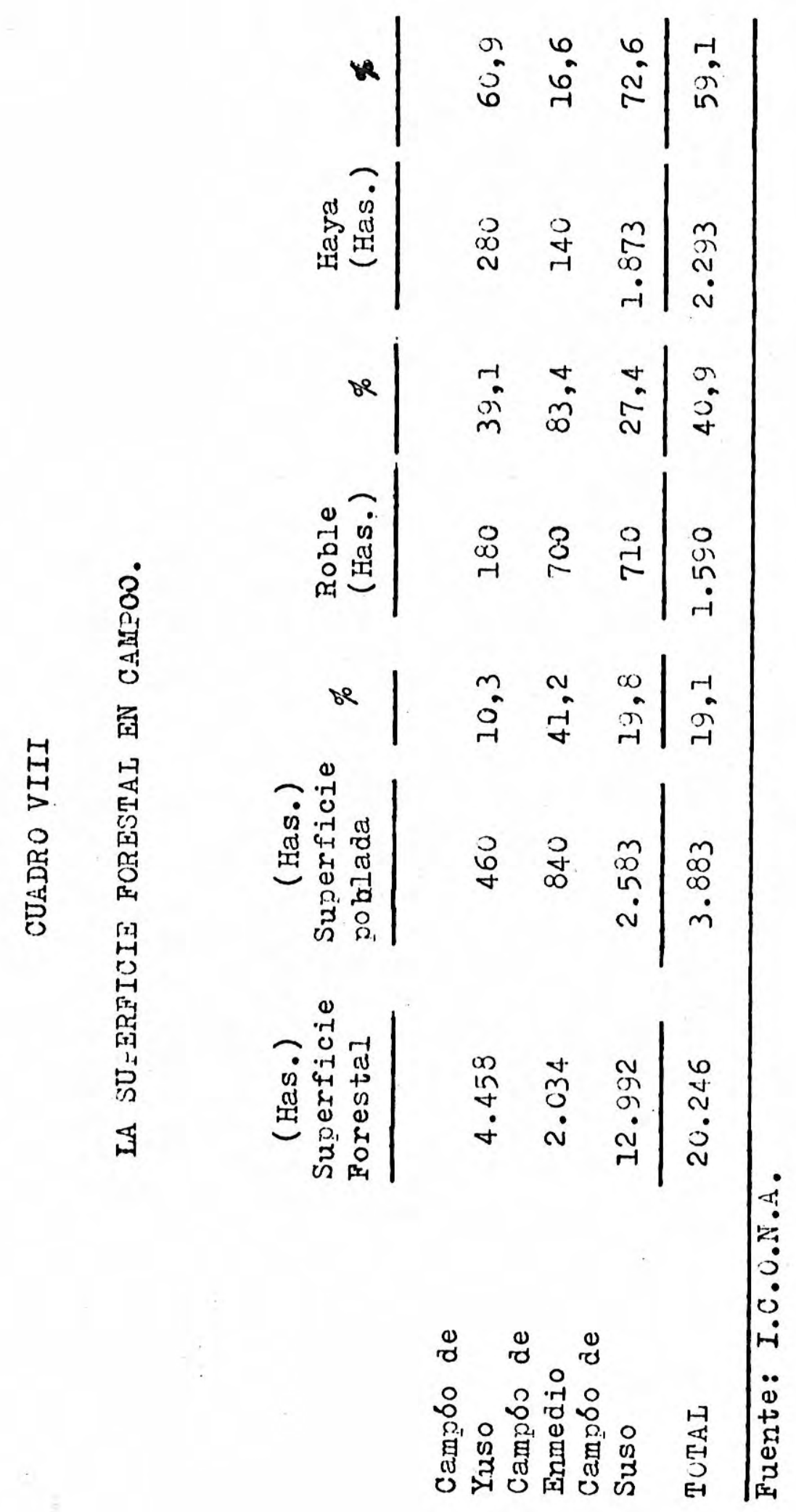


la primera variedad hacia el Norte y la segunda hacia el Sur. Como ya hemos apuntado, en su mayor parte se trata de montes inmaderables, siendo, salvo casos aislados, únicamente aprovechada la leña para calefacción de los hogares, práctica és ta en desuso por causa de la generalización de otros sistemas de calefacción. No es de extrañar por ello que, en muchos casos se estén reconstruyendo parcialmente, hecho que se apre cia en la gran densidad de las formaciones subseriales, que les hacen impenetrables.

Sin duda, la definitiva catalogación como montes de Utili dad lública en 1927, ha favorecido este hecho, unido a la menor importancia que tiene su aprovechamiento en la economfa familiar y comarcal en general.(40).

Una consideración aparte merece, por su acusado carácter residual el Quejigo - (uercus Lusitánica-; esta especie, denominada aqui roble, no forma masas nemorales, sino que aparece aislado, incluso a nivel de individuo, ocupando las partes bajas de las laderaa; en efecto, los "cajigos matorrizos inmaderables" o los cajigos de roble, como se les cenomina en la descripción de algunos montes, se encuentran por lo general en el IImite de los prados, dentro de ellos a modo de seto, - en el borde de los caminos. Cuando forma conjunto ocupa una superfice reducida, entre 4 y 14 hectáreas como 11 mites inferior $y$ superior respectivamente y con una densidad muy $\operatorname{baja}(41)$.

Por ser una especie que ocupa el "piso basal", hasta 10 s 800 metros, aunque en la comarca aparece a una altitud ligeramente superior, entre 800 y 900 metros, ha sido pronto pre sa de la continuada acción roturadora por parte del hombre,

(40) Ios montes de Utilidad Pública en Cantabria y la Ley de Montes. El Campo. Diciembre 1981 n 84 pág 81 .

( 41 ) Uno de estos montes, y no es más que un ejemplo, denominado el Cajigal o la Majada, perteneciente al pueblo de La Miña, linda al Sur con las fincas del mismo pueblo, al Veste con un terreno "de camino en todo tiempo" y al Norte con terrenos de comunidad del pueblo de Fontecha". Relacion comprensiva. Lugar de la Miña. 
buscando una ampliación del terrazgo agricola o ganadero, lo que explica su sensible reduccion ( 42 ).

Pero si en general el roble ocupa una superficie mucho me nor que en el siglo XVIII, a tenor de la información cualitati va que proporcionan diversas fuentes documentales, lo mismo ca brla decir del haya "Fagus sylvática", especte que, pese a todo y quizá por ocupar el piso montano, presenta una mayor extension, e]. 59,1 por 1.00 de la superficie arbolada.

$\mathrm{Se}$ encuentran los hayedos proximos, según E. Guinea, al extremo sudoccidental del. area geográfica del haya, lo cual da lugar a un empobrecimiento de la lista de plantas que for man parte de su cortejo en las zonas europeas de bptimo desarrollo(43). Pese a todo, en la comarca, y salvo en aquellos sectores degradados, los que obstaculizaban el pastoreo, for ma masas nemorales de cierta entidad.

Ocupa aquellos espacios umbrosos, en claro contraste con la solana, reducida a una etapa subserial en la que las árgo mas -Ulex Europeus-, distintas variedades de brezo y 103 pastizales han reemplazado al roble, especie a la que invaria blemente suceden en toda etapa regresiva del mismo. Sin duda una muestra más de tal degradación es el hecho de que estus sectores orientados al Sur, estén surcados por múltiples sendas, reflejo de au aprovechamiento por parte del. ganado ovino y caprino que, de la propia comarca o de fuera de ella, y previo pago del corrrespondiente cánon, "veraneaban" en los ruertos altos de la comarca.

Pese a todo, y al tgual que el ruble, el haya se ha visto sometida a una sistemática degradación, por ser su madera muy apreciada en la elaboración de aperos de labranza y otros útiles. Su estricta delimitación espacial as p parece confir-

(42).J. ORTEGA VALCARCEX.-

( 43 ) E. GUINEA LOHEZ.- Geografla... Op. cit. pág 204. 
marlo, junto al hecho de que, en aquellos sectores en los que mayor densidad y extensión adquiere, representa un porcentaje muy bajo respecto a la superficie forestal total de los mismos ( 44 ). Sin duda. el aprovechamiento económico de tales ha yedos ha tenido que ser intenso, hecho que parece probable, to da vez que los "puertos altos" acoglan durante el verano a ganados propios de cada concejo y a los de otros con los que el monte estuviese mancomunado.

Como se ha señalado ya para otros sectores, e]. haya no parece mostrar tan acusadamente las tópicas preferencias edáffoas; se asienta tanto sobre suelos caloareos, como sobre sue los siliceos, aunque bien es cierto que predomina en los primeros; si precisa en cambio una elevada humedad, o más bien una elevada nebulosidad, circustancias ambas que coinciden, co mo ya hemos apuntado, en la comarca, y que aún se acentúan por la permanencia de la niebla en el fondo de las pequeñas gargantas de los cursos de agua tributarios del Hijar, en Campóo de Suso. Gran parte de los hayedos se asientan sobre los suelos siliceos muy lavados de los conglomerados y areniscas del Buntsandstein, al menos los que corresponden al sector meridional de la comaroa - blarra de llifar-; en el extremo opuesto, -slerra del pico Cordel- los hayedos, parte de los cuales se encuentran en la Comunidad Campoo-Cabuerniga, tienen asiento sobre calizas jurásicas de modo preferente (45). En este seotor de común aprovechamiento, se encuentra una de las manchas verdes más extensas de la provincia de Santander, cuya pervivencia se debe en parte a su localización, en un enclave de

(44) En el monte Hijar, perteneciente a la Hermandad de Campóo de Suso, la superficie arbolada ocupa 400 hectáreas, frente a las más de 900 de pastizal y las 3.300 desarboladas en el mismo monte. I.C.O.N.A. Memoria forestal de la comarca de Reinosa. 115 .

J. ORTEGA VAJCARCEL. - La transformación... op. cit. pág. 
diffcil acceso ( 46 ). Pero con todo, con la importancia que tienen ésta y otras masas arboreas, su importancia queda ompe queñecida ante el práctico dominio en el paisaje del matorral $y$ prados, en una etapa subserial de la climax arborea.

2.- EL FREDOMINIU DE LAS FURMACIUNEN SUBSERIALEN: UN RHSULTADU DE ILA IRACTICA DESTRUCCION DE I,A CLIMAX ARBOREA.

Frente a lo que constituye una total dispersion de las su perficies arboladas, el matorral aparece con una mayor contuni dad, ocupando prácticamente todos los sectores que no se encuen tran empradizados. En conjunto representa más del 75 por 100 de la superficie forestal total de la comarca, extendiéndose por más de 13.000 hectáreas.

Es por ello por lo que su importancia económica y aun pa1 safiotica es fundamental; se extiende por todo espacio no culltivado o empradizado e incluso ocupa extensos sectores del. mon te arbolado cuando 6ste, y es un caso muy frecuente, esté muy aclarado y permite el paso de la luz. Constituye una etapa en la degradación de la formación arborea, en la mayor parte de los casos con un marcado carácter humano, pero la realidad es más compleja, puesto que en la actualidad bien puede considerarse como una etapa de reconstrucción de la superficie arbolada; no hay que olvidad, en efecto, que desde el primer tercio del presente siglo, las roturaciones han sido poco frecuen tes y que incluso el aprovechamiento de estos sectores margine les, ganados al monte para su conversión en prados son

(46)E. LORIENTE ESCALIADA.- Los hayedos del bosque de Saja. Publicaciones del Instituto de Etnografía y Folklore "Hoyos Sainz. Diputación provincial. Santander 1973. Vol. V pág 243-256. 
hoy desechados ante la mayor productividad lograda en los que presentan una mejor aptitud.

La asociación más representativa, con acusado significado geográfico, es la que los botánicos denominan Uleto-Erice tum; entran a formar parte de ella el. brezo -Erica Vagans L. y Erica Aragonensis- bien caracterizados ambos en la comarca, la segunda de las variedades especialmente en la cabecera del rio $\mathrm{HH}_{\mathrm{H}} \mathrm{jar}$, en torno a los 1.000 metros, y el árgoma -Ulex Europeusconsiderada como silicícola, que puede alcanzar niveles muy al tos, por encoma de los 1.000 metros como en el caso de la Erica Aragonensis. ( 47 ).

La importancia de esta comunidad no viene dada por su fí sonomfa, por su impronta en el paisaje vegetal, sino que el a provechamiento de alguna de sus especies, en especial el árgo ma ha sido fundamental en la agricultura tradicional; $y$ en es to no existen diferencias con otros sectores de la montaña con tábrica e incluso con otras regiones, como Galicia. Delárgoma, muy abundante en los "puertos altos" se alimentaba especialmente el ganado equino durante una parte sustancial del año, si bien es cierto que una excesiva presión de este ganado sobre esta especie, de la que solo se aprovechan los brotes más tiernos, daba lugar a un rápido descenso de la calidad del pasto ( 48 ); de ahf que los concejos propietarios del monte, aunque este estuviese mancomunado, se reservasen el privilegio de enviar sus ganados con antelación a los puertos altos. Aunque el resultado final es el mismo desde el punto de vista fisionómico, paisafistico, las formaciones arbustivas pueden considerarse en la actualided como un estadio intermedio en la reconstrucción del monte; en efecto bien se pueden considerar no como la solución de continuidad para la creación

\footnotetext{
(47) E. GUINEA LUPEZ.- Geografía... Up. cit. pág 220. ( 48 ) R. LION VALDERRABANO.- La cría caballar en Santander" Instituto de Estudios agropecuarios. I.C.C. Diputación provincial de Santander 1972. pag. 104.
} 
de una superficie empradizada, sino que desde 6stas, y dado el estado de abandono en que se encuentran en los sectores pró ximos al monte o intercaladas entre 61 , y en lugares siempre alejados de los núcleos de población se reconstruye el monte en un proceso que podemos considerar de retorno, de modo lento y gradual. Los prados ganados al monte subsisten mientras se les presta una atención continuada, pero en el momento en que tales cuidados cesan, hecho que sucede con cierta frecuen cla en los momentos actualles por causa de la emigración y con siguientie abandono de las explotaciones agrarias, se reconstru ye el matorral; brezos y árgomas conquistan el suelo para, muy a largo plazo terminar germinando las semillas de ruble, haya fresnos- fraxinus excelsior-, acebos -Ilex aquifolius- avella nos -Corylus avellana- y'otras especies, todas ellas de clara ascendencia atlántica.

Pero, obviamente, para que se produzca este proceso se ha tenido que producir el inverso, es decir la destrucción del monte; y éste también es resul.tado de un prolongado quehacer de]. hombre, en unas condiciones ecológicas adversas, sobre un terrazgo reducido que, periódicamente, se vela obligado a aumentar. Esta ampliacion se hizo secularmente sobre aquellos sectores que, sólo por ser de propiedad colectiva pudieron, en parte ser preservados de una total destruccion: los montes.

$\mathrm{Su}$ participación en la economla rural tradicional era sustancial, hecho que se debe sin duda a la gran extension que ocupaban - más del 70 por 100 de la superficie comarcalfrente al terrazgo aprovechable. Por ello, y por precisar el campesino tradicional de él para asegurar su subsistencia, la base de la economía de la comarca, la ganadería, habla de mantenerse en un terrazgo ganadero marginal, para el que se precisaban contínuas ampliaciones, máxime en aquellos periodos de plétora demográfica. Pese a todo, tales ampliaciones, 
para las que existía una constante y coherente limitación, to caban techo con frecuencia, y cuando esto aucedia, las crials de mortalidad - de las que era responsable en buena medida el estado de subalimentación crónica de la población campesina, y la emigración constitufan las inmediatas respuestas. Ni la ambivalencia del terrazgo -agrícola y ganadero-, ni el aprove chamiento del monte era suficiente para paliar los frecuentes desequilibrios de la economía rural tradicional. 
II PARTE

IAA ORGANIZACIUN TRADICIUNAI DEL ESPACIU: SOCIEDAD Y ECUNUMIA DE UN VALEE DE MONTAÑA. 
La comarca de Campó muestra una relativa homogeneidad en el modo de organizar el espacio, dentro de las numerosas limitaciones que, tanto las condictones ecológicas y aun mor fologicas, como la propia estructura socioeconómica, impusie ron a tal organizacion.

La adversidad de las condiciones climáticas, junto a la peculiar configuracion morfologica limita la extension del te rrazgo cultivado, estando éste concentrado en el fondo de los valles, en una estrecha franja que, sollo en el sector Este, en la llamada llanura o páramo de la Virga, adquiere ciertas dimensiones. Por ello, y a pesar de las sucesivas roturaciones y el consiguiente retroceso de la superficie arbolada, el terrazgo cultivado apenas representaba el 20 por 100 de la superficie total de la comarca en el siglo XVIII, contrastando con las casi tres cuartas partes que ocupaban los montes y ejidos.

La economfa tradicional puede ser considerada, por la relativa extension que alcanzan los labrantios, en unas condi 
ciones ecologicas adversas, as1 como por la escasa entidad de los intercambios, como una economia de subsistencia. Sin embargo el que tales intercambios fuesen escasos en valor no mer ma en absoluto su enorme significado en la economla tradicional; con ellos se lograba proveer a la comarca de todo aquello en lo que era deficitaria, especialmente de trigo y vino, empleando en tal intercambio los escasos excedentes ganaderos y sobre todo productos artesanales labrados en madera.

Prueba de la importancia e intensidad de los intercambios es el número de labradores que participan en ellos; más del 50 por 100 del total realizan entre dos y tres viajes a Castilla una vez finalizadas las labores agrfcolas. Con todo, estos des plazamientos temporales suponen una aportación fundamental a la economla de la comarca, en la que, la comercialización de los escasos excedentes agrarios era fundamental para completar la desequilibrada dieta alimenticia de subsistencia.

Pese a todo, una estructura de la propiedad en la que predomina el pequeño campesinado, unas explotaciones exiguas, $y$ unas condiciones ecológicas adversas, habrlan determinado que, el recurso a la emigración se convirtiese en una constante desde fechas muy tempranas, como respuesta, una más, a los tradicionales obstáculos presentes en la estructura económica de la comarca.

Los intentos de paliar en parte tales obstáculos y de lo gar una mejora en el nivel de vida de la poblacion fueron cong tantes; periodicamente se ampliaba el terrazgo cultivable, roturándose ejidos comunales y entregando una parcela a cada vecino para que la cultivase durante unos años, pasados los cuales se abandonaban; se explotaban colectivamente los prados $\mathrm{y}$ tierras propiedad de cada concejo, para repartirse después los frutos. Pero todo era en vano; en efecto, ni la expansión de las tierras cultivadas, ni el hecho de disponer de un rebaño 
relativamente numeroso era suficiente. Los rendimientos eran, en las tierras de labor muy reducidos, y los obtenidos de la ganoderia eran frecuentemente nulos para un número elevado de campesinos.

Frente a este sector de población, en permanente estado de miseria, se encontraban aquellos que tenian una propiedad mayor, sin ser en absoluto grandes propietarios puesto que, en el mejor de 1.08 casos, no so alcanzaban las 25 Has. La gran pro piedad era desconocida en la comarca; no hay, en efecto, grandes propietarios, en el sentido más amplio del término, sino mayores propietarios en cada lugar, cuyas tierras apenas supo nian el 1,5 por 100 de la superficic total.

Por ello, frente a la pequeira propiedad, frente al reducido terrazgo cultivado, se encuentra en contraste la gran pro piedad concejil; la mayor parte del monte y ejidos está en manos de los concejos, que regulan de modo muy estricto el aprovechamiento común de los prados, de las maderas de los montes y la extensión del. terrazgo cultivado a costa de ellos, sin que sean desconocidas roturaciones arbitrarias, hechas al ma gen de las disposiciones concejiles.

A la exiguedad del terrazgo disponible se añade el empleo de unas técnicas y sistemas de cultivo inqdecuadas, cuyo resul tado será la debilidad de los rendimientos agrlcolas; ocupan una posición, en cierto modo marginal el aprovechamiento de los pastos con carácter intensivo, siendo la ganaderfa una de las principeles fuentes de obtención de infresos de la economia campesina, sirviendo además de base para la organización del espacio agrario tradicional.

Habitualmente, el tamaño del rebaño de la comarca. era muy superior a la disponibilidad de pastos de la misma, casu sa por la cual era preciso establecer una organización del ospacio agrario tal, que permitiese compaginar la imprescindi- 
ble actividad agrlcola, con un aprovechamiento ganadero en el que el campesino cifraba todas las posibilidad de conseguir algún ingreso en metálico. Para ello se llevó a cabo una explotación colectiva tanto de los montes y ejidos como de la superficie cultivada en general.

Pero el espacio agrario tradicional. aparece además estrechamente condicionado en su organizacion por otros obstáculos, además de los citados. De entre ellos conviene destacar el volumen $y^{\prime}$ estructura de la población de la comarca; fuertemente condicionada en su crecimiento por los frenos tra dicionales -insuficiencia de las técnicas, debilidad de los rendimientos agricolas, crisis de mortalidad etc...-, la población de la comarca habrla visto alterado su ritmo normal de crecimiento por la regularidad, y en ocasiones intensidad, de la emigración, presente al menos desde la Baja Ldad Media como parece indicar la existencia de 6 despoblados ya desde ese periodo. El carácter estructural que presenta la emigracion dentro de la comarca, junto a las condiciones internas del crecimiento demográfico - fuerte mortalidad general e in fantil- dan lugar a que la densidad de población no supere, al menos hasta el siglo XIX, los $15-16 \mathrm{Hab} / \mathrm{Km}^{2}$.

Con posterioridad a la construcción del Camino Real de Reinosa a mediados del siglo XVII, y a partir de la introducción del cultivo de la patata en 1797, las crisis de subsistencia comienzan a hacerse más espaciadas hasta desaparecer, corriendo paralelo a este proceso un incremento de población de tal entidad que, hacia la mitad del siglo XIX habla dobla do prácticamente sus efectivos.

A lo large del siglo XVIII, y sin que se modifique en lo sustancial la estructura económica de la Comarca, se comienzan a suceder una serie de transformaciones de cierta im portancia que, al menos, representarán el abandono del tradi 
cional aislamiento de la misma. No obstante, la mayor parte de estos cambios, relacionados con la construcción de la ca 'rretera de Reinosa, no tendrán la entidad suficiente como pa ra modificar, en lo esencial, la estructura socioeconómica de la comarca, que seguirá presidida por una agricultura de sub sistencia y una explotación ganadera en regimen extensivo so bre las que gravito en gran medida la organización del. espacio agrario tradicional. 
CAPIDULO IV

UNA ECUNOMIA DE SUBSISTENCIA

Prácticamente toda. la organización del espacio agrario tradicional, enmarcada en unos especificos condicionantes eco 16 gicos y aun morfologicos, respondla a las necesidades impues tas por una actividad económica cuyo ultimo fin era proporcio nar, a costa de no pocos esfuerzos, la simple subsistencia de la población. Si la comarca, situada en un sector de montaña de la Cordillera Cantábrica, ofrecla inmejorables condiciones para el desarrollo de la ganaderla, prácticamente hasta media da la presente centuria, Gsta no pasaba de ser un complemento de otras actividadea, on las que la poblacion se ocupaba de modo preferente, obligada por la necesidad de asegurarse el sustento. Solo asl se puede explicar la importancia que tenfa el terrazgo cultivado, al que se le dedicaban los mejores sectores; estos representaban más del 18 por 100 de 1 a superficie total de la comarca, en fraca superioridad sobre 108 pra dos.

Bien es cierto que esta superficie ocupada por el terraz go a mediados del siglo XVIII, no responde tan sollo a las nece sidades de la población campesina, sino más bien a una coyuntu彑 ra alcista de los precios del cereal, y en especial del trigo, que habria orientado parte de la producción, no ya al consumo como era habitual, sino a su comercialización, facilitada en 
la segunda mitad del siglo XVIII y parte del siglo XIX por el tráfico de harinas con destino al puerto de Santander. As1 parece confirmarlo las series de diezmos consultadas. En todas ellas se aprecia una considerable reducción de los diezmos de cebada y centeno, en favor de un incremento del trigo, que pa sa a ser el cereal más cultivado sin excepción, en unos afos en los que, el crecimiento de la población no era, ni mucho menos espectacular.

Todo conduce a suponer que, en este largo periodo, se incrementa la superficie labrada, sin que, lamentablemente po damos cuantificar tal incremento por la carencia de informa-: ción en anos anteriores. Tenemos constancia, no obstante, de que esta expansión de las tierras cultivadas no se hace a con ta de la superficie destinada a praderas, sino recuperando parcelas abandonadas y poniendo en cultivo sectores marginales. Pero, la exiguedad del terrazgo disponible -más del 70 por 100 de la superficie de la comarca estaba ocupada par montes y ejidos-, los bajos rendimientos y la inseguridad de las cosechar en la mayor parte de los afos por el frio extremado, las heladas extemporaneas y la larga permanencia de la nieve en el suelo, tampoco favorecieron, evidentemente, una desmesura da ampliación de la superficte cultivada.

Una vez superada esta coyuntura alcista en el precio de los cereales y sobre todo cuando la construcción del Canal de Castilla y el ferrocarril Alar-Santander permita un más fácil acceso a los granos del interior del pals, la comarca entrará en un periodo de orlsis, de atonfa econbmica y demográfica, del que no saldrá hasta, al menos, mediada la presente centuria.

Hasta ese momento la estructura agraria apenas sufre modificaciones; el cultivo de un reducido terrazgo, la crla de ganado de "labor" para su venta en Castilla y la artesania de la madera, actividades estas de las que se obtenfan los escasos 
Ingresos en metálico, oonstituyen el quehacer esencial de la población campesina.

\section{1.- IA DUALIDAD EN EL APROVECHAMIENTO DEL ESPACIO AGRARIO}

Ia organización tradicional del éspacio agrario del Valle de Campbo presenta una serie de rasgos, que, si no son ex clusivos del mismo, si ofrecen ciertos aspectos singulares, re Plejo de la dilatada ocupación de un terrazgo exiguo, sobre el que se ha llevado a cabo un aprovechamiento econbmico inadecua do, pero inevitable. Tal inadecuacion procede sin duda de la imperiosa necesidad de diversificar la producción agraria, con el fin de paliar, en parte alguno de los obstáculos estructurales de la comarca.

El aislamiento secular de estos sectores de montaña, y sobre todo una estructura de la propiedad en la que el rasgo dominante era, y lo es aún, el minifundismo, habrian obligado a realizar una explotación intensa, que no intensiva, del terrazgo, más allá de la que las condiciones ecologicas permit $\underline{1}$ an, y estas permitian muy poco. El aprovechamiento del mismo, en la agricultura tradicional estaba orientado fundamentalmen te a cubrir las necesidades elementales de la población campe sina, por ello, el policultivo de subsistencia era el sistema de cultivo por excelencia. Son, en efecto numerosas las referenoias documentales sobre las insuficiencias estructurales que presentaba la comarca, si bien todas ellas tienen un deno minador común: las adversas condiciones ecológicas y el exiguo tamaño de sus haciendas ( 1 ). S6lo de este modo podemos

(1) Casi todos ellos viven de su trabajo, de cuidar algunos ganados vacunos $\mathrm{y}$ algunas yeguas $\mathrm{y}$ de sembrar sus heredades $\mathrm{y}$ de casi todos estas cosas ningún vecino hay que coja para la mitad del affo..." Averiguación para el encabezamiento de las Alcabalas. Lugar de Soto. Leg $70 \mathrm{Pol}$. 53. A.G.S. 


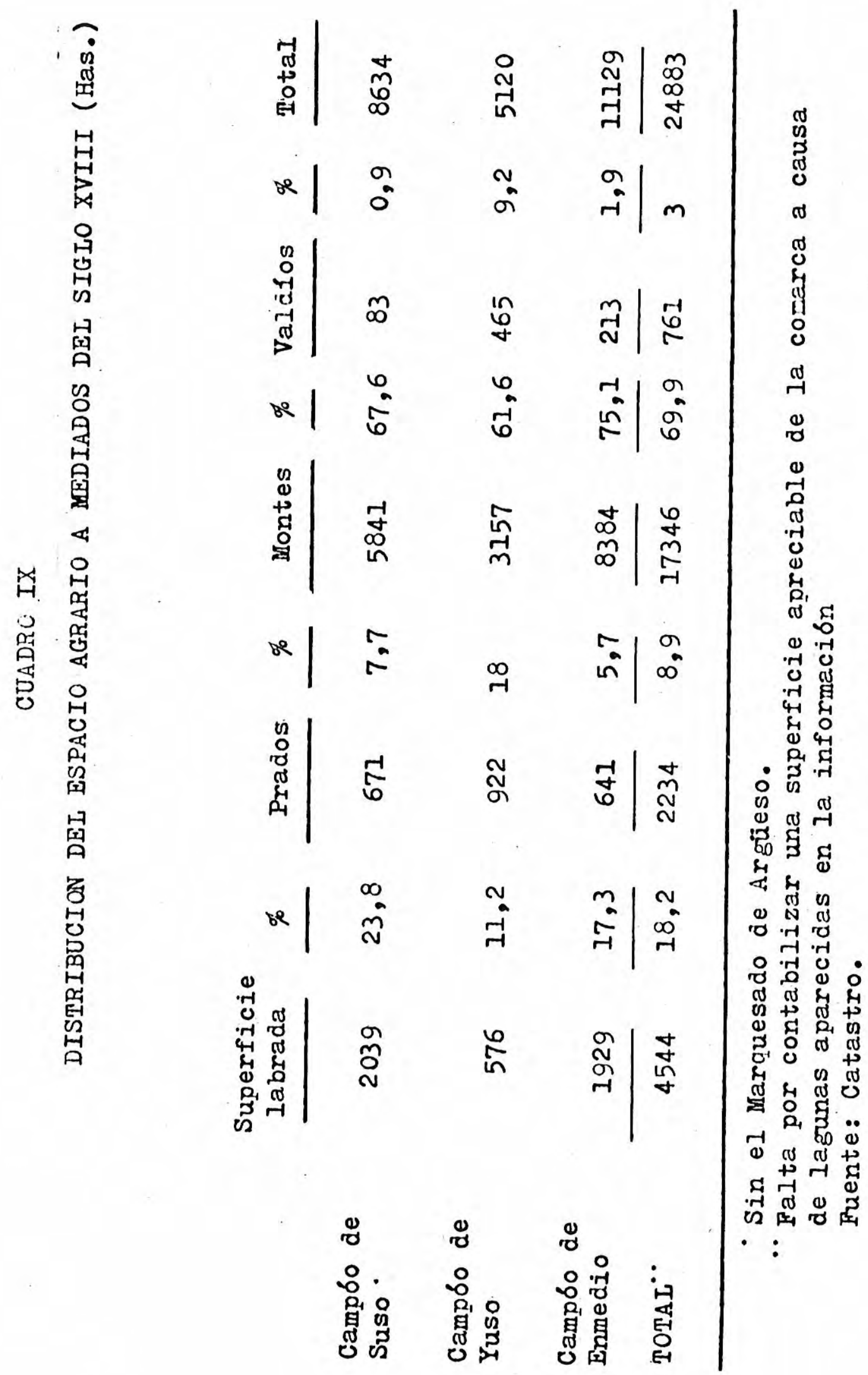


comprender la extensión del terrazgo cultivado, a costa de 10 que, paradogicamente, permite al campesino obtener los únicos y reducidos ingresos en metálico: la explotación ganadera.

Para llevar a cabo 6sta se contaba dentro de la comarca con un espacio, el monte, que representaba cerca del 70 por 100 de la superficie total de la misma. El aprovechamiento del mismo, as1 como del resto del terrazgo se basaba en una organizacion colectiva que trataba de hacer viable una economia ganadera sostenida por una agricultura de subsistencia( 2 ).

El monte era por lo general de aprovechamiento comunal; de 61 se obtenfa la madera necesaria para la elaboración de útiles y aperos, destinados a la venta en Castilla, si bien dentro de unos limites que las ordenanzas de los distintos con cejos fijaban puntualmente( 3 ). Igualmente, el monte y ejidos constituian extensos pastizales donde "veraneaban", desde la primavera hasta el final del otoño los ganados de cada concejo. Ciexto es que no todos los ejidos eran aprovechados de mo do colectivo; ciertos sectores de los mismos se "romplan" periodicamente, y una vez parcelados se entregaban a cada vecino, que, invariablemente destinaban a incrementar las tierras de "pan llevar", de por s1 exiguas en la comarca( 4 ). Trás una

(2)J. GARCIA FERNANDEZ - Organización... Op. cit. pág. 38. ( 3 ) "Otrosf ordenaron que fuera de las dichas conclas, en los montes de la dicha Hermandad, pueda hacer cada vecino de la d $\underline{1}$ cha Hermandad veinte docenas de palas y quince de garauja. Y el que no hiciere palas pueda hacer treinta y seis docenas de garauja y no más" Ordenanzas de la Hermandad de Campbo de Suso y Marquesado de Arglleso confirmadas por el Supremo Consejo en 1589. Art1culo 37.

( 4 ) "Otrosi ordenamos que por cuantio al dicho concejo hay hejidos (sic) tomados e ocupados de algunos vecinos, que los regi dores, por el perjuicio que a dicho pueblo viene, se nombren cada un año dos o tres personas ancianas que mejor sepan el tér mino, los cuales hayan de llebar (sic) y lleben (sic) consigo otros dos mozos; si estuviesen ocupados se desocupen e dejen libres al Concejo" Copia de la Hordenanza de heste pueblo de Requejo. Ano de 1896. Biblioteca Menéndez Pelayo Ms. 432, Doc. 485 folio 341, Art1culo 28. Se trata sin duda de una muestra de ocu pación de terrenos propiedad de la comunidad, al margen de esta. El proceso está documentado tgualmente en otros lugares de la
comarca. 
explotación intensa, de verios afos, estas tierras se abandona ban, pasando nuevamente a depender del Concejo, y por ende de la comunidad. Habitualmente estas roturaciones hechas en los ejidos comunales, por estar situadas en las proximidades de otras tierras que no se roturaban y que, por lo tanto se aprovechaban coleotivamente, deblan cercarse y permanecer totalmen te cerradas hasta que se levantaba la cosecha de grano ( 5 ).

Pero el aprovechamiento comunal del monte y ofidos, aun eatando generalizado en toda la comarca, tan s6lo permitla al campesino completar su dieta de subsistencia o, en el mejor de los casos, obtener unos ingresos marginales, un mero complemento a sus limitados recursos. En efecto, la prolongada permanen cia de la nieve en el suelo, sólo permitla el aprovechamiento de los pastos durante parte de la primavera, el verano y otoño, teniendo que permanecer el ganado,durante el largo invierno, en un régimen de semiestabulación en el fondo de los valles, all1 donde la superficie ocupada por los prados se habla ido reducien do a costa de una extensión del terrazgo cultivado. En consecuencia, el número de cabezas de ganado que cada familia podia poseer se vela limitado a aquellas que pudiese mantener duran te el invierno; y éstas era por 10 general muy poces ( 6 ).Pese a todo, y para hacer frente a estos grandes inconvenientes, el campesino dispuso de dos recursos, cuya puesta en explotación definirá en gran medida, los rasgos esenciales del paisaje y estructura agraria tradicionales: la ampliación de la explotación individual a costa de las propiedades colectivas $y$ la subordinación de todas las tierras individuales a la colec-

(5)" "Que las arroturas del Dueso y. Cabezo estén cercadas desde que se siembran hasta qe se desocupen del todo" Ordenanzas del Concejo de Entrambasaguas y la Loma por donde se rige y goblerna dicho Concejo, nuevemente reformadas en este año de 1716 años. Articulo 45. Igualmente en la misma ordenanza que "Ias arroturas del Cabezo los vecinos de la Loma las aren y rozen las Jinderas y las apropien y cierren de pared" Ibid.
Articulo 65 .

$(6)$ J. GARCIA FERNANDEZ.- Organizacion... Op. cit. pág 38. 
tividad una vez levantados los frutos de ellas. A estos dos re cursos se afradan 108 acuerdos o Comunidades de Pastos con 108 concejos de las Asturias de Santillana, próximos a la costa, gracias a 108 que, y mediante una trashumancia estacional muy rlgida, se podla mantener un rebafio muy numeroso ( 7 ).

Pero si de la ganaderfa se obtenfan log únicos ingresos. en metálico, gracias a la venta de los terneros, bueyes de labranza, уeguas y mulos que sobrovivian tras el largo invierno pasado on las cuadras, la actividad era esonolalmente agricola, muestra evidente de las condiciones de subsistencia en las que se desenvolvia la economfa tradicional. Para hacer compatibles ambas actividades, la agricola y la ganadera, era preciso que el terrazgo estuviese organizado colectivamente, máxime ai tonemos en cuenta que, øblo de este modo se podfan superer algunas de las difioultades que presenta el espacio comarcal.

\section{2.- IA ORGANIZACION COLECTIVA DEL TERRAZGO \&UNA RESPUES'TA A IAS INSUF ICIENCIAS ESTRUCTURALES DEL V.ALLE DE CAMPOO,}

Mediante una ordenación estricta, reflejada puntualmente en Las Ordenanzas de 108 distintos concejos, se mantenfa una adecuada distribución de las tierras de "pan llevar" y 108 pra dos dentro de los Ilmites que a cada lugar le eran propios, eg tando éstos subordinados a las primeras, y todos en conjunto a las necesidades de la ganaderla. Es por ello por lo que la

(7) En 1547, y en el pleito que sostiene la Hermandad contra la villa de Reinosa, se afirma que en los 25 pueblos de la Hernandad habrla 12000 vacas, 2000 yeguas, 6000 puercos y otras tantar ovejas y cabras. Se trata sin duda de un volumen que, por los caracteres del pleito, y a falta de otros elementos de juicio hemos de considerar exagerado. En efecto, la villa de Reinosa pretendfa obtener, gratuitamente, pastos, supuestamente sobrantes de la Hermandad, por 10 cual ésta precisaba justificar un aprovechamiento real de tales pastos. A. De Ios RIOS y RIOS.Memoria sobre las antiguas y modernas comunidades de pastos entre los valles de Campó de Suso, Cabuerniga y otros de la provincia de Santander. Santander 1878 Cfr. pág. 12 
economla tradicional de la montana cantábrica es esencialmente ganadera, pero está basada en una agricultura de subsisten cia ( 8 ). Esta oconomia tradicional tiene su fundamento on una organización colectiva del espacio utilizable: montes, prados y tierras de labor, si bien donde mayor significado te nla esta organización era en las últimas. En ellas se cultiva ban cereales y leguminosas con el fin de lograr "pan", que nunca llegaba para la mitad del axo, porque el terrazgo era reducido y porque la mayor parte de las tierras de labox no da ban cosecha todos los años (9). Pero el barbecho no era un re curso sठlo para reconstruir la fertilidad del suelo, era además un modo de obtener un complemento para la alimentación del ganado, durante el invierno, periodo durante el cual los pastos de montana no se podfan utilizar a causa de la nieve.

No todo el terrazgo cultivado tenla en los distintos valles el mismo significado. En todos ellos se conserva una oposición muy definida entre las llamadas "tierras trigaleg", 10calizadas en los mejores sectores, por lo general regados $y$ próximos a los pueblos, y la "tierra zefal", aquella que se siembra de centeno, sobre los terrenos más pobres, lo que, en gran medida explica que el sistema de cultivo en ellas empleado sea el"bienal", por oposición a las primeras, en las que estaba generalizado el sistema "trienal". Y esta división en hofas de las tierras de sembradura es la que hacla necesaria, y en cierto modo justificaba, la organización colectiva del terrazgo en la agricultura tradicional.

En efecto, en cada lugar, las tierras de sembradura ocupaban un espacio uniforme, comunmente cercado, alrededor del

(8) J. GARCIA FERNANDEZ. - Organización... Op. Cit. pág 39 ysig. ( 9 ) "... entre todos los vecinos, y cuando la nieve no mata la sementera se han cogido y cogen 240 cargas de pan, de suerte que en el dicho lugar no se coge la mitad del pan que han menester para un año..." Averiguación... Lugar de Suano Leg. 70
Fol. 53. 
caserio, espacio que posteriormente, cuando se consolida la opción ganadera de la comarca, conserva un carácter similar, a1 bien destinado a prados de diente o para la siega en verde. La obligación de cercar estas heredades tiene como funda mento evitar la entrada del ganado antes de recoger la cosecha, o la salida del mismo si tal heredad era un prado, por los daños que pudiese ocasionar; tales tierras deberlan de estar corradas, según las ordenanzas, para mediados de Marzo ( 10 ). Estos cercados, Llamados mieses o praderas quedaban a disposición de la comunidad para que, una vez levantadas las cosechas, pudiesen entrar los ganados en ellas "en vez" o en "cabafia", con pastores o "en derrota", cuando el Alcalde o concejo as1 lo determinasen. La misma práctica se observaba en los prados una vez recogida la hierba, con la peculiaridad de que si alguno de ellos estaba cercado, su propietario tenfa la obligación de abrir dos "camberas", es decir, dos entradas de carro, desde que se levantaba la cosecha hasta Febre ro o Marzo, en que los ganados sublan a los puertos de "primo vel", etapa obligada antes de acceder a los "puertos altos". Mediante esta práctica, conocida como "derrota de mieses" se podla mantener un mayor número de cabezas de ganado, y en suma se compaginaba la explotación agricola, que tenla un carácter individual, con la explotación ganadera en régimen comunal.

Igualmente, dentro del terrazgo existfan prados de apro vechamiento individual, aunque, como ya hemos apuntado, apenas representaban el 9 por 100 de la superficie de la comarca. Estos prados ocupaban los sectores marginales, a continua ción de las tierras de labor y hasta el limite de los montes - ejidos comunales. Los prados formaban una segunda aureola, delimitada frecuentemente por simples mojones con el fin de

(10) "Otrosi ordenamos y mandamos que porque parece que algunos vecinos del dicho lugar o de fuera parte tienen heredades o antuzaños del dicho concejo, e por no los cerrar se co men otras heredades o prados o huertos que están cerca de ellos que los dueños de tales heredades o prados o huertos los tengan cerrados para mediado del dicho Marzo..." Requejo, Ordenan zas. Articulo 26. 
facilitar la "derrota de mieses". Para hacer ésta posible, y cuando las tierras estaban cercadas, las ordenanzas de 108 dig tintos: lugares indicaban que las "aceras", es decir $10 s$ accesos o entradas a las 1108ag o heredades de propiedad particular próximas a las casas, doborlan abriroo y corrarao on las fechas qe indicagen 108 regidores. Era también obligado mante ner cerradas con "portillag" o "talanquerag", o bien con pared de escajo las heredades todo el afo, salvo los periodos de cul tivo-abonado, siembra y recolección-, y salvo el tiempo de "derrota". Existe no obstante una excepción a este imperativo comunal, representada por 108 huertos familiares que deblan estar cercados "sobre si" y por cuenta de su propietario; la cerca tenla que oer sblida con el fin de evitar la entrada de 108 ganados en derrota ( 11 ).

Pero quizá donde se encuente la fórmula más acabada de esta organización colectiva sea en la explotación del monte. De él no sólo se obtenfa la madera necesaria para el propio consumo y elaboración de útiles destinados a la venta, sino que en 108 numerosos seotores en los que estaba desprovisto de vegetación arborea, era aprovechado por los ganados de 108 distintos pueblos. Las Concordias y acuerdos de pastos estaban generalizadas entre ellos y aun entre otros sectores pró ximos ( 12 ).

Un elemento más dentro del terrazgo, ai bien no sometido a sujección colectiva alguna, salvo la obligación de que estuviesen cercados, es el representado por los huertos, que reciblan la denominación de "antuzaños" o "anialeg" En ellos

(II ) J. CALDERON ESCA LADA. Campbo... up. cit. pág. 138 (12) ".. y declaran tiene estee común para sus ganados comunidad de pastos en los montes y tierras de esta Hermandad de Campoo, permitiendoseles también sacar la leña que necesiten para el consumo de sus cocinas y edificación de sus casas y puentes; posee además 226 fanegas de ejidos y pastos de $10 s$ que no recibe utilidad, por ser para la manutención de los ganados del común. Catastro Ensenada. Lugar de Espinilla, Leg. 630 fol. 29. 
el aprovechamiento era individual, pero deblan estar cercadoa de tal modo que la cerca "fuese de resistencia y altura cual se necesitage a dicho de hombres", para que el ganado por si sólo no la quebrantase fácilmente(13). Preferentemen te servian para el cultivo de hortalizas, nabas -y más tarde patatas- para el consumo doméstico y de algunos pequeños tablares de lino que alimentaban pequeños telares familiares de los que se obtenfan, no sin precisar antes cuantiosas labores -empozarlo, esgargolarlo, espadarlo etc...- parte de las prendas de vestir y del ajuar familiar. No obstante solo en aquellos huertos bien regados se podla cultivar lino; on la gran mayorla, en cambio, junto a las hortalizas era muy: fre cuente destinar un pequefo fragmento a "alcacer" y más tarde a alfalfa, para su siega en verde. La importancia de ésto ele mento -el huerto- era tal que en algunos términos era obliga-

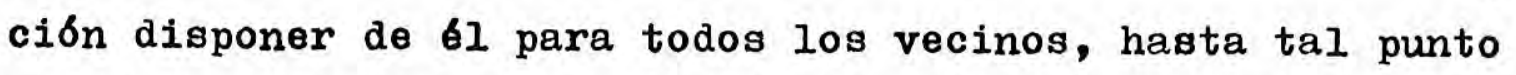
que,el que no dispusiese de tierra para este menester podfa hacerlo en los ofidos por tres afos (14).

Completaban el terrazgo las "eras", convertidas más tax de, al reducirse el terrazgo cultivado, en prados cercados. La superficie ocupada por 6stas y por 108 huertos no puede oer cuantificada, puesto que en la inmensa mayorla de los pueblos no se declara empero sabemos que ésta era muy reducida, dado el exiguo tamafio de cada uno de estos elementos.

(13) A. de 108 RIOS y RIOS.-Memoria... Op cit. pág 10. (14) "Que se desocupen los ejidos y que todos planten huerto y quien no lo tuviege lo haga en ejido por tres años" Ordenanzas del Conce jo de Entrambasaguas y la Loma.- 0p. cit. art1cu10 37. En ninguna de las ordenanzas de la comarca aparece especificada la causa por la que todos los vecinos hablan de con tar con un huerto, pero en otros concejos fuera de la comarca se justifica esta medida como una prevención contra el robo: en la villa de Santillana del Mar el articulo 51 de sus ordenanzas indica " se ordena, por cuanto se experimentan varios hurtos en los huertos y huertas de esta villa y sus barrios, se obligue a cada vecino, con tal destino, tenga medio carro de tierra a lo menos, el que deba tener todo el año con verduras..." Ordenanzas para la villa de Santillana aprobadas por el Real y Supremo Consejo de Castilla. Año 1773, citadas en Publicaciones del Instituto de Etnografla Hoyos Saiz, Vol V,
pág 347 y sig. 1973, 
Dentro del terrazgo, por 10 tanto, las sujecciones a la colectividad constituyen uno de los rasgos dominantes de la es tructura agraria; una estructura, en la que predominan las tierras cultivadas, las tierras de "pan llevar", imperativo de una economla de subsistencia.

3.- EL PREDOMINIU DE LAS PIERRAS DE PAN LLLVAR : UN APRUVECHAMIENTO DEL POTENCIAL ECOLOGICO DE CARA AL AUTOABASTECIMIENTO

Destinado a cubrir las necesidades elementales de la po blacion campesina, a proporcionar una autosuficiencia alimenticia, no sorprende que más del 70 por 100 del terrazgo esté ocupado por las tierras de pan llevar, si bien, su importancia cuantitativa en el conjunto del espacio comarcal es muy limita da, menos del 9 por 100. Dentro de este terrazgo, la mayor ex tension corresponde a cereales panificables, trigo y especial mente centeno, mejor adaptado a las condiciones ecológica.s.

Los sistemas de cultivo empleados son los tradicionales "bienal" y "al Tercio", que responden tanto a la pobreza de los suelos por las dificultades para reconstruir su fertilidad mediante el recurso al abono orgánico, como a la necesidad de obtener pastos suplementarios en estas tierras durante el invierno y parte de la primavera y otoño. En las mejores tierras en cambio aparece generalizado, en el siglo XVIII, el sistema "trienal", meced al cual se obtenfan unos rendimientos mejores que con los anteriores, sin que ello suponga en ningún ca so que éstos fuesen elevados.

Por 10 general todas las tierras labradas estaban agrupadas en las proximidades de los pueblos y divididas en hojas. Este sector recibla la denominación de mies, si bien este nom- 
bre, junto con el de praderas se daba también a la superficie ocupada por los prados de guadaña.

Las técnicas empleadas eran, sin duda alguna deficientes, 10 que obligaba a una intensa acumulación de trabajo humano, superior a la que era preciso emplear en los prados. Las numerosas labores agricolas -levantar la tierra, abinarla, sem brarla, surcarla, limpiarlos surcos, estercolarla, segar, trillar y beldar- ocupaban una parte sustuncial on la actividad de la población campesina a lo largo del año, para obtener unos rendimientos que, en el mejor de los casos, no pasaban de ser mediocres ( 15 ). Por otra parte, el recurso al regadio, emplea do en sectores limitados, tampoco permitla mejorar, por su pro pia inseguridad, los rendimientos globales de la explotación(16).

\section{a/ Unas técntcas y sistemas de cultivo adaptados al medio, pero inadecuadas.}

Sobre uniterrazgo reducido, de que era preciso extraer el mayor partido posible para atender a la alimentación de la población y del ganado se llevo a cabo tradicionalmente una explotación todo 10 intensa que las condiciones ecoloficas per mitlan. Ia superficie destinada a tierras de labor ocupaba una fracción muy reducida dentro del total do la comarca, al bien, era superior a la ocupada por los prados (Cfr. cuadro IX). Eate inconveniente se ve agravado porque no todas las tierras se cultivaban todos los años, causa por la cual el porcentaje que representaban ha de ser sensiblemente reducido en función de la calidad y aptitud de la tierra.

En el conjunto de la comarca, por lo general, las tierras

(15) Los gastos de cultivo representaban, habitualmente más del 85 por 100 del producto obtenido en las tierras de primera calidad, el 87 por 100 en las de segunda y más del 90 por 100 en las de tercera. Amillaramientos. Marquesado de Argüeso 1850. Archivo del Ayuntamiento de Espinilla. Sin catalogar. ( 16 ) "... una tierra zeñal en dicho lugar, término y sitio, de regadlo con el agua que sale de la fuente de éste lugar, aunque se seca la mitad del añocon la fuerza del calor..." Catastro Ensenada. lugar de Soto.Lib. 634, Fol.395. A.G.S. 
de primera calidad se sembraban todos 108 afos, especialmente las que podfan ser regadas, mediante una rotación de cereal, generalmente trigo, y leguminosas, arvejas o franco, La superficie que reunfa eatas condiciones ara muy reducida; apenas representaba un 5 por 100 en el valle de Campoo de Suso, siendo mucho más reducida en el resto. En las otras tierras, tanto de regadlo como de secano -estas muy numerosas-, 10s sig temas de cultivo son variados, si bien todos ellos tienen una caracteristica común: el obligado descanso.

Con independencia de la calidad distiguen dos tipos de tierra, la que llaman trigal, que se siembra dos años seguidos, el primero de trigo, el segundo de cebada y el tercero descan sa, y la llamada "zefial", en la que se siembra centeno, que produce un año de cada dos( 16). El primer sistema, el trienall es en el siglo XVIII el más extendido en las tierras de mejor calldad; con bl se lograba una reconstrucción adecuada de la fertillidad del suelo, puesto que se rotaban cereales y leguminosas, y al mismo tiempo una alimentación suplementaria para el ganado, y no solo suplementaria si tenemos en cuenta que los prados, que ol producian todos 108 afos, pero que tan ablo permitian un corte, apenas representaben el 10 por 100 del terrazgo( 17 ).

De $10 s$ datos de que disponemos para siglos anteriores al XVIII, se puede apuntar que, en este ultimo, tiene lugar un incremento notable de la producción, logrado tanto a base de la extensión de la superficie cultivada, frecuentemente

(16) "A la cuarta pregunta respondieron que en este término las tierras son de secano, que se siembran de centeno cada segundo afro, necesitando de otro intermedio para descanso $\mathrm{y}$ poder abarbechar. Catastro Ensenada. Lib. 634, fol.446. A.G.S.
Luger de La serna.

( 17 ) "... todo 10 que hay en este término fructifica de este modo, lo que es y llaman trigal se siembra dos afos seguidos, el primero de trigo $y$ el segundo de cebada o de una especie que llaman franco y el tercero descansa, la zeñal, que es aqueIla que se siembra centeno produce con un año de intermedio y descanso y los prados de guadafia que producen generalmente todos los años." Catastro Ensenada, lugar de Requejo. Iib.633 fol.273. A.G.S. 
sobre tierras marginales, como por un supuesto incremento de la productividad, toda vez que la ampliación del terrazgo no pudo ser muy amplia. Es significativo, en efecto, que sólo se mantenga en el siglo XVIII el sistema bienal en las tierras marginales, y para el cultivo del centeno (18). El sistema trienal se generaliza en la mayor parte del terrazgo, en este siglo, no sólo como consecuencia de un crecimiento de la población, sino tambien como respuesta a una favorable coyuntura del mercado de granos(19).

La reducción, y el algún caso la eliminación del barbecho se consigue de modo invariable en las tierras de primera calidad, susceptibles de ser regadas; es, en efecto, en estos casos, especialmente cuando las tierras están próximas al núoleo de población, en $10 s$ que el cultivo continuado, sin descanso se encuentra generalizado. A un abonado intenso se añade una rotación con leguminosas o con lino, planta esta cuyo concurso es imprescindible dentro de la economla autárquica tradicional(20). Pese a todo, la escasa entidad de estastierras -apenas un 5 por 100 del terrazgo-, permite suponer que su incidencia en la producción global no era muy importante; gran parte de ellas están cercadas y regadas, pese a lo cual, y a que,como apuntabamos, están bien abonadas, no se consigue más de una cosecha anual (2l). La diferencia de calidad de las tierras, la dispontbilidad de agua y abono, da lugar a

(18) Nb era el sistema bienal el más extensivo de los empleados; en efecto, sobre determinadas tierras, probablemente ejidos comunales encontramos, en bastantes lugares el olstema "al tercio". En el lugar de Pontibre responden a la cuarta pregunta "...todo 10 que hay produce y fructifica con esta diferencia: las de primera calidad y segunda dos anos seguidamente $y$ al tercero descansa y la de tercera calidad fructifica sठlo un afio de cada trea" Catastro Ensenada, Fontibre Lib. 630 fol 177. A.G.S.

( 19 )G. ANES ALVAREZ - Las cr1sis agrarias en la España Moderna. 'Taurus 1970, pág 434 y sig.

( 20 ) "... Hay en este término tierras que producen un ano trigo y otro lino sin descanso..." Catastro Ensenada. La Riva, Lib. 633, fol. 343. A.G.S.

( 21 ) "... no conociendo heredad que produzca más de una cosecha al año." Catastro Ensenada, Lib. 634, fol 261. A.G.S. 
que el sistema trienal no se encuentre en absoluto generalizado. A riesgo de simplificar en exceso los hechos, siempre complejos, se puede apuntar la siguiente distribución de los sig tamas de cultivo empleados en la comarca. En las tierras de regadio de primera calidad se obtiene cosecha todos 103 afos, rotando el trigo con leguminosas o lino, si bien en algún caso, supuestamente en tierras mal regadas, se sigue practicando el sistema trienal ( 22 ); en las tierras de segunda calidad tanto de regadlo como de secano se encuentra generalizado el sistema trienal, alternando el trigo, que encabeza la serio, con la cebada y arvejas el segundo afo, para descansar el ter cero( 23 ). Por último en las tierras de trecera calidad ol sig tema practicado era fundamentalmente el bienal, aunque tampoco son desconocidos sistemas mas extensivos, en particular el sistema "al tercio"(:24).

No ha mejorado pese a todo sustancialmente ni la estruotura del terrazgo cultivado ni los rendimientos en él obtenidos; en efecto, si en el siglo XVI, y según testimonio de la mayor parte de 108 pueblos, la cosecha de grano recogida apenas alcanzaba para el consumo de la mitad del año, viendose obligados a traerlo"de acarreto" de las tierras del interior, en el siglo XVIII el sistema permanece inalterado. ( 25 ). Cierto es que en este último ha aumentado la población, y por lo tanto las necesidades son mayores, pero también ha aumentado (22)"... la que es trigal fructifica la misma especie de trigo y el inmediato segundo cebada o franco y el tercero descansa..." Catastro Ensenada, 1ib.629, fol. 417. A.G.S. Cervatos. ( 23 ) También, junto al sistema trienal en algunos términos se sigue practicando el bienal. "...las tierras de pan llevar y lino producen un año y descansan otro..." Ibid. lugar de Lanchares 1ib. 630 Fol.531. Respuesta 4 . ( 24 )"... Ia de segunda produce de tres años dos, el uno trigo y el otro centeno, cebada habas y la de tercera produce con dos años de descanso." Ibid. Respuesta 4 . lugar de Servillejas
Leg. 634 Fol. 408 .

( 25 )"... porque en el dicho lugar ni los pobres ni los ricos el que más pan coje de su labranza no coje de su labranza para cuatro meses del año, y 108 más ni para dos ni para uno..." Averiguación... 1597 lugar de Proaño Leg. 70 fol.56. A.G.S. 
la superficie cultivada y los rendimientos, pese a lo cual la producción no alcanzaba a satisfacer las necesidades de la po blación. Para lograr este equilibrio se habla procedido trad cionalmente, a una rotación del terrazgo cultivado, cuando $\underline{\underline{B}}$ te era propio de la comunidad. Habitualmente los ejidos se "romplan cada tres años, al término de los cuales las tierras se abandonaban, ocupándose otras nuevas. Empero, tal solución no era suficiente para mejorar la precaria situación de gran parte de la población campesina, al ser las parcelas en que se dividla cada "rotura" muy pequeñas, siendo preciso acumular sobre ellas una gran cantidad de trabajo que, apenas era. compensado por los rendimientos en ellas obtenidos durante el breve periodo en el que eran explotadas( 26 ).

Pero sin. lugar a duda es la pervivencia del sistema bienal to que tiene un mayor significado para entender la debilidad habitual de los rendimientos globales de la producción agrlcola. Se encuentra generalizado este sistema en las tierras de secano de segunda y tercera calidad, representando más del 90 por 100 de la superficie cultivada. Su importancia en el paisaje agrario tradicional era por ello esencial.

Resulta prácticamente imposible cuantificar la extensión de cada sistema sobre el terrazgo de la comarca; no obstunte, si podemos apuntar una valoración cualitativa, dado el carácter más o menos riguroso con que cada uno de ellos aparece relacio nado con la calidad de la tierra. De acuerdo con ello, el cultivo sin "Yntermisión", es decir, sin descanso representarla un 5 por 100 del terrazgo cultivado; entre un 15 y un 30 por 100 de las tierras se cultivarlan por el sistema trienal y el resto por sistemas más extensivos, bienal y "al tercio".

(26) J. CALDERON ESCALADA-- Que se hagan roturas de tres en tres años" Fontibre, Mayo 1957 no 9, pág 4. 


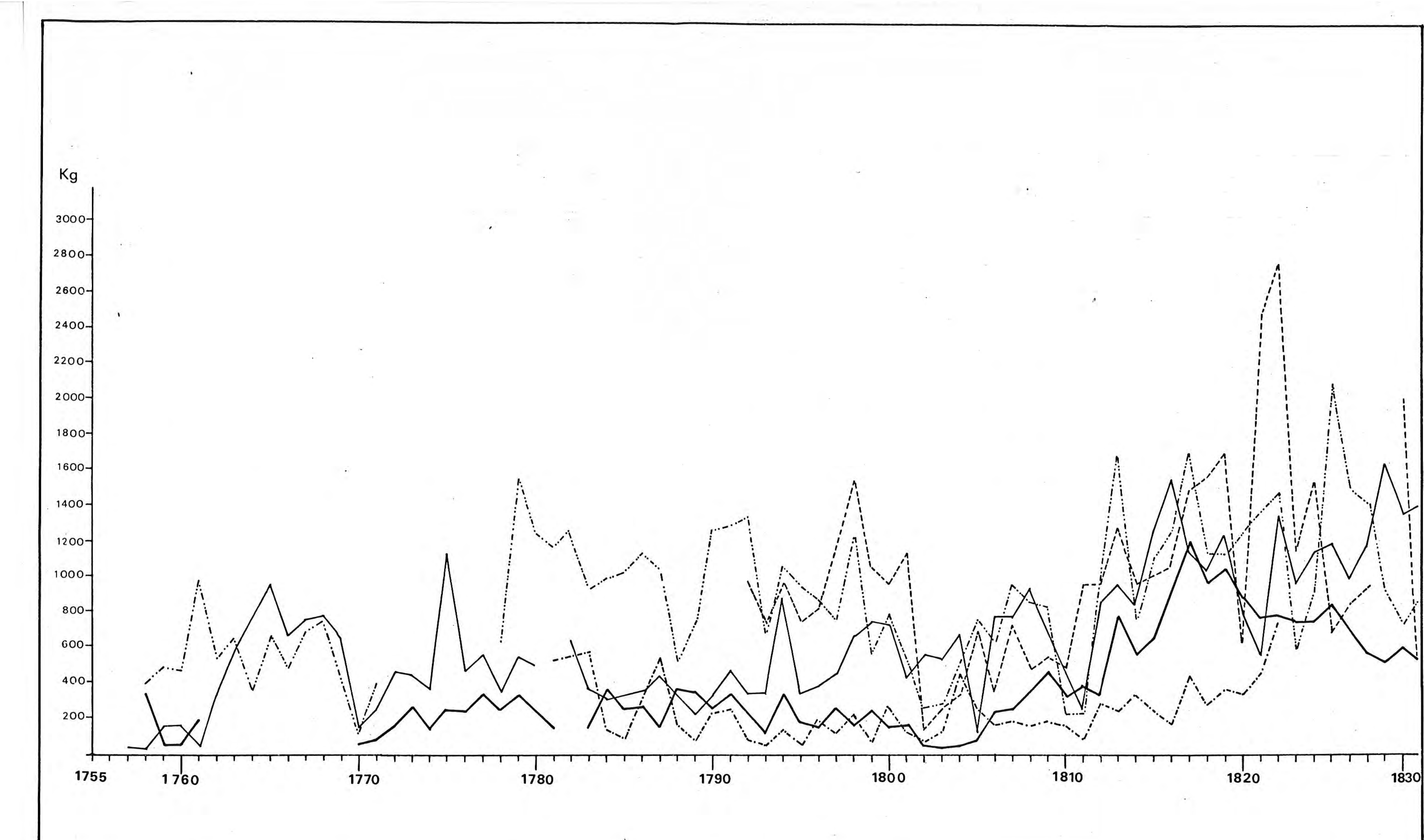


El resultado de la pervivencia de sistemas de cultivo extensivos no puede ser otro que la obtencion de unos rend 1 'mientos bajos, que, además adolecen de falta de regularidad a consecuencia de las condiciones ecologicas limite en que se obtenfan.

b/ La debilidad e irregularidad de los rendimientog: una constante en la actividad agraria tradicional.

Pese a que desde mediados del aiglo XVII se aprecia una tendencia alcista en la producción agrlcola, que se hace más evidente en los primeros años del siglo XIX, el incremento cuantitativo que reflejan todas las series de diezmos consul tadas en la comarca puede resultar engañoso. En efecto, si bien es cierto que existe una progresion en los rendimientos, especialmente en los cereales, hay que destacar que tal aumento no es sostenido, sino sumamente irregular, y que probablemente fuese insuficiente para satisfacer las necesidades de la población, que seguirá abasteciéndose en los mercados del interior del pals.

A pesar de que en algunos afros el volumen de las cose chas fuese muy elevado los rendimientos por unidad de superficie continuaban siendo muy bajos; prácticamente no hay dife rencia entre los siglos XVIII y XIX.

La pequeña diferencia, el ligero incremento del producto anual por fanega de tierra es insuficiente para explicar la intensidad del crecimjiento de la producción agraria, máxime cuando la irregularidad de los rendimientos constitula una constante de la misma. En efecto, la enorme variabilidad interanual de la produccion, excede las dimensiones habituales propias de un sistema en el que las rotaciones obligadas son la nota dominante. Los contrastes en algún caso son tan acusa 
dos, que, y ast parecen indicarlo las cantidades diezmadas, la producción de algunos cereales no pasaba de ser meramente simbolica, y ello a pesar de que su concurso era imprescindible en la dieta humana y animal.

Cabe suponer por ello que el progreso de las técnicas ha sido muy limitado y que el aumento de la producción, cuando aparece, se logra más por una extensión del terrazgo culti vado que por un incremento de la productividad.

\section{CUADRO X}

RENDIMIENTOS MEDIOS DEL CEREAL. RELACION SIMIENTE PRODUCTO.

\begin{tabular}{|c|c|c|c|c|c|c|}
\hline & 19 & 20 & 30 & 19 & 29 & 30 \\
\hline $\begin{array}{l}\text { Campbo de } \\
\text { Yuso }\end{array}$ & 3,5 & 2,5 & 2 & -- & - & - \\
\hline Campbo de & & & & & & \\
\hline Enmedto & 4 & 3 & 2 & 4,9 & 4,3 & 3 \\
\hline Campbo de & & & & & & \\
\hline Suso & 4 & 3 & 2 & 3,5 & 4,5 & 4,5 \\
\hline
\end{tabular}

Fuente: Catastro y Amillaramientos.

La favorable coyuntura del mercado de granos de Reinosa, en el que los precios del trigo prácticamente se duplican entre 1795 y 1804, podria explicar la expansión de la producción de este cereal que reflefan las senies de diezmos en distintos lugares de la comarca. No obstante, y siendo limitadas las posibilidades de ampliación del terrazgo a costa de los ejidos comunales, hay que suponer que lo que realmente se produce durante el primer tercio del siglo XIX es una sustitución del 


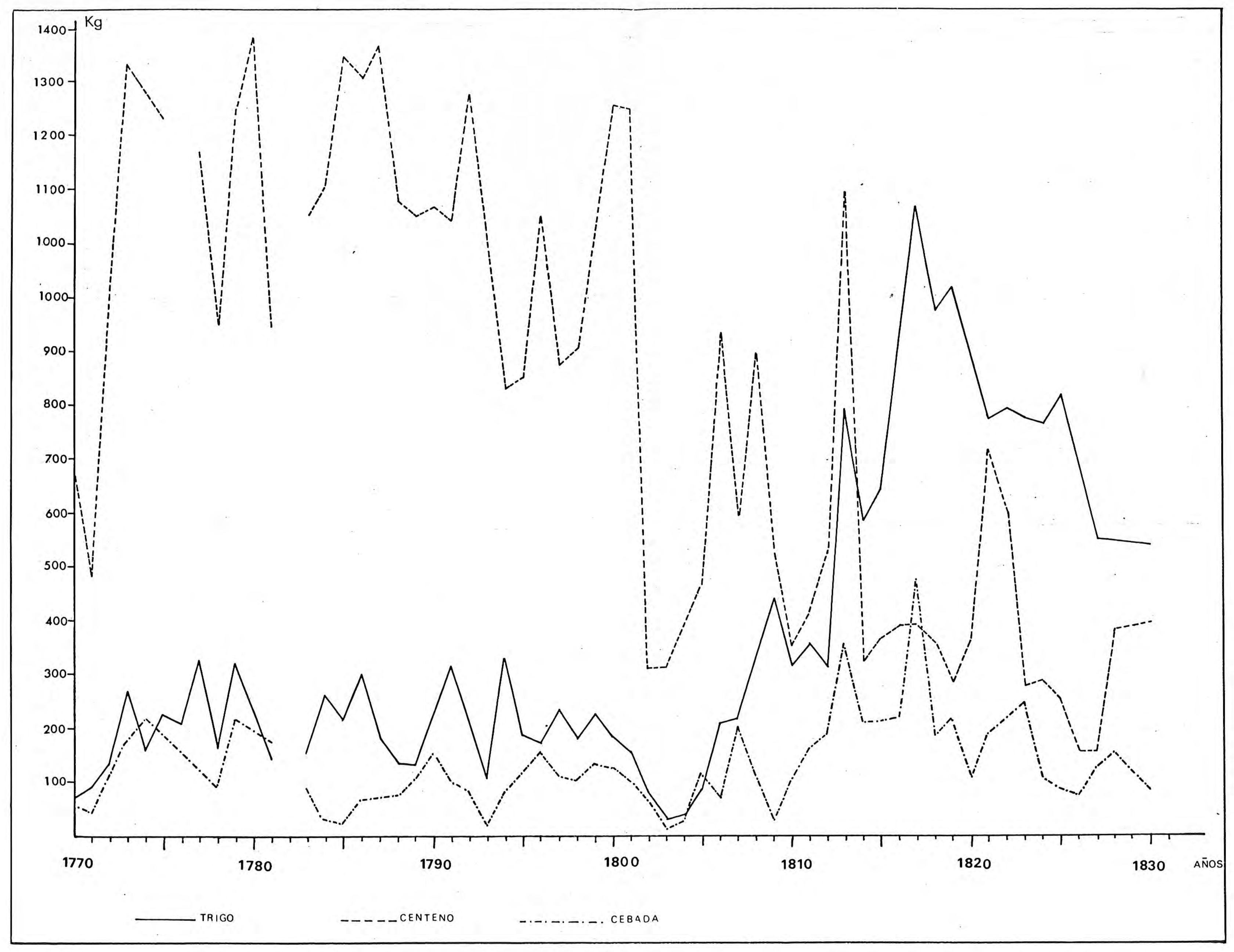

Fig. 11 Evolucion de los diezmos de trigo, centeno y cebada en Villacantid 
cereal cultivado (27). El trigo, para el que tradicionalmente se hablan reservado las mejores tierras, se extiende sobre otras de inferior calidad, a costa de otros cereales, especial mente del centeno : La evolución de los diezmos de ambos -tri go y cebada- en la comarca asl parece indicarlo (ver figura 11).

A lo largo del primer decento del siglo XIX se generali za, en efecto, el incremento de la producción de trigo frente a otros cereales mejor adaptados a las condiciones ecologi cas. Destaca especialmente la sensible reducción de la producción de centeno desde 1814, hecho observado en otros secto res próximos a la comarca(28). Ia interrupción de las series entre 1830 y 1835 nos impide apreciar la evolución posterior en unos años en los que el precio del trigo recupera, y aun desciende por debajo de 108 niveles alcanzados a finales del aiglo XVIII; tan s610 podemos apreciar, entre 1810 y 1830 una interrupción de la tendencia alcista, cuando no una notable disminucion del total cosechado ( ver figura 10).

Este cambio en la coyuntura de la producción de trigo unido a la acusada variabilidad interanual de los rendimientos, que en ocasiones representaban diferencias de más del 80 por 100 no harla aino agravar la precartedad en la que se desenvolvia la economia tradioional. Una economla de subsistencia que precisaba comercializar sus escasos excedentes obtenidos de la explotación ganadera; y esta aparente paradoja, común por otra parte a otros sectores de montana se ve acentuada por la escasa entidad que tiene, frente al terrazgo cultivado, la superficie ocupada por los prados: (29)

(27) Sobre las coyunturas del mercado triguero ver G. ANES ALVAREZ. - Las crisis.... Op.cit. pág 245. (28 ) A. RODRIGUEZ FERNANDEZ . L Los Carabeos... Op. cit. pág. 196 (29) J. ORTEGA VALCARCEL.- Las transformaciones... Op. cit. pág. 174 . 
c/ El carácter subsidiario de $10 \mathrm{~s}$ prados

Por la superficie que ocupan dentro del terrazgo -apro ximadamente el 30 por $100-\mathrm{y}$ por la proporción menor -el 9 por 100 del conjunto de la comarca- los prados, tanto los de secano como los de regadio son en cierto modo marginales den tro de la comarca, hecho que contrasta con el cáracter ganadero de la economia tradicional. Bien es cierto que la compe tencia entre la alimentacion humana y animul obligb a estable cer formulas de aprovechamiento del terrazgo complejas, con el fin de adecuar ambas necesidades, y paliar el inconveniente que representa la reducida extensión de los prados. lin su ma yor parte éstos s $\delta 10$ permiten un corte anual, de rendimientos por lo general bajos salvo en aquellos casos en los que estaban regados y bien abonados.

La práctica habitual consistia en abonalos, de modo alterno cada tres años con tres carros de estfercol por cada fa nega, es decir 15 carros por cada hectárea, cantidad que resulta insuficiente, pero que es la única con que se podla con tar a causa del reducido número del ganado estabulado( 30 ). La producción de los mismos era variada en función de la calidad de la tierra, pero, en cualquier caso, insuficiente, he cho que permite explicar en parte la pervivencia del carácter comunal en el aprovechamiento del terrazgo ( 31 ).

En efcto, a las necesidades habituale:s del ganado estan te se añadian las del rebaño procedente de los puertos altos, durante el invierno, resultando insuficiente el heno almacena

(30) Ayuntamiento del Marquesado de Argüeso.-Cartill.a de eva luacion 1850. Archivo del Ayuntamiento de la Hermandad de Campoo de Suso. Sin oatalogar.

(31) "...los prados de primera clase de secano producen el palimento (sic) de un carro, osean 20 areas, $460 \mathrm{Kg}$. los pra dos de segunda calidad y secano $391 \mathrm{Kg}$. y los de tercera y se cano $345 \mathrm{Kg} . . . . "$ Amillaramiento de la riqueza rústica y pecuaria Ayuntamiento de la Hermandad de Campoo de Suso 1881. Archivo Espinilla. Sin catalogar. 
do con este fin. Por esta causa el ganado que cada explotación podfa mantener era muy reducido, acorde no con la ingente dig ponibilidad de pastos estacionales, sino con el volumen de he no que se pudiese recoger y almacenar procedente de los prados de propiedad particular.

Frecuentemente, al ser el ganado el único recurso de que se disponla para la obtención de ingresos en metálico, el cam pegino se vela obligado a mantener un rebaño numeroso, o al me nos superior al que sus limitados prados podfan mantaner, con el fin de asegurarse unos excedentes seguros. En los inviernos no demasiado rigurosos, se podla mantener el ganado en régimen de semiestabulacion, aprovechando los pastos de los montes y ejidos comunales próximos al pueblo, con lo que sobrevivirla la mayor parte del mismo y los ingresos obtenidos serfan elevados; pero en aquellos inviernos en los que la presencia de la nieve era habitual -la mayor parte de ellos-, la estabulación serla obligada, la hierba almacenada se consumirla con rapidez, y una parte del ganado perecerfa por inanición. Llegada la primavera estas explotaciones apenas podrian vender algún ganado para comprar "pan" y otros productos de los que se carec1a.

Para paliar estas dificultades era práctica habitual recurrix a la hoja del acebo para alimentar el ganado, de ahl que en todas las ordenanzas se prohiba tajantemente la tala de este arbusto en los montes comunales (32). No obstante, y de modo regular, Los vecinos de cada lugar tenlan derecho a "cortar la cantidad que se determine y en las acebas previa mente señaladas por una comisión de marcadores". Posteriormen

(32) As1 lo expresan las ordenanzas de Celada Marlantes del año 1697 en su artf́culo I " Que no se corte en las dehesas ningún pié de roble o acebo o haya ni otro género pequeño grande salvo para reparar su casa". Biblioteca Menendez Pelayo Colección Pedraja. Ms. 432, doc 485 fol. 66. En el mismo sentido abunda la Ordenanza de Requejo en su art1culo 43 "que ninguno sea osado cortar ninguna cosa verde ni seca, hescepto (sic) pértigas de avellano para el servicio de sus casas, e que si alguno cortase roble, aya (sic) o acebo pague de pena..." Ibid. fol. 341 . 
te se reparten por adras, es decir, sorteándolas públicamente en la casa del concejo ( 33 ).

El recurso a la ampliación de la superficie destinada a prados de guadaña o de diente no era, frecuentemente, viable; las roturaciones del monte estaban muy limitadas por la necesidad que de él se tenla, y los ejidos comunales, cuando se rozaban se destinaba a ampliar la superficie cultivada. Cierto es que gran parte del ganado no se explotaba en régimen de estabulación permanente, sino en forma extensiva, por 10 cual su alimentación no podla competir con la alimentación humana; era, en cierto modo marginal, siendo como era el terrazgo muy reducido.

El remedio a los inconvenientes estructurales representados por una propiedad individual muy pequeña, se encontraba tanto en el aprovechamiento colectivo -en derrota- de todos los prados y tierras de propiedad particular, por parte del ganado que bajaba de los puertos altos en el otoro, como en el aprovechamiento de aquellos de propiedad comunal; sobre estos se realizaban las labores colectivamente, repartiéndose los frutos " a partes iguales entre los vecinos" ( 34 ). Era, sin duda una parcial solución a la escasez y aun a la falta de tierras propias de un gran número de vecinos.

No es extraño por ello que, si el terrazgo cultivado apenas podla asegurar la subsistencia de la población y que los prados también eran insuficientes para alimentar al ganado,la solución se encuentre en el aprovechamiento del monte, recurso obligado en la economfa de subsistencia tradicional.

(33) J. CALDER ON ESCALADA - Campó... 0p. cit. pág. 140 y sig. ( 34 ) "... posee este común igualmente varias tierras y prados que las administra por si dicho común repartiendo sus frutos a partes iguales entre los vecinos..." Catastro Ensenada, Iu gar de Abiada, resp. 23. Lib. 626 fol. 282. A.G.S. 
4a- EL APROVECHANIENTO DEL MUN'LE: UNA AC'TIVIDAD COMPLEIELNTARIA SOMETIDA A NUMLROSAS RESTRICCIONES.

En la economla rural, generadora de rentas escasas, capaz tan solo de mantener en precario equilibrio a una población reducida, el aprovechamiento del monte jugaba un papel de primer orden. De él obtendrá el campeaino una parte sustan cial de sus ingresos en metálico merced a la elaboración de carbón con destino a su venta, y de una variada gama de aperos destinados, tanto a cubrir sus necesidades como a la venta en las tierras del interior.

Frecuentemente la única forma de obtención de ingresos para una parte de los vecinos de los valles, carentes de tierras e incluso de ganados en propiedad ( 35 ). La importancia de este recurso viene dada por la superficie que ocupa en la comarca -más del 70 por cien del total-, si bien no toda ella es susceptible de un aprovechamiento econbmico similar. En efecto, la superficie arbolada ea muy pequeña, entre el 7 y el 15 por 100 , en relación con la ocupada por los partizales y arbustos, causa por la cual su aprovechamiento general y ma derero en particular, aparece estrictamente regulado. ( 36 ). Pese a ello, el carboneo y la artesanfa de la madera eran prác tica habitual, desordenada en ocasiones, en la comarca.

a) E1 artesanado de la madera: una actividad tradicional. destinada al intercambio.

La elaboración de aperos de labranza para el autoconsumo y para su venta en Castilla ocupaba un lugar preferente en la

(35) "... y otros vecinos que no tienen ganados labran maderas en los montes porque no tienen otra granjerla y con las $\mathrm{m}$ deras que llevan a vender a Castilla compran pan para sus hijos y mujeres, durmiendo en los montes comen de pan y agua y s6lo de esto se sustentan..." Averiguación... Año 1597. Iugar de Soto, Leg. 70, flo. 53 .

( 36 ) Estos porcentajes corresponden al estado actual de los montes, pero cabe suponer que a mediados del siglo XVIII la situacion no fuese muy diferente por causa de la sistematica explotación en ellos realizada. 
preocupación de gran parte de la población campesina, que, junto con el ganado y en ocasiones la sal adquirida en las saIInas de Cabezón de la Sal para su posterior reventa, proporcionaba el conjunto de los ingresos en metálico, a los que, desde la segunda mitad del siglo XVIII, hay que añadir los ob tenidos por el acarreo de granos desde $\Lambda$ lar del Rey hasta las fábricas de harina y almacenes de grano de Reinosa.

Era no obstante del artesanado de la madera del que se obtenfa una parte sustanclal de tales ingresos, y ello pese a que la disponibilidad de madera no era ilimitada. Habitualmente cada vecino podfa hacer, fuera de las partes vedadas o conclas, dos carros de madera anualmente, uno por San Juan y otro por San Martin, de cualquier especie menos de roble. Pero no solo estaba regulada la madera que se podla cor tar, sino que también aquelia que se podla vender fuera de la comarca. En apariencia esta limitación estaba destinada a pro teger a aquellos vecinos que, no teniendo ganado con el que transportar las maderas elaboradas para su venta, pudiesen rea lizar esta operación dentro de la comarca, a través del mercado de Reinosa ( 37 ). De este modo se posibilitaba la obtención de estos ingresos marginales para la gren mayorla de los vecinos, con independencia del tamaño de sus "haciendas"( 38 ). Por contra estaba tajantemente prohibido vender lena fuera de la comarca, reservándose ésta para el propio consumo ( 39 ). Oon es (37) Para vender fuera de la comarca se podlan hacer según la ordenanza de La Hermandad de Campbo de Suso del año 1551 30 docenas de palas, valoradas en 30 reales, 35 docenas de "garau,ja" -horcas, rastrillos, bieldos etc...-, 16 artesas, y 60 sillas mayores y menores. A. de los RIOS y RIOS.- Copia de unas ordenanzas de la Hermandad de Campoo de Suso. 1551. Antologla de escritores y artistas montañeses. Santander 1952 pag. 87 ( 38 )"...0trosi por cuanto hay gentes en la dicha hermandad que no tienen bueyes con que carretear se han de mantener con el tra bajo de sus personas, ordenaron que los tales que no hicieran otras maderas para llevar a vender, puedan hacerse y hagan fuera de las conclas de dicha Hermandad, en los montes bravos, cada vecino veinticinco pares de abarcas e no más" Ordenanza de la Hermandad de Campóo de Suso y Marquesado 3.589. Art1culo 34. (39) "...otroat que ningún vecino puedu llevar leka a vender fuera de los lugares de la dicha Hermandad que sea de los montes $y$ conclas de ella" Ibid. articulo 49. 
tos productos, y siempre que se vendieran, obtenfan aquellos productos que para el consumo familiar necesitaban, toda vez que los bajos rendimientos de las tierras labrantlas no alcan zaban, en el mejor de los casos para medio año.

Pero no sólo se explotaba el monte para la obtención de leña para el consumo de los hogares y madera para la elaboración de útiles de labranza; tambión se elaboraba, y era práctica muy extendida carbon con destino a las pequena fragua locales y a las ferrerfas que se instalaron en la comarca $y$ proximas a ella a mediados del siglo XVIII ( 40$)$. Las limitaciones a esta actividad encuentran también eco preciso en las ordenanzas, en las que se limita a dos el número de carros de carbón que se podfan hacer anualmente, o bien se prohibe totalmente su elaboración ( 41 ).

En cuanto bien común escaso no sorprende que la explotacion del monte estuviese limitada; son en efecto numerosos los obstáculos impuestos a su aprovechamiento.

\section{b/ los obstáculog a la explotación del monte.}

La compleja explotación que del nonte se hacla en la agricultura tradicional, y la intensa degradación a que éste se vela sometido obligó a poner en práctica formulas restrictivas para prácticamente todas las actividades que en ell se desarrollaban. A las limitaciones impuestas al aprovechamiento

(40) En 1754 se instalo en la comarca la primera y única ferrerla que ha habido. El lugar elegido fue Orna, a orillas del rio Ebro, siendo su propietario un vecino de Reinosa. Punciono regularmente hasta 1840 , año en el que figura ya como arruinada. Tropezó con numerosos obstáculos en su funcionamiento debido sobre todo a "no dejarle coxtar la madera de roble que necesitaba y estando noticioso de haber muchos tirados de despofos en el monte del Concejo Mayor de Valdearroyo, los vecinos se lo estorban" C. GONZALEZ ECHEGARAY.- Aportación al estudio de las ferrerlas montañesas. Publicaciones del Instituto de Etnografla Hoyos Sainz. Santander 1973. pág 200. (41)"Otrosi por cuanto algunos vecinos de dicha Hemandad hacen carbón para vender fuera de ella, desde aqui adelante tengan esta ordenanza: que cualquiera que hiciere madera y gozare de su adra no pueda hacer carbón para vender fuera" Urdenanza de la Hermandad de Campó de Suso. 1589. 
de 10s pastos, que respondlan más a una organización colectiva de todo el espacio agrario, y en particular del terrazgo cultivado, hay que añadir las que al carboneo y a la extracción de la madera se hablan venido observando desde la elaboración de las primeras ordenanzas en cada lugar, y que en numerosas ocasiones venfan a poner coto a prácticas abusivas tradicional mente observadas( 42 ).

Ambas actividades, pero especialmente la segunda eran desarrolladas por una parte nada despreciable de la población campesina, toda vez que, en ocasiones, era el único recurso, la única forma de obtener ingresos en metálico. Para evitar el expolio sistemático del monte se emplearon dos fórmulas; una de ellas consistla en acotar parte del mismo -las conclag-, per mitiéndose cortar en ellas tan solo madera para el consumo interno, ya fuese para la reparación o construcción de las casas. De la importancia concedida a estos sectores puede ser expresi vo el hecho de que en ocasiones las ordenanzas se redactan pa ra regular, entre otros elementos, el aprovechamiento de las citadas conclas ( 43 ).

Otra de las formulas empleadas consjatia en limitar la cantidad de madera extralda a dos carros o si, caso muy frecuente, la madera se labraba en el monte, existlan limitaciones en el número de piezas de madera que se podlan hacer.

Las Iimitaciones alcanzaban también a los acuerdos entre las distintas comarcas y concejos, realizados para el apro

(42) "Otrosi ordeno e mando que por cuanto por no haber buena diligencia en los procuradores pasados por cuya causa los montes se talaron, se tenga la forma siguiente: que en cada puebilo haya dos personas señaladas por los procuradores, a las cuales los dichos procuradores sean obligados de los señalar el segundo dla de cuaresma en cada un ario, los cuales sobre juramento tengan cuenta en sus pueblos de todas las maderas que se hizieren, as1 mayores como menores..." A. de los RIOS y RIOS.Copia de unas ordenanzas... Op.cit. art1culo 64. (43) "Otrosi ordenaros que ni en las Conclas ni demás montes de dicha Hermandad ni fuera de ella pueda cortar ningún roble mayor ni menon, sino fuera para sus casas e para vender en la dicha Hermandad..." Ordenanzas de la Hermandad de Campbo de Suso y marquesado 1589. Art1culo 63. 
vechamiento de los pastos. En efecto, tal es lo que sucede en los Acuerdos de la Comunidad Campo-Cabuérniga; en ellos se prohibe la tala del acebo, se limita el número de maderas que se podfan elaborar y los lugares a. los que se podlan llevar a vender. Tan soflo se permitla acarrear con bueyes el borne, es decir, la madera torcida, y llevar a Campóo la madera que pudiesen sacar a cuestas de los montes de la citada comunidad. Se pretendla sin duda, evitar la competencia con las maderas elaboradas en Campoo, que de este modo monopolizarla parte de la oferta en las tierras del interior (44).

A todas estas limitaciones se añaden las que, a mediados del. siglo XVIII, establece la Urdenanza de la Real. Mnnina en los montes comunes y particulares -estos, inexistentes en la comarca-. En ella, la tala de árboles se limito considerablemente para la mayor parte de los concejos, suponiendo un serio quebranto para la economia de subsistencia. En efecto, porque si bien la Marina pagaba a los propietarios de los montes

(44) "Otrosi ordenaron que cualesquier vecino de los dichos valles que cortasen árboles de la dicha cueva del Poyo e Bu llevaniego arriba, hiciese de él madera, asi palas como artesas, lo hayan de llevar a su valle, e no lo puedan sacar a Mostajo ni a Tajahierro más de 10 que hayan de llevar a car gar a dicho valle de Cabuerniga, so pena de que al de otra manera lo cargaren que lo puedan tomar sin pena alguna salvo el borne que 10 puedan llevar con bueyes e la madera que no la puedan llevar, salvo a cuestas, al dicho valle". Concordia celebrada entre Campoo y los vecinos del Valle de Cabuérniga A. de los RIOS y RIOS.- Memoria... Op. cit. pág 53.

Cuando el acuerdo de pastos se realizaba con otros valles, al margen de los que comprendla la concordia anterior, las limitaciones eran mucho más estrictas; tan solo se permitla "... a los pastores que guardaren las dichas vacas, que puedan hacer cabañas para que duerman y abarcas las que hubieren menester para sus personas e jarras para sus cabañas y puedan cortar madera en los dichos términos para hacer lo susodicho e cortar leña para quemar." Concordia celebrada entre Campóo y los vecinos del valle de Cabrzón. Año 1561. M. ESCAGEDO SALMUN.- Costumbres pastoriles cántabro-montañesas. Santander. Imprenta Provincial 1921. pág.114 y sig. 
un real por cada "codo cúbico" de madera de roble y cuatro por cada "codo cúbico" de haya, con ello sठlo se lograba sanear la economla de los concejos, propietarios de los montes, perdiendo la población campesina una considerable fuente de ingre sos (45).

Tanto por la tradicional explotación realizada por la población de la comarca, como por la realizada por la Marina, los montes sufrieron un progresivo deterioro, salvándose sólo aquellos de diffcil acceso. Lin el resto fue preciso imponer severas restricciones, dado que, a mediados del siglo XIX se encontraban ya en un lamentable estado de conservación (46).

(45) "... si se escuchara el voto de la provincia, acaso no se hallará en ell un hombre que deje de decir que han sido los reglamentos sobre montes y matricula las dos únicas causas, o las más principales de todos los males que padece, y efectos de ellas la emigración, la desidia y todos los otros vicios referidos como causas..." J. M. " Estado de las fábricas, comercio industria y agricultura en las montañas de Samtander. Santander. Ed. Librerla Estvdio 1979. (46)" Otrosi ordenamos que por cuanto el dicho monte de Soto es muy corto y combiene (sic) mucho que se guarde y conserbe (sic) y que no se tale, que el dicho concejo no pued̆a dar ningún pie de roble ni haya ni otra cosa sino es que hespecialmente (sic) se halle junto todo el concejo" Requejo. Copia.... Op. Cit, articulo 44 。 


\section{CAPITULO V:}

UNA BCONOMIA AGRARIA BASA IAA EN LAA EXI LOTACIUN GANADIBRA EXTENSIVA.

Pese a que tradicionalmente el paisaje agrario estuviese dominado por las tierras de labor, las tierras de pan llevar, la organización de éstas, y por ende de toda la actividad eco nomica tenfa como base la ganaderla. Aún a mediados del siglo XIX, la importancia producción agrlcola era similar a la "cria" de ganado, actividad ésta que, solo desde la mitad del presente siglo, y merced a la introducción de ganado vacuno orientado a la producción de leche, pasará a ocupar un lugar fundamen tal en la economfa agraria, sin que por ello desaparezcan de modo inmediato las reminiscencias de una tradicional actividad agrlcola cuyo fundamento era la subsistencia。Y es que si esta última era imprescindible en la economla tradicional, fue la actividad ganadera la que modelo, o. través de sus servidumbres, de sus necesidades, el paisaje agrario. In torno a ella se desarrollanformulas especificas de aprovechamiento del espacio disponible, basadas todas ellas en la trashumancia, en el trán sito de todos los ganados, salvo los de labor y parte del gana do menor, a la búsqueda de espacios que proporcionasen en cada estación del año los mejores pastos. Una trashumancia que, por imperativo del tiempo y el cambio de orientación de la explota ción ganadera fue remitiendo en intensidad, pero que, al menos 
hasta el siglo XVIII implicaba un práctico desplazamiento de una parte de la explotación agraria ( 47 ).

Al margen de este sistema de explotación extensivo de la ganaderla, cuyos rasgos esenciales se conservan en el momento presente, pero sin el significado e importancia que tradicional mente tuvo, en el valle de Campoo el aprovechamiento ganadero se bas6 sobre un pastoreo extensivo de carácter colectivo, para el que durante todo el año, o tamporalmente, se disponfa de la mayor parte del espacio agrario.

La base de la ganaderla tradicional estaba constitulda por el ganado vacuno y equino, explotado de modo extensivo y orientado a la venta en los mercados del interior, de Castilla, cuya importancia numerica tan solo parcialmente podemos evaluar. No obstante, y si bien es cierto que el tamaño del reba no reviste importancia, su verdadero significado, al menos de de un punto de vista geográfico, viene dado, no por su número, siempre mayor del que reflejan las fuentes puesto que se ocultaba aquél que se llevaba en aparcerla, sino por la organización del espacio que, en torno a él se desarrolla ( 48 ).

\section{1.- LA CUMPLEJ IDAD DE LA CUMPUSICIUN Y SIGNIFICANO DE LA EXPLOTACION GANADERA}

La ganaderla, junto a los condicionantes que en la organización del espacio su explotación introduce, juega un papel

(47)" ...Que el dicho concejo e vecinos de êl y de los demás lugares de esta valle de Cabezón de tiempo inmemorial a esta parte hemos tenido e tenemos costumbre e usadia de pacer las yerbas e beber las aguas con nuestras vacas e pastores e vaqueros e collazos e bestias e caballos e rozines y otros armenticios.." Concordia celebrada entre los vecinos del valle de Cabezon y Camp6o. M. ESCAGEDO SALMON. Costumbres... Op. cit pág 1.14 .

( 48) En el dicho lugar no hay más que 60 bueyes de labranza y 40 cabezas de vacas jatos y vacunos y declaran que del dicho. ganado son más de 40 cabezas las de aparcerla las que tienen los dichos vecinos con vecinos de la villa de Aguilar y de Reinosa.." Averiguación... Lugar de Suano Leg. 70 fol. 3,A.G.S. 
fundamental en la economla campesina, variado en función de ca da tipo de ganado; de este modo, si la orientación o especiali zación bovina aparece como destacada, no se puede por ello olvidar el significado que tienen otros ganados en la comarca. Y este signdificado viene dado tanto por su número como por su concurso dentro de los lfmites determinados por una explotación agraria basada en la subsistencia. El mayor número correg pondla al ganado vacuno, pero el rendimiento que de él se obte nla en régimen extensivo era muy limitado; frecuentemente éste quedaba reducido a un pequeño número de crlas cuyo destino era la venta en Castilla con motivo de los dos a tres viajes que cada labrador hacla a lo largo del afo y siempre que tuviese medios para ello -un par de labranza-. Lo mismo cabe decir del ganado equino, en el que se aprecia una progresiva especialización, a causa de la creciente estimación por los mulos y potros criados en la comarca.

En la preocupacion del campesino todo este ganado que, aparentemente precidaba pocos cuidados, intervenfa de modo decisivo; era preciso alimentarlo una parte del afro, para lo cual habla que contar con suficiente hierba almacenada en los pajares, hecho que no siempre era posible por el enorme desfase existente entre una cabaña numerosa y una exigua superficie destinada a la alimentación del mismo dentro del terrazgo. Por ello no sblo era frecuente que se malograse la cosecha de cereal y leguminosas, sino que también se perdiesen, por falta de alimento algunos ganados durante los inviernos (49). La relativa facilidad -los ganados permanecian en los puertos altos, de aprovechamiento comunal, gran parte del año-, con que se podian obtener ingresos mediante el recurso al in-

(49) "... los vecinos que hay en este lugar no tienen trato, solamente sembrar algín grano y criar alguna baca (sic) y oveja y yegua y desto se crla muy poco por la nieve que viene en los inviernos y pierden la sementera y muchos ganados..." Averiguacibr.... Lugar de Fontibre 1597 Lg. 70 fol 56. 


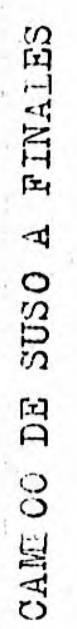

觜呞

鼻 要

in

:

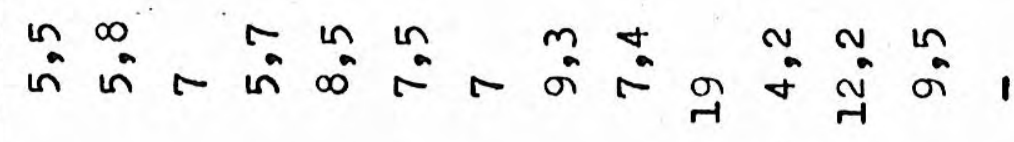

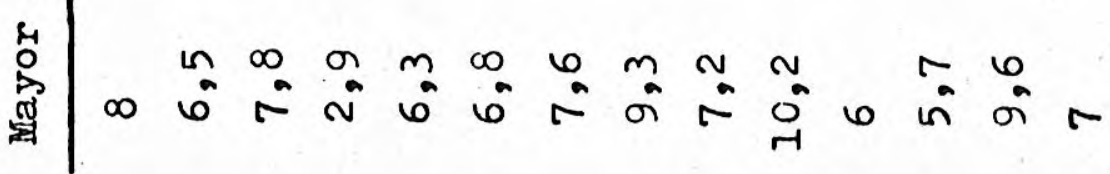

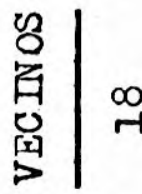

n m

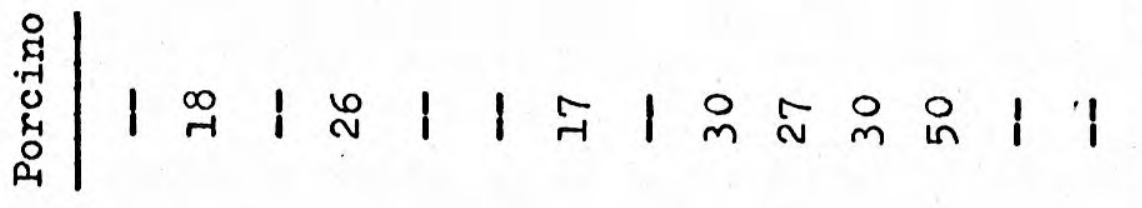

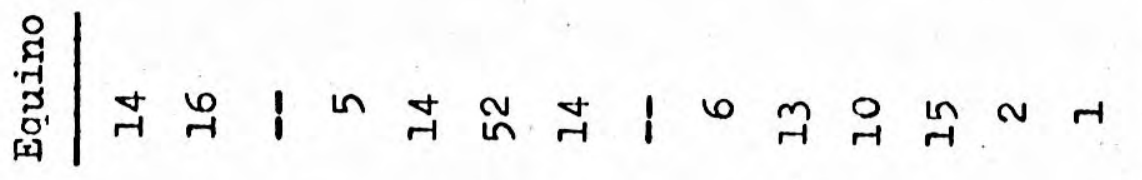

$\sum_{i=1}^{i-1}$

告|

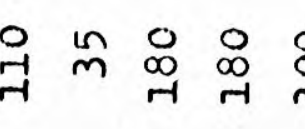

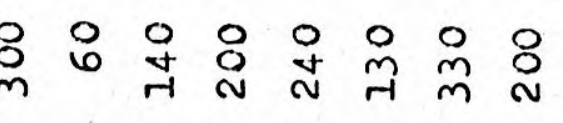

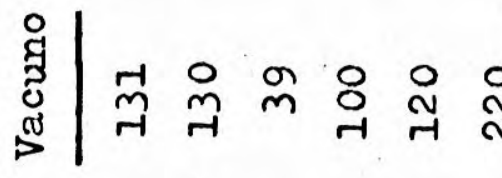

N

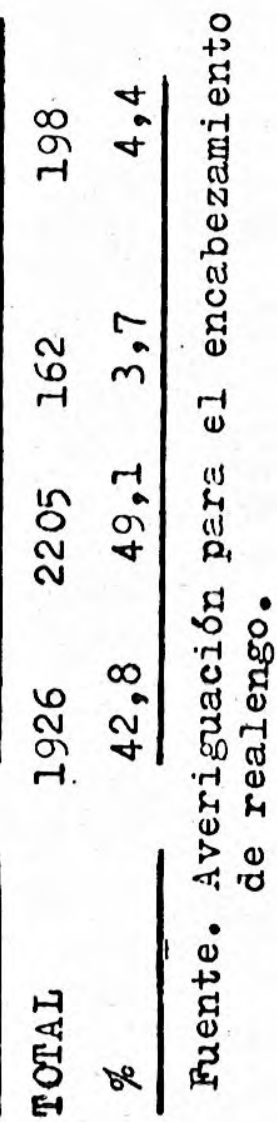


cremento, más alla de las posibilidades reales, del tamaño del rebafo, Io cual djió lugar a frecuentes catástrofes porque "en los dlas de mayor apuro un pan de trigo para matar el hambre de los hijos, donde le pidas te le dan, pero un saco de hierba para las vacas no le encuentra ni por un ojo de la cara (50). Pese a ello la importancia económica de la ganaderla va más allá de un mero complemento de la actividad agrícola; aparece Imbricada con ésta, en un terrazgo de aprovechamiento com plejo, y proporcioma ingresos superiores $y$ frecuentemente los únicos, al conjunto del excedente agricola bruto.

A finales del siglo XVI el. ganado vacuno representa un porcentaje similar al del ganado ovino $-42,8$ y 49,1 por 100 respectivamente, siendo la participación del resto de los ganados mayores y menores prácticamente insignificante en número, que no en valor ni en aignificado. En este periodo la enorme importancia que tenfa el sistema de aparcerfa, el ganado "de a mediag" como se le conoce en la comarca, nos obliga a limitar, en una consideración estrictamente cualitativa la partici pación del mismo en las rentas agrarias. Las referencias a éste sistema son múltiples en todas las fuentes documentales, constituyendo en ocasiones una parte sustancial del rebano(51). Y esta generalización viene dada por la propia estructura so cial de la comarca, en la que se oponfa una minorla no de gran des propietarios, sino de labradores acomodados, a la gran mayorla, que todo 10 más "tiene algún buey e vaca de a medias" (52) :-

(50) J. CALDERON ESCALADA _- Camp6o.... Op. cit. pág 141. (51) "...todos 108 dichos vecinos no tienen sino solamente 39 cabezas de ganado vacuno y de bueyes y vacas y jatos, y las más de las vacas son de aparcerla con vecinos de la villa de Reinosa y Aguilar..." Averiguación... Lugar de la Mtrna 1597. Leg 70 fol. 56.

(52)"... tan s $\$ 110$ dos o tres vecinos siembran un poco de centeno con que se sustentar y solo de estos dos o tres vecinos tienen un par de bueyes y dos pares de vicas y uns o dos yeguas con que se sustentar los demás vecinos tienen algún buey e vaca de a medias..." Ibid. id. lugar de Quintanamanil. Sumamente expresivo del reducido tamaño de la explotación ganadera es la respuesta dada por el lugar de villasuso "... y que el vecino que más ganados tiene no tieno doze (sic) cabezas de ganado vacuno y una o dos yeguas..." Ibid. Id. Lugar citado. 
- Sea cual fuere el régimen de tenencia, la explotación ganadera está en función del abastecimiento de bueyes de la'branza y mulos a Castilla, donde era imprescindible su concurso en las labores agricolas; no obstante, dentro de la co marca también eran apreciados por esta y otras causas. En efec to, no sólo se empleaban en las labores agrfcolas, sino que también, por su sobriedad, fuerza y resistencia, se destinaban al acarreo de productos hacia y desde Castilla. Como vere mos, el ocaso de la carreterla señala el inicio de la paulati na desaparición de este ganado en la comarca, pero hasta este momento -segunda mitad del siglo XIX-, su importancia cuantita tiva era similar a la de las vacas, de las que, al margen de las crias -una cada dos años en el mejor de los casos- apenas se obtenla leche para el consumo doméstico ( 53 ).

\section{CUADRO XII}

'LA COMPOSICION DEL REBAINO EN EL MARQUESADO DE ARGUESO A FINALES DEL SIGLO XVIII.

\begin{tabular}{llllllllll}
1787 & 244 & 400 & 347 & 251 & 37 & 6 & 1285 \\
1790 & 248 & 312 & 239 & 197 & 50 & - & 1046 \\
1791 & 258 & 304 & 219 & 136 & 34 & - & 951 \\
\hline
\end{tabular}

FUENTE: Estado de los frutos y manufacturas. Año 1787

Un significado similar al vacuno, al menos por las rentas de él obtenidas, tiene el ganado equino; su importancia ha ido aumentando progresivamente. Gran parte de ésta estaba centrada, por la demanda castellana, en la adquisición de mulos para la labranza fundamentalmente; por ello era frecuente

(53)"... y no se hace regulación de leche ni queso porque se lo reservan todo para la alimentación de las crlas por ser un pals muy frlo..." Catastro Ensenada. Lugar de abiada. Lib 626 
destinar una parte sustancial de las yeguas - más del 60 por 100- para el apareamiento con el garañon, gracias a lo cual, y mediante la venta de las cxlas mulares lechuzas, obtenfan unos rendimientos muy superiores a los de la venta de potros $y$ potras $(54)$.

Pero si el ganado vacuno y equino representan aproximadamente la mitad del rebafio y proporcionan una parte sustancial de las rentas, el concurso del ganado menor era esencial en la economia agraria. En efecto, además de fuente de ingresos en metálico, tenla el significado de complemento en la subsistencla familiar, ocupando, por su importancia cuantitativa un lugar destacado en la regulación del aprovechamiento colectivo del espacio agrario. Destaca en el conjunto de este ganado, el ovino, que supone más del 40 por 100 , cuyo fin es, en parte la venta en las ferias y mercados de Reinosa; en cambio el ganado porcino tiene un significado diferente.

\section{CUADRO XIII}

LA IMPORTANCIA CUANT ITATIVA DEL GANADO MENOR EN EL MARQUESADO DE ARGUESO.

\begin{tabular}{|c|c|c|c|c|}
\hline & Ovino & Caprino & Porcino & TOTAL \\
\hline 1787 & 984 & 270 & 219 & 1473 \\
\hline 1790 & 598 & 186 & 178 & 962 \\
\hline 1791 & 57.9 & 167 & 180 & 926 \\
\hline
\end{tabular}

Puente: Estado de los frutos y manufacturas.1787.

La importancia numérica del ganado porcino es inferior a la del ganado ovino, pero sustentado sobre la base del belloteo o montanera en los montes de roble y haya del concejo participaba al igual que el ganado vacuno y equino de su apro-

(55) A. RODRIGUEL FERNANDEZ.- Los Carabeos... On. cit. pág. 207 
vechamiento, si bien estaba completamente subordinado a éstos en el mismo ( 56 ).

En conjunto, y pese a que era habitual disponer de un rebaño numeroso por los inconvenientes apuntados, las posibilidades económicas de la inmensa mayorla de la población eran tan reducidas que el tamaño medio del mismo en cada explotación era muy pequeño.

$$
\text { CUADLO XIV }
$$

TAMAN̈O MEDIO DE IAA EXPLOTACION GANADERA A MEDIADOS DEL SIGLO XVIII. MAYORES HAGENDADOS.

Vacuno

Campbo de

Enmedio

4,4

7.5

11,1

4,6

18,8

2,3

Campoo de

Suso

3

7,7

9

3,6

$30,5 \quad 4,3$

Campóo de

Yuso

$\frac{3,6 \quad 8,4 \quad 9,5}{\text { Fuente: Hacendado Mayor. }}$

Tomando como referencia las explotaciones de 108 mayores propietarios en cada lugar, se puede comprobar que, en todos los casos el rebaño es poco numeroso. El ganado mayor no excedla de las 20 cabezas, mientras que el menor, especialmente el ovino tenfa una cierta entidad, que, pese a todo hemos de considerar insuficiente, máxime si tenemos en cuenta que se trata de explotaciones de labradores acomodados. Ovbiamente la situación de la gran mayorla de pequeños propietarios habla de ser mucho mejor de la que reflejaban las fuentes en el siglo XVI.

Parece pues seguro que ni la posibilidad de aprovechar los pastos comunales era suficiente para estimular un incremen (56)"Otrosi ordenaron que ningun puerco de la dicha Hermandad no puedan dormir en los seles donde duermen las vacas, más de sblo pacer de dia y de noche dormir fuera de los dichos seles" Ordenanzas de la Hermandad de Campó de Suso. 1589. Op. Cit. art. 42 . 
to del rebaño, ocupada como estaba, gran parte de la población en asegurar su subsistencia en el terrazgo.

2.- EL PREDOMINIO DE SISTEMAS EXTENSIVOS PARA EI APROVECHAMIENTO DE LOS PASTOS.

Prácticamente en toda la comarca campurriana, el aprovechamiento ganadero se basaba en un pastoreo extensivo de carác ter colectivo, en los amplios espacios de monte, e incluso sobre los sectores cultivados una vez recogidas las cosechas.

La fórmula más generalizada para llevar a cabo tal aprovechamiento la constitula el rebaño comunal o concejil cuidado por los propios vecinos en vez en función del número de cabezas de cada uno, o por un pastor común, que mantenfa gran parte del rebaño, en su mayox parte vacuno y de razas autóctonas - tudanca y campurriana- en los puertos altos, salvo en la época de habitual presencia de la nieve (57)

Cada vecino, o en su defecto un pastor contratado estaba obigado a guardar los rebaños propios y del resto de los vecinos un número de das determinados en función dol tamańo de su propio rebaño; esta práctica, conocida como vez o vecer1a, debla ser escrupulosamente respetada, saliendo los pastores con las vacas y yeguas, permaneciendo con ellos todo el dla "sin correrlos ni maltratarlos" (58). De este modo todos los gana-

(57) "Otrosi ordenamos y mandamos que el que tuviere dos bacas (sic) dos lechones, dos jatos o dos obejas (sic), asf sucesivamente, guarde un dia por cada dos ovejas, hesceto que el que no tubiera más de un lechón.... y cada una yegua un dia y por cada potro o potra desde el dia primero de Abril en adelante

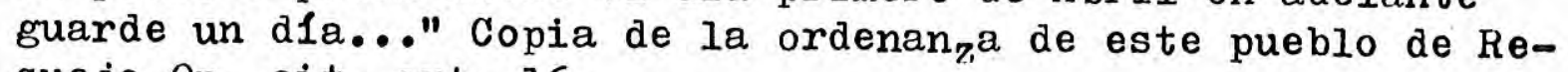
que jo Op. cit. art. 16.

(58) "Otrosi ordenamos que cualquiera vecino del dicho concejo que tuviere alguna de las veces de los ganados tenga obligación de enviar con la dicha vez pastor suficiente, y que tenga de 15 años arriba..." Ibid. art. 19. 
dos sallan cada dla al mismo tiempo, con la única salvedad del orden de salida; en efecto, primeramente hablan de ir las vacas y yeguas "saliendo el sol", seguidas más tarde por los re bafios de ovejas y puercos ( 59). Al margen del aprovechamiento de los pastos de la Comunidad Campoo-Cabuerniga, cuya formula especifica merece una atención mayor, el resto de los mon tes de Campóo de Suso, Yuso y Enmedio eran aprovechados en cada concejo por los ganados mayores y menorea con la particula ridad de que ningún vecino podia ocupar un sel con parte de su cabaña, sino con todo el ganado que tuviese en su casa o al menos con veinte cabezas mayores y menores $(60)$.

De entre el ganado menor, el porcino representaba, como vimos un papel primordial en la economla de subsistencia tradicional, no siendo aventurado presumir una media de 5 a 10 ca bezas por vecino, especialmente en aquellos años en los que la grana -hayucos, bellotas- era abundante en el monte (61). Con el se hacla una primera derrota, saliendo en vez cuando se levantaban las mieses de tierras y prados; permaneclan en ellos hasta que bajaban los ganados mayores de los puertos altos, mo mento en el que se les enviaba a las brañas más lejanas, desde donde léntamente emprendlan el regreso hacia las conclas. Se trataba con ello de evitar que los ganados de otros concejos aprovechasen, antes que 108 propiog, la grana de los montes (62).

59) "Otrost ordenamos y mandamos que los pastores de ovejas - puercos salgan luego que se hayan ido las vacas y yeguas y de la misma manera qye hestá (aic) declarado 10 traigan..." Copia de la ordenanza de eate pueblo de Requejo. Op. cit. art. 20. (60)"Otrosi ordenamos e mandamos que en el primovel minguno. pueda-tomar sel sino fuese con todo el ganado que tuviese en casa..." Ordenanza de la Hermamdad de Campóo de Suso... Op. cit. art. 19. Sobre el mismo particular abunda el articulo 21 de la misma ordenanza "Otrosi que minguna persona ni vecino de dicha Hermandad pueda tomar sel con cabaña si no fuese la mayor parte del ganado de ella o al menos con 20 cabezas mayores y meno res.

(61) J. CALDERON ESCALADA. - Campóo. Op, cit. pág. 132. (62) "... Item que todos los que tomaren puercos a guarda para comer la grana en los términos de la dicha Hermandad, luego que los lleven a monte los pongan entre los términos junto a los mojones que parten con las Asturias, y desde aqul los vengan comiendo hasta las conclas porque no coman los de Asturias la grana de los montes" Ibid. art 24. 
La armonizacion de las necesidades del ganado porcino, en cuanto elemento clave de la economla de subsistencia, con las de los ganados mayores, y aún menores es otro claro ejem plo de la vocación comunitaria en el aprovechamiento del espa cio agrario, Su número, sin que pueda ser cuantificado en forma adecuada por la insuficiencia de las fuentes documentales, era variado, aun de año en año, en función de la cantidad de grana que tuviesen los montes; en conjunto, y aunque su número en relación con otros ganados fuese reducido, su importancia y significado econbmico era primordial, de ahi que se tratase de repartir proporcionalmente la grana de los montes, cuan do la habla. Cada vecino tenfa derecho a una parte de la mí ma, hasta tal punto que, si no tenfa ningún puerco podla traer los de un vecino de otro lugar a cambio, cabe suponer, de un beneficio similar (63). El número de puercos que se podlan introducir el los montes para aprovechar la grana debla ser estimado por los procuradores anualmente,, pero por lo general, al menos para los que no los tenian en propiedad, este número era de cuatro.(64). La importincia concedida a este ganado era tal,que no se permitla la entrada, cuando habla grana en e.l. monte a los rebaños de ovejas, vecus y cabrus.

Junto al aprovechamiento de los pastos y grana de los montes, tenfa también carácter colectivo el aprovechamiento de las tierras de cultivo, ya fuesen de labrantio o prados. En efecto, en todos los concejos existe la obligación de "abrir" las tierras que estuviesen cercadas con la doble finalidad de alimentar el ganado y fertilizar el suelo, para lo cual se permitia la entrada de todos los ganados, primero los puercos y después el resto. La derrota de mieses era por lo

(63) "Que se guarde la grana de la dehesa y quien no tuviese cochino que la coma, sino le hubiere en el lugar, que le trai-

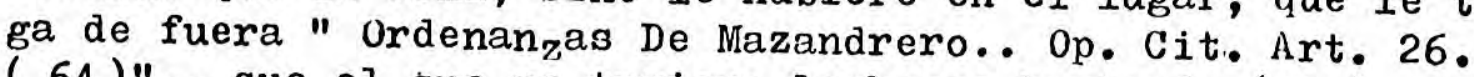
(64)".. que el que no tuviera lechones huviendo (sic) grana traiga cuatro." Ordenanza de la Hermandad de Campó de Suso... 0p. cit. art. 68. 
tanto un elemento esencial para el labrador campurriano, más atento a la subsistencia inmediata, pero necesitado de los ingresos que le proporcionaba un ganado, explotado en régimen ex tensivo. Esta era también la causa de que no se pudiesen intro ducir reformas en el terrazgo cultivado y por ende causa del estado de postración en que se encontraba la agricultura tradicional ( 65$)$.

a) Las Comunidades de pastos: e] aprovechamiento extensivo de los pastos de montaña.

Tradicionalmente en los tres valles, pero particularmen te en Campóo de Suso, y con el fin de paliar en parte la redu. cida disponibilidad de pastos se habla desarrollado una migra cion anual de gran parte del rebaño en una doble dirección: en busca de los pastos de los "puertos altos" durante el verano, $y$ hacia los valles de la costa durante el invierno. Este doble movimiento se reproducla de modo invariable todos los años entre los meses de Abril y Septiembre, interviniendo en él no só lo los ganados de la Hermandad de Campóo de Suso, sino también los de aquellos concejos con los que estaba establecido el con venio.

Las primeras noticias de estos acuerdos se remontan,al menos a mediados del siglo IX, pero no es hasta finales del siglo XV cuando se tiene constancia cierta y suficientemente documentada de los mismos. Estos acuerdos eran de dos tipos, por una parte los que se establecieron entre Campó y Cabuér-

(65) "... que sea raro el pueblo que tenga pastor para los ganados, pues aunque hay en algunos para las vacas, los bueyes caballos, cerdos y demas todos andan infrenes gozando de entera libertad en las derrotas. Esto ocasiona que nadie pueda mejorar su agricultura, no sembrar lino, vejal o morisco, ni sem brar trifo hasta el inés de Enero, ni navos, ni hacer prados ar tificiales." J. M. .- Estado de las fábricas... Up. cit. P. 243 
niga para el aprovechamiento de un espacio de propiedad compartida -la Comunidad Campbo-Cabuérniga-, y por otra aquellos que, de modo particular, la Hermandad de Campóo de Suso estabfecio con varios pueblos de las Asturias de Santillana para el aprovechamiento reclproco de los pastos de cada uno de ellos en fun ción de la época del año.

Los acuerdos o concordias de pastos entre Campbo y Cabuér niga datan del año 1479 , pero a éstos se añaden paulatinnmente numerosas enmiendas por causa de los frecuentes pleitos que ambos valles sostienen, hasta el año 1903 , en que se redacta el primer regilamento de la Asociación y Comunidad. En la primera concordia -año 1479- se determinaba que los ganados de Camp6o de Suso podlan pastar en el "pals bajo" durante el invierno y siempre que hubiera nieve, sin más limitación que "andar al pie de la nieve misma" ( 66 ); durante el verano los ganados de Cabuérniga sublan a los puertos de Campoo, pero solo a aquellos que eran comunes de la Hermandad, no a los propios de cada uno de los pueblos. Esta salvedad, importante sin auda, se debe a que,para la explotación y aprovechamiento de las pastos y maderas de los montes se siguen dos fórmulas diferentes; en efecto, cada concejo -unidad básica de poblamiento y de explotación del suelo- posela una cierta reserva inculta -montes y ejidos- de uso exclusivo de sus vecinos. En ella, o en otros sectores similares podfa el concejo hacer extensivo el aprovechamiento a otros concejos, dando lugar a una nueva figura juridica, la Nancomunidad ( 67$)$. Un sector escapa en alguna medida a esta norma, aquél -la comunidad Campó-Cabuérniga-que conserva el caracter comunal tanto en propiedad como en apro-

(66) A. de los RIOS y RIOS.- Memoria... Op. cit. pág. 4 y sig. ( 67 ) $" .$. tiene la mancomunidad de pastos del monte de roble que está en el término de Villasuso..." Catastro Ensenada. lugar de Bustamante y su agregado Quintanilla Respuesta 23. Lib 628 Fol 443. A.G.S. 
vechamiento, heredado de costumbres y derechos de pastoreo, de origen, sin duda, medieval ( 68 ). Las vicisitudes por las que atraviesa esta Comunidad tienen como elemento común el proble ma de los limites del territorio de común aprovechamiento, por ser habitual, especialmente desde mediados del siglo XVIII, la apropiación para uno $u$ otro valle de algún sector del mismo en el que poder acoger a los rebaños de "merinas" de otras regiones y obtener con ello unos ingresos suplementarios. La presencia de estos rebaños se hará más frecuente desde la desapari= ción de la Mesta, y a ello se achaca la reducción y aun la inferior calidad del ganado vacuno de lampoo y otras comarcas de la Montaña. Este hecho es hasta cierto punto explicable si tenemos en cuenta que, las cantidades satisfechas por los grandes propietarios de ganado lanar, eran mucho más elevadas que las que se obtenfan acogiendo al ganado vacuno de los valles de la costa, como tradicionalmente se habla venido haciendo (69). Diferentes eran, en cambio los acuerdos de pastos entre la hermandad de Campoo de Suso y varios pueblos de las Asturias de Santillana, en particular del valle de Cabezón de la Sal. La primera concordia se celebr $\delta$ el año 1561, pero en ella se hace referencia a que esta práctica se venia observando "desde tiempo inmemorial". Por medio de este acuerdo, los ganados de lampbo podian pastar durante el largo invierno en los términos de los pueblos de las Asturias de Santillana que firmaban el mismo, y desde la Hoz de Santa Lucla hacia abajo, puesto que entre este límite y Campoo se encuentra el valle de cabuér

(68) A. de los RIOS y RIOS.- Memoria... Op. cit. pág 6. (69) "... Desde que relajada la constitución de la Mesta se hicieron ganaderos trashumantes las Comunidades religiosas, grandes y ricos hombres que viven en Madrid y otras ciudades del Reyno, ha perdido esta baja Montaña la mayor de sus ventajas en el número $\mathrm{y}$ bondad de sus bacas: porque las merindades de Campjo les han negado o encarecido extraordinariamente las yerbas de verano que disfrutaban por inmemoriales contratas en común beneficio, prefiriendo las excesivas cantidades con que les contrubuyen aquellos opulentos ganaderos por la acojida de sus obejas, las cuales antisuamente estaban reducidas a pastar en las sierras de las jurisdicciones en que habitaban sus duehoo. Por aquella causa se ven precisados hoy los montañeses a mantener una mitad menos de ganado..." J.lih..- l'stado... up. cit. pá, 
niga, con el que ya existla acuerdo de pastos desde 1497; en reciprocidad, los ganados de las Asturias de Santillana, que habian aprovechado los pastos de los "puertos altos" de Campóo tradicionalmente, desplazándo para ello anualmente toda la explotacion-familia, enseres, criados, pastores y todo tipo de ganado mayor y menor- podfan seguir disfrutando de los citados pastos, pero la entrada a los puertos quedaba reducida al ganado vacuno de cabaña, es decir, las vacas con sus crias y novillos no domados. Asimismo, y frente a la absoluta libertad de que hablan gozado tradicionalmente, se les limitaba el espacio que podfan aprovechar; cada pueblo tenfa señalado un sel, del cual no podían salir.

Para compensar, en parte, estas restricciones, se amplis el periodo de tiempo durante el cual podfan permanecer los ganados en los puertos de Campoo, pussto que, en lugar de tener que abandonarlos el dfa de San Miguel -29 de septiembre-, podfan prolongar la estancia hasta el dia de San Lucas.

Con ello se hacla más equitativo ell aprovechamiento de los pạ tos en los valles respectivos, puesto que los ganudos de Campoo permaneclan durante todo el invierno, jue, medido por la permanencia de la nieve en el suelo, era bastante largo, superior a los cinco meses. ( 70 )

En estos acuerdos se fijaba tambión el lugar o lugares por los que podla entrar el ganado de Campbo en las Asturias de Santillana y viceversa. Estos eran, según A. de los Rfos, el camino Real - o camino del collado de Somahoz -, que atravesaba Campóo de Suso y, por el puerto de Palombera entraba en Cabuérniga y valles de la costa, y el camino que seguirá más tarde la carretera de Reinosa, hasta llegar a Buelna y desde aquí dirigirse a Cabezón de la Sal. In cambio según

(70) A. de los RIOS y RIUS .r Memoria.... Op. cit. pág 18. 
M. Escagedo Salmon, este segundo camino no se utilizaba, bajan do el ganado de Campoo directamente a Cabezón por el Camino real ( 71 ).

\section{CUADRO XV}

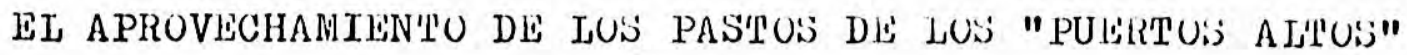
DE CAMPOO POR EIJ RE'BANO DE LAS AIJ'IUIRIAS DE SANTILLANA.

\begin{tabular}{|c|c|c|c|}
\hline & 1891 & 1892 & 1893 \\
\hline Cabezon de la Sal & 290 & -- & 326 \\
\hline Torrelavega & 264 & 133 & 130 \\
\hline Reocin & 616 & 381 & 544 \\
\hline Alfoz de Lloredo & 524 & 475 & 1.30 \\
\hline Polanco & 150 & 120 & 163 \\
\hline Piélagoos & 98 & 71 & 136 \\
\hline Cartes & 237 & 114 & 181 \\
\hline Los Corrales & 314 & 33 & 45 \\
\hline Ricombo & -- & 127 & -- \\
\hline Mazcuerras & 501 & 309 & 722 \\
\hline Udias & 97 & -- & 85 \\
\hline Total Rebano & 3091 & 1636 & 2162 \\
\hline
\end{tabular}

El ganado que pasaba el verano el Campó, era relativamente numeroso, y variado en función de los años, pero en cual quier caso inferior al ganado de Campbo. Para poder acceder a estos pastos tenia que estar marcado e ir acompañado de uno o varios pastores continuamente, con el fin de evitar que trang grediese los limites del sel que a cada rebaño le estaba asig nado.

Pero no sólo en la Hermandad de Campó de Suso se observa ban estos sistemas para el aprovechamiento de los pastos; las

(71) M. Escagedo nó está de acuerdo con la opinión sostenida por A, de los Ríos sobre el número de cañadas por las que se accedla a las Asturias de Santillana. En su opinión tan sblo uno de ellos, el camino de Somahoz era el empleado. Pura esta; aspectos ver. M. ESCAGEDU SALLiUN.- Costumbres... Op. cit. p. 118 
mancomunidades estaban también generalizadas entre los distintos pueblos de los valles de Campoo de Enmedio y Yuso, si bien el número de pueblos que integraban cada una de ellas era redu cido, en ocasiones tan sblo el concejo propietario del monte y otro concejo proximo. Asimismo era habitual, al menos desde el siglo XVIII que tales mancomunidades se limitasen al aprovechamiento de los pastos por estar los montes bajo la jurisdicción de la Intendencia de Marina de Guarnizo, y no poderse cortar en ellos madera alguna. ( 72 )

Al margen de los acuerdos o mancomunidades entre distintos pueblos, el aprovechaniento de los pastos de los montes y ejidos que cada uno tiene como propios estaba sometido a una. estricta regulación, toda vez que de ellos depencila la alimentación de los ganados en una parte sustancial del año. Se limita., en efecto, el número de reses que cada vecino podla enviar a pastar en los montes y ejidos comunales ( 73 ). Se lograba asf corregir los posibles desequilibrios a la hora de disfrutar de un bien común y escaso; no llama la atención por ello que se prohiba introducir en las "pastizas" y "cotos" del común, ganado en aparcerla ( 74 ).

(72) A mediados del siglo XVIII existian varias mancomunidades de pastos, cuya entidad era variable. In efecto, desde las que disponen de una superficie condiderable, como las de Servillejas - 1030 fanegas de monte-, la de Aradillos - 1150 fanegashasta aquellas que disponen de una superficie muy reducida, como la mancornunidad de Fombellida-Castrillo de. Haya, de 200 fanegas y otras incluso con superficie menor. Catastro Ĺnsenada ('73 )" Otrosi ordenamos y mandamos que por cuanto el dicho con cejo tiene poco termino, y en él se mantiene mucho ganado e no se puede sustentar y mantener, que de haoui (sic) en adelante ningúnvecino del dicho concejo pueda traer en los dichos términos más de ocho yeguas ni más de cincuenta carneros ni ovejas, ni más de treinta cabezas de ganados de bueyes o bacas, dos más o menos" Ordenanza.. de Requejo... Art. 15

(74) " Otrosi ordenamos y mandamos que ninguna persona de dicho concejo que trajere ganado apartado no pueda entrar ni pacer las dichas pastizas ni cotos, sopena..." Ibid. artfculo 24 . 
CAPITULO VI

IA BUSQUEDA DE UN COMPLEMENTO A LUS BAJUS RENDIMIENTUS AGRICOLAS

La sociedad campesina tradicional se habla debatido en los Ifmites de una economla de subsistencia en la que, el intercambio para obtener los productos en los que era deficitaria llegb a tener un carácter estructural, y no solo porque inveriablemente se realizaba todos los años, sino porque en el estaba implicada una parte sustancial -más del 50 por 100del campesinado de la comarca.

Pese a todo ello nos es, como en otros sectores de la misma una actividad exclusiva, que ocupe todo el afho a la población; muy al contrario, y salvo las excepciones de rigor, la dedicación era exclusivamente temporal - 3 meses al año -, el número de productos que se comercializa muy reducido, y sin apenas variación en el tiempo. En efecto, si al final del siglo XVI la base de este comercio la constitulan los productos artesanales, crias de ganado vacuno y bueyes de labranza, y los productos adquiridos trigo y vino para el propio consumo, dos siglos más tarde apenas se habla modificado. Quizá cambió coyunturalmente el destino de los productos, puesto que desde mediados del siglo XVIII se aprecian indicios de comercialización del cereal, merced al desarrolllo de la industria harinera 
de Reinosa, y del vino en las ferias y mercados del mismo núcleo; pero el volumen de este comercio seguía siendo reducido, al menos en lo que corresponde a la participación de la pobla ción de la comarca, y los ingresos en él obtenidos eran entecos. Cada carretero obtenfa en cada viaje por cada "par de la branza", es decir, por cada yunta de bueyes o de vacas tudancas un beneficio medio de 30 reales, que, en ol conjunto dol año, y puesto que habitualmente se realizaban tres viajes, su ponfa una renta neta de 90 reales.

Con todo, las rentas asf obtenidas eran un mero complemento; nada más cierto si tenemos en cuenta el nivel de los precios de algunos articulos imprescindibles, y si los comparamos con los rendimientos estimados, a mediados del siglo ! XVIII, para el ganado mayor y menor. ( 75 ). Todo ello nos 11eva a pensar que estos desplazamientos temporales, realizados "una vez acabada la labranza", tienen más el carácter de complemento en una economla de subsistencia, que una vinculación al sistema de transportes entre Castilla y los puertos cantábricos; lo demuestra además el hecho de que, prácticamente en toda la documentación se hace clara referencia a que el motivo de tales desplazamientos se encontraba en la necesidad de proveerse de lo que les faltaba, incluso de productos que, como sucede con los cereales, se cultivaban en la comarca $a$ pesar de las adversas condiciones ecológicas.

No sorprende por ello que el sentido de estos desplazamientos apenas se modifique hasta su desaparición, o mejor hasta que se inicia su declive, a raíz de la construcción del (75) Con pequeñas diferencias entre los distintos concejos, una yegua produce anualmente "regulado por un quinquenio" 220 Rv., una vaca $25 \mathrm{Rv}$, un novillo de un año $80 \mathrm{Rv}$, , de dos años $140 \mathrm{Rv}$. , de tres años $200 \mathrm{Rv}$, , de cuatro años $300 \mathrm{Rv}$, de tinándole con más de cinco a la labranza. Catastro Ensenada lugar de la Miña $0 p$, cit. resp. 18. Los precios de algunos articulos a mediados del siglo XVIII indican en cambio que los rendimientos obtenidos con la carreterla no podian constituir finalidad exclusiva del labrador-carretero, en efecto, un dalle estaba valorado en 12 reales, un hacha costaba 11 reales, un arca de carga y media costaba 26 reales etc... A. RUDRIGUEL FERNANDEZ.- Los Carabeos... Op. cit pág 302 . 
ferrocarril. Pero esta vinculación temporal o coyuntural al transporte de cereales con destino a las fábricas de harina de Reinosa, no sirve, empero, para ocultar el verdadero significado de la carreterla campurriana; y este no es otro que el complemento a una agricultura de subsistencia, un complemento imprescindible y de honda raigambre en la comarca.

\section{1.- EL CARACTER TRADICIONAL DEL INTERCAMBIU CON EI INTERIOR DEL PAIS}

Si bien es cierto que, al amparo de coyunturas ajenas a la propia comarca -creación del Consulado del Mar en Santander en 1785i y construcción de la carretera de Reinosa en 1752pero incluso desde el momento en que Santander fue autorizado en 17.51 para comercializar con las Antillas, la carreterla adquiere un cierto impulso y pasa a ser en si misma una forma se gura de obtención de ingresos, no por ello pierde parde del sig nificado que tradicionalmente habla tenido, puesto que seguirá conservando un marcado ritmo estacional y será marginal en la preocupación del campesino oampurriano.

Sin que nos sea posible precisar el momento en que tal actividad aparece en la comarca, parece suponer, y asf lo deja entrever la documentación existente, que su origen está indiso lublemente unido a los orlgenes del poblamiento y actividad agraria en general; en efecto para que apareciese se contaba con inmejorables condiciones, por una parte la relativa proxi midad a centros proveedores de los productios de los que la comarca era deficitaria -cereales y vino-, y por otra, la facilidad con que se podian vender los productos, los excedentes ganaderos de la comarca. Se trata de dos economfas complementarias, llamadas inevitablemente a relacionarse.

En efecto, era la necesidad de proveerse de pan y vino la que obligaba, en parte, a realizar estos desplazamientos en los que participaban buena parte de los labradores por el gra- 


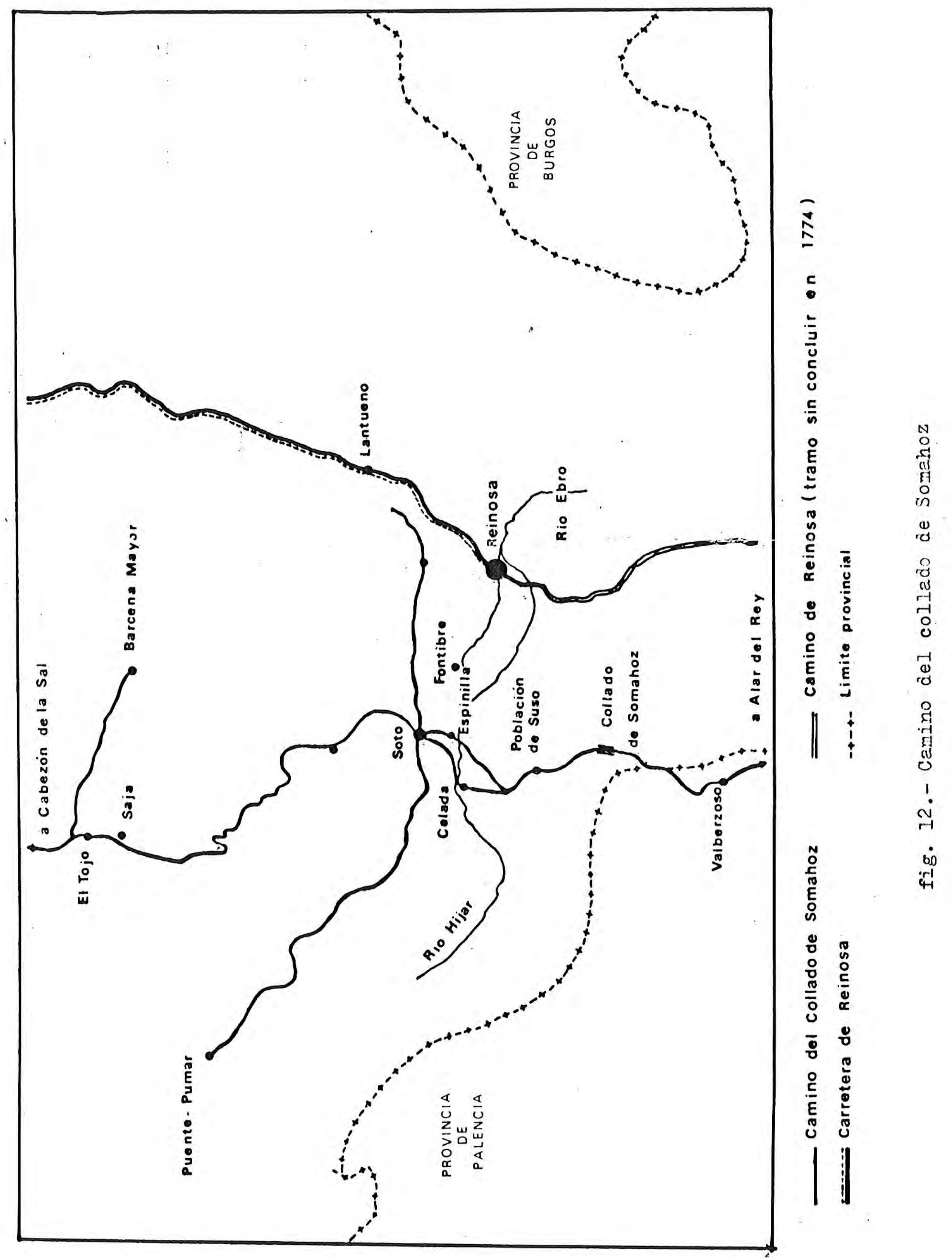


do extremo de necesidad en que se encontraban (76). Tan s6́lo existe una excepción, y el la de aquellos que, carentes de otros recursos se ocupaban en acarrear sal de Cabezón de la Sal o de Poza de la Sal para su posterior reventa en la comar ca o en Castilla. Era, que duda cabe una forma más de obtener ingresos que invariablemente destinaban a la adquisición de "pan e vino para sustento de sus casas" ( $\left.77^{\circ}\right)$.

Este grupo de campesinos, que por otra parte parece ser numeroso, encontraria por este procedimiento una forma más de obtener ingresos, a la que habrla que afradir la elaboración de "maderas" para la venta en los mismos mercados.( 78 ). Empero, el volumen de productos comercializados no podfa ser elevado por la escasa entidad de los excedentes ganadicos, y por las numerosas restricciones impuestas al aprovechamiento del monto.

Antes de la construcción de la llamada carretera de Reinosa, la ruta seguida en estos desplazamientos era la conocida como el camino del collado de Somahoz, que se unfa, en Aguilar de Campó, con el Camino Real. El camino de Somahoz penetraba en Campóo por las laderas del monte Escalera, atravasaba el collado del mismo nombre, donde, muestra de la intenaidad del tráfico,habla una "vente.", para, acercarse a La Población de Suso bordeando el curso del arroyo parralozas, y atravesando el rio Hljar en Celada de los Calderones o Espinilla, llegar a Soto. Desde este punto, el camino ascendla por Palombera

(76)"... y de los treinta y uno vecinos que han quedado, los más dellos son pobres y pasan su vida con mucho trabajo y haciendo maderas en los montes y llevanlas a vender a Tierra de Campos y Castilla para traer pan para comer y del que se susten tar a sus hijos..." Averiguación... Proaño $1597 \mathrm{Leg} .70$ fol. $5 \overline{6}$. ( 77 )"...No se coge vino en este lugar ni en los demas de la dicha Hermandad porque lo traen de acarreto y el pan los dichos vecinos de la Tierra de Campos con lo que les dan por los ganados que venden y por la Sal que llevan de las salinas de Poza." Averiguación... Ibid. Lugar de La Izara. ( 78 ) "... que hay más de 12 vecinos muy pobres que no tienen nada por no tener en que lo ganar en esta tierra..." Averiguación.... Ibid. lugar de Villasuso 
para caer por la Hozcaba a Barcena mayor, desde donde so dirigla a Cabezón de la Sal.( 79)。

Aunque su importancia económica era menor, en Soto, el camino de Somahoz se cruzaba con el que tenla como punto de destino la liébana, completando lo que podrfamos denominar la infraestructura de las comunicaciones de la comarca, funcional hasta mediados del siglo XVIII, hasta el. momento en que se cong truya el llamado Camino de Reinosa.

2.- EL DESARROLLO DE IA CARRETGRIA EN ET SIGJO XVIIT: UNA ACTIVIDAD DE MARCANO RITMU ËSTACIONAI.

A mediados del siglo XVIII, y aún antes de que se terminase de construir el camino Real de Santander a Reinosa en 1753, que dis un nuevo impulso a la actividad de la villa de Reinosa, y por ende a toda la comarca, la carreterla campurria na se encontraba plenamente desarrollada. El número de carrete ros, bien es cierto que con una dedicación parcial, era elevado; más del 50 por $\$ 00$ de los labradores se ocupaban temporalmente en esta actividad, que les proporcionaba el complemento necesario de su agricultura de subsistencia. No se trata por ello de una actiwidad nueva, surgida al calor de las ventajas proporcionadas por el tráfico de harinas con destino al puerto de santander, sino que, aun antes de que éste se inicie, eg taba ya plenamente desarrollada; es probable que, en las condiciones apuntadas aumentase el número de labradores ocupados en ella, hecho que nos es imposible precisar, pero, salvo casos aislados en los que se acarrea un volumen de productos ma-

(79) En su término se encuentran los restos de un antiguo edificio que dicen fue convento de los templarios y una venta llamada Somahoz, situada en el camino por donde se pasaba antes a los valles de Cabuérniga, Cabezón y Liébana." P. MaDOz.- Diccio-

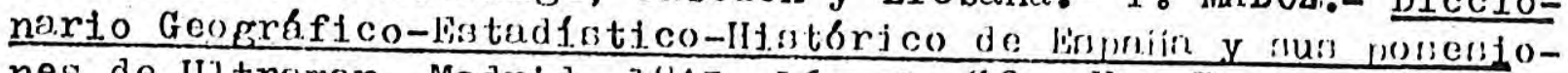
nes de U1tramar. Madrid. 1845. 16 vol. Cfr. Voz Suano vol. XIV 


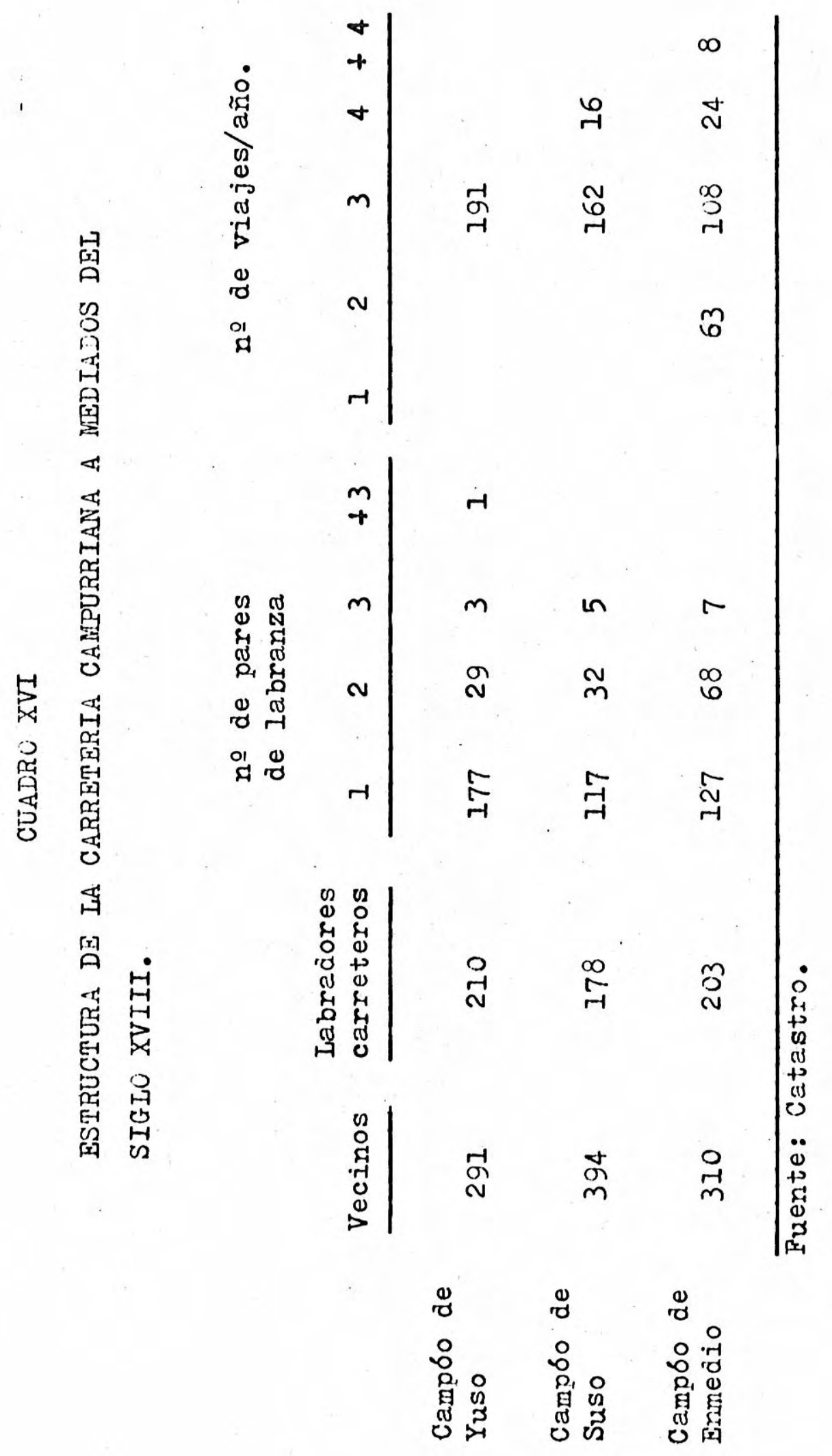


yor del estrictamente necesario para el propio consumo, el trang porte de mercanclas no excede los Ilmites de las necesidades do mésticas, 10 cual nos hace suponer que no ha cambiado sustancialmente el sentido que, tradicionalmente, tenfa este desplazamiento en la comarca $(80)$.

En efecto, más del 70 por 100 de los labradores hace el desplazamiento con tan solo un par de labranza, siendo poco lo que con este medio se podla acarrear; el resto acude a Castila a con tan sollo dos pares de labranza, salvo un porcentaje insignificante, el 3,6 por 100, que emplea trés o mas. Es tan s610 en este último y reducido grupo en el que podemos presumir un transporte de mayor envergadura, sin que por ello pierda el. carácter estacional; el tiempo empleado y, cabe suponer, el momento del desplazamiento, es similar en todos los casos. La mayor parte de los labradores hacen tres viajes a Castilla, empleando en cada uno de ellos 18 dias, una vez concluldas las labores agricolas, siendo muy pocos los que escapan a esta re gla general ( 81 ).

Pese a que gran parte de los carreteros-labradores reali za los viajes sin afán de comercializar los productos porteados, la realidad, al menos coyunturalmente pudo ser muy otra, Desde el segundo tercio del siglo XVIII se aprecia en la comarca un incremento en la producción agraria, especialmente en lo que respecta al txigo, cuya causa fue sin duda la posibilidad de comercializar parte de los excedentes, o parte de (80) "... los vecinos que tratan de ir a tierra de Castilla a portear trigo o vino para si o para otro son los siguientes...." Catastro Ensenada. Lugar de Ormas Lib. 631, fol 410. Respuesta 32. Además del concejo de Ormas decjara en el mislio sintirlo e? de Espinilla, sin que en ninguno de los dos casos pierda el desplazamiento su ritmo estacional. (81) "...hay 16 labradores carreteros que hacen 4 viajes a Castilla y en cada uno les queda de utilidad 22 Rv..." Ibid,Iugar de Izara 1ib. 630, fol. 361. Se trata de uno de los pocos lugares en los que globalmente se declara la realización de más de tres viajes; en el resto de la comarca tan sollo algún caso aislado e individual, y siempre con más de un par de labranza escapa a la regla general. 
los granos transportados ante la favorable coyuntura del mercado triguero. Las condiciones para realizar esta comercializa - c1ón de grano eran sin duda bptimas, y no solo porque el trigo alcanzase precios elevados, sino porque el portazgo establecí do en Reinosa al concluir el trazado de la nueva carretera, de claraba exentos $10 s$ carros que transportasen cereales, manteniéndose tal franquicia hasta, al menos 1763, es decir, 10 años después de que concluyesen las obras de la nueva carretera.( 82 ).

Las rentas que de esta actividad se obtenfan no eran, sal vo excepciones, demasiado elevadas; oscilaban por cada viaje y "par de labranza" entre 22 y 50 reales, lo cual supone un mfnimo de 66 reales y un máximo de 150 reales anualmente. Las diferencias obedecen al tipo de mercancla transportado, y al destino final de la misma. Eran, en efecto, más elevadas cuando se transportaba vino para su posterior venta el el mercado de Reinosa ( 83 ).

Por ello, esta actividad no se puede contemplar, en una perspectiva rigurosa, más que como un mero complemento, eso s1, importante e imprescindible, pero complemento al fín. Lil abastecimiento de productos de cierta calidad y aun de productos básicos, cuando, hecho muy frecuente, se carecla de ellos, se realizaba, necesariamente, en Reinosa. Aquf, semanalmente, el labrador-carretero, ponfa a la venta sus escasos excedentes agricolas, cuando los habla, y las maderas, prendas de lino y otros articulos elaborados con este fin.( 84 ). A este mercado

(82) V. PAIACIO ATARD. - El comercio de vastilla y el wuerto de Santander en e. siglo XVIII. Nadrid 1460. p. 85 y sig. (83) En alguna medida el bajo rendimiento medio obtenido por los carreteros campurrianos permite suponer que tan sólo una pequeña porción de lo transportado se ponfa a la venta en el mercado de Reinosa, máxime si tenemos en cuenta que " un carro podla conducir 100 arrobas y el porte de cada una de ellas se calculaba en dos reales y cuarto" F. BARREDA Y FlRRER DE IA VEGA.- Prosveridad de Santander y desarrollo industrial desde el Biglo XVIII. Banco de Santander. 1957. pag. 556. (84) ".. que en esta villa el dla lunes de cada semana se celebra mercado de granos de acarreo y a lomo se traen de tierra de Castilla pare el. consumo de los naturales de este puls" (antratro Ensenada... Lugar de Reinosa I,ib. 638 Fol. 33. A.G.S. Respuesta
no 29. 
acudian también arrieros de otras regiones, en particular de las Montañas de Burgos, que transportaban granos, de los que, y a pesar del acarreo, la comarca era deficitaria ( 85). Basta ba una mala cosecha, catástrofe frecuente, para que la carencia de grano durante una parte sustancial del año fuese casi absoluta, siendo preciso adquirirlo en el mercado de Reinosa, o en el pósito del mismo lugar para asegurar, al menos, la siembra del año siguiente $(86)$.

En parte la orientación de la carretería sufrixá un cambio a rafz de la construcción del camino de Reinosa en la segunda mitad del siglo XVIII. Desde este momento, parte de los carreteros campurrianos, sin que podamos precisar su número, pa san a formar parte del sistema de transporte de granos con destino al puerto de Santander; parece no obstante que esta actividad adquirió cierto desarrollo porque, a mediados del siglo XIX, la mayor parte de los pueblos declaran que sus vecinos se ocupan del "transporte de efectos comerciales" o del "transporte de granos de Castilla" e incluso en la "importación de vino y otros articulos que faltan", lo que nos hace suponer que todavia el significado de la carreterla tradicional no se ha perdido ( 87 ).

\section{a) La construcción de la carretera de Reinosa: el ocaso del aislamiento tradicional del Valle de Campó.}

Pese a los avatares que sufrió su construccion desde el año 1749, fecha en que ésta se inició, la carretera de Reinosa estaba llamada a jugar un papel de primer orden en la economfa regional, y por ende en la de la propia comarca campurriana.

(85) J. ORTEGA VALCARCEL. - La transformación... Op. cit. pág. 141 y sig.

( 86 ) G. ANES ALVAREZ.- Los pósitos en la lispaña del siglo XVIII. Moneda y Crédito Junio 1968, no 105 pág 48 y sig. (87) P. MADOZ.- Diccionario. Voz Reinosa T. XIII, pag. 406. 
La actividad desplegada en torno a ella hará que la comarca vaya perdiendo parte de los obstáculos que condicionaban la agricultura tradicional; y el mayor de ellos ere sin duda el aislamiento. En efecto, la comercialización de los escasos excedentes agricolas será más segura, sin que ello suponga que la orientación de la actividad agraria se transforme sustancialmente; más bien al contrario, y al amparo de la favorable coyuntura del mercado triguero, el labrador campurriano aumentará, dentro de los estrechos limites que el terrazgo permitia, la superficie cultivada, detrayendo una parte de los granos acarreados desde Castilla para su comercialización en el morcade de Reinosa. Ello dará lugar, especialmente cuando el precio del grano era elevado, a un incremento de estas rentas que hemos denominado marginales y que, pese a ello, siguen siéndo10.

En la comarca no aparece la figura del transportista pro fesional como sucede en otras regiones, pero si se generaliza y aun se acentúa en su rigidez estacional la carreterla a tiem po parcial ( 88 ). Se trata en cualquier caso de una actividad más compleja que la desarrollada hasta la construcción de la

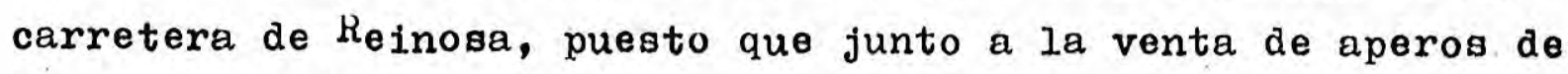
labranza y alguna crla de ganado, hay que añadir los ingresos obtenidos por el transporte, en el viaje de ida hacia Castilla, de efectos coloniales desembarcados en el puerto de Santander y llevados a Reinosa por los carreteros de La llontaña. No sorprende por lo tanto que esta actividad ocupe a más del 50 por 100 de los labradores, durante los meses en los que éstos se velan liberados de las labores agricolas, es decir, durante los tres meses de verano por 10 menos.

(88) Existen, no obstante, excepciones dentro de lo que constituye la actividad dominante; los carreteros profesionales poco o nada tienen que ver con la actividad e intereses de la comarca y aun de la región. A mediados del siglo XVII un vecino de Argüeso declara "... mi exercicio es ir a Andalucla, a. la cirdad de Jerez de la Prontera, donde me exercito en las corredurfas de las extracciones de vinos para fuera del reino" Memoriales de seglares y eclesiásticos. Argüeso. Archivo Histórico Provincial. Santander. Sig. E-64. 
Sin duda la intensidad de este transporte se debe a la construcción de la carretera de Reinosa. En 1752 estaba conclui do el primer tramo, entre Santander y Reinosa, para dirigirse más tarde hacia Palencia en lugar de hacia Burgos como inicial mente estaba proyectada; la causa de este cambio se encuentra en la intensidad y significado del tráfico de granos que, con destino al puerto de Santander se desarrollo a ralz de la prag mática de comercio libre con América del año 1778 y la consiguiente habilitación dada al puerto de Santander para lievarle a cabo. Gracias a estas disposiciones, y gracias también a que log productos de la industria vascongada son gravados en 1779 con el derecho de extranjerla para su introducción en Castilla, el comercio de granos e incluso la elaboración de harinas se desplazará en beneficio de puerto de Santander y, de modo indirecto del núcleo de Reinosa, convertido en paso obligado, so bre todo desde que se concluyó la carretera, para los granos castellanos ( 89 ). Pero no solo se convertirá en un centro-al macén para $10 s$ citados productos, sino que participará también en la elaboración de buena parte de $10 s$ mismos.

b/ El auge de la industria harinera en Reinosa: una consecuencia del tráfico de trigo con destino al puerto de Santander.

A consecuencia de la pragmática de libre comercio con América, y del desplazamiento hacia el puerto de Santander de gran parte de la actividad monopolizada hasta entonces por los puertos cantábricos, comenzarán a surgir numerosas fábricas de harina jalonando el rlo Besaya, o lo que es lo mismo, la carre- 


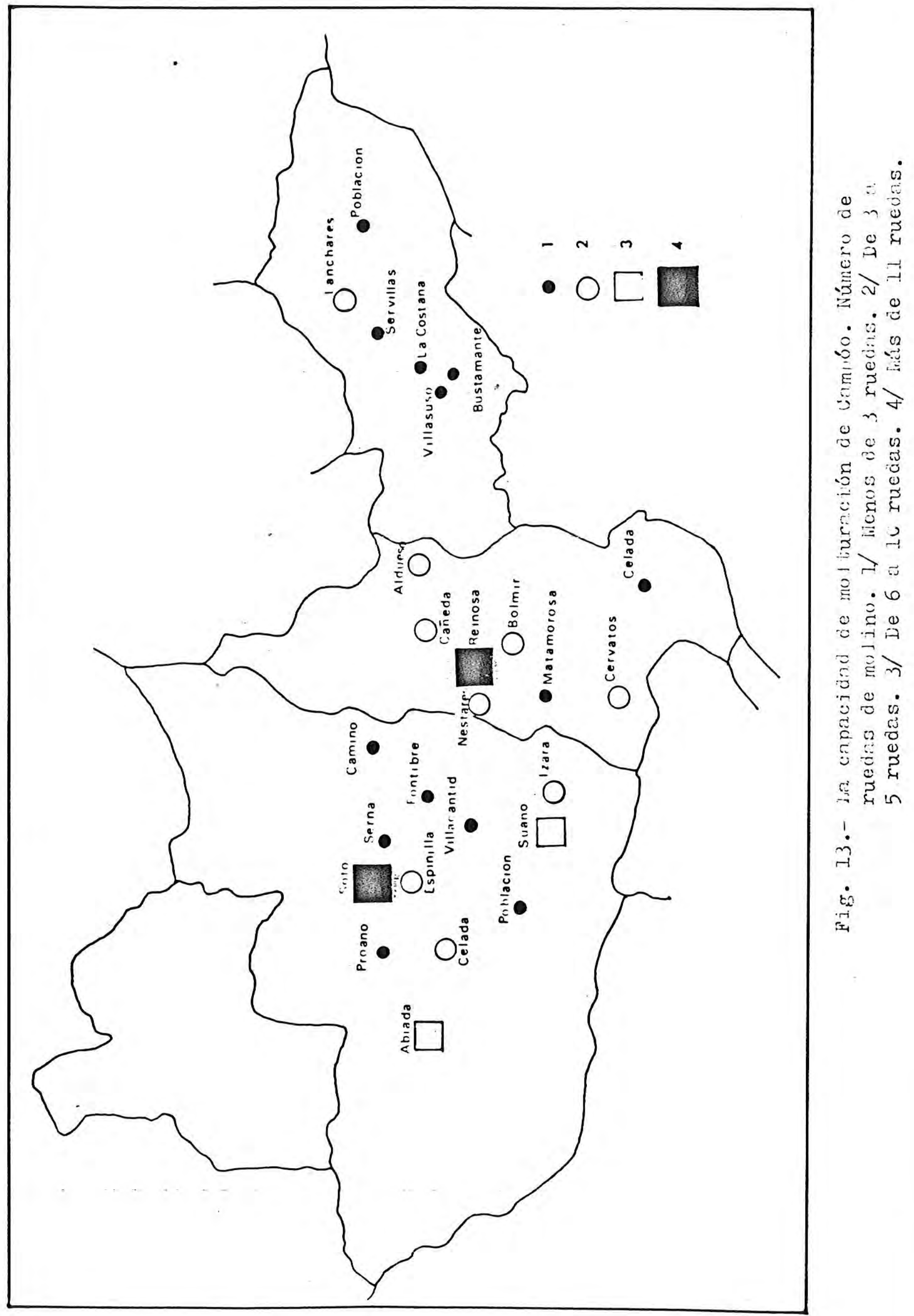


tera de Reinosa. Se desarrolla asi un intenso tráfico, complejo en ocasiones, puesto que muchas fábricas empleaban granos 'extranjeros importados a través del puerto de Santander, bien porque su precio era menor o bien porque la carreteria no tenfa la suficiente entidad para hacer frente a una demanda creciente.

I actividad de la carreterla proseguirá, con frecuentes altibajos en función de las coyunturas del mercado triguero, prácticamente hasta la construcción del ferrocarril, y con ella la fabricación de harinas. En este tiempo, prácticamente un siglo, Reinosa se convertirá en almacén de los granos castellanos, parte de los cuales serán transformados en las fábricas de harina de la propia comarca.

Merced a esta actividad, Reinosa adquiere parte de su fisonomía y estructura actuales. El núcleo se extiende a ambos lados de la carretera, jalonada de almacenes para el trigo y los productos ultramarinos que, más tarde serán reexpedidos desde aqui hacia el interior del pals, con el concurso de los carreteros de la comarca. El tráfico de curretas era intenso, puesto que aqui conflufan por una parte los carreteros de la Montaña, que transportaban ultramarinos y regresaban a Santan! der con los granos y harina elaborada en Reinosa, y por otra parte los carreteros campurrianos, que transportaban los citados productos ultramarinos hasta Alar del Rey, final del ramal Norte del Canal de Castilla, y regresaban a Reinosa con trigo.

No es extraño que, en relación con este intenso tráfico, la comarca, y Reinosa en particular viviese un periodo de cier ta euforia que no fue suficiente, no obstante para evitar que el tradicional éxodo rural se redujese; las rentas de este modo obtenidas seguian siendo marginales a una actividad agraria que no habla perdido su significado de subsistencia. 
Si las condiciones para haber cambiado sustancialmente la estructura económica de la comarca fueron idoneas, 10 cierto es que, salvo Reinosa, esta conservará gran parte de los condicionantes que estructuralmente se hablan opuesto a su de sarrollo. En efecto, la infraestuctura técnica con ue se contaba para hacer frente a la febril actividad de la molturacion del trigo, era claramente insuficiente, y ni siquiera se mejoro. Existlan en la comarca un número ciertamente elevado de mo linos, pero las condiciones de su instalación eran muy deficien. tes; la mayor parte de ellos no estaban preparados para moler grano más ae una parte del año, instalados como lo estaban aprovechando log cursos de pequeños arroyos. Por esta criusa po$\cos$ eran 108 que tenfar mas de una ruede. y, muchos menos los que orientaron su actividad al comercio harinero ( 90 )

De los 73 molinos existentes a mediados del siglo XVIII, $\tan$ sరlo 8 funcionaban todo el año, y de éstos sólo los de Re nosa ofrecian condiciones para competir con los que más tarde se instalarán a lo largo de la carretera de Reinosa a Santander. Los 5 molinos de Reinosa tenfan un número de ruedas suficiente para hacer frente a la demanda de harina con destino al puerto de Santander, y el regimen de functonamiento era, al menos en trés de ellos, anual. A estos se añadirán más tarde dos nuevas fábricas de harina "osean, molinos montados a la mo derna" en Nestares -Campóo de Enmedio-, comnletando la escasa participación de la comarca en esta actividad ( 91 ).

Por contra, la principal actividad de gran parte de la

(90) El elevado número de molinos existente a mediados del siglo XVIII en algunos lugares, 15 en Soto para 45 vecinos, 7 en Abiada para 36 vecinos por citar algunos ejemplos, es sin duda una reminiscencia de origen medieval, al ser estos otro modo más de incrementar las rentas señoriales.

(91) En Nestares "hay dos fábricas de harinas, osean molinos montados a la moderna, cuya maquinaria muele, cierne limpia y ensaca simultaneamente sobre 300 fanegas de grano diarias que por lo general exportan a Santander para el embarque con dirección a la Isla de Cuba y Cataluña." P. MADOZ, voz Nestares T, XII, pág 157。 
población seguirá siendo, al menos hasta la construcción del ferrocarril, la carreteria, una parte de la cual se"profesio'naliza". En efecto, una parte sustancial de los carreteros se dedicarán a conducir trigos y harinas de "Castilla la Vieja" y Alar del Rey, en donde concluía el ramal Norte del Canal de Castilla. El tráfico era intenso porque al trígo se anaden las harinas molturadas en las fábricas castellanas, asentadas a lo largo del Canal de Castilla, desde al menos el año 1780; en un principio el transporte de harinas encuentra ciertas facili dades,al estar libre del pago del Portazgo, pero, años más tar de,el Gobierno establece un cánon muy elevado con la finalidad sin duda de proteger las fábricas asentadas a ambos lados del camino real de Reinosa. No es diff́cil avanzar esta hipótesis si tenemos en cuenta que, en 1788, el Gobierno iguala el cánon del trigo y de las harinas, ante la oposición del Consulado de Santander ( 92$)$.

Junto a estos carreteros se encuentran aquellos que aún tienen como actividad preferente el acarreo de vino de la $\mathrm{Na}-$ va del Rey y su tierra, Toro, ribera de Aranda y la Rioja, con destino al consumo interno; buena parte de este vino se vendfa en los mercados de Relnosa donde la demanda era muy alta por causa del elevado volumen de población que, habitualmente y a causa de la carreterla, all1 se daba cita; no en vano, "los frutos, en su mayor parte hacen escala en Reinosa, para ser conducidos a los puertos de La Requejada y Santander" ( 93 ). La impronta de toda esta febril actividad en la comarca será, empero, muy reducida; los obstáculos, los condicionantes estructurales seguirán siendo decisivos una vez que, conclufda

(92) V. PALACIO ATARD.- El comercio... Up. cit. pág 160. ( 93 ) " gran parte de sus moradores se dedican al acarreo de vino de la Nava del Rey y su tierra, Toro, ribera de Aranda, y Rioja, pero muy particularmente y en mayor porcion a conducir trifos y harinas de Castilla la Vieja y $\Lambda$ lar del Rey, en donde concluye el ramal del Norte perteneciente al Canal de Castilla" P. MADOZ. Diccionario. Voz Reinosa (término) T. XIII, pág 406. 
su participación en el sistema de transporte a escala nacional a consecuencia de la construcción del ferrocarril, la población 'de la comarca retorne al modo de vida, a la actividad económica tradicional. 


\section{CAPITULO VII}

LOS OBSTACULOS Y CONDICIONANTEW LEN LA ORGANILACIUN PRADICIONAL DEI ESPACIO

La organización tradicional del espacio ha estado durante un periodo de tiempo muy dilatado, prácticamente hasta que se inicia el proceso de industrialización espafol en general, y del núcleo de Reinosa en particular, estrechamente condicionada por una población exigua, sometida a los sobresaltos de la mortalidad, verdadero protagonista de la evolución demográfica, en la que el recurso a la emigración no dejo de ser un elemento clave, una constante, una respuesta a los inconvenien tes estructurales que, en su organizacion, presentaba la comar ca campurriana. No sorprende por ello que, la falta de ritmo en el crecimiento, o mejor, la ausencia de un patrón o modelo sea un aspecto destacado de la evolución demográfica.

La población campurriana se mantiene en niveles relativa mente bajos hasta finales del siglo XIX, sin que ello implique un cambio en la trayectoria demográfica; en efecto, el siglo XIX conserva los mismos rasgos de la evolución tradicional, es decir, una sucesion de pequeños incrementos de población segui dos de años en los que las pérdidas podian representar más de un tercio de la misma, teniendo como telón de fondo, $y$ ante el 
precario equilibrio en el que se encontraba en relación a la capacidad para movilizar los propios recursos, la emigracion.

Esta constituia un novimiento de respuesta inmediata an te las frecuentes adversidades -pérdidas de coseches, ganados etc...- que se velan además agravados por una estructura de la propiedad en la que el predominio de la muy pequeña propiedad era casi absoluto, paliada, solo en parte, por una organización colectiva fuertemente arraigada en la comarca, pero que muy a menudo era claramente insuficiente. A este colectivo se oponfa un tipo de propiedad de mayores dimensiones, sin que se pueda por ello considerar como una gran propiedad, cuya situación,empero, no era mucho mejor que la del resto de la población.

La sociedad tradicional, sin duda condicionada por el abrumador predominio de los pequeños propietarios cuyas únicas posibilidades de supervivencia estaban centradas en una explotación colectiva del terrazgo, tropezaba además con otros obstáculos derivados de las múltíples insuficiencias que, estructuralmente presentaba la comarca.

1.- UNA PUBLACION EXIGUA EN UN REGIMLN DEGUGRANTCO TRADICIUNAJ.

Con independencia de lo que constituye la irregular evo lución de los efectivos totales de la población del Valle de Campbo, irregularidad acentuada por la constancia y regularidad de la emigración, el primer rasgo sobresaliente es la escasa entidad de los efectivos totales de la comarca a lo largo de los siglos XVII, XVIII y aun hasta la primera mitad del siglo XIX.

El siglo XVI se cierra con una crlsis de mortalidad en la que se suman las malas cosechas y la peste de 1597-1602, re 
duciendo, cabe suponer los efectivos globales de manera considerable (94). En algunos lugares, a estas pérdidas se añaden las debidas a la emigración, representando en conjunto descen sos de hasta un 20 por 100 en el número de vecinos ( 95 ). La poblacion no debio alcanzar por ello valores elevados, manteniéndose a lo largo del siglo XVII si apenas modificaciones, en un periodo regresivo, común por otra parte a todo el pals, $y$ en el que se suceden avances y retrocesos relacionados, sin duda,con la repetición esporádica de pequeños brotes epidémi$\cos \mathrm{y}$, sobre todo, con una mortalidad infantil muy elevada.

La trayectoria de la curva de mortalidad de Reinosa durante la segunda mitad del siglo XVII es suficientemente expre siva de esta alternancia entre largos periodos de crisis y breves periodos de recuperación, propios de un régimen demográfico tradicional; asimismo, y pese a la insuficiencia de los registros parece constante una elevada participacion en la mor talidad general de las defunciones infantiles, que en algunos años llegan a representar más del 50 por 100 del total.(96)

Hacia la mitad del siglo XVII, la población de la comarca se encontraba sensiblemente mermada en sus efectivos totales, merma que, por las causas anteriormente citadas, se habria iniciado en el último tercio del siglo anterior; en conjunto, y al margen de los lugares que quedan prácticamente despoblados, Campoo pierde aproximadamente un 50 por t, 00 de su población. Un testimonio de esta reducción lo ofrece el Padrón de

(94) V. PEREL MOREDA.- Jas crlasin de mortrilidad en la lispaña interior. Siglos XVI-XIX. Siglo XXI, Madrid 1980. 526 pág. Ver pág 243 y sig.

(95)"...que en el dicho lugar de Proaño hay 31 vecinos y no más porque de cinco años a esta parte se han ido del dicho lugar y de la vecindad más de 10 vecinos, porque se fueron con sus mujeres e hijos para Andalucla por la esterilidad de los años malos que han venido a causa de las grandes nieves que han sobrevenido en los inviernos e han dejado las casas despobladas e yermas e de los 31 que han quedado los más de ellos son pobres.." Averiguación... Lugar de Proaño 1597. Leg 70 folio 56. A.G.S. (96) Archivo diocesano de Santander. Santillana del Mar. Lugar de Reinosa, parroquias de San Esteban y San Sebastián. Sig 1841 Fol. 1-62. 
la Merindad de Campóo del año 1645; en él, y ciñéndonos exclusivamente a la comarca son numerosas las referencias a lugares deshabitados, casas derruidas y al estado general de miseria en que se encontraban los vecinos que en los distintos pueblos que daban ( 97 ).

CUADRO XVII

LA RELUUCCIUN DE LA PUBLACIUN LEN CAMPOU LN SIGLO XVII.

\begin{tabular}{|c|c|c|c|}
\hline & 1561 & 1646 & $\%$ reducción \\
\hline $\begin{array}{l}\text { Campó de } \\
\text { Suso. }\end{array}$ & 157 & 161 & 37,3 \\
\hline $\begin{array}{l}\text { Campbo de } \\
\text { Yuso. }\end{array}$ & 90 & 34 & 62,2 \\
\hline $\begin{array}{l}\text { Campbo de } \\
\text { Enmedio } \ldots *\end{array}$ & 197 & 74 & 62,4 \\
\hline Reinова & 80 & 50 & 37,5 \\
\hline TOTAL & 642 & 319 & 50,3 \\
\hline
\end{tabular}

En el siglo XVIII se inicia una etapa de crecimiento sog tenido de la población, que se prolongará hasta al menos media da la centuria siguiente. Conservando las pequeñas clsis de mox talidad que, como hemos apuntado frecuentemente se deben a la sobremortalidad infantil y de la primera infancia en general, la poblacón de Campoo inicia una trayectorìia ascendente, sólo interrumpida por la incidencia de dos fuertes crisis, fuera ya del citado siglo, es decir en el siglo XIX. Corresponden a los (97.) Vecindario de la Merindad de Campóo. Archivo Historico provincial Santander, Centro de Éstudios Montaneses. Sig. 6-19. 


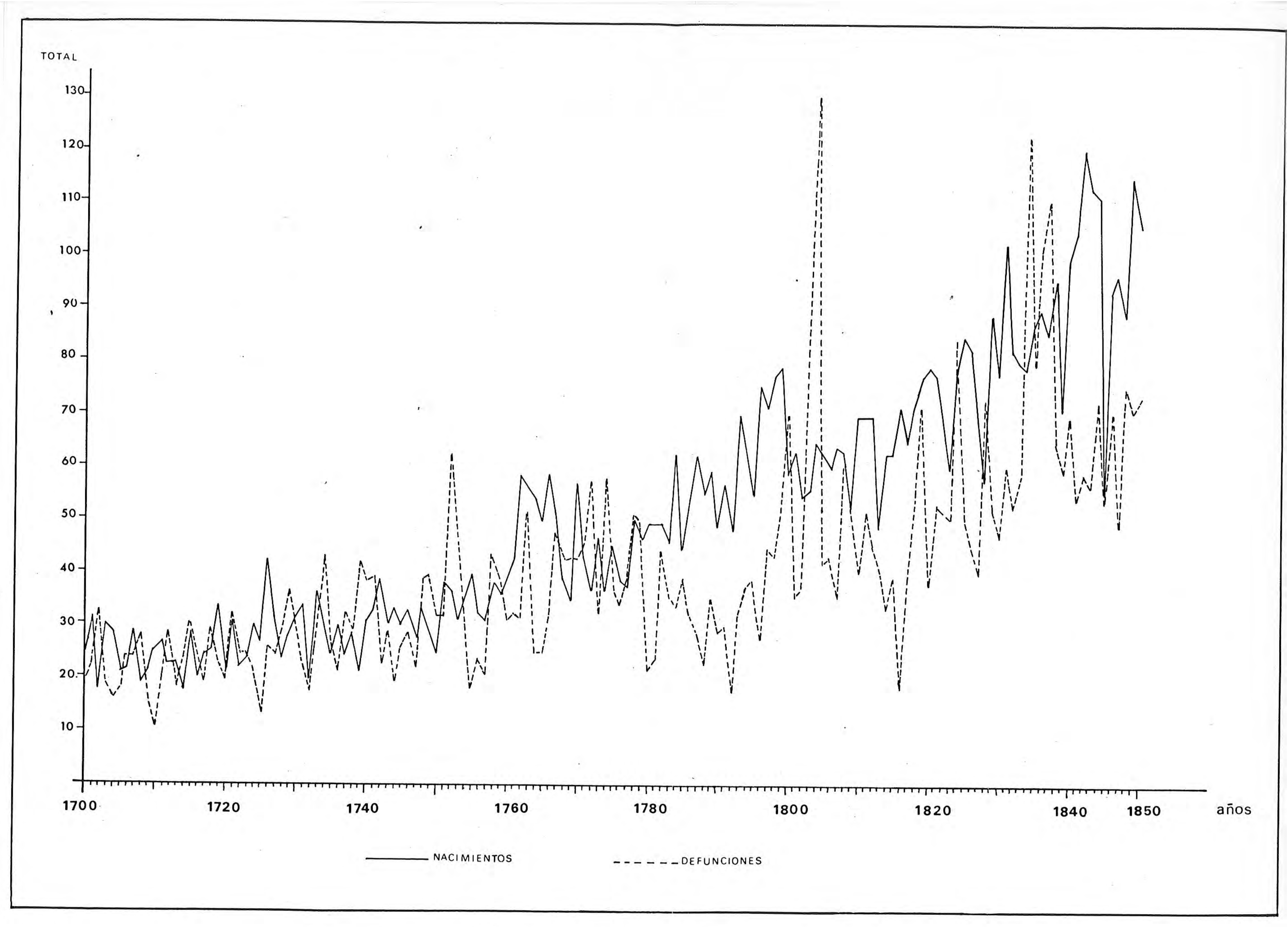

Fig.15.- Evolucion de nacimientos ydefunciones en Reinosa, Espinilla y Ormas. 
años 1804 y 1834. En el primer caso, la sucesión de una serie de años muy secos e inviernos muy frfos, arruinaron la mayor parte de las cosechas, haciendo aparicion, en numerosas regio nes, el hambre, acompañado de pequeños brotes epidémicos -pa ludismo y disenterla-, que incrementan la cifra de fallecidos muy por encima de los anos de mortalidad habitual. Lil segundo accidente se inicia en 1834 y se prolonga hasta 1837, años durante los que, las regiones del interior se ven afectadas por un brote de cólera, cuyos efectos muy bien pudieron dejarse sentir en la comarca; asl parece deducirse de la elevada y sog tenida mortalidad de los años citados ( 98 ). (ver figura 15).

Pero, pese a la intensidad de tajes accidentes, no se a]. tera la general tendencia al incremento de la población, inicia da en la segunda mitad del siglo XVIII, al amparo, sin duda del desarrollo de la carreterla e industria harinera en la comarca.

CUADRO XVIII

EVOLUCION DE LA POBLACION DE CAMPOO HASTA MEDIADOS DEL SIGLO XIX.

Campoo de

Suso

Campoo de Enmedio

131

Campó de

Yuso 164 434

262

446

239

233

Reinosa

49

90

157

133

314

732

Marquesado

Argüeso

309

$146 \quad 178$

El crecimiento es, en algunos casos, espectacular; tal (98) V. PERE' MUREDA.- Las crlsis... Op. cit. pág. 375 y sig.• 
es lo que sucede en Reinosa, centro obligado de paso y almacén de los cereales y productos coloniales transportados por los carreteros hasta la construcción del ferrocarril, donde la población se multiplica por 8 entre los siglos XVIII y XIX.

Ia espectacularidad del crecimiento, no sólo de Reinosa, sino de toda la comarca en general, no puede ser explicada por la propia dinámica interna, puesto que habrla que suponer un fuerte descenso de la mortalidad, hecho que como hemos visto no sucede; es en cambio bastante probable que, en las condicio nes de recuperación económica por las que atravieaa la comarca se contuviese la tradicional emjgración de la misma, si bien de modo coyuntural, puesto que en Ja segunda mitad del siglo XIX ésta recuperará el ritmo y la intensidad habituales.

a) El recurso a $\underline{\text { la }}$ emigración: una constante en la evolución demográfica de la comarcá.

En el precario equilibrio en el que se encontraba la población respecto a la capacidad para movilizar los escasos recursos disponibles, la emigración constituye en la comarca cum purriana una constante; aparece con frecuencia documentada como una respuesta a la ruptura del citado equilibrio, y por la frecuencia con que este hecho sucede, adquiere un cierto carác ter estructural.

Junto a la mortalidad habitual y, sobre todo catastrofica, la emigración es en gran mecida la responsable del declivedemográfico iniciado en la segunda mitad del siglo XVI, del que la comarca no se recuperará hasta el siglo XVIII (99). Aunque

(99)"...faltan del dicho lugar más de 15 vecinos porque se han muerto algunos y los más han dejado la vecindad por no se poder sustentar y se han ido para la Andaluc1a..." Averiguación... Lugar de Salces. Leg 70, Fol 56. A.G.S. 
las noticias son escasas e incompletas pareoe ser que tal declive se inicio con la "peste" de Jon ańos 1.596 y 1602, toda 'vez que la referencia a la muerte aparece reflejada en alguros, lugares junto a la emigración, para explicar el despoblamiento; pensamos por ello que no puede tratarse de defunciones habitua les, al no ser común proporcionar tal información (100).

Invariablemente, el destino de la poblacion que abandona la comarca es Andalucla, una región "puente" en el sentido glo bal de la emigración, al tener ésta como punto de destino las provincias ultramarinas (101). En efecto, junto a la emifración familiar, defivitiva, impulsada por la imposibllidad de hacer frente a las adversidades a las que, pese a "pasar suví da con mucho trabajo" se velan sometida gran parte de la poblacion, existe otro tipo de emigración, individual, y a tenor de la información exclusivamente masculina, cuyo punto de destino era la Nueva España. Los testimonios en este sentido son muy numerosos a lo largo del siglo XVIII; muchos eran, en efec to las familias que tenfan a uno o más hijos on Indias, a donde acudian no sollo impulsados por el afán de hacer fortuna, sino también por las escasas oportunidades que en la comarca se les ofrecian al ser "cortas las heredades" (102).

(100) En el año 1597, prácticamente todos los lugares hacen re ferencia a la intensidad de la emigración, iniciada como reapuesta a desfavorables coyunturas. En el lugar de La Miña declaran "...que hay solamente 5 vecinos y solla haber más, pero con la esterilidad de los años se van e han ido e dejan el. lugar y sus casas yermas..." Averiguación... Leg. 70, Fol. 56. (101) "...tengo tres hijos, dos varones y una hembra, el. uno de edad de 20 años y se llama Felipe Diez y se halla en la Nueva España, en la villa de Zacatecas."Memorial... Declaración de la Vda. de Fco. Diez Garcla, de estado noble. Iugar de Nave da. Archivo Hist. Provincial. Santander. Sig. E-541. (102)" Juan Diez de Bedoya, vecino, hijodalgo, de oficio labrador del campo, casado con $1 \mathrm{a}$ G Gerrero, de edad de 52 años, tenemos de nuestro matrimonio 3 varones y dos hembras, los varones uno de 30 años y otro de 26 años, ambos en los reinos de la Nueva España.." Memorial Ibid, id. En el mismo sentido declara Catalina Diez, vecina de Argüeso "... advierto que mi hijo Jesús Garcla se halla en la Nueva España, en la ciudad de Veracruz, con un t1o el que le tiene ocupado en sus menesteres..." Memorial... Lugar de Arguleso. 
Un significado no menor tiene también la emigración tem porera, máxime si tenemos en cuenta que una parte nada despre ciable de la población apenas tenfa en la comarca medios para asegurarse su subsistencia. Por ello, a las formas de emigración como respuesta a determinadas coyunturas adversas, hay que añadir aquella que, de modo estructural, resulta de unas estructuras agrarias incapaces de hicer frente a las necesidu des de una población creciente (103).

Prueba, una más, de que la comarca, pese a alcanzar una cierta prosperidad, seguirá perdiendo población, y que tan sరlo Reinosa mantiene un ritmo de crecimiento continuado, es el hecho de que, entre 1751 y 1847, el caserio de la comarca se reduce en más de un 10 por 100, mientras que ell de keinosa se multiplica casi por cuatro, pasando de 110 edificios en el primer año citado,a 400 en el segundo. Se está iniciando lo que, más adelante, será un rasgo esencial en la distribución de la población comarcal: la concentración de la misma en el núcleo de Reinosa.

2. - UIA SOCIEDAD CAMPESIINA DE PEOULINUS PRULIETARIUS: ELL WSCANO SIGNIFICADO DE LA GRAN PROPIEDAI) TRI DICIUNAJ.

La mayor parte de la superficie del espacio comarcal se encuentra, a mediados del siglo XVIII sumamente fragmentada

(103) "... que hay más de doce vecinos muy pobres que no tienen nada y lo que ganan por su jornal y trabajo, por no tener en que lo ganar en esta tierra van a ganar fuera de su tierra por no tener ningún trato ni granjerfa con que se mantener..." Averiguación... Lugar de Villasuso. Leg 70, fol. 56. A.G.S. La miisma situación se refleja en 1798 en el Informe sobre el estado de las fábricas, comercio, industria y agricultura en las Montañas de Santander. En efecto en el "Primer estorvo" se indica que ". .los habitantes que permanecen en el pais no son más que unos meros jornaleros que solo a temporadas tienen una ocupación transeunte y precaria: el resto del año jimen sumerjidos en la miseria; sus hijos y mujeres carecen de ocupación..." Informe... Op. Cit. pág. 193. 
en pequeñas propiedades, divididas a su vez en un sinfin de minúsculas parcelas de entre las que destacan aquellas que se destinaban a huertos o linares, en las que la exiguedad es la nota dominante (104). A esta estructura, apenas alterada por la propiedad señorial, inexistente salvo el dominio jurisdiclonal del Marquesado de Argüeso, y por la propiedad eclesiá tica, que en su tamaño -muy reducido- y en su estructura del resto de las pequeñas propiedades, se oponla la gran propiedad concejil, bajo cuyo control se encontraba la práctica totalidad de los montes y ejidos de la comarca (105). Bien es cierto que no toda la propiedad de los Concejos estaba constitulda por montes de aprovechamiento comunal; cada común posela por lo general cierto número de tierras y prados dentro del terraz go, cuyo aprovechamiento era individual cuando, caso muy frecuente, se arrendaban a los citados Concejos. Ia entidad de este tipo de propiedad es diffcil de evaluar, pero parece ser grue, en algunos casos, bien podian ser considerados como los mayores propietarios.

Al margen de éstos, se puede indicar que apenas existe gran propiedad individual; al menos, los mayores propietarios de cada pueblo no pueden ser considerados como Grandes propie tarios prácticamente en ningún caso - el mayor de ellos no posela más de 25 Has.... Por e110. y aun a riearo de abundar on el tópico, podemos concluir que, la comarca de Campóo desde el

(104) El celemín equivale aproximadamente a 2 áreas, superficie que debe ser reducida en algunos sectores de la comarca en los que la fanega equivalla a 20 áreas; en este caso el celemin representa una suferficie de $20: 12=1,66$ áreas. (105) Sin entrar en los avatares por los que atravesó la comarca, y en particular el Valle de Campóo de Suso, donde estaba localizado el Niarquesado de Arguleso, conviene apuntar que,"éste dominio señorial alcanzaba sठlo a ejercer la justicia civil y criminal, sin más apelación que a la Audiencia del Key, dividida después en varias Chancillerlas y Keales Audiéncias; la autoridad administrativa permanecio siempre indivisa en la Hermandad de Campó y Marquesado de Argüeso, y no reconocib en el territorio común de puertos y montes otra jurisdicción de ninguna clase más que la realenga de la Merindad o Corregimiento de Campóo, que más tarde tomó el nombre de su capital Reino8a. A. De los RIOS y RIOS. - Carta enviada al Gobernador Civil en 1865. Archivo del Ayuntamiento de la Hermandad de Campóo de 
punto de vịta de la propiedad aparece estructurada on dos extremos claramente contrapuestos: unn microproplodad, la do la inmensa mayorla de los propietarios, aun de aquellos labradores más acomodados, y una gran propiedad comunal ocupando la mayor superficie de los valles.

Como consecuencia de ello, y ante el exiguo tamaño de sus propiedades gran número de campesinos se velan obligados, o bien a buscar recursos fuera de la comarca, lo que explica como hemos visto la existencia de un desplazamiento temporero o de mayor duración, con carácter estructural, o bien a organizar su explotacion sobre tierras ajenas, en renta o aparcerfa, sis tema este muy extendido tanto para la tierra como para el gana do. Asimismo, cuando no se optaba, o no se podfa optar por las soluciones apuntadas, el campesino malvivia ocupándose de labores al margen de la explotación agrlcola: artesanado de la madera o empleándose como jornalero en otras explotaciones.

Al igual que sucede en otras regiones, la propiedad se encuentra sumamente fragmentada, predominando además en cada pueblo, pequeñas propiedades de vecinos de otros lugares próxi mos, si bien la superficie de cada uno de ellos, asl como la superficie total era muy reducida; en efecto, más del 80 por 100 de ellos no llegan a poseer ni siquiera media hectára (108).

Por lo que respecta a los propietarios vecinos de cada concejo, habitualmente no superaban siquiera las 2 Has., sien do milas del 60 por 100 los que se encontraban por debajo del citado unbral. Las posibilidades que el campesino tenfa de alterer esta estructura eran muy reducidas, y no sollo porque sus ingresos en metálico eran muy reducidos, sino también porque el precio de la tierra era muy elevado, lejos de sus posibilidades. Por ello en numerosas ocasiones el campesino se vela

(108) En el lugar de Náveda -Marquesado de Argüeso- de los 107 propietarios existentes a mediados del siglo XVIII, 81 , es decir el 75,7 por 100, eran vecinos de otros pueblos; en minúg culas parcelas de hasta $0,1 \mathrm{Ha}$. representaban el 33,3 por $100^{-}$ de la superficie cultivada y prados. Memoriales... Nuveda. 
obligado a vender sus tierras en aĭos de extrema carencta, pa sando a integrar el número de jornaleros existentes en la comarca (106).

Hacia la mitad del siglo XVIII, periodo en el que la renta obtenida por el acarreo de grano se evaluaba en 90 reales al año por término medio, que habla de dedicar invariablemente al "sustentó de sus casas", el precio medio del celemin de tierra era de aproximadamente 17 reajes, lo que supone 204 reales para la fanega de sembradura; estos precios, muy inestables, podlan llegar a niveles to talmente inalcanzables para el pequeño campesino, e incluso para el labrador ecomodado (107).

Junto a la que hemos denominado micropropiedad, y no muy lejos de ella en lo que a tamaño se refiere, se encontraban lo que podemos denominar "mayores propietarios", cuya mejor situa ción económica no deriva tanto de la explotación de sus tierras sino de la posibilidad de arrendar las ajenas. LLama la atención en efecto que, tales propietarios sean los que mayor número de tierras y prados llevan en renta. Y es que, este procedimiento para incrementar el tamaño de la explotación va per diendo importancia conforme descendemos en la escala social; en efecto, el arrendamiento de tierras no siempre es garantla de rendimientos seguros, y aún menos en la comarca- con los que poder hacer frente al pago de la renta, por lo cual era mas frecuente acudir al sistema de aparcerla, en el que tanto ingresos como gastos se dividfan a partes igualos entre propie tario y aparcero.

(106) "...este lufar se compone de seis vecinos y todos pobres. El sitio del lugar es la ribero del kbro. Tlienese noticia de que en este lugar hay unos cimientos... $\therefore$ y es estimada por casa solariega de Garcia y Urna y ha tenido caudal y al presente se halla el dueño pobre y ha vendido la hacienda ralz que le mantenla, asf casa como prados y heredades que las posee y goza por mano de granjeros un caballero de Reinosa. Vecindario de 1654. Lugar de Orna. Archivo Histórico Provincial. C.E.M. Leg. 6 fol. 19. Santander.

(107) En 1780 el precio del celemfn de tierra alcanzo un precio de 60 reales, es decir 1200 reales la fanega, cantidad inalcanzable para la mayor perte de la población campesina. Al año sigiente el precio era ya de 22 reales. A. RUDRIGUEL HERNANDEL.Los Carabeos. Up. Cit. pág 251. 
Por la superficie total que poseen estos mayores propietarios, parece fácil suponer que su incidencia y significado en la organización del espacio agrario era más bien peque na, máxime si tenemos en cuenta que se trata también de una propiedad muy fragmentada, con una media de tan sólo 0,4 Has: por parcela tanto de tierras de labor como de prados. CUADRO XIX

ESTRUCTURA DE IA GRAN PROPIEDAD INDIVIDUAL EN CAMPOO A MEDIADOS DEL SIGLO XVIII.

Tamaño de la

\begin{tabular}{|c|c|c|c|c|}
\hline propiedad (Has) & $\mathrm{N} Q$ de propietar & $\%$ & Superficie & $\%$ \\
\hline Menos de 2 & 2 & 5 & 1,8 & 0,4 \\
\hline de 2 a 5 & 5 & 12,5 & 20,3 & 5,3 \\
\hline De 5 a 10 & 16 & 40 & 115,6 & 30,3 \\
\hline De 10 a 15 & 11 & 27,5 & 136,9 & 35,8 \\
\hline De 15 a 20 & 4 & 10 & 62,7 & 16,4 \\
\hline De más de 20 & 2 & 5 & 44,2 & 11,8 \\
\hline TOTAL & 40 & 100 & 381,5 & 100 \\
\hline
\end{tabular}

Puente: Catastro, Libro del Mayor Hacendado.

Frente a la propiedad individual, la gran propiedad conaejil es la que por su tamaño y significado juega un papel fun damental en la economia y aun en el paisaje agrario de la comar ca. En efecto, en los montes y ejidos de propiedad comunal, ade mas de pastar ell rebaño del concejo lo hacian otros, previo pa so del correspondiente cánon (109). Esta era sin duda una prác (109) "... se suelen introducir mucho despues que el ganado vacuno alpunos rebaños de ovejas y cabras que aprovechan lo que aquél deja y los peñascos más altos o sitios escarpados, únicamente accesibles a esta clase de ganado. La pequeña retribución que dan estos últimos apenas alcanza a los gastos de la Hermandad, y como la componen dos ayuntamientos y el recurso es eventual, no se ha consignado nada en los respectivos presupuestos". Copia del expediente de excepción de venta de terrenos comunes, osean puertos de Hijar, Palombera, Fuentes, el 'lronquillo y otros muchos que en el escrito se mencionan. Archivo del Ayuntamiento de la Hermandad de Campo de Suso. 1865. Sin Catalogir. 
tica habitual, bastante irregular como lo prueba ell hecho de que muchos años ni siquiera se diezme por este concepto (110). Pese a todo, y como hemos venido apuntando, ni este ni otros procedimientos eran suficientes para mejorar el nivel de vida, para incrementar las rentas de la población campes na; tan sollo contribuyen a alcanzar el minimo vital, frecuentemente mermado por la sucesión de malas cosechas e incluso por la pérdida de las mismas.

(110) El arriendo de los pastos de alta montaña, de los "puertos altos" parece que tuvo mayor importancia en los lugares de Abiada y Hoz de Abiada. Entre 1755 y 1837 se diezma por este concepto en 29 ocasiones. En el año 1792 se diezman " $150 \mathrm{Rv}$. que anualmente pagan por las merinas que embernan (sic) en el "puerto" de La Rasa, término privativo de la Hoz" Tazmias de Abiada y La Hoz. Archivo diocesano de Santander. Sig. 3584 folios 1 a 221 .

Otro testimonio, sin duda interesante es el que proporciona el lugar de Villacantid. Declara " percibir anualmente $400 \mathrm{Rv}$. por permitir entren a pastar en su término, con los garados del pueblo 200 cabezas de ganado lanar propiedad de Dña. Ma Carrillo vecina de Briviesca, en virtud de la Real cédula despachada por S. M. Felipa V. " Catastro. Lugar de Villacantid.Lib 628 pág. 


\section{CAPI'PUOO VIII}

IA ECONOMIA RURA L TRADICIONAL

Hasta mediados del siglo XVIII, en que se abren nuevas espectativas al desarrollo de la comarca merced a la carrete$r$ la, la estructura agraria de la comarca era fiel refiejo de las adversas condiciones ecolbgicas y de unas superestructuras de Indole institucional, que mantenfan a la población en el 11 mite - frecuentemente quebrado- de la subsistencia. La inmensa mayorla de las explotaciones eran minúsculas, al estar prácticamente vedado el acceso al arrendamiento de la tierra para una parte sustancial de la población campesina los pequeños propietarios.

A estas deficiencias de Indole jurłdica se añadirán las insuficiencias en el orden ecologico, agravadas por las deficientes técnicas de cultivo empleadas en la mayor parte de las tierras, dando como resultado unos rendimientos muy bajo:s cuan do éstos -caso muy frecuente- no se peralan completamente a causa de las heladas extemporaneas y las nieves, elementos habituales del clima de la comarca. Por ello, los excedentes agra 
rios, cuando los habla, apenas bastaban para cubrir las necesidades elementales de la población durante una parte del año. En alguna medida, tales necesidades se satisfaclan mediante la comercialización del ganado, que no siempre se poda llevar a cabo porque éste, mal alimentado, apenas proporcionaba una crla cada dos o tres años, y de una serie de productos artesanales, labrados en el monte cuando las labores agricolas no ocupaban la atención del campesino. Con estos productos se lograba un cierto grado de comercialización que, aun siendo muy primario, era elemento esencial de la economfa campesina, carente de productos imprescindibles en la dieta alimenticia tradicional: el pan y el vino.

Por otra parte, al ser el único medio de obtención de in gresos para aquellos campesinos carentes de tierras e incluso de ganado, no es extraño que,adquiera un cierto carácter estruc tural, al mismo nivel que tenlan otras actividades en la comar ca. Pero, pese a todo ello, y pese al volumen que en ciertos momentos llega a alcanzar este comercio, la sociedad tradicional se desenvuelve en un marco en el que la nota dominante es la presencia de la miseria.

1.- UNA ECONOMIA GEINERADURA DE ENCANAN RINTAS: INA MUSELRIA DE GRAN PARTE DE IA PUBIACIUN CAMPIHISINA.

Con una deficiente estructura de la propiedad, agravada por la gran dispersión de las parcelas que la conforman a nivel individual, no resulta aventurado afirmar que las rentas obtenidas de la actividad agraria habian de ser entecas, $y$ que la más pequeña adversidad era suficiente para reducirlas considerablemente. Pero no sblo las condiciones ecológicas con 
tribulan a mermar dichas rentas; cualquier modificacion en el sistema impositivo era suficiente para anular las escasas ren tas de la población campesina. Tal es lo que sucede a partir del. momento -año 1797- en que los carros cargados de cereales, exentos del pago del portazgo en Reinosa desde la apertura de la carretera, se ven obligados a pagarlo, o con las medidas tomadas en 1802 y 1803 para el fomento de la crla caballar, que gravaban el apareamiento de yegua con garañon como medida disuasoria e indirecta de lograr el fin propuesto, estimular la crla caballar (1ll). En este caso los problemas creados son enormes, puesto que, ante los malos años que se venfan suce diendo."el único auxilio que les habfa auedado para la mayor de su subsistencia era el ramo de las crlas mulares lechuzns"(112). La comercialización de éstas era mucho más segura que la de potros y potras, y isu precio bastante más elevado.

El estado de miseria de gran parte de la población era sin duda el rasgo más sobresaliente de la sociedad tradicional; en efecto, el terrazgo es reducido, los suelos, carentes del abono suficiente, muy pobres, y por ende, los rendimiontos muy bajos (113).

(111) bn 1803 se rebajb a un tercio el cupo de yetruas que se podlan aparear con el garañon, medida que produjo una enorme conmoción en la comarca. In efecto, en un poder de las Hermandades de Cinco Vij.las y Enmedio se lamentaban de esta nueva situación que, además gravaba a los criadores de yeguas con 30 reales por cada una que echasen al garañón, puesto que " se hablan de seguir considerables perjuicios por estar bien cerciora dos de ser imposible hacer a los criadores la contribución de 30 reales.... mediante la calamidad y miseria que actualmente experimenta toda esta jurisdicción y partido cuyou moradores se hallan reducidos a la mayor estrechez y necesidad, sin tener con que alimentarse ni arbitrio alguno para ello a causa de la estre chez de granos y carestia de los pocos que panecen, cuyo precio es de a. 94 la fanega..." Protocolos Leg. 4/72 fol 16-17 Año 1803. Archivo Historico Provincial. Santander.

(112) Protocolos. Ibid. Id.

(113) " por ser el suelo estéril que sólo produce algunos pastos útiles en el corto verano de cuatro meses y para el resto del ano, que son ocho meses de imberno ripuroso se recoge una porción de hierba de prados naturalescon la cual se animan a sostener sus yeguas, esperanzados de que las dos terceras partes les produzcan crlas mulares para compensar sus gastos y cui- 
Pero si graves eran todas estas disposiciones con las que se mermaba la posibilidad de obtener ingresos, no lo fueron menos las medidas tomadas en 1790 para controlar el comer cio del cereal, medidas que en slntesis facultaban a las auto ridades locales para que pudiesen obligar a los cosecheros y a cualquier otra persona que poseyese tigo en cantidad que ex cediese la necesaria "para el mantenimiento de sus casas y familias y para hacer sus siembras a que 10 vondiesen al precio corriente" para hacer frente a las necesidades del abastecimiento (114). Esta medida,que pasó más o menos desapercibida mientras las cosechas de la comarca fueron suficientes, fué contestada con acritud en 1802 y 1804 , ви̃os en los que las co sechas fueron catastroficas y fue necesario poner en circula ción la mayor parte de los granos almacenados en los pósitos donde el labrador podla adquirir lo necesario para hacer la siembra del año próximo cuando la cosecha del presente hubiese sido mala.(115). El papel desempeñado por el Pósito General de Granos de Reinosa era, por lo tanto vital en la economfa de la comarca, puesto que sus ventas eran "más arregladas a los cortos medios de los pobres que no siempre tienen dinero en los dias de mercado para proveerse de granos al por menor, que las que realizaban los trajineros"(116).

Las frecuentes crísis agrarias acentuaban aún más la mi-

(114) G. ANES ALVAREZ - Las crlsis... Op. cit. pág 402.

(115) En el año 1802 los representantes de la lilerindad de Campó alegan que ".el auxilio general estaba afianzado hasta ahora en el libre comercio ds branos que excrcitaban muchon indibiduos de esta villa, en términos que aunque los arrieros y trajineros no concurriesen tenía la Merindad un Pósito General para el surtido al por menor de todo necesitado, en sus paneras abiertas continuamente, prefiriéndole la opinión pública a los mismos tra jineros.... todo lo cual persuade que esta villa y su merindad no debe estar comprendida en la prohibición general prevenida por dicha Real Cédula, pues en otro caso se verfan sus habitantes expuestos a la escasez de un género tan de primera necesidad aún en las temporadas más benignas del año porque dependerla el surtido de la arbitraria inclinación de unos pocos trajineros, insuficientes a proveer el consumo tan considerable que se realiza." A.H.P. Santander. Protocolos Leg. 4172 Fol 17. (116) Protocolos. Ibid. Id. 
seria del pequefo campesino y no solo porque a causa de ellas vela mermado el periodo, en si corto, durunte ej que podfa auto abastecerse, sino también porque al incrementarse el precio del trigo y escasear en términos generales, se esfumaban las posibilidades de obtener, con el acarreo de los mismos, unos ingresos marginales pero imprescindibles.

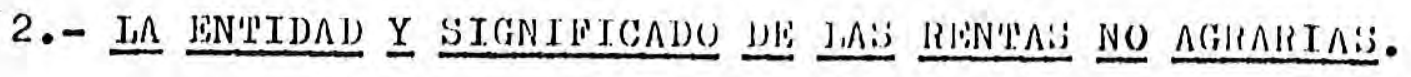

Tanto para los pequeños propietarios como para los jorna leros, aparceros e incluso para los que poselan una muyor propiedad, la obtención de ingresos al margen de la actividad agraria era fundamental, y ello pese a que el grado de autocon sumo era muy elevado.

Ia comarca,deficitaria en productos básicos en la dieta alimenticia tradicional, especialmente de cereales, necesitaba proveerse de ellos para una parte sustancial del ario, para lo cual habla de comercializar sus escasos excedentes -crlas de ganado o productos artesanales- en los mercados castellanos - en las ferias de Reinosa. Gran parte de la población campesina necesitaba imperiosamente llevar a cabo esta actividad, y para ello disponfa de una infraestructura suficiente; en efecto, a los pastos aprovechados comunalmente en los montes y ejidos se añadia la madera en ellos obtenida para elaborar aperos de labranza con destino a su venta, completando los recursos oon los que se podla obtener alguna renta.

La actividad del campesino tradicional se dividfa entre, por una parte lo que constituye su atención preferente, la agricultura -"mi exercicio es el de cultivar mi hacienda"-, y por otra en elaborar maderus para su venta - "y el de hacer ma- 
dera para el agosto en Lastilla"- (117). Cuando no se disponfa de medios para llevar a vender estas maderas, el monte,y la ela boración de maderas eran también fuente de obtención de ingre sos para una parte nada despreciable de los labradores,(118).

Las rentas obtenidas por esta actividad no eran, pese a todo muy elevadas; la elabotación de un carro de "maderas", es decir de palas, artesas, horcas, bieldos, abarcas etc... preci saba 5 meses de tribujo aproximadnmente, y ol valon del. mismo era de 300 reales. Asimismo, el trabajo de extracción de las maderas por parte de labradores a jornal proporcionaba, a lo largo de los dos meses en que de ello se ocupaban no más de 100 reales, cantidad insuficiente si tenemos en cuenta el precio de los productos de primera necesidad. -la fanega de trigo a mediados del siglo XVIII tenla un precio medio superior a los 20 reales-.

(UUADRO XX

ESTRUCTURA SOCIAL EN CALPOO A MEDIADUS DEI SIGLU XVIII.

\begin{tabular}{|c|c|c|c|c|c|}
\hline & $\begin{array}{l}\text { Campoo de } \\
\text { Suso }\end{array}$ & $\begin{array}{l}\text { Campoo de } \\
\text { Yuso }\end{array}$ & $\begin{array}{l}\text { Campóo de } \\
\text { linmedio }\end{array}$ & Total & $\%$ \\
\hline Labradores & 259 & 180 & 208 & 647 & 81,6 \\
\hline Criados & 34 & 21 & 24 & 79 & 9,9 \\
\hline Jornaleros & 25 & 24 & 13 & 62 & 7,7 \\
\hline Pastores & 5 & - & 2 & 7 & 0,8 \\
\hline
\end{tabular}

Fuente: Catastro.

Distinta era en cambio la situación de otro sector de la población campurriana, el de los criados de labranza, que, en número mayor que en número mayor que los jornaleros, disponfan

(117) Memorial... Lugar de Argüeso A.H.P. Santander Sig. E-64. Decleración de Juan Rodriguez de los Rfos.

(1].8) Asf parece indicarlo la declaración de Juan Macho Gutierrez propietario tan sólo de un huerto de medio celemln "... y mi oficio es el de labrador del campo y jornalero en los montes en tiempo de verano gano en los dilas que me ocupo que será un tiempo de dos meses 2 reales en cada dia.." Memorial. Ibid, Id. 
de jornal seguro todo el año -de dis a tres reules diarios- y estaban mantenidos por el labrador que les empleaba, siendo en ocasiones los que realizaban el acarreo de maderas y otros pro ductos a Castilla (119).

Otra forma de obtener ingresos marginales o paralelos a los obtenidos de la explotación agraria es la de aquellos que, en número reducido, simultaneaban el cultivo de la tierra y/o la crla de algún ganado, con la prestación de algún servicio -herreros, tejedores, satres etc...-. Salvo casos aislados, la Eran mayorla declara ocuparse temporalmente de estas actividades (120). Su número es muy reductdo, y el tiempo que dedican a estas actividades también es escaso.

Pero de los reducidos ingresos obtenidos por la población campesina habria que deducir las, en ocasiones elevadas detrac. ciones, representadas por los "censos". La propiedad de los mis mos corresponde, en la mayor parte de los casos a vecinos de

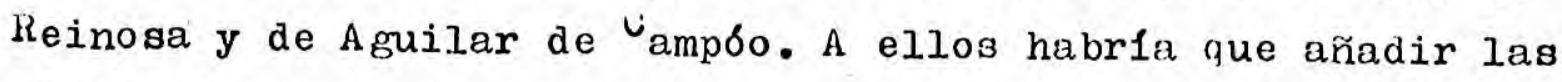
obligaciones de tipo religioso -misas, aniversarios etc,...- con que estaban grabadas numerosas explotaciones y que suponfan una forma más de reducir las escasas rentas campesinas.(121)

(119) "... en este pueblo sólo D. Manuel Gutierrez de los Rios por medio de su criado y D. Pedro Gutierrez tambien por medio de su criado hacen tres viajes a la Nava del Rey y tierra de Campos por pan y vino con dos pares de labranza." Catastro Ensenada. Lugar de Fontibre.A.G.S. Lib. 630 Fol 177. (120) "... y mi exercicio es oficio de satre y labrar y cultivar las tierras y prados y del dicho oficio de sastre gano cada dla 2 reales para el sustento de mi familia " Memorial, Lugar de Naveda Sig. E-541. A.H.P. Santander. (127.) Francisco Antonio de Iglesias, vecino de Abiada declara tener una carga de 30 reales anualmente de réditos pagados al convento de San Francisco de Reinosa por un censo de 1000 reales a razón del tres por ciento." Libro del Mayor Hacendado. Lugar
de Abiada. Lib. 635. A.G.S. 
III PARTE

CAMBION Y PERMANENCIAS EN IA QUCIEDAD Y ECUNURIA TRAUICIUNAIJES 
$L_{a}$ sociedad campesina tradicional sufre, desde la segunda mitad del siglo pasado, y hasta mediada la centuria presente una serie de transformaciones que, lejos de representar pro greso, la hacen retornar a modos de vida y sistemas de aprovechamiento del espacio agrario en parte superados durante el bre ve pero intenso periodo de esplendor del siglo XVIII y primera mitad del XIX. Esta vuelta al. pasacio, esta marcha atrás se lle vará a cabo en circustancias complejas, diffciles, a consecuen cia de la mayor presión ejercida sobre el suelo por una población numerosa, mucho más de l.o que éste era capaz de soportar.

El punto de partida lo constituye la profunda crlsis que afecto a los sistemas de transporte tradicionales a raíz de la construcción del ferrocarril Alar-Santander, yue, al no tener siquiera la contrapartida de la modificación de la estructura de la propiedad por la escosa incidencio del proceso desamorti zador, obligará a emigrar, siguiendo una tradición secular a una parte sustancial de la población.

En efecto la comarca seguirá caracterizándose por una es tructura de la propiedad desequilibrada y por el preáminio de unas explotaciones de muy reducido tamaño, de las que se obtenfa, 
con no pocos esfuerzos, lo imprescidible para malvivir.

En parte se salvará de una crísis más profunda por con'servar intacto el sistema de explotación colectiva del monte, desde el que, y de modo muy lento, se iniciará un cambio en la estructura económica, cuyo resultado final será la definitiva orientación o especialización ganadera de la comarca. En efecto, a costa de él se siguió aumentando la superficie cultivada, en un principio para atender a las mayores necesidades de alimentación de una población más numerosa, pero más adelante, des de principios de siglo, la introducción de razas de mayor productividad obligo, paulatinamente, a transformar dichas tierras en prados, dado que sus exigencias alimenticias eran mayores y no se adaptaban al régimen de pastoreo extensivo con que se ex plotaban las razas autóctonas.

Coyunturalmente, esta práctica tradicional aḍuirirá mayores proporciones, tal y como sucede desde principios de siglo, obligando a la Administración a publicar un decreto, conocido como "Ley de Roturaciones Arbitrarias", por el que se autorizaba a legitimar, previo pago de su importe, las parcelas ganadas a los montes para su conversión en prados ( 1 ). En toda la pro vincia de Santander fueron más de 50.000 Has. las que se legitimaron por este procedimiento, pero en la comarca ta.l proceso tuvo una importancia secundaria porque la introducción de razas de ganado vacuno especializadas el la producción de leche, art1 culo de gran demanda por causa del rápido desarrollo urbano, fue muy limitada, y porque la crla de ganado vacuno autóctono, destinado al trabajo, segirá realizándose en forma extensiva no siendo preciso modificar el sistema tradicional basado en el aprovechamiento de los pastos comunales de los que todos los vecinos, en mayor o menor medida se beneficiaban. Prueba de que

(1) M. FLRRER REGALES - La ganaderla bovina en la región Asturcántabra. Diputación de Oviedo. Instituto de Listudios Asturianos. Oviedo 1963. Pág 29. 
el grado de comercialización ea muy reductio, es ol hecho do que, a mediados de la presente centuria,todavla era similar, o ligeramente superior, dentro de la explotación agraria familiar, la superficie destinada a tierras de labor y la destinada a praderas permanentes, y que el total de ganado de labor era netamente superior el ganado de renta.

En este contexto de escasa renovación de la estructura agraria $t$ del paisaje agrario en general se enmarcan una serie de intentos, frustrados los más de ellos, de industrialización de la comarca, que solo desde 1918, a ralz de la construcción de una factorla de la Sociedad lispañola de Construcción Naval, adquiriran cierto significado y contribuirán a frenar, en parte el éxodo rural. Del mismo modo se irán introduciendo nuevas formas de vida, nuevas espectativas de desurrollo que obligarán a modificar el sistema de explotación agraria y provocarán cambios sustanciales en el paisaje agrario; pero este proceso, no adquirirá verdadero significado prácticamente hasta la década de 1960.

Hasto. ese momento, las transformeciones serón poco notorias y su consolidación estará plagada de no pocas dificultades. 
CAPITULO IX

IA PRUGRESTVA TRANSFURMACION DLi LAS E:T'RUCTURAS AGRARIAS TRADICIONALES: UN PROCESO LENTO Y PLAGADO DE DIFICULITADES.

La intensidad de la crisis sufrida por la comarca a mediados deI siglo XIX, lejos de impulsar de modo inmediato una transformación, siquiera para recuperar o mantener el nivel de bienestar -nunca demasiado elevado-,alcanzado al amparo de la actividad de la carreterfa, provocó una fuerte recesión, una vuelta a sistemas de vida tradicionales, claramente inviables ante las nuevas condiciones aparecidas en la comarca, y aún en toda la region.

En parte, esta falta de respuesta ante el declive economico viene dada por la permanencia de una estructura de ja pro piedad apenas modificada por la desamortización. En efecto, el escaso volumen de tierras desamortizadas, adquiridas ademés por un reducido número de compradores como sucede en todo el pals, y la preservación del a rovechamiento comunal de extensos sectores de la comarca, poco podfan contribuir a impulsar un cambio sustancial en la misma. La pequeña propiedad seguirá predo 
minando de modo casi absoluto, y por ende, los siatemas de aprovechamiento del espacio agrario serán, aún durante bastante tiempo,los tradicionales.

Tan sblo un cambio parece apuntarse en este contexto de permanencia casi absoluta de una estructura heredada, cambio que representa en cierto modo una superación del carácter au tárquico de la economía tradicional. Se transforma, en efecto parte de la superficie cultivada en prador, ante la beruro co mercialización de los excedentes ganaderos, especialmente a ralz de determinadas coyunturas, como fue por ejemplo la fuer te demanda de ganado de labor tras la guerra civil. Los progresos asl logrados permanecerán y servirán de base en la con solidación de la estructura agraria actual.

1.- UNA ESTRUCTURA AGRARIA HEREDADA: EL ESCAOU IMPACTU DEI PRUCLNU DEDANORLIZANUR.

Pese a no tener constancia documental de la incidencia del proceso desamortizador con anterioridad al año 1855 , y pe se a que la Desamortización General de Madoz del citado año apenas tiene significado,por la escasa entidad de las tranaactones realizadas, merece la pena que nos detengamos en él, por cuanto refleja fielmente la estructura de la propiedad, inclu so de la propiedad vinculada, y porque permite comprobar que, la pequeña propiedad seguirá siendo un condicionante estructural de enorme importancia. Por otra parte, los sistemas de apro vechamiento del espacio agrario apenas varfan porque los terrenos de aprovechamiento comunal quedarán exceptuados de la venta, y estos son parte sustancial, en superficie y significado, de la economia de la comarca. 
a/ Ios resultados del proceso desamortizador: una estructura de la propiedad inalterada.

Durante los años en que se llevó a cabo la desamortización general de Madoz, desde 1855, el trasvase de fincas que se realizb fue elevado, pero la superficie realmente afectada apenas tiene entidad alguna. Sin duda, la causa se encuentra, como hemos apuntado, en el reducido volumen y aignificado de la gran propiedad en general y de la vinculada en particular, tanto eclesiástica como civil. Cierto es que la pro piedad de los concejos era importante, pero al ser la mayor parte de ella de aprovechamiento comunal, quedará exceptuada de la venta. Una parte de estos bienes, salieron a subasta, los propios del común, pero tampoco sufrieron merma aparente, sin duda porque se trataba de pequeñas fincas, dispersas, y porque, procediendo de sucesivas roturaciones sobre los montes y ejidos, su calidad era, al menos "a priori", más que dụ dosa.( 2 )

En conjunto, el número de fincas vendidas, de propiedad municipal, fueron 111 , pero la superficie fue insignificante, 45,9 Has. Por ello los vecinos de cada pueblo no solo pudieron seguir aprovechando colectivamente los montes excluidos de la desamortización - la práctica totalidad de los mismos-, sino que, además continuaron disfrutando de la posibilidad de incrementar el reducido tamaño de sus explotaciónes, arrendando las tierras y prados del concejo.

(2) Conviene destacar que la carencia de documentación es, para la desamortización anterior a Madoz, absoluta, perdida en su mayor parte en el incendio de la ciudad de Santander. No obstante, testimonios indireotos y estudios realizados en sectores proximos, parecen apuntar al hecho de que, hasta la desamortización de 1855, los bienes de propios permanecieron en la práctica sin cambios, y aun en esta, no tuvieron demasiado significado. A. RODRIGUl'z.- Los Larabeos... Op. cit. pág. 184 y sig.

La documentación de que disponemos tampoco permite conocer la relación entre fincas desamortizadas y fincas afectidas, pero por su volumen cabe suponer que las procedentes del clero fueron compradas en parte sustancial, mientras que las de propiedad municipal apenas fueron adquiridas. 
CUADRU XXI

SUPERFICIE MUNICIPAI DEWANIORIIZAJA LNTRE 1.855 y 1881

\begin{tabular}{|c|c|c|c|c|c|}
\hline ' & no de fincas & $\%$ & Superficie & $\%$ & Has/finca \\
\hline $\begin{array}{l}\text { Campóo de } \\
\text { Enmedio } \\
\text { Campó de }\end{array}$ & 41 & 36,9 & 14,4 & 31,3 & 0,36 \\
\hline $\begin{array}{l}\text { Suso } \\
\text { Campoo de }\end{array}$ & 51 & 45,9 & 25,5 & 55,6 & 0,5 \\
\hline Yuso & 9 & 8,1 & 1,5 & 3,3 & 0,1 \\
\hline Reinosa & 10 & 9,1 & 4,5 & 9,8 & 0,4 \\
\hline TOTAI & 111 & 100 & 45,9 & 100 & 0,34 \\
\hline
\end{tabular}

Fuente: Expedientes de desamortización.

Al igual que la superficie de propiedad municipal, las tierras vendidas procedentes del clero fueron muy reuucidas, 189,9 Has., fragmentadas además en 649 fincas, lo que representa una media de a.lgo más de 20 áreas por finca. Sie trata en su mayor parte de tierras de labor y pequeños huertos, por Io que era preciso realizar una reducida inversión para su adquisición. Pero con todo no parece que tenga lugar una redistribución de la propiedad, dado que una parte sustancial de las fincas fue adquirida por un número reducido de compradores, en su mayor parte vecinos de keinosa ( 3 ).

La inmensa mayorla de los bienes eclesiásticos sacados a subasta perteneclan a la Iglesia y Beneficio de las distintas parroquias, y en su mayorla consistian en huertos recibidos las más de las ocasiones por medio de donaciones. A esta titularidad hay que añadir la de las Cofradlas de las Animas y, con mayor significado la del Convento de Montes Claros y la Colegiata de Cervatos, ésta última, sin lugar a dudas la más importante.

(3) La falta en los expedientes del lugar de residencia del. comprador en muchas ocasiones nos impide precisar aún más este aspecto; no obstante, por el volumen de tierras adquiridas la mayor parte de los compradores debieron ser labradores con escasos recursos que, por este medio pudieron acrecentar una propiedad que, pese a todo segurla siendo pequeña. 
CUADIRO XXII

LA ESCASA ENI'IDAD DE LA DESAMUR'IZACIUN LCLE'SIAS'LICA. 1855

Campoo de

Enmedio

Campoo de

Suso

Uampठo de

Yuso

Reino日

TOTAL

\begin{tabular}{cccccc} 
ne de fincas & $\%$ & Superficie(Has.) & $\%$ & Has./finca \\
233 & 38,3 & 60,9 & 36,2 & 0,2 \\
272 & 44,6 & 72,8 & 43,3 & 0,2 \\
44 & 7,3 & 18 & 10,9 & 0,4 \\
60 & 9,8 & 16,2 & 9,6 & 0,2 \\
\hline 609 & $\frac{100}{100}$ & $\frac{167,9}{100}$ & $\frac{100}{10,27}$
\end{tabular}

Fuente: Lixpedientes de desamortización.

En conjunto, el total desamortizado entre 1855 y 1881 represento un porcentaje insignificante de la superficie de la comarca - 0,57 por 100- pero pese a esta escesa entidad permite comprobar nuevamente la peculiar estructura de la propiedad de una comarca en la que hasta la gran propiedad es pequeña.

\section{b/ La pervivenoio del caracter comunal en el aprovecha- mjento dol monte.}

Gracias a la favorable predisposición del gobierno liberal hacia la polftica de conservación de montes, la ley de 1 de Mayo de 1855 - la ley lladoz- exceptuó de la venta general de los predios públicos por lo menos los montes y bosque cuya enagenación no crea oportuna el Gobierno. Para lograr la excepción de los montes de aprovechamiento comunal era prediso que los ayuntamientos elaborasen un informe que, a través de las Diputaciones debla ser enviado al Gobierno. La recopilación de todas estas informaciones dará lugar a la primera clasificación de los montes públicos realizada por el Cuervo de Ingenieros de Montes. En esta clasificacion, y por lo que respecta a 
la provincia de Santander, aparecen exccptuados de la desamortización 1112 montes, entre los que se encuentran todos los de 'la comarca, que conservarán el caracter comunal en propiedad y aprovechamiento. ( 4 ).

A este catálogo seguiran otros en los años 1862, 1901 y el actualmente en vigor del año 1927. En éste, los 49 montes de la comarca son declarados de utilidad pública, siendo su importancia fundamental para comprender, no sólo la extraordinaria pervivencia del sistema extensivo de aprovechamiento de los pastos, sino incluso la mera supervivencia de muchos pequeños pueblos que, de no haber contado con estos montes habrlan visto emigxar e la mayor parte de su poblacion ( 5 )

Graclas a ellos, en efecto, se podrá paliar el impacto producido por la construcción del ferrocarril, manteniendo inal terada la estructura tradicional hasta la segunda mitad de la presente centuria. Las explotaciones familiares basadas en el aprovechamiento colectivo de los pastos en los montes y ejidos propiedad de cada pueblo, seguirán siendo dominantes hasta fechas muy recientes.

2.- JAA CONSTTRUCCIUN DEL FEIRROCARRIJ AIAR-ijANTANDER: LA CRITLLS

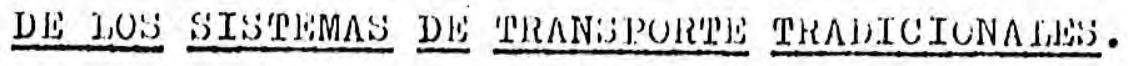

Si la desamortización apenas modifica la estructura de la propledad, e incluso la propia organizacion del oupacio arra ( 4 )!.. en vista de todo a v.ï. supicamos que, previo informe de la Diputacion Provincial con arreglo al artfculo 20 de la ley de 1 de líayo de 1855 se sirva Us. elevar, con el auyo favorable esta solicitud al gobierno de S. H. para la declaración de ser comunes a esta Hermandad y por consecuencia exceptuados de enajenación..." Expedientes de excepción de los terrenos comunes, osean los puertos di Hijar, Palombera. Jaja y otros... Ayuntam. Hermandad Campóo de Suso. Año 1865.

( 5 ) Sobre estos aspectos ver: L. BAUER MIANDLRSCHEID.- 1.05 moth tes en lla historia de España. Madrid 1980. Cfr. p. 67-82, y A. DIAZ de PAZ.- los montes de Utilidad rública en Cantabria y la ley de Montes. Ej. Campo 1981, $\mathrm{n}^{2} 84$, págra. 81-8\%. 
rio por la pervivencia del aprovechamiento colectivo del mismo, el sistema de vida tradicional se verá seriamente afecta'do en sus fundamentos por la construcción del ferrocarril, y el consiguiente retroceso de los s1stemas de transporte tradicionales -la carreterla- que proporcionaban gran parte de los ingresos de la población campesina.

E1 tráfico de harinas y productos coloniales en uno $u$ otro sentido,comenzs a tener dificultades a ralz de la terminación de la construcción del Canal de Castilla, puesto que gracias a él, el tráfico de trigo y harinas se incremento con siderablemente, al menos hasta Alar del Rey, en donde se hizo necesario construir almacenes para estos productos por no poder la carreterfa hacer frente a la mayor oferta de transporte presente desde la segunda mitad del siglo XIX. ( 6 ).

Desde que se puso en explotación del ramal Norte del Canal de Castilla, en Abril de 1842, y vista la imposibilidad de prolongarlo hasta Bolmir, como en un principio estaba previsto, a causa de las enormes dificultades técnicas, se hizo necesario dotar el trayecto entre Alar del Rey y Santander de un sig tema de transporte de mayor capacidad, más rápido y barato, re

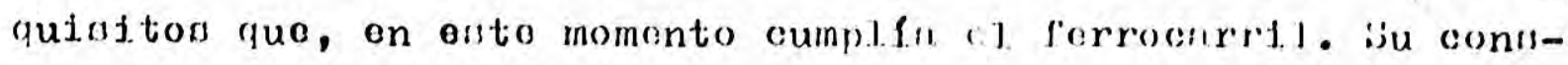
trucción se concedis en 1845 , pero las obras no dicron comienzo hasta 1852, concluyéndose en 1857 el tramo de Alar del Rey a Reinosa, precisamente el que mayor significado tenia para la carreterla de la comarca de Campóo.

Desde que se concluyó este tramo, la carreterfa práctica mente desaparecerá, al no poder competir con el ferrocarril en precios ni en capacidad y rapidez, pero, al menos temporalmente,el ocaso será parcial. En efecto, hasta el año 1866, en que

(6) La navegación por el Canal permitla, en 1840 transportar 15.000 arrobas diarias, aunque tan extraordinario esfuerzo quedaba. malogrado, pues faltaban carros para conducir los grenos, no pudiendo salir de Alar del Rey más de 5000 arrobas diarias" F. BARREDA .- Prosperidad... Op. cit. pág. 559. 
quedo unido el tramo de vla ferrea Alar-Reinosa con el de ían tander-Los Corrales, las harinas y el trigo todavia erun trang

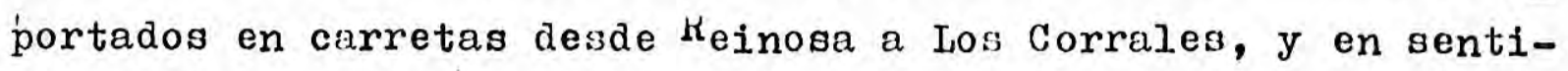
do inverso los ultramarinos. Pero, la puesta en servicio de to do el trayecto dio lugar a una reducción de la actividad econó mica de Reinosa, al perder su función de almacén de los citados productos, y a una progresivo decadencia de la carreteria $(7)$.

A ralz de ella, la comerca recupera la tradicional atonfa, tan s81o interrumpida en 1874, año en el que el ferrocarril de Isabel II pasb a depender de la Compañla del. lierrocarril del Norte que, al fijar unos precios de trensporte muy elevados posibilitó un effmero resurgir de la carreterla, pero, poco después, su escasa competitividad hará que decaiga,hasta desaparecer como sistema de transporte especializado y, en cier to modo, profesionalizado ( 8 ).

En cambio, seguirá desempeñando durante bastante tiempo una funcion similar a la tradicional, ea decir, el transporte de los excedentes agrarios a los mercados castellanos, donde se podlan además adquirir, en mejores condiciones que en las ferias y "mercados", estos últimos celebrados scmanalmente, de Reinosa, el trigo y el vino.

Las consecuencias del declive de la carreterla seran, tan to el recrudecimiento de la emigración, como la vuelta a sistemas de aprovechamiento y organización del espacio agrario tradicionales que, como hemos apuntado perviven gracias a la insignificancia del proceso desamortizador. Wllos servirán de bese para iniciar una somera transformación en el sistema económico de la comarca.

( 7 ) M. de TElRAN.- Santander puerto de embarcue para jas harinas de Castilla" Estudios Geográficos 1947 no 29, pág 746 y sig. (8) "... lo cierto es que, muerta la carreterfa en cuanto el tren anduvo de veras, cosa que ni viéndola podia yo creer, na se me amañaba en casa, ni discurrla onde ganar una peseta..." J. Ma de PEREDA.- De Cantabria. Articulo "Cutres". 
3.- DE UNA ECONOMIA AUTARQUICA A UNA ECONGMIA DE INTERCAMBIO: IA PROGRE:SIVA CONSOLIDACIUN DE JAA UPCIUN GANADERA.

No se puede afirmar que, tras la crisis de la segunda mitad del siglo XIX, la comarca entre en una etapa de reconversión de sus estructuras. Estas habrán de cambiar de modo muy lento, conservando, sin apenas variación sustancial, algunas constantes del quehacer agrario tracicional. Pese a que en otras regiones tal reconversión se inicia y se consolida con rapidez, gracias a la introducción de ganado vacuno especializado en la producción de leche, en el Valle de campóo tal cambio es muy tardio, reciente podrlamos indicar.

Pero ello no significa que no se aprecie un cambio de signo en la orientación de la estructura económica de la comarca. En efecto, tal transformación partirá de la potenciación de un aprovechamiento intenso de las condiciones peculia res que ofrecia la comarca, tanto desde el punto de vista eco lógico como estructural, arrastrando, incluso, algunos de los inconvenientes que en ambos casos se presentaban. Se logrará de este modo una cierta especialización en lo que, por otra parte ya habla caracterizado a la comarca: la cria de ganado de labor y de carne.

A mediados del siglo XIX, y merced a las fertas de Reino sa, el ganado campurriano era conocido y apreciado por su resistencia y sobriedad, y a su explotación se dedicará el cam pesino con ahínco hasta mediada la centuria siguiente (9)

Pero junto a la especialización en la crla de ganado bo vino, hay que tener presente tambien la importancia y signifi

(9)" disputa lo mejor del pals" P. MAlJuZ.- Diccionario... Voz Requejo. Tomo XIII, pág. 418. 
cado del ganado equino, muy apreciado fuera de la comarca e incluso fuera del pals (10).

Pero no fue sollo la bondad del ganado de la comarca la que posibilitará una expansión y una especialización del rebaño; a ella hay que añadir el notable incremento de la deman da de productos ganaderos -carne y leche- que, hasta principios de siglo habla sido más bien reducida; tal demanda, hay que relacionarla con el desarrollo general y urbano en par ticular, iniciado a principios de siglo en toda la nacion(Il).

Por si ello no fuera suficiente, de modo coyuntural, particularmente una vez conclufda la Guerra Civil, se incrementará también la demanda de ganado de labor, por causa de la falta de combustibles y energla electrica, hecho que eati mulará la crla de este ganado -en especial de razas autóctonassobre cualquier otro, puesto que las condiciones para llevarla a cabo eran idoneas.

Ia venta de estos ganados junto a otros productos -ape ros de labranza etc...-, que tradicionalmente se realizaba en forma directa acudịendo a los mercados castellanos, pasará a efectuarse progresivamente en las ferias de Reinosa, que, mer ced a ello adquieren cierto renombre en la region, atrayendo a un elevado número de compradores.

Para lograr esta reconocida especialización, la comarca campurriana apenas precisará modificar el sistema de apro vechamiento del espacio agrario; la alimentación del ganado seguirá teniendo como competidora a la alimentación humana, y por ello se continuarán aprovechando los pautos comunales, y se mantendrán prácticas de aprovechamiento colectivo en el te rrazgo cultivado, base todavla de una economla de subsistencia. Este sistema extensivo, que el campesino no podla abandonar

( 10$) " . .0$ crla ganado cabrio, vacuno, lanar y de cerda. El caba llar se destina por lo general a la cria mular, siendo el ramo más productivo por la mucha salida que tiene en la feria de San Pedro." P. MANO'Z.- Diccionario... Voz Reinosa. l'omo XIII
pág 406. (11) J。 GARCIA FELRANDEZ.- Urganización ... Op. cit. pág 44 y
sig. 
al no disponer de tierras y prados suficientes en su propia explotación era, sin duda, un gran obstáculo a la expansión 'de la ganaderla; pese a ello, el ganadero campurriano siempre recrió mucho ganado, más de lo que realmente podfa, hasta un punto que, "su afición a poseer número le llevaba a vecen a recriar todo lo que a su juicio reuniera las condiciones zootécnicas minimas" ( 12 ).

Para lograrlo, los pastos de los "puertos altos" segulan siendo el recurso fundamental, pero, la frecuente anticipación de la presencia de la nieve obligaba al desalojo de los mismos, bajando el ganado al fondo de los valles, donde permanecla semiestabulado, consumiendo las cortas reservas de hierba almace nadas. Habitualmente la cabaña campurriana se vela sometidacon anticipación a los inevitables periodos de hambre anuales, hecho que redundaba en el mejor de los casos en perdidas sustanciales de peso -de hasta el 25 por 100-, graves para un ganado que, junto a la recrla, su destino final era la venta para el sacrificio. En estos años en los que el invierno se prolon gaba o se anticipaba, el volumen de transaciones efectuadas en las ferias de Reinosa se vela sensiblemente mermado, en ocasio ners hasta en 3 cuartas partes respecto a jos años considerados como normales ( 13 )

Todos estos inconvenientes se enmarcan dentro de una es tructura de la propiedad que permanece inalterada, y que obli ga de modo indirecto a retrasar la modernización de la explotación ganadera. Prueba de ello es el hecho de que, a medindos del presente siglo, todavla predominaba el ganado autóctono, de raza tudanca, en toda la comarca, predominio que era abso luto en Campóo de Suso y que en el resto de la comarca repre sentaba más del 80 por 100 de todo el rebaño.( 14 ).

(12) FONTIBRE, $\mathrm{n}^{0} 5$ Enero 1957, pág 9. Articulo "Ferias y Mercados.

( 13 ) FONTIBRE, no 3 Noviembre 1956, pág 9. "El pnoblema gana-
dero de Cambó.

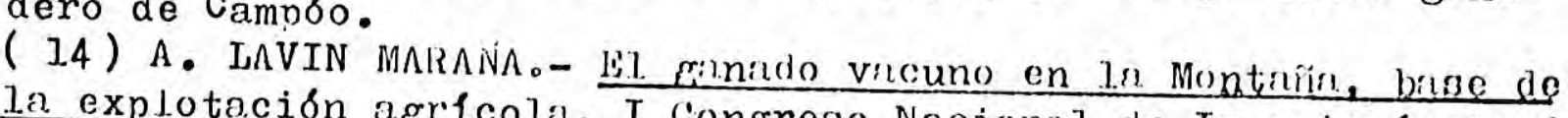
$\frac{\text { la explotacion agricola. I Congreso Nacional de Ingenier1a Agr1- }}{\text { cola. Madrid } 1950 \text { pág 232-250. }}$ 


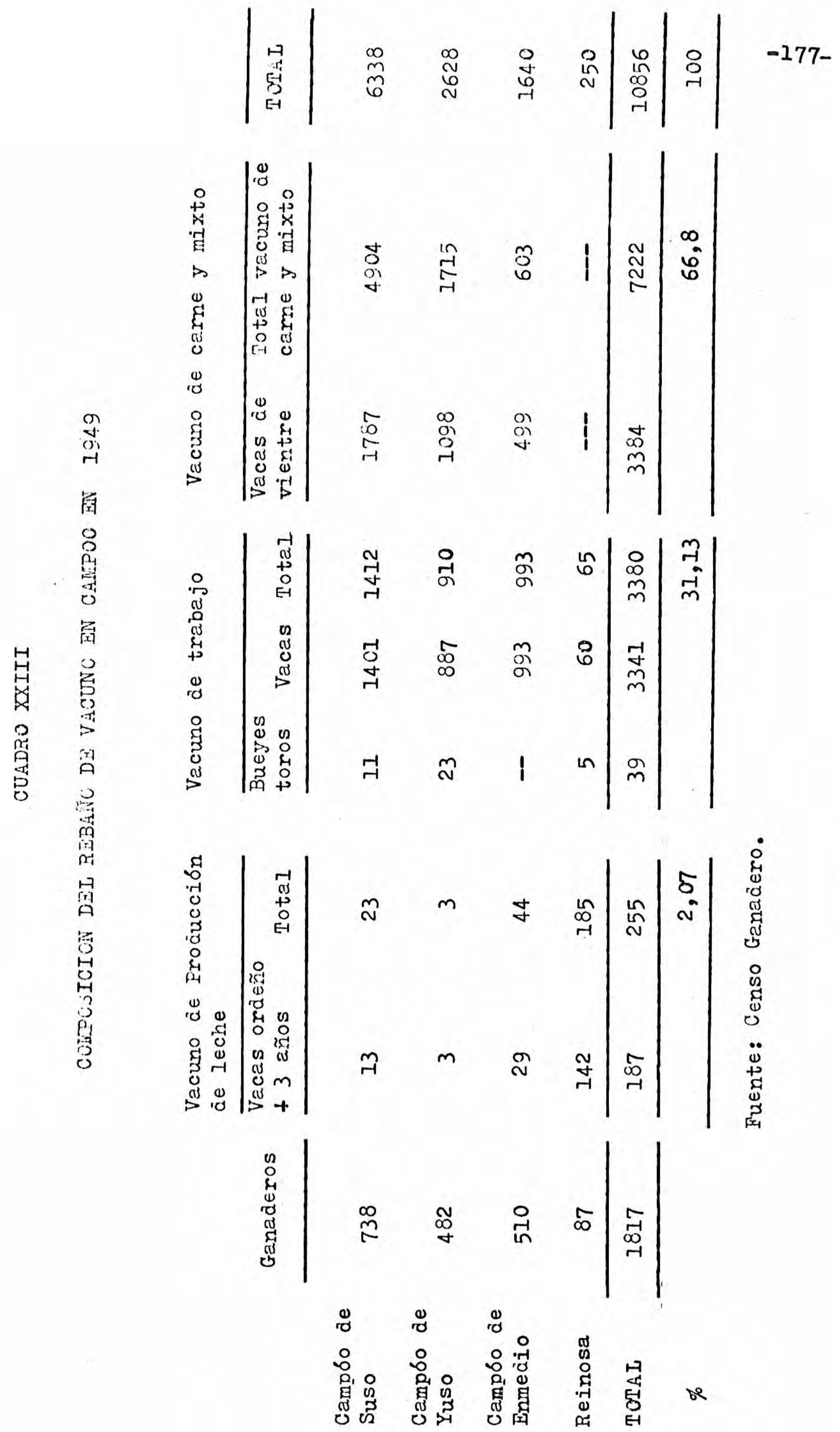


El tamaño medio de la explotación representaba sin duda uno de los mayores inconvenientes a la hora de proceder a su reconversión. En efecto, a mediados de siglo-1949- el patrimonio familiar se evaluaba en 1,18 Has. de tierras de labor y 1,93 Has. de praderas, que, además de reflejar claramente la preservación del carácter de subsistencia de la economla agra ria tradicional, resulta claramente insuliciente para proporcionar alimento a un ganado más exigente, que, no se podria mantener en el limite de la subalimentación so pena de mermar considerablemente sus rendimientos y, obviamente, los ingresos de la explotacion.

El mismo carácter de subsistencia presenta la composición de rebaño en cada explotacion; en efecto, en todos los casos la ausencia de especialización es la nota dominante, Se mantiene un conjunto variado de especies -vacas, mulos, ovejas, puercos etc..-, gran parte de las cuales cumplen la función exclusiva de proporcionai alimento a su propietario, no exis tiendo, por lo tanto, comercialización de excedentes ( 15$)$.

Escapa. en parte a esta norma el ganado vacuno, en su ma yor parte formado por razas autóctonas; su número era mayor, exigla un menor esfuerzo en su manutención, conservándose en precario estado de nutrición casi de modo permanente, y de êl se obtenlan unos ingresos bajos, pero seguros. lin el primer tercio del presente siglo se estimaban unas ventas anuales superiores a las 3000 cabezas de ganado, de las cuales un 25 por 100 aproximadamente correspondlan al ganado equino -caba llos y sobre todo mulos-, mientras que a mediados de siglo, en el año 1957 las ventas fueron superiores a las 19000 cabezas de las que tan s6lo el 13 por 100 eran de ganado equino. Gran

(15) El patrimonio ganadero medio en 1949 se cifraba en 6,13 cabezas de ganado vácuno, 0,32 de caballar, 0,15 de asnal, 5,32 de lanar, 1,38 de cabrlo, 0,48 de porcino, 10 que supone un total de 6,6 cabezas de ganado mayor y 7,18 de ganado menor. A. LAVIN MARAIIA.- El ganado vacuno.... Op. cit. pág 242. Se trata sin duda de una insuficiencia más de la comarca, puesto que la rentabilidad de un rebar̃o de ganado mayor vacuno de la raza dominante -tudanca- comienza con un minimo de 40 a 50 vacas de vientre. 
parte de estas transaciones se realizaban en las cuatro ferias extraordinarias, celebradas en Abril, Julio, Septiembre y Niciembre, y en menor medida en los lunes feriales -primero y tercero de cada mes-. Al margen de las ferias de Reinosa, adquirieron alguna importancia la celebrada en bispinilla - Lampoo de Suso- los dfas 15 y 16 de Agosto, de ganado vacuno, lanar, cabrio y de cerda ( 16$)$.

Pese a todo ello, los intentos para llevar a cabo cualquier transformación tropezaban con los obstáculos de Indole institucional, de entre los que, la estructura de la propiedad era capltulo primordial.

(16 )J. GARCIA DE LA PUENTE. - Reinosa y el valle de Campóo. Santander 1916, pág 85. 


\section{CAPITULO X}

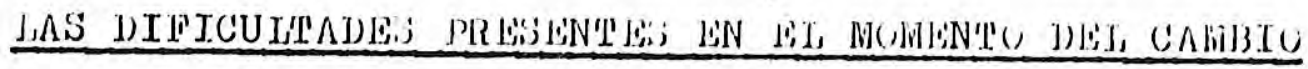

El proceso de transformación que se abre al perder la comarca una fuente primordial de obtención de ingresos, la ca rreterla, tropezará con un serio obstáculo como es el que representa la estructura de la propiedad. En efecto, una propie dad exigua, una parcelación excesiva y la omnipresencia de espacios de aprovechamiento colectivo, dificultarán, en gran me dida las, por otra parte escasas todavla, iniciativas para 11 e var a cabo una transformación del espacio agrario.

Las roturaciones realizadas a principios de siglo poco pudieron aportar porque la calidad de las tierras era cieficien te, $y$ sobre todo porque allf donde habla posibilidad de roturar, se habla venido haciendo tradicionalmente bajo el amparo de los propios concejos; por ello, el terrazgo apenas se amplia. Por el contrario, a mediados del presente siglo se verá reducido en 2000 Has, en uno de los municipios, Camobo de Yuso, a consecuencia de la construcción del Pantano del Ebro.

Cierto es que of se produce un cambio en los sistemas de explotación del suelo, motivado en parte por la intensificacion 
del cultivo de determinadas plantas, en especial de la patata, cuyos primeros ensayos para su adaptación en la comarca se remontan a finales del siglo XVIII, y en parte también por la mayor extensión que alcanza la superficie de prados.

Pero, pese a todo, cualquier innovación habia de tropezar, invariablemente con el obstáculo que representa una propiedad pequeña y muy fragmentada.

1.- EL IASTRE DEL PASALO: UNA LETRUCIPURA DIE IAA PRUPIEDAD INADECUADA

la estructura de la propiedad en el valle de Campoo, man tenida sin apenas cambios desde mediados del siglo XVIII, representará un serio inconveniente a la hora de introducir las modificaciones que, para adptarse a las necesidades actuales, las explotaciones agrarias demandaban.

Se trata en todos 10 s casos de una propiedad muy reducida, de la que tan solo escapa, obviamente, aquella de titularidad no individual, es decir la gran propiedad comunnl. A mediados de la presente centuria, el patrimonio familiar medio apenas alcanzaba las 3 Has., y ello sumando la propiedad de cada uno de los conyuges.

CUADRO XXIV

PATRIMUNIU FAMILIAR RLSLIU. ANU 1949

\begin{tabular}{|c|c|c|c|}
\hline & 1,abrant1o & Praderas & I'otil] (Has.) \\
\hline Campbo de Suso & 1.1 & 1,9 & 3 \\
\hline Campóo de Enmedio & 1,1 & 0,9 & 2 \\
\hline Campठo de Yuso & 1,4 & 2,4 & 3,8 \\
\hline Patrimonio medio & 1,2 & 1,7 & 2,9 \\
\hline
\end{tabular}

Fuente: Censo 1949

La situación que, años más tarde refleja el Censo Agrario 
de 1962 no ha variado sustancialmente; siguen predominando las pequeñas explotaciones, de menos de 5 Has., y aún de menos de ' 3 Has., representando estas últimas en el conjunto de la comar ca más del 86 por 100. Conviene desdacar, no obstante, que en los datos aportados por el Censo Agrario de 1962 aparecen englobadas todo tipo de explotaciones, con independencia de su titularidad, es decir, incluyendo tanto a las personas flsicas como a las jurldicas, y estas últimas - $n$ yuntamientos, Juntas Vecinales etc...- agrupan más del 70 por 100 de la superficie censada. Por ello, aunque el total de explotaciones -1909- pue da parecer pequeño en relación a la superficie total, 10 cierto es que un número reducido de ellas detentan la propiedad de la mayor parte de la superficie, miontras que máa del. 80 por 100 de las explotaciones tan solo agrupan el 9 por 100 de la misma.

CUADRO XXV

NUMLIRU Y SUPERFICIE DE LA, EXPLUTACIUNEN WIV 1962

\begin{tabular}{|c|c|c|c|c|c|}
\hline & $\begin{array}{l}\text { no según } \\
\text { tamaño }\end{array}$ & $\%$ & $\begin{array}{l}\text { Superfi- } \\
\text { cie (Has.) }\end{array}$ & $\%$ & $\begin{array}{l}\text { Media Has. } \\
\text { explotación }\end{array}$ \\
\hline Sin tierra & 50 & 2,9 & $-\infty$ & $-\infty$ & $-\infty$ \\
\hline $0-\quad 1$ Has. & 265 & 13,9 & 154 & 0,3 & 0,58 \\
\hline $1-5 \mathrm{Has}$ & 1167 & 61,4 & 3375 & 8,7 & 2,89 \\
\hline $5-10 \mathrm{Has}$ & 318 & 16,9 & 2283 & 5,9 & 7,17 \\
\hline $10-20 \mathrm{Has}$ & 51 & 2,9 & 664 & 1,7 & 13,01 \\
\hline $20-30 \mathrm{Has}$ & 2 & 0,1 & 66 & 0,1 & 33,00 \\
\hline $30-50 \mathrm{Has}$ & 2 & 0,1 & 109 & 0,2 & 54,50 \\
\hline $50-100 \mathrm{Has}$ & 5 & 0,2 & 432 & 1,1 & 86,40 \\
\hline $100-200$ Has. & 11 & 0,6 & 2430 & 6,3 & 220,90 \\
\hline 200-300 Has & 5 & 0,2 & 1406 & 3,6 & 281,20 \\
\hline $300-500$ Ha.s & 19 & 1,2 & 6939 & 17,9 & 365,21 \\
\hline $500-1000$ Has & 11 & 0,6 & 7293 & 18,9 & 663,00 \\
\hline Más de 1000 Has. & 3 & 0,1 & 13419 & 35,3 & 4473,00 \\
\hline TOTAL & 1909 & 100 & 38570 & 100 & -- \\
\hline
\end{tabular}

Pero, además de pequeña, se trata de una propiedad sumamente fragmentada, hecho que se ve agravado cuando a las tierras propias se añaden pequeñas parcelas en renta, si bien esteti. - 
po de regimen de tenencia no se halla muy extendido. Lil total de explotaciones inferiores a 5 Has. se encontarban divididas en 27779 parcelas, lo cual representa una media por parcela de aproximadamente 12 áreas. La exiguedad de estas y la dispersión con que se localizan dentro del terrazgo en cada explotación era, y 10 es aún en la mayor parte de los casos, uno de los mayores inconvenientes estructurales, que hace poco rentable la mecanización y modernizacion general de las explotaciones.

En contrate con estas se encuentra la gran propiedad con cejil, sobre la que se basaba, y se basa aún en alsunos sectores, gran parte de la explotación ganaderu, gracias a una organizada trashumancia estacional. Ocuna una superficie superior al 70 por 100 del total.

CUADRO XXVI

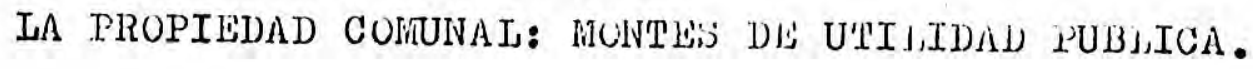

\begin{tabular}{|c|c|c|c|c|c|c|c|c|c|c|c|c|}
\hline & \multicolumn{2}{|c|}{$50-100$} & \multicolumn{2}{|c|}{$100-300$} & \multicolumn{2}{|c|}{$300-500$} & \multicolumn{2}{|c|}{$500-1000$} & \multicolumn{3}{|c|}{ Inas delovo } & \multirow{2}{*}{$\frac{\text { TOTAL }}{\text { Has. }}$} \\
\hline & $\mathrm{n}^{9}$ & Has. & $\mathrm{n}$ 은 & Has. & $\mathrm{n} 2$ & Has. & no & Has. & $\mathrm{n}^{2}$ & Has. & $n !$ & \\
\hline Campóo & & & & & & & & & & & & \\
\hline $\begin{array}{l}\text { Yuso } \\
\text { Campbo }\end{array}$ & 2 & 153 & 8 & .1355 & 3 & 11.30 & 1 & 740 & 1. & 1340 & 1.5 & 47.18 \\
\hline $\begin{array}{l}\text { Enmedio } \\
\text { Campdo }\end{array}$ & - & -- & 4 & 923 & 7 & 2956 & 2 & 1429 & - & $-\cdots$ & 13 & 5308 \\
\hline Suso & - & $-\cdots$ & 8 & 1440 & 6 & 2403 & 3 & 1856 & 3 & 11210 & 20 & 16909 \\
\hline Total & 2 & 152 & 20 & 3718 & 16 & 6489 & 6 & 4025 & 4 & 12550 & 48 & 26935 \\
\hline
\end{tabular}

Fuente: Icona.

Esta superficie comunal, aprovechada por la práctica totalidad del rebaño vacuno, sirvio tradicionalmente para la supervivencia de una gran parte del campesinado, ya fuese un pequeño propietario -la inmensa mayorla- o jornalero. Por ello, cualquier modificación en su extensión superficial, o en el aprovechamiento de la misma se acompaña, invariablemente, de una ruptura del precario equilibrio en que se encontraba la mayor parte de la población. 
2.- IA CON:TRRUCCIUN DLI EMBAISES DEL EBRO: IAA WI:SLUCACIUN DE DAS ESTRRUCTURAS TRADICIUNATEE: EN CARIPOU DE YUSO.

A las dificultades que presentaba la comarca para llevar a cabo una transformación del sistema de vida y estructura económica, sol.o parcialmente superadas modiante una pequena especialización en la producción lechera con destino a las fá bricas, o mejor a los pequeños centros artesanales, de elaboración de queso de Reinosa, y mediante la liberación de parte de las servidumbres de la agricultura tradicional gracias al trabajo asalariado de parte de su población en las pequeñas industrias de Reinosa y de la comarca en general -fábricas de vidrio, minas de carbon etc...- surgidas a finales del siglo $X I X$, se va a añadir una nueva en uno de los sectores de la co marca: la construcción del embalse del rlo Lbbro, que ocupará gran parte de la llamada "llanura" o "párand" de la Virga, las mejores tierras sin duda del valle de Campóo de Yuso.(17).

Para la realización de este embalse fue preciso inundar varios pueblos, parde del caserfo de otros y un total de 6168 Has., de las que 4306 Has. correspondlan a terrenos yermos -montes y ejidos- de propiedad pública y aprovechamiento colectivo, 1756 Has. eran de prados y el resto, 107 Has. de terrenos de cultivo. De este total, anroximadamente 2400 Has. es decir, el 38 por 100 correspondfan al valle de Campóo de

(17) El proyecto de construcción de un gran embalse, regulador del curso del rlo Ebro, surgió en el año 1912, trás la fuerte sequia sufrida por todo el pals, obligando a la Junta del lanal Imperial de Aragón a patrocinar el proyecto del ingeniero Manuel Lorenzo Pardo. Las condiciones para la construccion de un gran embalse eran, desde el punto de vista geomorfologico e hidrologico muy favorables. In efecto, el decrecimiento de la pendiente del rlo Ebro no es progresiva, sino que, antes de la construcción del embalse, segula una suave pendiente hasta Arroyo, lugar en donde se iniciaba un régimen torrencial. A esto se añade el hecho de que dos de sus afluentes, el Virga y el Proncio, de trazaäo sinuoso e irregular, te nlan un perfil que, lejos de resultar envuelto por el. curso principal, el Ebro, auedaban por debajo de êl, hecho que facilitaba la retención de las aguas del kbro. M. JURLNLU PARLU.lij. Pantano del Ébro. Zaragoza 1918. pág. 40 y sig. 
Yuso ( 18 ). Ello suponfa que se iban a limitar extraordinaria mente los recursos de que este sector de la comarca disponfa, de por si escasos, y que inevitablemente se reactivarla la co rriente emigratoria, presente desde mucho tiempo atrás, y sólo coyunturalmente contenida durante el tiempo que duraron las obras de construcción del embalse del Lbro.(19). Lin efecto, desaparecida la carreterla, y no siendo ya preciso acudir a los mercados castellanos para proveerse de nan y vino, la actividad agraria estaba limitada al cultivo de las escasas tierras que cada explotacion posefa, cuyo fin inmediato era la subsistencia y a comercializar pequeñas cantidades de leche con destino a las "queserfas" de Reinosa, actividades realiza das por muchos vecinos "a ticmpo parclal" nor est tar emplendos en la fábrica de vidrio de Arija, en las minas de carbón de las Rozas o en la construcción del embalse del lubro ( 20 ).

Pero los problemas no solo vendrín dados por la desaparición bajo las aguas de tierras de labor y pastizales, sino que derivarán también del largo periodo transcurrido entre el comienzo de las obras y su finalizacion en 1947; por esta causa el presupuestó de las mismas se incrementó notablemente, y se depreciaron las indemnizaciones previstus on concopto de expropiación forzosa, que ya de por si exan muy parcas. In

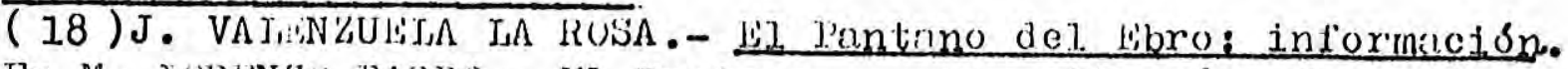
En M. JURLNZU PARDO. - lil Pantano.... up. cit. pág. 21 y sig. (19) El alcalde de Campó de Yuso responde a la entrevista realizada para conocer la repercusión que podfa tener la construcción dol antano lo siguiente: "... mi ayuntuniento tiene 14 pueblos con 500 vecinos o acaso más. lintre todos tendrán sus 4000 cabezas de ganado de todas clases, dominando el vacuno y el caballar. Viven de la labranza, según permitan la sementera y el precio del ganado, que se regula por el mercado de Reinosa. La tierra es rica en pastos, de tal manera que, mientras no "echa nieve" el ganado permanece en el campo y de el se mantiene. Hay alpuna gente del pals en America, y todavia se embarcan otros que quieren mejorar de fortuna. En estos dlas se han embarcado tres." J. MuNIERu.- por tierras de campóo. Una información sobre el pantan del kbro. Lin M. IURRERU PARIJU, Up. cit. pág 168.

(20) En otro momento de la citada entrevista el alcalde de Lampóo de Yuso afirma que "... Hoy tienen ya arregrlacia su vida con las tierras que cultivan y la leche que dedican a las fábricas de queso y al consumo en Reinosa y principalmente en Arija. Ibia. pág 169. 
cambio durante este tiempo -prácticamente 20 años-, y con la única interrupción de la Guerra Civil, se proporcionó trabajo a una parte de la población de los ayuntamientos afectados, pero al término de las obras la diáspora fue brutal, quedando la población reducida a la mitad ( 21$)$.

Pero no $3 \delta 1.0$ se perderán cierto númcro de lueston de tra bajo, se perderá también más del 30 por cien de la superficie de todo el municipio de campoo de Yuso, que además eron las mejores tierras. El quebranto que esto supondrá fue tal que obligó a emigrar a numerosas familias. Ln efecto, las que poselan tierras afectadas, al ser la propicdad tan pegueña recibieron en concepto de indemnización una cantidad insignificante, que no less compensaba de tal pérdida, máxime si tenemos en cuenta que además se inundaron montes y ejidos de propiedad comunal. En estas condiciones era prácticamente imposi ble reconstruir la explotación agraria, por lo cual parte de estas familias optó por emigrar.( 22 ). Ln peor situación quedaron aquellos que no tenfan tierras en propiedad y basaban la explotacion sobre tierras arrendadas que también fueron inunda das; de ellos partio en buena medida la primera emigración generalizada.

La périida de las praderas y lierras de labor del sec tor meridional del municipio - la llanura de la Virga- hizo de $\underline{3}$ cender incluso el número de cabezas de ganado de aclueljas explotaciones que continuaron activas tras la inundación de las citadas tierras, mermándose considerablemente las rentas de la población campesina. No hay que olvidar que la explotación agraria tradicional. se basaba sobre el aprovechamiento de lo:s terrenos comunales, cuya desaparición se dejo sentir con fuer-

(21) E. ARIJA RIVARLï.- (jamnoo de Yuso, listudio Georrafice $y$ socielósico del valle del Jantano dej jibro. C.E.S.P. Wantander 1963. Pág 39 y siğ.

(22) "... un labrador que tiene cuatro hijos, a los cuales mantiene con su trabajo, con el producto de su casa alueana, tres prados y tres tierras que en totil. vales $30 \%$ Pts. al darle 5000 empieza por no saber gue hacer con ellas." i. L.,kinLC PARIU. El Pantano... up cit. pág 150. 
za haciendo inviables parte de las mismas.

La solución adoptada ante la necesidad de tierras y prados de gran parte de la población campesina, fue la concesión por el Mintsterio de Agricultura do uno pequeria parcela proce dente de los comunales, con el fin de incrementar con carácter de usufructo el tamaño de la explotación. $\nu_{c}$ este modo, y reduciendo el tamaño del rebaño se pudo hacer frente a la situación hasta 1960. lin esto ario, y a propuosta tambion dol. MI nisterio de Agricultura se declara de Utilidad Pública y de urgente repobjación los diferentes montes que forman la cuen ca del Pantano dol libro. Campó de Yuao se verá afectado en 1250 has., siendo preciso desalojar el ganado de los "puertos" comunales, y al no poderlo mantener en los prados propios y en los pastos comunales no afectados por la anterior medida, el campesino se verá obligado a venderlos y a cambiar el significado de la explotación, optando por un ganado de mayor ren dimiento, el de producción de leche.

Para poder emprender este cambio fue preciso disponer de un volumen de tierras mayor, a las que se pudo acceder merced al abandono de numerosas explotaciones, cuyos titulares abando naron la comarca entre 1947 y 1960.

La contrapartida, no sólo en Campóo de Yuso, sino en toda la comarca, a las cont1nuas crisis, a los graves inconvenientes estructurales, la ofrecio la progresiva industrializacion de la misma, y en particular del núcleo de Reinosa. 
CAPI'PUIO XI

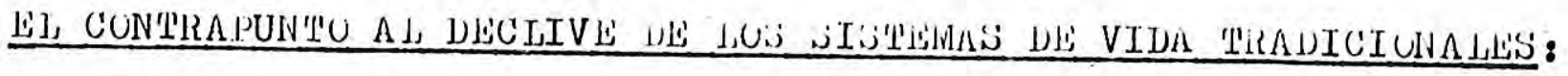
LUS PRIMERU:S INTENTUS INDUSTRIAJIZANURE, DEL, VAJJEE DE CANIPOU.

La crlsis abierta tras la practica desaparición de la carreterla, será paliada en parte por una serie de actividades industriales, aparecidas durante el periodo de auje cie aquella actividad -las fábricas de harinas-. Listas irán no ob! tante irán perdiendo parte de su sanacidad al construlrse, a lo largo dej. Canal de Castilla, otras factorlas destinadis al mismo menester.

Junto a las fábricas de harinas - 4 en el momento de máxima actividad-surgen otras, tanto en kinosa como en otros puntos de la comarca y fuera de ella, al amparo de la explota ción del carbón de las minas de las Rozas, orientadas en su to taliaaa a obtención de vidrio. La construcción del ĺmbalse del L'bro y la escasa competitividad del carbón de las citadas minas, acabarán pronto con estas actividades que, a principios 
de siglo ocupaban a una parte de la población de Reinosa y Campóo de Yuso sustancialmente.

Paralelamente van surgiendo algunas "fábricas de quesos" que con carácter semiartesanal irán estimulando el cambio en la composición del rebaño de ganado vacuno, cambio que parcial mente tendrá lugar en Campóo de Enmedio y Yuso, puesto que en Campóo de Suso se conservará sin merma alguna la tradicional dedicación a la recrla de ganado vacuno del pala. Tal cambio no se llevará a cabo por causa de la introducción de razas más selectas, más especiajizadas en la producción de leche, sino por la introducción de razas mixtas, que proporcionasen, adenás de una pequeria cantidad de leche, trabajo en los labores agrlcolas de la explotacion.

En conjunto estas actividades industriales no se caracte rizan, ni mucho menos, por su pujanza, por su capaciclad para crear puestos de trabajo; muy al contrario se trata de pequeños talleres, con un empleo asalariado marginal, entendido como un complemento del trabajo de la explotación agraria familiar. Constituyen, pese a todo, lo que poürlamos denominar la primera generación de la industria en Campóo.

Tras ellas harán su aparición otras más dinámicas, con mayor capacidad para generar empleo, pero estas responden ya a otros hechos y son ajenas completamente a la dinámica y aún a la iniciativa de la población de Ja propia comarca. Son en cambio estas inäustrias, surgidas en la primera mitad del siglo actual, las que mayor continuidad han tenido; han llegado con alguna transformación interna, hasta ej. presente, y a ellas debe, no sólo Reinosa, sino Campóo en general parte de las trans formaciones recientes. 


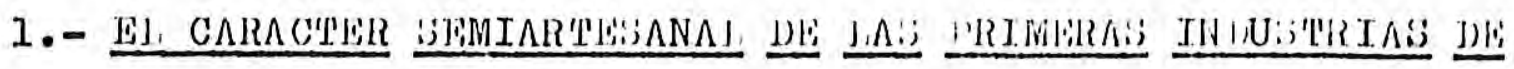
CAMPOOU.

La industrialización de Reinosa aparece a finales del siglo XIX y principios del siglo presente como ej. contrapunto al. declive de los astomas de vidu trudiclonules, constituyendo la sojución de continuidad para lo que será el desarroli.o de una industria de mayores dimensiones y significado, a partir de la década de 1950 .

Hasta ese momento, las actividades existentes no pasan de tener un mero carácter testimonial, que en nada o en muy poco modifican la estructura económica de la comarca, y apenas sirven para contener la corriente emigratoria impulsada por la crlsis de los sistemas de transporte tradicionales en la segunda mitad del siglo XIX, y cuyos efectos se prolongan, al menos desde el punto de vista demográfico hasta el primer tercio del siglo $\mathrm{xx}$.

Las primeras actividades que tienen este carácter son las relacionadas con el transporte de trigo y harina con des tino al puerto de Santander: las Jlamadas fábricas de Harina. Durante el periodo de máxima actividad de la carreterfa pare ce ser que su número fué de 6 , de las que dos estaban ubicadas en el pueblo de Nestares, aprovechando, al igual que las de Reinosa, las aguas del rlo kbro. Su actividad decae progresi vamente a partir del año 1866, al entrar en funcionamiento el ferrocarril y perder Reinosa la función de centro almacenador del trigo y harina en tránsito hacia Santander. Bien es cierto que,desde la puesta en servicio del ramal Norte del Canal de Castilla y la consiguiente instalación de "fabricas de Harina" a lo largo de él, las fábricas de Campóo perciieron parte de la otrora intensa actividad. 
Completaban durante este periodo el panorama industrial una fábrica de curtidos, en funcionamiento al menos desde 1815, y "diferentes fábricas de tejidos de lino y lana" (23). Estas últimas se abastecian de materias primas, sin duda en la propia comarca; el rebaño de ganado ovino era, en efecto, suficientemente numeroso como para suministrar lana a estas pequeñas fábricas, cuya demanda era casi exclusivamente regional. Del mismo modo existian en la comurca, y especialmonte en campóo de Suso pequeños linares que, además de satisfacer el consumo familiar, proporcionaban, a través de su venta en el mercado semanal de Reinosa o en las ferias del mismo núcleo, unos pequeños ingresos marginales al campesino, amén de abastecer de esta materia prima a las citadas fábricas o pequeños talleres artesaneles.(24).

Son no obstante las fábricas de vidrio las que tienen, desde el momento de su instalación, mayor importancia, pudien do considerarse como las primeras actividades que responden, por su propia organización interna, a la categorfa de industrias. Recogiendo las experiencias de otras iniciativas desarrolladas en otros sectores proximos -Arija, Arroyo...., en 1891 se crea en Reinosa una fábrica de vidrio, la Vidriera Santa Clara, cuya vida sera por otra parte eff́mera; en efecto, 26 años mas tarde, en 1917, habla dejado de funcionar. Ia acti

(23) La información oue proporciona el Diccionario de P. MADUZ es claramente insuficiente; tan sólo hace referencia a "varias fábricas" tanto para el. caso de las harinas como para las texliles. Pensamos que tanto en uno como en otro caso no debieron ser muy numerosas, en ell primer caso pornue el. curso del rlo Ebro no ofrece condiciones para la instalación de más de los 4 molinos de más de cinco ruedas existentes a mediados del sig.jo XVIII, y en el segundo norque su desaparición ha sido abBoluta, y tampoco figuran en otras fuentes como actividad destacada.

( 24 ) Solo en el liarquesado de Argüeso, a finales del siglo XVIII existian 21 telares, con 21 operarios en los que se elaboraban tejidos de lino, lienzo y estopa. En las mismas fechas, el pueblo de Argüeso declara que " toda la lana se consumió en el pueblo, y parte del lino se vendio en Keinosa en las ferias y mer cados". Hermandad de Campo de Suso y liarquesado de Ar Elleso.Estado de los frutos.... up. cit. año 1787 . 
vidad de ésta. y de otras factorlas próximas tropezó con grandes dificultades, siendo sin duda la mayor la derivada del pre cio del transporte; en efecto, el principal mercado para los productos aquí eleborados estaba en "las provincias de levan te", perdiéndose pronto al no poder competir con los vidrios extranjeros cuyo transporte era, paradógicamente, más barato y por ende el. precio final de los mismos ( 25) Pese a todo, estas fábricar, propiedad todas ellas de un solo emiresario, llegaron a proporciónar empleo a mas de 600 trabajadores ( 26 ). In 1917, tan solo subsistlan dos fubricas, ambas fuera de la comarca, la Cristaleria Lspañola en Arija, que daba ocu pación a 450 obreros, parte de los cuales procedlan de lampóo de Yuso, y la Cantábrtea, que empleaba a 300 trnbajadores on el proceso de fabricación de vidrio y extracción de carbón de las minas de Las Rozas, donde estaba localizada.

Por último, desde principios de siglo comenzaron a funcionar pequeiras fábricas dedicadas a la elaboración de quesos, aunque se trata más bien de simples centros artesanales, cuyos vroductos abasteclan casi exclusivamente el mercado local ( 27 ).

En parte, estas pequeñas industrias nacidas al amparo de coyunturas especificas gructass ul dinumjumo de une pecueín bueguesfa comercial de corte decimonónico,y para aprovechar los escasos recursos de que disponfa la comarca -las arenas de Arija y el carbón de las Rozas-, desapareceran paulatinamente sin apenas dejar huella en la misma. Será la insuficien-

(25) J. GARCIA DE IA PUENTE.- Reinosa... Op. cit. pag 33. (26) La fábrica de Reinosa fue la tercera que tuvo el excelentisimo señor D. Telesforo Fernandez lastaîeda, pues primero fundo la luisiana" en las Rozas, pueblo práximo a la villa, cuyos vidrios planos adquirieron tal fama que, vara dar cumplimiento a los pedidos se vió obligado a construir lia Cantábrica en el pueblo de Arroyo, a una legua de Reinosa. J. GARCIA DL IJA UENTÉ Ibid, pág 34 .

(27) Prueba de la escasa entidad que tenla esta actividad puede ser el hecho de que, con motivo de la construcción del pantano del Ebro se esperaba que el ferrocarril de Ja Robla pasase por Reinosa y con ello se pudiese recibir cómodamente " la rica y abundante leche de las villas pasiegas, que actualmente no tiene fácil colocación. M. LURENLO PARLO.- El pantano... Up. cit. pág 159. 
cia de capital, e incluso la inexistencia del mismo la que, junto al enorme obstáculo que supone la insuficiencia del sis tema de transporte de la comarca y del conjunto de ta nación las causas que arruinarán la embrionaria actividad de la que hemos denominado primera generación de industrias camourrianas.

La superación de estos obstáculos solo podfa llevarse a cabo mediante una capitalización exterior, ajena a la comarca, y eso es precisamente lo que sucederá deside el aîio 1918.

2.- ET, NACIMIENTU DE LA INDUSTRIA MUDLRNA: IIA ,jOCILDAD E.jPANOULA DE CONGTRUCCIUN NAVAI

Trás el ocaso de las primeras industrias surgidas a finales del siglo XIX y principios del XX en Reinosa y en la comarca en general, se iniciará un desarrollo industrial de cierta entidad, localizado de modo exclusivo en el núcleo de Reinosa. Tal desarrollo, impulsado en su totalidad desde el exterior, es tará dotado de una cierta entidad, hasta el punto que fue capaz de estimular, en un principio, lea instalación de otras industrias, otras actividades, cuya iniciativa procederá también de fuera de la comarca. La participación de la pequeña burguesla local fue en este proceso muy limitada; no fue más alla de la creación de pequeñas empresas de servicios, al margen en mu chas ocasiones de la actividad industrial domininte.

A pesar de tener ciertas dimensiones, este conjunto de industrias, instaladas en la comarca por causas puramente estratégicas, no servirá siquiera, durante la primera etapa de su actividad, para satisfacer la demanda de trabajo de la co marca, de una población agraria en suma, inmersa en unis estructuras dislocadas, inviables e inadaptadas a las nuevas ne 
cesidades de una demanda de productos agrarios en expansión continua. No sirvieron, en suma para contener el éxodo rural. presente con cierta intensidad desde los últimos años de la década de 1950.

En cierta medida podemos alirmar que se trata de una in dustria dinámica, sometida a las coyunturas del mercado inte rior, cuya actividad en cambio apenas sirvió para dinamizar la economfa de la comarca; es por ello una industria ajena a los intereses y estructura de un espacio que se constituye, de modo exclusivo, en un mero soporte ffsico de ella.

por ello, el impacto de la misma en la transformacion del espacio, ha sjdo menor de lo que cabrla esperar; no se ha creado un paisaje industrial propiamente dicho, sino que, todo lo más ha servido para dotar de algunos caracteres urbanos a un núcleo tradicional de servicios, Reinosa, y para, por vía de la capitalización individual, a partir de las rentas en ella obtenidas por parte de la población campesina, transformar el carácter de la explotación agraria y dotarla de medios y estruc tura modernos.

Se inician estas actividades inciustriales, que podemos considerar, y lo son, plenamente modernas a rafz de la creacion, por causas puramente estratégicas, del. polo Industrial de Reinosa. En El, y dentro del contexto de la ordenación de las industrias militares, se instald, en el año 1918, una fac torla de la Sociedad Española de Construcción Naval, a la que seguirá, años más tarde, la Constructora Nacionaj. de Maquinaria Eléctrica -CLNEMLí, en 1930; posteriormente se instala la factorla de Forjas de Reinosa is.A., en 1954, completando prácticamente el conjunto de la industria reinosana. Una industria que, con pequeñas excepciones, se ha mantenido sin alteración hasta los momentos actuales, lo que da idea suficiente de su escaso, más bien nulo, efecto multiplicador. 
Con todo, será la factorla de la Sociedad Española de Construcción Naval - la Naval, como se la conoce en la comarca-, la que, por sus dimensiones, por el volumen de mano de obra ocupada en ella, ha servido de base para impulsar gran parte de las transformaciones que se han ido sucediendo, tanto en Reino sa como en la comarca en general; su construcción se inició el año 1918, entrando en funcionamiento dos años más tarde, con una producción de acero modesta en un principio y notable des pués, exceptuando el paréntesis de la década de 1930, de marcado carácter regresivo, y durante la cual la producción fue meramente testimonial ( 28 ).

Desde el primer momento, desde que se iniciaron las obras de construcción de las dependencias de que iba a estar dotada se pudo contener, parcialmente, el éxodo rural, cuya intensidad se habla incrementado tras la quiebra de las fábricas de vidrio de la comarca. El impacto que causo su instalación fue, por lo tanto, de cierta magnitud, máxime si tenemos en cuenta que, desde su puesta en funcionamiento dió ocupación a más de 1000 trabajadores, que en su mayor parte procedlan de la comar ca. Obviamente fue preciso disponer también de una mano de obra cualificada, que, en número considerable, llegs de otras regiones; as 1 parece demostrarlo la intensidad de la inmigración entre 1918 y 1920.

Al poco tiempo de iniciar su actividad se acomete una ampliación de las instalaciones y actividades, que no concluirá hasta 1927; durante este periodo se creará una escueli de aprendices cuyo fin era proporcionar a la factorla los espe cialistas y mandos intermedios, que como ya homos apuntado procedlan en su mayor parte de otras regiones.

(28) Los productos elaborados en la factorla de Reinosa estuvieron destinados a abastecer el mercado interior, en especialcon destino a la Armada y marina mercante. Coyunturalmente se fabricó tambión armaménto pesado. Breve Historia de la entidad A.E.S.A. y sus actividades.- rroyecto de investigación sobre fabricación y propiedades de aceros aleados y chapas gruesas. ne 602 . 
La década de 1930 representará para la industria instalada en reinosa una fuerte recesion, al igual que sucede en el resto del pals, de la que sठ́lo saldrá parcialmente tras la intervención estatal a principios de la década de 1950 (2y). A partir de esta fecha la factorla de Reinosa se ampliará, actua lizándose sus lineas de producción, lo cual supondrá, cuando menos mantener j.os niveles de empleo alcanzados on los nîos fi nales de la década de 1920. l'osteriormente, y al amparo de la Acción Concertada con el Estado se procederá, en 1965, a una nueva ampliación y modernización de sus instalaciones, sufrien do la producción un fuerte incremento que se mantendrá en años posteriores, particularmente desde 1969, año en el que se inte gra en el grupo de Astilleros Lispároles ( 30 ).

En general, el polo industrial de Reinosa sufrirá una rápida expansión en la década de 1950. Durante este periodo, a la Sociedad Española de Construcción Navai y CLNEMESA se añaden la fábrica Forjas de Reinosa, la fábrica de Galletas Cuétara en 1950 y la fábrica de productos quimicos derivados de algas marinas -QUIMESA-, esta última trasladada en 1968 por exigencias de la concentración industriali en el polo de desarrollo industrial de Burgos. En conjunto proporcionan un volumen de empleo, variable segúr los años, pero próximo a los 3000 puestos de trabajo, de los cuales mas de 2000 corres ponden a Astilleros Españoles 3.A. Pero mayor interés que el. volumen de población ocupada, tiene el hecho de que éste haya permanecido invariado desde la década de 1950, lo que da idea suficiente del dinamismo de la industria de Reinosa. Se trata

(29) M. FERRER REGAJES.- La industria de la España cantábrica" Ed, Moretón. Bilbao 1968, pág. 61 y sig. (30) Reinosa: The manufacture of steel forgings and costings en THE MOTOR SHIP: This is Astilleros Españoles S.A. June 1974, A special survey pág 73-75. 
en efecto de una actividad estancada, que empero ha sido suficiente para estimular un proceso de cambio de ciertas proporcio nes en toda la comarca, un proceso que corre paralelo a la propia evolución en número y estructura de la población campurriana, agente del mismo. 


\section{CAI'I'PULO XII}

LA IRREGUI,AR EVOLUCION DEMOGRAFICA DE CAMPOU: UN LWNTO CRLCIMIENTO DE IJA POBLACION, POIAARIZADO EN TORNO A REINOSA.

La evolución demográfica de Campóo no difiere sustancial mente de una trayectoria social y econónice como la segujada por la comarca, en la que se amalgaman cambios y permanencias en forma compleja, condicionando su propia evolución intena. $Y$ en ésta, presidida durante largo tiempo por unas estructuras tradicionales, son frecuentes coyunturas adversas, cuyo reflejo en la estructura de la población era inmediato a través de las dos únicas respuestus que ésta ero capaz de ofrecer: la enigración y la muerte, verladeros limitadores del crecimiento de la pobla ción en un regimen demográfico tradicional.

Eliminadas en parte las frecuentes crlsis de subsistencia, y sin que por ello la población mejorase, sustancialmente, su estedo de subalimenteción crónica que la hacla especialmente vulnerable a cualquier accidente, e iniciado un retroceso de la 
mortalidad "habitual", la población deberla haber crecido en forma notoria, hecho que no sucede al dispararse el segundo resorte limitador del crecimiento: la emigracion. Esta se con vierte en verdadera protagonista de la trayectoria seguida por la población de Campóo desde que, perdida una gran fuente de obtención de ingresos, la carreterla, se inicia una recesión económica notable que, en la práctica supone una nueva adapta ción a las precarias condiciones de vida tradicionales.

Se trata empero, de una emigración de doble signo; de una parte la que conlleva el abandono definitivo de la comarca, cuyo destino es casi de modo invariable América, y de otra el desplazamiento temporal de mano de obra hacia regiones más desarrolladas - el Pals Vasco, y Vizcaya en particular-, susti tuyendo, en cierto modo, a la emigración temporera tredicional que habla tenido como punto de destino preferente Andalucla. Si la primera remite en parte tras la perdida de las Provincias Ultramarinas, la segunda de ellas se acentúa hasta el punto de que en ella participa la mayor parte de la población joven de algunos sectores de la comarca.

A consecuencia de esta emigración, desde la segunda mitad del siglo XIX, o mejor aún, desde que se construye el ferro carril Alar-Santander, la comarca invierte el signo de su crecimiento, y de claramente ascendente pasa a observar un carácter regresivo, al menos hasta 1910. A lo largo del segundo decenio del presente siglo, y sin que el proceso se interrumpa en el siguiente, la población de Campóo entrará en un periodo de signo diferente; el saldo vegetativo se duplica y el saldo migratorio pasa a ser positivo, pero el esplendor será effmero. En 1940 se recupera nuevamente la trayectoria habitual, presidida por un constante éxodo rural, y ésta ha llegado hasta la actualidad sin apenas sufrir modificaciones.

Durante este proceso se irá consolidando lo que hoy es un rasgo sobresaliente en la distribución de la población: la 


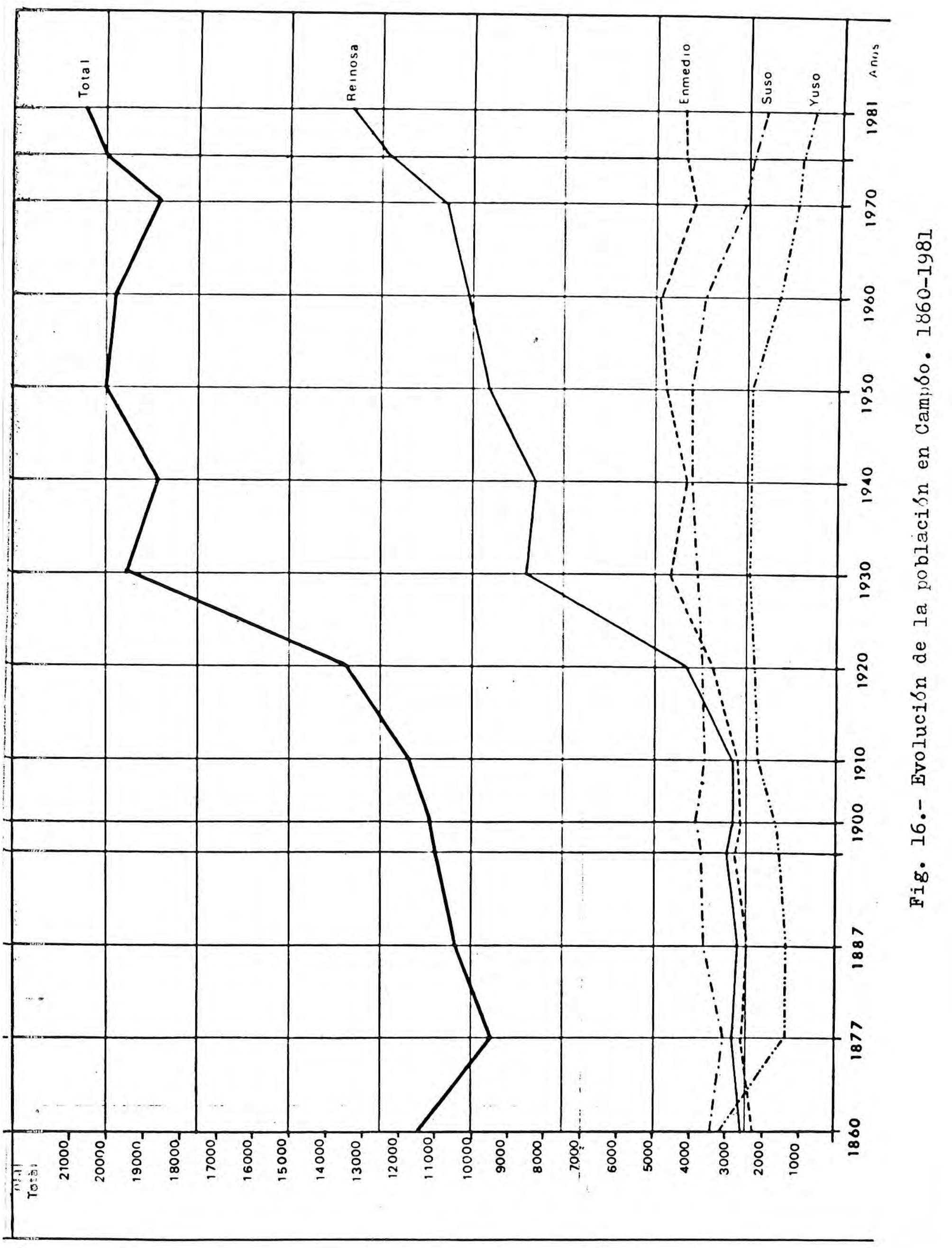


concentración de la misma en el núcleo de Reinosa, cuyos efec 'tivos representan actualmente más del 60 por 100 del total de la comarca.

1.- UNA POBLACION EN IRIREGULAR Y DHBBIL, PERO CONSTANTE CRLCIMIEN'O.

Tres son las coordenadas en las que se enmarca la evolu ción de la población de Campoo: la debilidad, irregularidad, $y$, pese a todo, la constancia en el crecimiento, con pequeños sobresaltos, de sus efectivos totales. Intre 1860 y 1980 los incrementos de población decenales no superan habitualmente el 8 por 100, siendo el promedio ligeramente superior al 5 por 100 en todo el periodo; se trata de un crecimiento bajo, que no se corresponde, durante gran parte de los 120 años con un régimen demográfico moderno. La natalidad y mortalidad permanecen elevadas hasta 1930, invirtirtiendose la trayectoria posteriormente, como sucede en las áreas más deprimidas de la mación, a consecuencia de la emigración y consiguiente en vejecimiento.

Pero, además de reducido, se trata de un crecimiento 1rregular; se alternan decenios de fuerte expansión -15,9 y 43,7 por 100 en 1910 y 1920 respectivamente-, con otros de ligero retroceso, no superior, salvo el del año 1877 al 10 por 100. El resultado es un crecimiento sostenido, de pequeña entidad, resultado de la constante emigración que habitualmente caracteriza a la comarca.

a) La contención del éxodo rural y el estancamiento de la población en el último tercio del siglo XIX.

Si la primera mitad del siglo XIX se habla cerrado con 
una relativa expansión de la población de la comarca, tras la crlsis iniciada a ralz de la construcción del ferrocarril AlarSantander, se desata un intenso éxodo rural en la misma. Su en tidad es tal, que, pocos años más tarde, en 1877, se alcanza el nivel más bajo del siglo - 9502 habitantes-. De ahl en adelante, el crecimiento de la población será progresivo, en gran parte por la contención, que no eliminación del éxodo rural, lo grada en el contexto de una débil industrialización impulaada por la burguesfa decimonónica.

CUADRU XXVII

EL DESEQUILIBRIO EN LA LVOLUCION DEMOGRAFIGA DE LA COMARCA EN EL ULTIMO TERCIO DEL SIGLO XIX.

Crecimiento intercensal

\begin{tabular}{|c|c|c|c|c|}
\hline & 1860 & 1877 & Total & $\%$ \\
\hline Reinosa & 2781 & 2952 & 171 & 6,14 \\
\hline C. de Enmedio & 2279 & 2672 & 393 & 17,2 \\
\hline c. de Yuso & 3161 & 1556 & -1605 & $-50,7$ \\
\hline C. de Suso & 3278 & 2322 & -956 & $-29,1$ \\
\hline TOTAL & 11499 & 9502 & -1997 & $-1.7,3$ \\
\hline
\end{tabular}

Fuente: Censos de poblacion.

Desde 1887 hasta 1910, la población permanece prácticamente estancada, con pequeños incrementos decenales que apenas elevan, en la última fecha, el total de la misma on un miljar de habitantes.

No obstante, la población de los municipios de Reinosa y de Campó de Enmedio escapan a esta trayectoria, como resultado,sin duda, de la continuidad de determinadas actividades semiartesanales y a la creación de otras de más entidad, en es pecial la fábrica de vidrio "Santa Clara" en Reinosa. Por con tra Campoo de Yuso y de Suso, son los sectores que sufren muy acusados descensos de su población. 
b/ De una población estancada a una población en crecimiento: un resultado de la expansión económica de Reinosa.

Entre 1920 y 1950 la comarca atraviesa el periodo de ma yor crecimiento, hasta tal punto que, en estas tres décadas la población prácticamente se duplica. Las además el único mo mento en que se invierte la trayectoria de los movimientos mi gratorios, siendo muy intensa la inmigración por causa sin du da de las condiciones económicas en las que se va a ver inmer so el núcleo de Reinosa desde 1918.

En efecto, dede este año comienzan las obras para la cons trucción de la fábrica de la Sociedad Española de Construcción Naval, entrando en funcionamiento con una plantilla inicial superior a los 1000 empleados, de los que una gran parte proceden de la propia comarca, y el resto de fuera de ella. Años más tarde, en 1930, se instala la factoria de CENEMESA, y la población total vuelve a incrementarse, en este caso en un 42,7 por 100.

No obstante, este crecimiento no supone que la comarca haya recuperado un dinamismo perdido en el siglo pasado, sino que muy al contrario, al ser la atonfa el. uspecto más sobrese liente de gran parte de la misma, las proporciones que alcanza el incremento de poblacion, se deben tan sólo a la especta cularidad del crecimiento de Reinosa ( 31 ).

Tras el breve paréntesis impuesto por la guerra Civil y la postguerra inmediata, durante el cual la emigración supera incluso en volumen, los niveles de princtpios de 31 glo, y en el que la pobJación contiene su ritmo de crecimiento, éste volverá a ser positivo - 7,1 por 100- al finalizar la década de 1940. En conjunto durante todo el periodo -30 años- se asiste

(31) El crecimiento de Reinosa fue ciertamente espectacular. Si en 1920 el incremento habla sido, respecto a la década anterior, superior al 40 por 100, en 1930 éste será del 105,8 por 100, pasando la población de 4180 a 8606 habitantes. 
a una intensa afluencia de población a Reinosa, atralda sin duda por la incipiente industrializacion, y ante la crisis 'de la agricultura tradicional, incapaz de proporcionar unas rentas tan elevadas como las de la industria, puesto que la modernización de la explotación agraria tardará todavla en realizarse.

\section{CUADRU XXVIII}

EVOLUCION RECIENTE DE IA POBLACIUN COMARCAL

\begin{tabular}{|c|c|c|c|c|}
\hline & \multirow[t]{2}{*}{$\begin{array}{l}\text { Poblacion } \\
\text { Totill }\end{array}$} & \multicolumn{2}{|c|}{$\begin{array}{l}\text { Crecimiento } \\
\text { Intercenan? }\end{array}$} & \multirow[b]{2}{*}{$1860=100$} \\
\hline & & Num. & $\%$ & \\
\hline 1860 & 11.436 & -- & -- & 100 \\
\hline 1877 & 9.502 & -1.934 & $-16,9$ & 83 \\
\hline 1887 & 10.525 & 1.023 & 10,7 & 92 \\
\hline 1897 & 11.005 & 480 & 4,5 & 96,2 \\
\hline 1900 & 11.104 & 99 & 0,8 & 97 \\
\hline 1910 & 11.577 & 473 & 4,2 & 101,2 \\
\hline 1920 & 13.482 & 1.851 & 15,9 & 117,4 \\
\hline 1930 & 19.244 & 5.762 & 42,7 & 168.2 \\
\hline 1940 & 18.846 & - $\quad 398$ & $-2,6$ & 164,7 \\
\hline 1950 & 20.188 & 1.342 & 7,1 & 176.5 \\
\hline 1960 & 19.709 & - $\quad 479$ & $-2,3$ & 172,3 \\
\hline 1970 & 18.436 & -1.273 & $-\quad 6,4$ & 152,4 \\
\hline 1975 & 20.033 & 1.597 & 8,6 & 175,1 \\
\hline 1981 & 20.511 & 478 & 2,3 & 179,3 \\
\hline
\end{tabular}

Fuente: Censos de poblacion.

Gran parte de la población llegada a Reinosa y Matamorosa, los dos núcleos en los que aparece concentrado el crecimien to, procede de los pueblos de la propia comarca y municipios pŕo ximos a ella -Cinco Villas, Las Rozas de Valdearroyo, Los Carabeos, Valdeolea-. As1 parece demostralo el análisis de los padrones de los dos municipios de la comarca citados. En ambos el crecimiento fue espectacular, muy por encima del experimentado por Campbo de suso y Campbo de Yuso, en los que el creci 
miento acumulado el las tres décadas apenas superó el 5 por 100 en el primer caso, y fue incluso negativo en el segundo, - 2,1 por 100, hecho explicable por el impacto causado a rafz de la construcción del Pantano del Ebro -inagurado en 1947y el traslado a Asturias de la fábrica de vidrio de Arija.

\section{c/ La vuelta al estancamiento: un fenomeno rectente de sienificado contradictorio.}

Tra es fuerte periodo de creotmiento del primer tercio del presente siglo, y la pequeña recesión posterior, se inicla una nueva etapa -décadas de 1950 y 1960-durante las que se registran nuevos retrocesos en el volumen de población to tal, que suponen una pérdida de efectivos próxima al 9 por 100 en los 20 años, si bien es cierto que en los 11 años siguientes -1970-1981- se aprecia una recuperación que enjuga las pérdidas de años anteriores; de este modo, y aunque con diferencias muy corta, la comarca alcanza un total de pobla ción superior al de ápocas pasadas.

Pero, la evolución apuntada no se puede considerar en absoluto como satisfactoria, porque, pese a los incrementos decenales, la comarca sigue perdiendo población, y en un volumen muy superior al de los citados incrementos. Listas pérdidas se deben sin duda a las condiciones generales por las que atraviear España, en particular las creadas tras el Plan de Estabilización de 1959 ( 32 ). En efecto, la emigración, a duras penas contenida tras la Guerra Civil, adquiera ahora unas proporciones considerables, orientándose hacia la capital de la provincia y hacia las provincias Vascongadas. En

(32) A. GARCIA BARBANCHO.- Las migraciones interiores españolas: estudio cuantitativo desde 1900. Estudios del Instituto de Desarrollo económico. Madrid 1967. Cfr. pág. 95 y sig. y tabla A-1. 


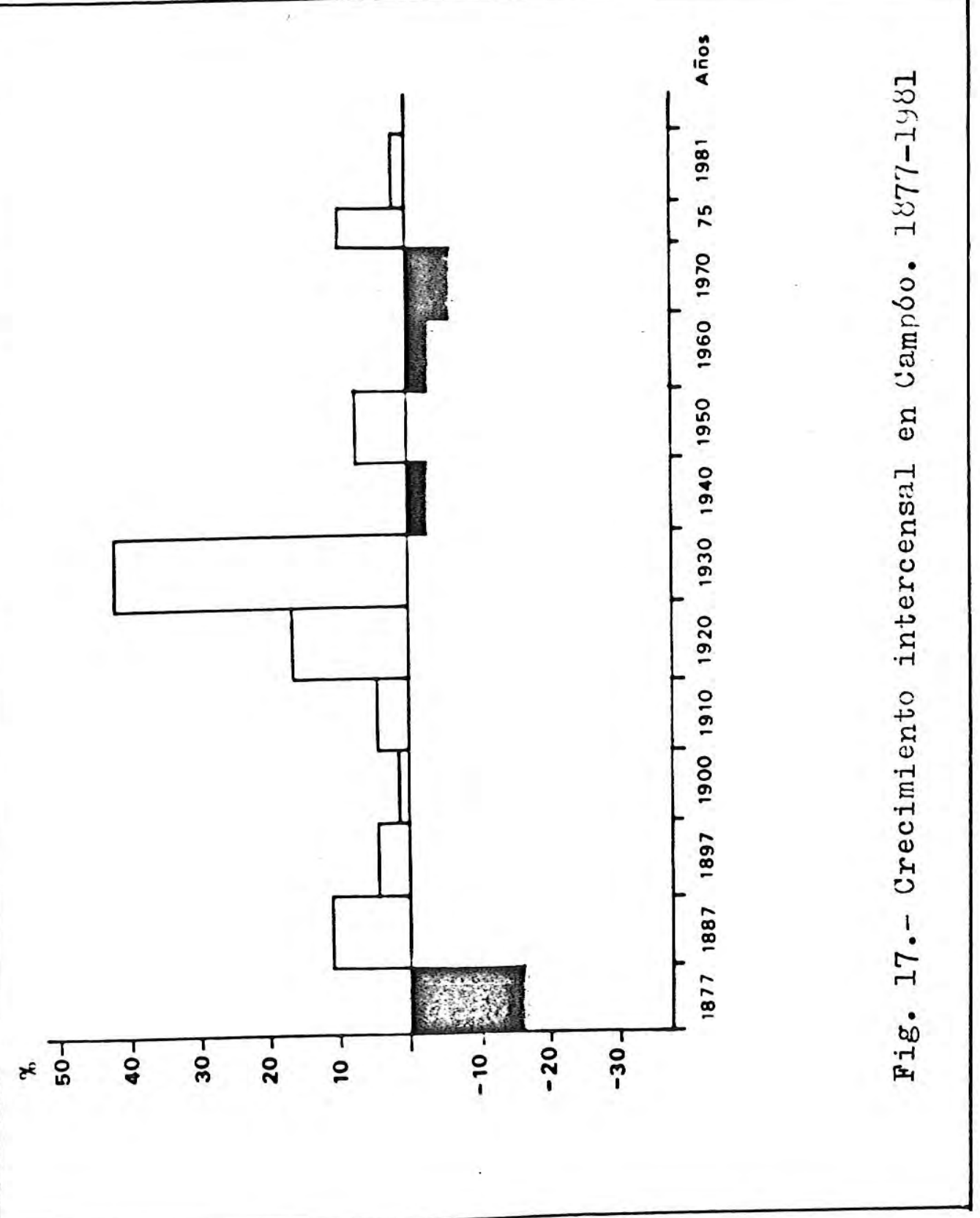


esta emigración participa también, y aportando casi el 50 por 100 de los efectivos, la población de Reinosa; una muestra sin 'uda de que,tras la euforia de los años veinte, la capacidad de generar empleo por parte de la industria de este núcleo habla tocado $t \in c h o, y$ de que si se rebistran incrementos pequehos en cada decenio, estos se deben más al dinamismo del comer cio y de los servicios, dinamismo que hay que relacionar con el aumento del nivel de vida y rentas de la población campesi na desde la década de 1960.

Este. emigrac1ón reciente representa unas pérdidas de población próximas al 16 por 100, y en parte constituye el resul tado Ibgico de los elevados Indices de crecimiento vegetativo de las décadas anteriores, asl como del fuerte deterioro de las rentas agrarias de una parte de la población campesina,que tras unos años en los que se mantiene en condiciones de vida precarias, se decide a abandonar la comarca ante las mejores espectativas de desarrollo de otras regiones.

Por ello, si bien la población de la comarca ha seguido crectendo, to ha hecho muy por debajo de au propio dinamismo interno. Lia emigrecton, de proporctonen constiderubles, se con vierte en el verdadero protagonista de la evolución demográfica reciente en Campó.

2.- UNA DINAMICA DEMUGRAFICA IRREGULAR, PRESIDIDA POR EL EXODO RURAL.

El saldo vegetativo de la población ha sido siempre en la comarca de signo positivo; los nacimientos han compensado y superado las pérdidas por defunción, pero el crecimiento ha ido por debajo de las posibilidades reales al ser 
parte de él derivado nacia la emigración. Salvo episodios coyunturales -epidemia de gripe de 1918 y Guerra Civil-, en el siglo XX se supera la irregular trayectoria, propia de un regimen demográfico tradicional, en el que, periódicamente,la mortalidad superaba a la natalidad, convirtiéndose la primera en verdadero regulador del crecimiento.

Paulatinamente, y salvo los accidentes apuntados, al mortalidad inicia un retroceso, pasando a ser la natalidad la variable, de cuyo control depende el crecimiento demográfico. Pero esta evolución, habitual en el tránsito de un regimen tradicional a un regimen moderno, se verá profundamente alte rada por los movimientos migratorios; a ellos hay que achacar la intermapción del descenso de la natalidad en la década de 1930 y el acusado envejecimiento posterior a 1960 en toda la comarce.

a) La desigual trayectoria de la natalidad y mortalidad hacia la consecución de un bajo crecimiento vegetativo.

La inexorable marcha hacia una natalidad y mortalidad bajas, no es continua, sin sobresaltos, en la comarca; ambas variables se verán afectadas por acontecimientos que distorsio nan la trayectoria habitual de transformación, general al con junto de la población española. Pero, en cambio, si no es similar la andadura, si lo son el punto de partida y el final de la evolucion.

En efecto, partiendo de Indices muy elevadors a finules del aiglo XIX y principios del presente siglo - 35 por 1000 y 23 por 1000 de natalidad y mortalidad respectivamente-, se irá produciendo una disminución progresiva de ambas tasas, con sobresaltos frecuentes, al compás del cambio en la estructura 
social y económica de la comarca.

Como reflejo de estos cambios, la tasa de natalidad no muestra una continuidad, una regularidad en su trayectoria descendente. Hasta 1910 esta tasa se mantiene elevada, con va lores propios de un regimen demográfico trudicional-más de 30 por 1000-; inicia un pequeño descenso en la década de 1910, para volver a recuperar, en el decenio siguiente, los valores propios de principios de siglo. Se trata de un proceso, en el. que lo realmente sorprendente no es el hecho en s1, sino sus dimensiones ( 33 ).

La posterior evolución de la tasa de natalidad se enmar ca en el. contexto descendente, propio de una sociedad cadavez más moderna en sus comportamientos demográficos; pero los hechos no son tan sencillos. In efecto, la fuerte emigración que afecto a la comarca desde 1940, en la que participa la po blación más joven, y una clara tendencia hacia el envejecimien to, son en gran parte responsables de este descenso de la nata lidad. Tras la Guerra Civil la tasa desciende, superado ya el anbmalo accidente que representa la elevada natalidad de la. década de 1920 -explicable por la inmigración de población jo ven con destino a la industria recien instalada-.

El posterior declive de la década de 1930, constituye la solución de continuidad pare una nueva, pero menos intensa, trayectoria ascendente de las décadas de 1940 y 1950, inicián dose definitivamente en 1960 la modernización real de la demografla de la comarca. Varios son en efecto los indicios que (33) Calculandola tasa de natalidad anualmente, a partir de la estimación de la población intercensal, se pueden conocer aún mejor las dimensiones del citado proceso. Entre 1925 y 1930 la tasa de natalidad se mantiene invariablemente por encima del 35 por 1000, llegando en 1929 y 1930 a alcanzar 39 y 38 por 1000 respectivamente. Desde este último año y a lo largo de la década de 1930 las tasas descienden notablemente, como reflejo sin duda de la depresión económica y las secuelas propias del periodo bélico -separación de matrimonios, imposibilidad de celebrar otros, dificultades en el abastesimiento de productos de primera necesidud etc...- 
apuntan en esa dirección, además del ya indicado descenso de la natalidad. La nupcialidad y sobre todo el número de hijos por mujer sufren una considerable reducción, como parecen in dicar los registros de matrimonios y la composición del núcleo familiar en los últimos años; no obstante ambos hechos deben ser muy matizados por las defliciencias que presentan las fuentes estadisticas ( 35 ).

CUADRO XXIX

EVOLUCIUN DEMOGRAFICA DE CAMPOO. 1877-1970

\begin{tabular}{|c|c|c|c|c|c|}
\hline & Nacimientos & $\begin{array}{c}\text { Tasa } \\
\% / 00\end{array}$ & Defunciones & $\begin{array}{l}\text { Tasa } \\
\% / 00\end{array}$ & $\begin{array}{l}\text { Crecimiento } \\
\text { vegetativo \% }\end{array}$ \\
\hline 1877 & 324 & 34 & 253 & 26,6 & 0,7 \\
\hline 1887 & 365 & 34,6 & 253 & 24 & 1 \\
\hline 1897 & 470 & 42,7 & 271 & 24,6 & 1,8 \\
\hline 1900 & 442 & 39,8 & 296 & 26,6 & 1,3 \\
\hline 1910 & 363 & 31,3 & 210 & 18,1 & 1,3 \\
\hline 1920 & 377 & 27,9 & 307 & 22,7 & 0,5 \\
\hline 1930 & 740 & 38,4 & 286 & 14,8 & 2,3 \\
\hline 1940 & 358 & 18,9 & 200 & 10,6 & 0,8 \\
\hline 1950 & 447 & 22,1 & 253 & 12,5 & 0,9 \\
\hline 1960 & 426 & 21,6 & 149 & 7,5 & 1,4 \\
\hline 1970 & 198 & 10,7 & 134 & 7,2 & 0,3 \\
\hline
\end{tabular}

Fuente: Censos de población y Registro Civil.

Al margen de los dos accidentes del.presente siglo, comunes a toda la población española -epjdemia de gripe de 1918 y Guerra Civil-, la evolución de la mortalidad, en sus valores absolutos y relativos sigue una tendencia descendente, muy acusada desde 1930. Pero si a este año se llega con una mortaliciad (35) Las múltiples irregularidades que presenta el análisis de ambos Indices desaconse jan su consideración en sentido amplio. Ia nupcialidad es un acontecimiento que solo puede ser valorado desde una perspectiva de análisis mucho más amplia, porque en la práctica habitual los matrimonios se celebran fuera de la comarca cuando la contrayente es de un municipio extracomarcal; También puede distorsionar la realidad la consideración de aquellos matrimonios celebrados en la comarca por causas familiares, cuando ambos contrayentes viven fuera de ella. Pese a todo, si conviene dejar constancia del fuerte retroceso del número de matrimonios celebrados en la comarca; otra consecuencia más del intenso éxodo rural. 
baja, en los posteriores, y hasta 1970, el descenso será aún mayor, hasta alcanzar en el citado año una tasa de 7,2 por 1000. Desde ese momento se inicia una nueva etapa de signo di ferente, en la que, como resultado 16 gico de un proceso de envejecimiento, las tasas inician un ascenso $-11,1$ por 1000 en 1975 y 12,4 en 1981-. Ln cierto modo se ha producido una inver sión de la componente de edad en las defunciones; en efecto, Si a principios de siglo un elevado porcentaje de las defuncio nes totales correspondlan a la población infantil -más del 30 por 100 de los fallecidos anualmente no habian cumplido el año de vida-, lo que representa una tasa de mortalidad infantil muy elevada, superior a 160 por cada 1000 nacidos vivos, desde la mitad del siglo se inicia una reducción notable, hasta tal punto que el 1960 la mortalidad infentil se puede conside rar reducida a aquellos casos inevitables, a la mortalidad endoggena en suma. La participación de las defunciones infantiles en el total de fallecidos es por ello progresivamente menor. CUADIRO XXX

LA MURTALIDAD INFANTIL IN CAMPOO

\begin{tabular}{|c|c|c|c|c|c|c|c|}
\hline \multirow{3}{*}{$\begin{array}{l}\text { Total defuncio- } \\
\text { nes. } \\
\text { Defunciones in- } \\
\text { fantiles }\end{array}$} & 1900 & 7.910 & 1920 & 1930 & 1940 & 1950 & 1260 \\
\hline & 100 & 88 & 120 & 109 & 65 & 96 & 53 \\
\hline & 37 & 21 & 18 & 37 & 12 & 9 & 3 \\
\hline $\begin{array}{l}\% / \text { o } \\
\% \text { mortalidad in- } \\
\text { fantil sobre el }\end{array}$ & 168 & 144 & 116 & 138 & 87 & 67,6 & 22,5 \\
\hline total & 37 & 23 & 15 & 33 & 18 & 9,3 & 5,6 \\
\hline
\end{tabular}

La mortalidad infantil ha dejado de ser un componente esencial de la mortalidad total, correspondiendo este papel en la actualidad a los fallecidos de más de 60 años, cuya propor- 
ción, a causa del progresivo envejecimiento de la población de la comarca, es actualmente muy elevada.

La consecuencia de una mortalidad y una natalidad bajas es un crecimiento vegetativo muy bajo. In 1970 era de un 0,3 por 100, si bien los datos de este año han de ser observados con cierta prevención ( 34 ). Por este hecho nos inclinamos a pensar que tal crecimiento es ligeramente superior, aunque la no disponibilidad de información continun nos impide precisar aún más este hecho.

b/ El exodo rural: una constante en la evolución demográ fica de la comarca.

La emigración es sin duda la clave de la evolución demo gráfica de la comarca; gracias a ella, la población ha mantenido un ritmo de crecimiento muy bajo, menor de los que, las coyunturalmente altas tasas de natalidad podlan hacer presumir. Muestra de ello es, sin duda, el hecho de que, entre 1930 y 1981, la población se ha incrementado en tan sólo 1267 habi tantes; un crecimiento que más bien debe ser considerado como un práctico estancamiento.

La causa se encuentra en que, tras la fuerte inmigracion de la década de 1920, la emigración no ha dejado de gravitar

(34) Desde principios de la década de 1970 e irrcluso anten, los datos que ofrece el Registro Civil dejan de ser expresivos, por causa de la concentración de la natalidad en las areas urbanas, fenomeno común a todo el pals. Es por lo tanto preciso contrastarlos con los que ofrece el Moviniento Natural de la POblación Española. A través de ellos constatamos el rápido descenso de la natalidad de la comarca. El número de nacimientos es siempre inferior a 350 e incluso a 300 , en contraste con los más de 400 de la década de 1960; en alguno de los municipios la reducción ha sido de más del 50 por 100 -Campó de Yuso-. I.N.E. Movimiento Natural de la Población Española. Años 1975, 1976 y 1977. 
sobre la comarca, llegando a superar en algunos años el creci miento vegetativo. Se trata por otra parte de un desplazamien to que tenla, bajo diversas modalidades, unas rafces muy pro funsas en Campó, antes de la emigración ultramarina, durante la misma, y una vez que concluye ésta. En efecto, si Andalucla y América fueron puntos de destino tradicionales para los emigrantes campurrianos, desde principios de siglo serán reemplazados, casi en su totalidad por las provincias vuscas y por Vizcaya en particular ( 36 ), En parte, esta nueva emigración no es definitiva, pero pese a las logicas dificultades que pre senta su cuantificación, en una valoración estrictamente cuali tativa, parece ser que su incidencia no fue pequeña, sino todo lo contrario; salvando las 16 gicas diferencias, habrla venido a sustituir esta nueva emigrución temporal a los desplazamien tos anuales que, tradicionalmente, se realizaban como complemento de una economfa de subsistencia.

Frente a esta emigración temporal, en ocasiones de muy larga duración, son los desplazamientos definitivos los que verdaderamente actúan como freno al crecimiento de la población de la comarca; hasta el año 1910 repressentan pérdidas decenales de población superiores, en promedio al 5 por 100.

En las dos décadas siguientes la emigración se contiene, y el saldo migratorio es netamente positivo; gracias a êl la comarca alcanza un total de población que ha permanecido invariado hasta 1981. La instalación de las primeras industrias en Reinosa y la consiguiente afluencia de trabajadores se tra duce en saldos positivos, de 5,1 por 100 y 21,7 por 100 en 1920 y 1930 respectivamente. Tras la euforia de estas dos dé-

(36)" Mi Ayuntamiento esta formado por 16 pueblos .... que tendrán, digo yo, sus quinientos vecinos, o puede que más. Viven de la ganaderia y de la sementera y de algo de los jornales que ganan en Vizcaya, trabajando en las minas, pues se largan a temporadas, sinque permanezcan en la tierra más que los viejos." J. MUN'PERO. - Una información... en M. LORLNZU PARDO. - El pantano... Op. cit. pág. 169. 


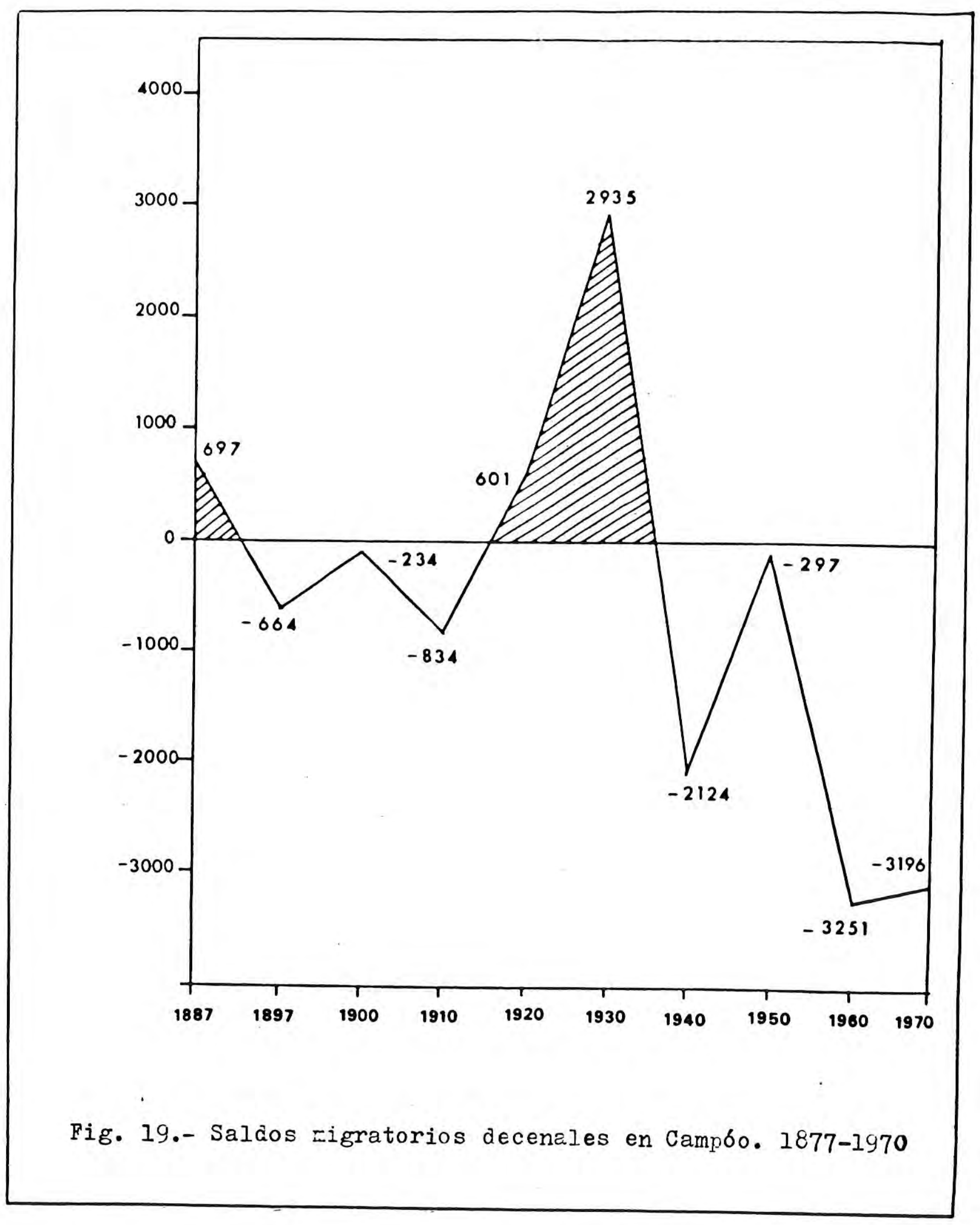


cadas citadas, la comarca recupera su trayectoria habitual. Los saldos migratorios decenales vuelven a ser negativos, especialmente durante las décadas de 1950 y 1960.

\section{CUADRO XXXI}

SALDO MIGRATORIO DECLNAL EN CAMPOO. 1887-1970

\begin{tabular}{|c|c|c|c|c|c|}
\hline & & Diferencie & Crecimiento & Saldo m & ieratoric \\
\hline & Poblacion & Interconsal & Vegetativo & [ota &.$\%$ \\
\hline 1877 & 9.502 & -1.934 & - & -- & - \\
\hline 1887 & 10.525 & 1.023 & 326 & 697 & 7,3 \\
\hline 1897 & 11.005 & 480 & 1.1 .44 & 664 & 6,3 \\
\hline 1900 & 11.104 & 99 & 333 & 234 & 2,1 \\
\hline 1910 & 11.577 & 473 & 1.307 & 834 & 7,5 \\
\hline 1920 & 13.482 & 1.851 & 1.250 & 601 & 5,1 \\
\hline 1930 & 19.244 & 5.762 & 2.827 & 2.935 & 21,7 \\
\hline 1940 & 18.846 & $-\quad 398$ & 1.726 & -2.124 & -11 \\
\hline 1950 & 20.188 & 1.342 & 1.639 & -297 & $-\quad 1,5$ \\
\hline 1960 & 19.709 & - 479 & 2.772 & -3.251 & $-16,1$ \\
\hline 1970 & 18.436 & -1.273 & 1.293 & -3.196 & $-16,2$ \\
\hline
\end{tabular}

Fuentes Censos de poblacion y Kegistro Civil.

No obstante, la consideración en forma global del saldo migratorio esconde los intensos desequilibrios internos de la comarca. Cierto es que la participación de Reinosa es esencial en la entidad de tal saldo, sea negativo o positivo-, pero no en todos los casos responde al mismo origen. L'n Campbo de Yuso, la emigración ha sido una constante en todas las décadar, salvo la de 1910, sin duda por causa de la Intense actividad de las fábricas de vidrio; pero cuando más intensidad adquiere es en la década de 1950 al sumarse el clerre de las citadas fábricas, la construcción del Pantano del bibro y la repoblación forestal decretada por el Gobierno de la Nación. En estas condiciones resulta perfectamente explicable que $1 a$ población de 1981 sea prácticamente la mitad de la existente a principios de siglo. Identica trayectoria observa Campóo de 
Suso, con la salvedad de que, desde 1900, todos los decenios se caracterizan por un saldo negativo, de escasa entidad en algunos de ellos, pero acusado en otros, como sucede en la década de 1950, en las pérdidas por emigración representan el 21,4 por 100 .

Campoo de Enmedio y Reinosa siguen una trayectoria similar, es decir, dos decenios de inmigración -1910 y 1920 y emigración más o menos intensa en el resto, que, por su vo lumen define la propia evolución de toda la comarca; una evolución cuyo resultado final, perceptible con nitidez en las fuentes estadisticas, y apreciable on la observacion directa, ha sido el acusado envejecimiento, aspecto que define, con cla ridad meridiana la estructura actual de la población campurria na.

3.- UN TIPO DE LNVEJECIMIENTO COMPLEJO: DIMINNSIUNES Y CONTRASTES ENPACIALES.

Quizá uno de los aspectos que más llame la atención sea el hecho de que en los últimos años parte de la comarca se esté despoblando paulatinamente, que estel pérdida de población se acompañe de un intenso envejecimiento, y que, ej. único núcleo que observa ligeros incrementos de población, Reinosa, muestra también una indudable marcha hacia el envejecimiento de la misma.

En parte el fenómeno es perfectamente explicable; en efecto, el estancamiento o los ligeros retrocesos en el total de población no se alcanza por causa de un incremento de la mortalidad, sino por emigración, una emigración en la que par ticipa el grupo de población joven, y que se traduce en un aumento relativo de las personas de edad avanzada, en un contex- 
to de continuo incremento de la esperanza de vida.

Pero, el aumento de la población do máa de 60 años en cifras absolutas, se acompaña también de un incremento en cifras relativas, toda vez que, otra de las consecuencias del éxodo será también el descenso de la natalidad, reduciéndose por esta causa el total de población de menos de 20 años considerablemente.

Este proceso de envejecimiento, en cierto modo complejo, hunde sus rafces en la dislocación de las estructuras demográ ficas que provoco la fuerte emigración posterior a 1950. Iras ella tiene lugar la reducción de la natalideld, que unida al descenso de la fecundidad incrementa las dimensiones del c1tado proceso.

$1950 \mathrm{es}$, con todo, un ano en el que, y tomando como referencia Reinosa, ya se dejan sentir alguno de esos efectos. El grupo de población senil representa un porcentaje del 11,1 por 100, muy lejos ya del 4,2 y 7,9 por 100 de los años 1860 y 1877. Sin duda entre aquél y éstos media todo un abismo on las condiciones de mortalidad y esperanza de vida; un raggo más del periodo de transición en el que se verá inmersa la po blación española, en general, a lo largo del presente siglo ( 37 ).

A pesar de todo, e incluso en unas condiciones de morta lidad tradicionales, el envejectmiento era, en alguno de los sectores de la comarca, notable. Asl parece demostralo el que Campoo de Yuso y de Suso tengan un porcentaje de población de más de 60 años superior al 10 por 100. Son sin duda, dos claros ejemplos de dislocación de las estructuras demográficas por causa de la emigración, en este caso de la emigración que podemos denominar tradicional y que, como ya hemos apuntado constitula un mecanismo de respuesta ante las frecuentes crlsis a las que se vela sometida la población.

(37) J. Nadal.- La población española (siglos XVI al XX). Ariel. Barcelona, 1973. Cfr. p. 

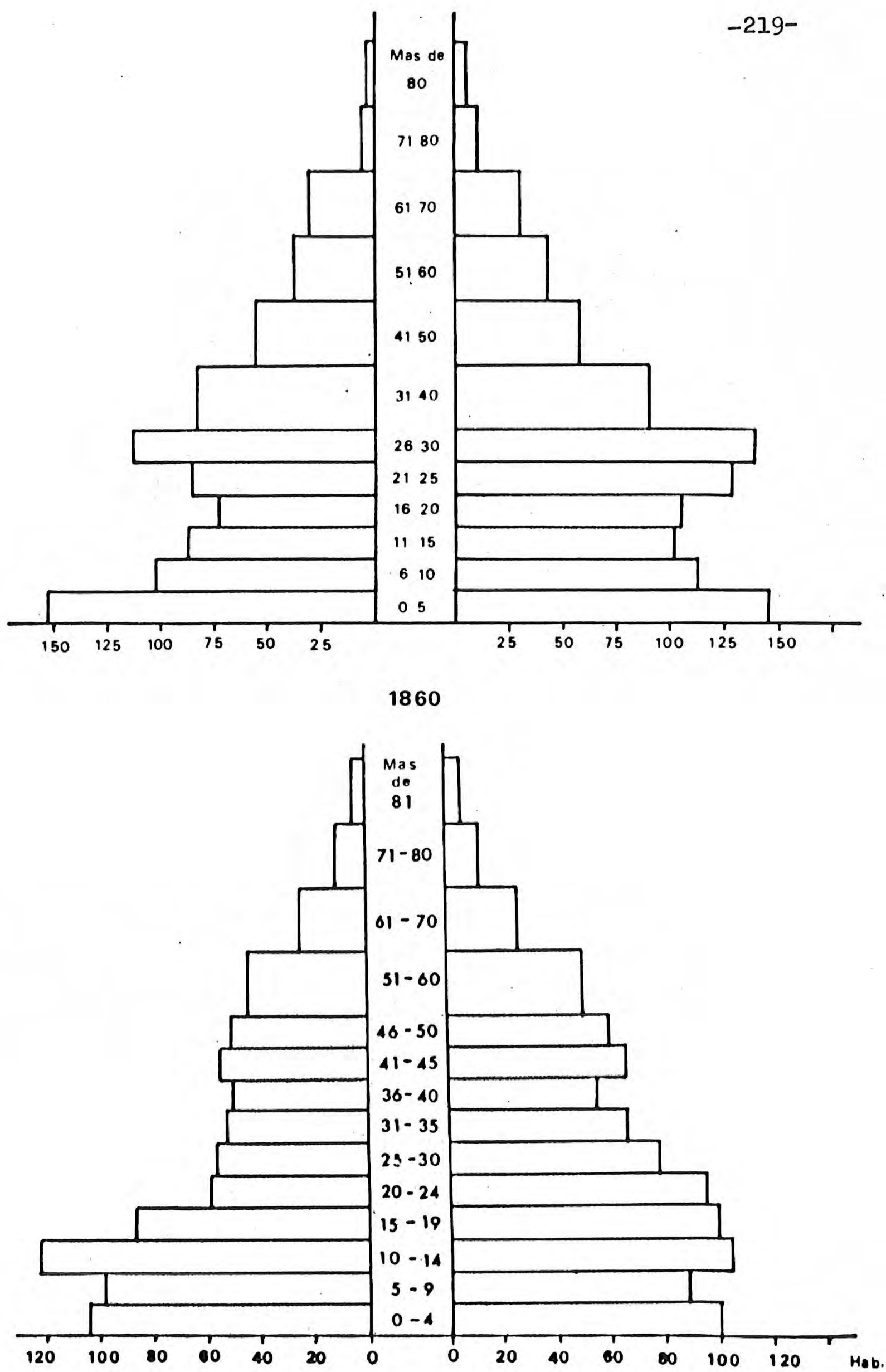

1877

Fig. 20.- La población de Camp6o en 1860 y $18^{\prime} 77$ 
IA PARTICIPACION RELATIVA DE LOS DISTINTOS GRUPOS DE EDAD EN CAMPOO.EN IA SEGUNDA MITAD DEL SIGLO XIX.

\begin{tabular}{|c|c|c|c|c|c|c|c|c|}
\hline \multirow{2}{*}{ ' } & \multicolumn{4}{|c|}{1860} & \multicolumn{4}{|c|}{1877} \\
\hline & $0-19$ & $20-40$ & $41-60$ & +60 & $0-19$ & $20-40$ & $41-60$ & +60 \\
\hline Campoo de & & & & & & & & \\
\hline $\begin{array}{l}\text { Suso } \\
\text { Campbo de }\end{array}$ & 34,2 & 39 & 16,9 & 9,9 & 38,7 & 28,6 & 22,3 & 10,4 \\
\hline $\begin{array}{l}\text { Yuso } \\
\text { Cumpoo de }\end{array}$ & 39,7 & 34,1 & $18,1$. & 8,1 & 36,2 & 27,4 & 25,9 & 10,5 \\
\hline Linmedio & 41,6 & 36 & 15,8 & 6,6 & 44,6 & 25,2 & 23,3 & 6,9 \\
\hline Reinosa & 41,8 & 37 & 17 & 4,2 & 42,9 & 32,3 & 18,9 & 5,9 \\
\hline TOTAL & 38,7 & & 3,4 & 7,2 & 41,4 & 50 & & 8,4 \\
\hline
\end{tabular}

Los efectos de este incipiente proceso de envejecimiento aparecen reflejados con cierta nitidez en la pirámide de población que hemos tomado como referencia, la del año 1860 . En ella se puede apreciar un acusado entrante entre los 6 y $10 s 21$ años. debido en parte,casi con toda seguridad, a la emigración dado que ésta, especialmente cuando tenla como punto de destino Amérlca, se realizaba desde fecha muy temprana. Las dimensiones de este accidente rompen el normal efecto de edad de la pirámide, que queda asf estrangulada en sus tramos medio e inferior.

Pero oi importante, on la conaideracion dol onvejoolmion to, es el peso relativo de la población de más de 60 años, una importancia no menor tiene el grupo de población adulta; y éste, que para el conjunto de la comarca es elevado en el mismo periodo que estamos analizando, 10 es aún más en Campbo de Yuso y Campbo de Suso -54 y 55,9 por 100 respectivamente-. Por esta causa, la estructura de la comarca no puede ser caracterizada como joven en su totalidad; el predominio corresponde a la población adulta, siendo bastante similar la proporción de adultos jovenes y de jovenes propiamente dichos. 


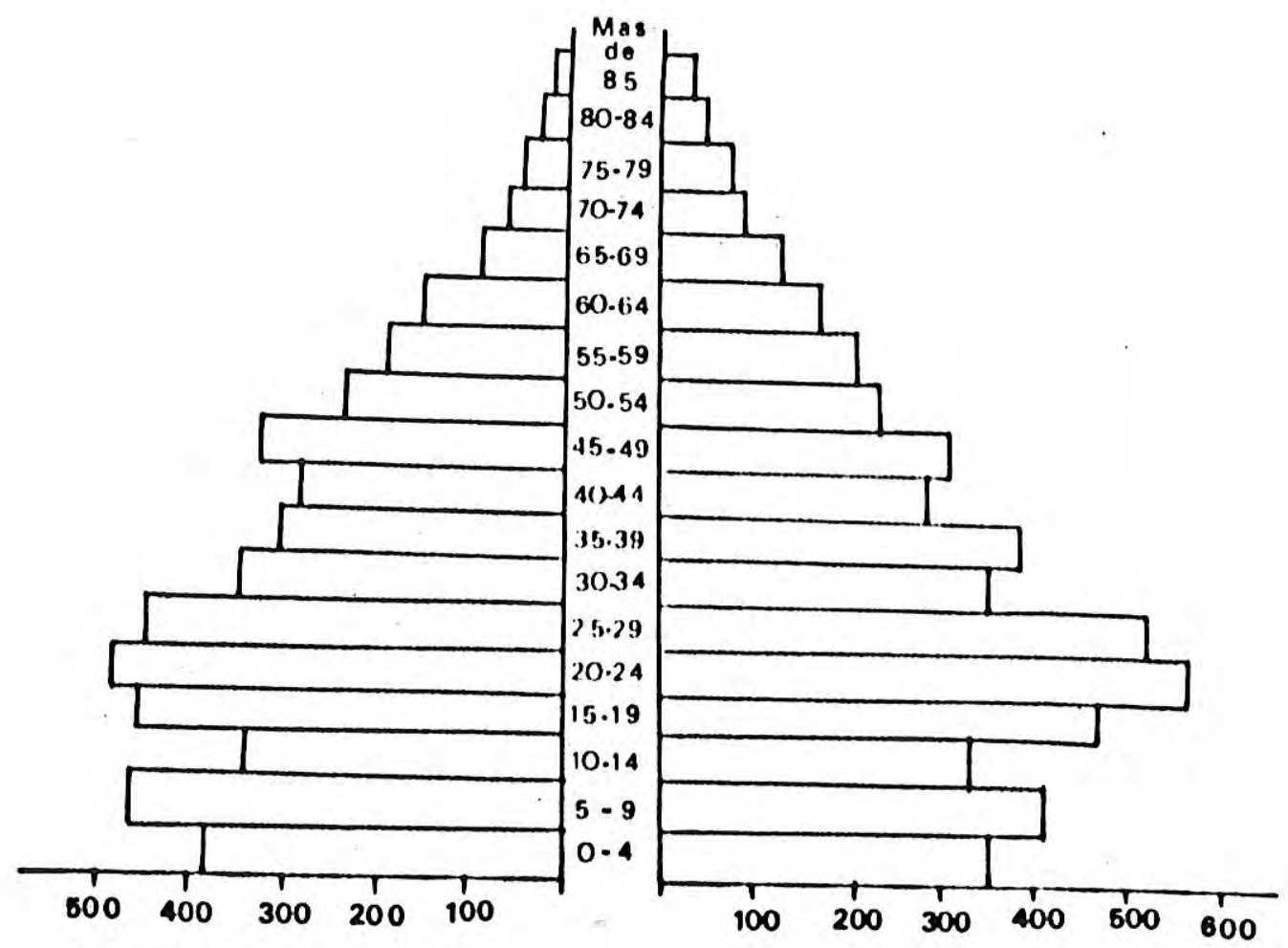

Reinosa 1950

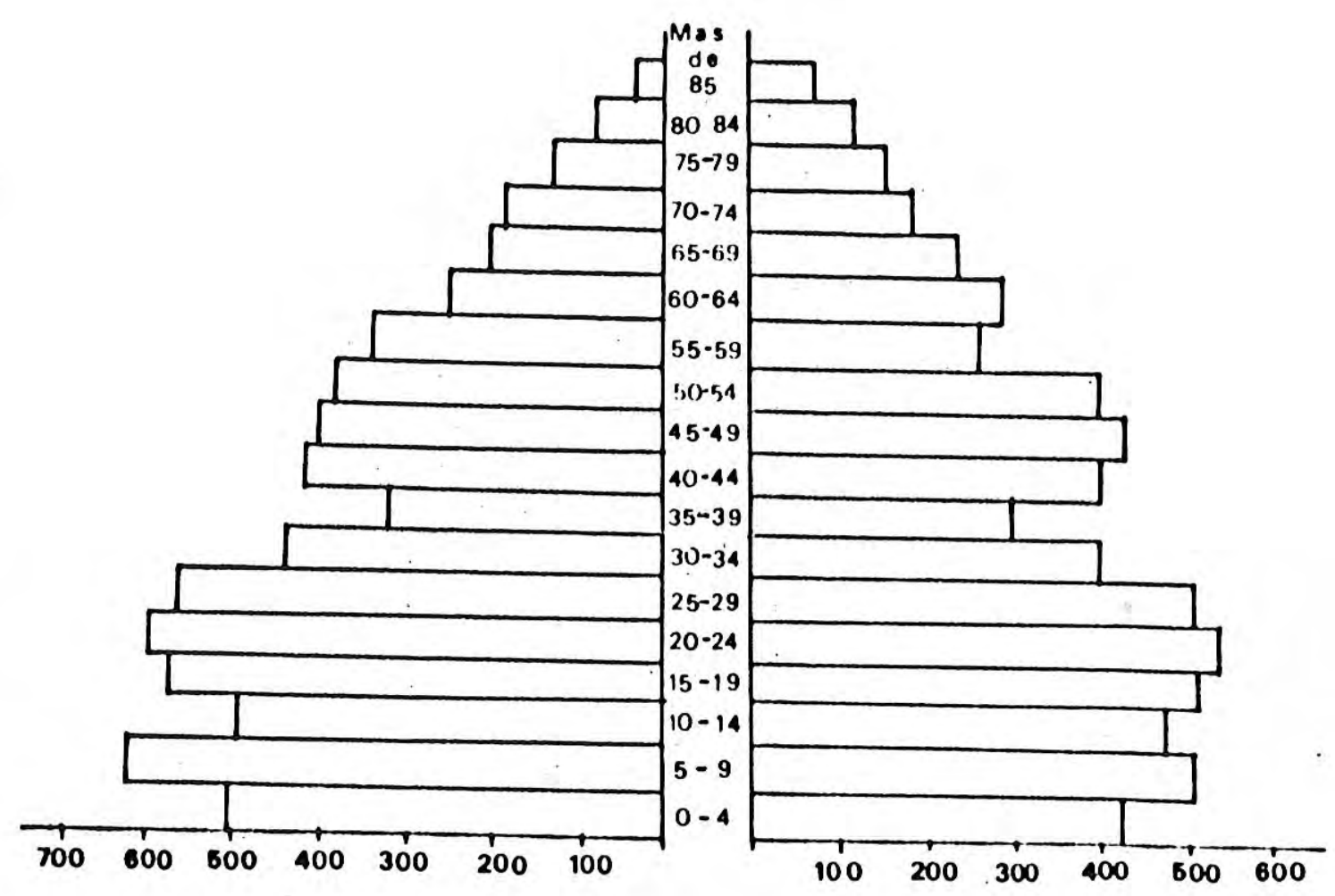

Reinosa 1975

Fig. 21.- La población de Reinosa. 1950 y 1975 
Desconocemos los rasgos que presenta la evolución de la estructura de la población en los primeros años del presente siglo, pero, en 1950 nos encontramos, en el caso de Reinosa con una estructura en clara progresión hacia el envejecimiento, no sólo porque el grupo de más de 60 años supere el 11 por 100, sino también por la importancia relativa del grupo de edad comprendido entre los 40 y los 59 años, que representa el 35,8 por 100.; aqui es donde se ha producido un verdadero cambio respecto a la estructura de la población docimonónica, un cambio que preludia lo que será un envejecimiento acusado en las próximas décadas.

La pirámide de Reinosa del mismo año muestra ya en su perfil los sintomas de envejecimiento que apuntamos; ha desaparecido el efecto de edad en la base, es decir, los tramos de edades no se presentan escalonadamente, suno que muy al contrario, penetran en la silueta dejando entever las dimen siones de la desnatalidad debida a la emigración. Globalmente considerada, la población de Reinosa aparece transformada en su estructura, apuntando firmes rasgos de modernidad demogrâ fica, que, bien es cierto le vienen dados por un acontecimien to adverso más que por propia evolución interna; y es que la emigración se ha vuelto a recrudecer trus el paréntesis de la década de 1920.

Es por ello significativo que tales rasgos de modernidad demográfica, localizados en la base de la pirámide, den como resultado indirecto una mayor modernidad en la cúspide, superior a la que por propia evolución en este momento le corres ponderla; dan lugar, en suma, a un envejecimiento.

Tal envejecimiento progresa con rapidez, no solo en Reinosa, sino también en el resto de los municipios, dado que, el éxodo rural, lejos de remitir en intensidad, se incremen ta en forma apreciable. Por ello, la población, en 1975 mues- 
tra ya una estructura muy envejecida. En Keinosa el porcentaje de población senil alcanza el 15,1 por 100, superando pues la convencional barrera del 12 por 100 , considerada como barrera o umbral del envejecimiento; lo mismo sucede en el re $\underline{\mathbf{g}}$ to de la comarca, incluso con mayor, y logica por otra parte, intensidad.

\section{CUADRO XXXIII}

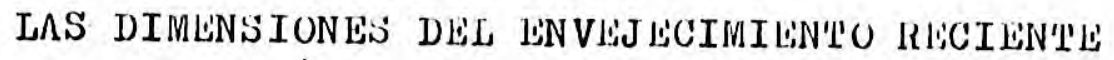
EN CALIPOO. 1975.

\begin{tabular}{|c|c|c|c|c|}
\hline & $0-19$ & $20-39$ & $40-59$ & más de 60 años \\
\hline Reinosa & 32,5 & 28,3 & 24,1 & 15,1 \\
\hline $\begin{array}{l}\text { Resto de la } \\
\text { Comarca }\end{array}$ & 31,2 & 20,7 & 28,7 & 19,4 \\
\hline Total & 31,8 & 24,5 & 26,5 & 17,2 \\
\hline
\end{tabular}

Fuente: Padrón Municipal de Habitantes 1975.

El envejecimiento es menos acusado en Reinosa que en el resto de la comarca, y no sólo porque el grupo de más de 60 años sea menos, sino porque la población de más de 40 afíos no alcanza el 40 por $100-39,2-$, mientras que en los municiplos restantes llega al 48,1 por 100 .

Pese a todo, el envejecimiento muestra unos caracteres que no son enteramente propios de una sociedad moderna. Én efec to, si en éstas el rasgo más sobresaliente es el elevado porcentaje de población comprendida entre los 20 y $10 s 59$ años, que puede estar próximo al 60 por 100, en Campóo el envejecimiento es en cierto modo anómalo, pero explicable si tenemos en cuenta las dimensiones de la emigración.

Por su causa, la pobación aparece estrángulada en las edades centrales de la vida, resaltando en forma desmesurada am bos extremos; el inferior, que se debate entre un malthusiani mo y una enteca recuperación, perceptible con cierta nitidez el 1981, y el superior, en diffcil equilibrio entre la muerte y la prolongación de la vida, equilibrio roto en parte en fa- 
vor de la primera, como demuestra el ligero incremento de las , tasas de mortalidad, pero sin, afortunadamente, la suficiente 'entidad para romper la estructura apuntada.

Por ello, todavia en la población de Campóo se segula acentuando el grado de envejecimiento, patente en la mayor acu mulación de efectivos entre los 20 y los 60 años, que alcanza el 51,8 por 100, as1 como en el grupo de más de 60 años, con un porcentaje de 19,8 por 100 ( 38 ).

Las pirámides de Campóo de 1975 y 1981 reflejan puntualmente los caracteres apuntados. En ellas sorprende la dimension que adquiere el proceso emigratorio, común a ambos sexos, si bien es más acusado en la población masculina. En la pirámide de 1975, el fenómeno, muy acusado en la comarca, aparece mit1gado en Reinosa, cuyos gráficos hemos individualizado con el fin de resaltar los contrastes existentes; en efecto, mientras en este núcleo la emigración aparece $\tan s \delta l o$ insinuada, en el xesto de la comarca, es la nota dominante. Ia emigración es especialmente notoria entre la población femenina joven, I6gico si tenemos en cuenta que las posibilidades de encontrar empleo en Reinosa son menores que para la población masculina, y ello obliga necesariamente a un desplazamiento en busca de mayores oportunidades. En 1981 en cambio, este accidente afecta a ambou sexos con una intensidad similar (Ver figura 22).

El resultado de esta intensa emigracion, sostenida on las últimas décadas, no puede ser otro que la despoblación; y es aqul donde se nos muestra la realidad del acusado desequilibrio en la distribución de la población campurriana.

(38) Conviene destacar que estos porcentajes corresponden tan s6lo a Campóo de Suso, Yuso y Enmedio. Cabe suponer que el núcleo de Reinosa mantendrá una estructura similar a la de 1975. 


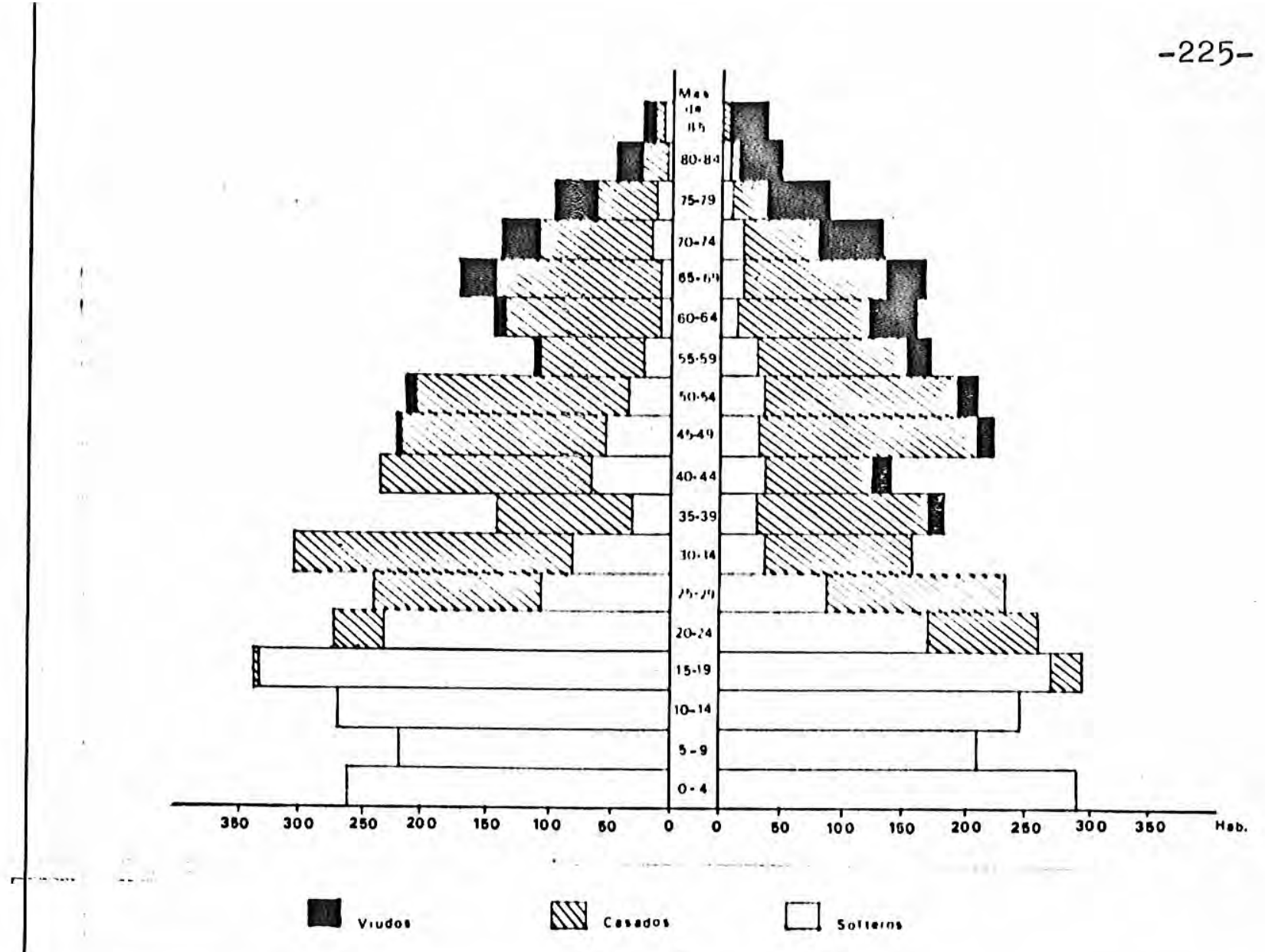

1975

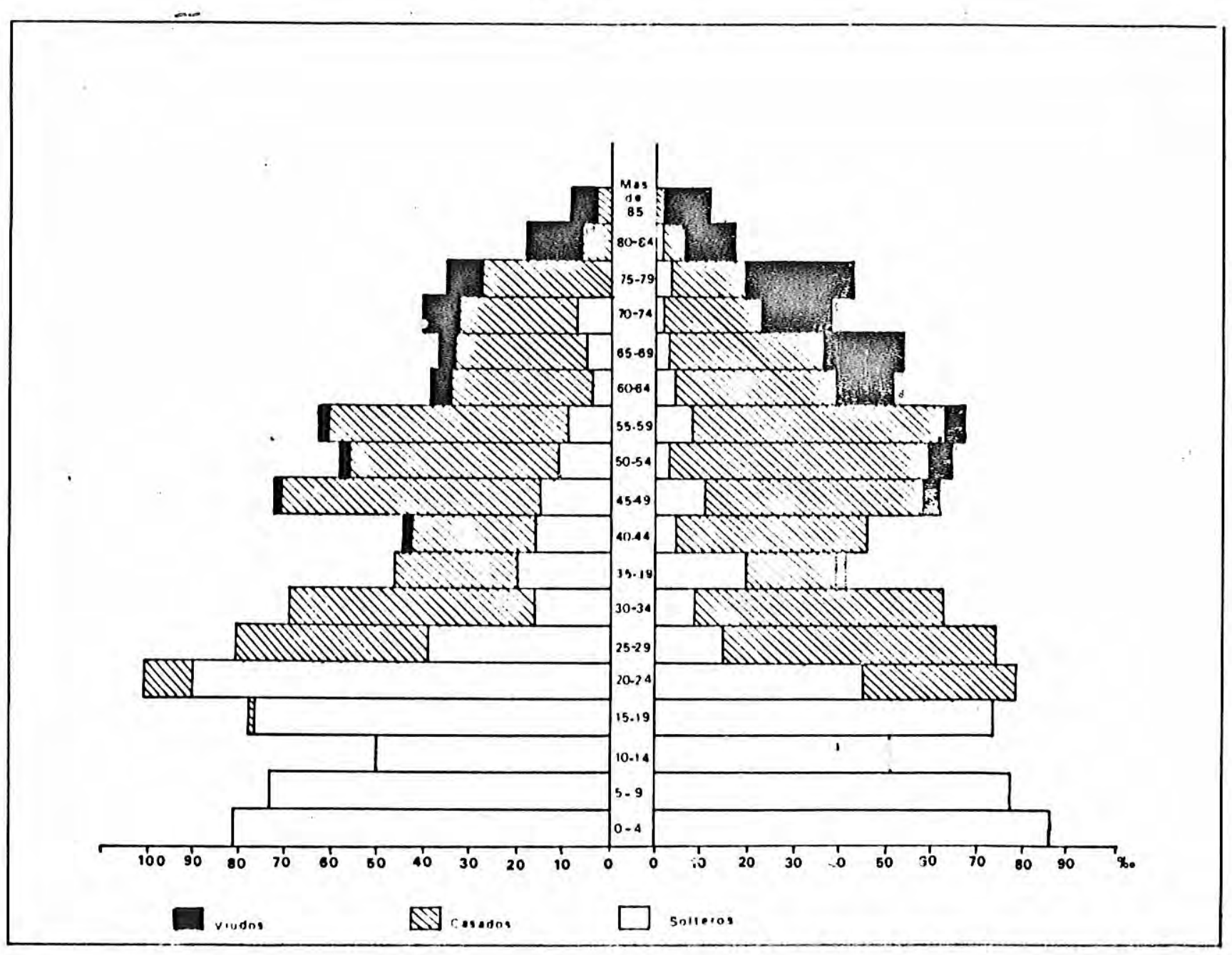


4.- IA DESPOBLACION: UNA CONSECUENCIA DE LA CONCENTRACION DE IA POBLACION EN EL NUCLEO DE REINOSA.

Desde 1920, y sin interrupción, en la comarca se asiste a una progresiva concentración de la población en Reinosa, en contraste con la progresiva pérdida de población de Campóo de Suso y Campbo de Yuso en particular.

Si que con ello queramos dar a entender que toda la poblacion emigrada de estos dos municipios lo haya hecho hacia Reinosa, este núcleo ha actuado como polo de atracción para una parte sustancial de ella, como ya habiamos apuntado.

Por ello, el aumento de la densidad de población de la comarca en general se debe a la participación de Reinosa; sin ella, la tendencia es claramente regresiva ( 39 ). Pese a todo el incremento ha sido notable, puesto que de 23,2 habitantes por kilbmetro cuadrado, se ha pasado a 50,1 en 1981.

Por encima de todo ello, lo que verdaderamente tijene un significado espacial es el grado de concentración de la población, y en este orden de cosas lo primero que destaca es la polarización de una parte sustancial de la misma en un sólo núcleo, Reinosa. Este, en 1981,tenfa el 64,8 por 100 de toda la población de la comarca. En contraste, Campóo de Suso y Campóo de Yuso han perdido prácticamente la mitad de sus efectivos desde principios de siglo, acentuando aún más el fenómeno. De este modo, la singuralidad de Reinosa resulta, tanto de su pro pio crecimiento, como de la pérdida de población del resto de la comarca.

( 39 ) Campóo de Suso pas6 de una densidad de 9,2 $\mathrm{Hab} / \mathrm{Km}^{2}$ a principios de siglo, a 9,2 en 1981; lo mismo podemos decir de Campóo de Yuso, que de 17,3 Hab. / $\mathrm{K}^{2}{ }^{2}$ paso , en 1981 a $11 \mathrm{Hab}, / \mathrm{Km}^{2}$. En Reinosa y Campó de Enmedio, la tendencia ha sido inversa, de mayores proporciones en el primer caso que en el segundo; Reinosa pars, en efecto de una densidad de $720 \mathrm{H} / \mathrm{Km}^{2}$
en 1877 a $3242 \mathrm{H} / \mathrm{Km}_{2}$ en 1981 , hecho que se explica por la in-
tensa inmigracion tensa inmigración del primer tercio de $3 i g l o$, como por la reducida extensión de su término Municipal $\left(4,11 \mathrm{Km}^{2}{ }^{2}\right)$. 


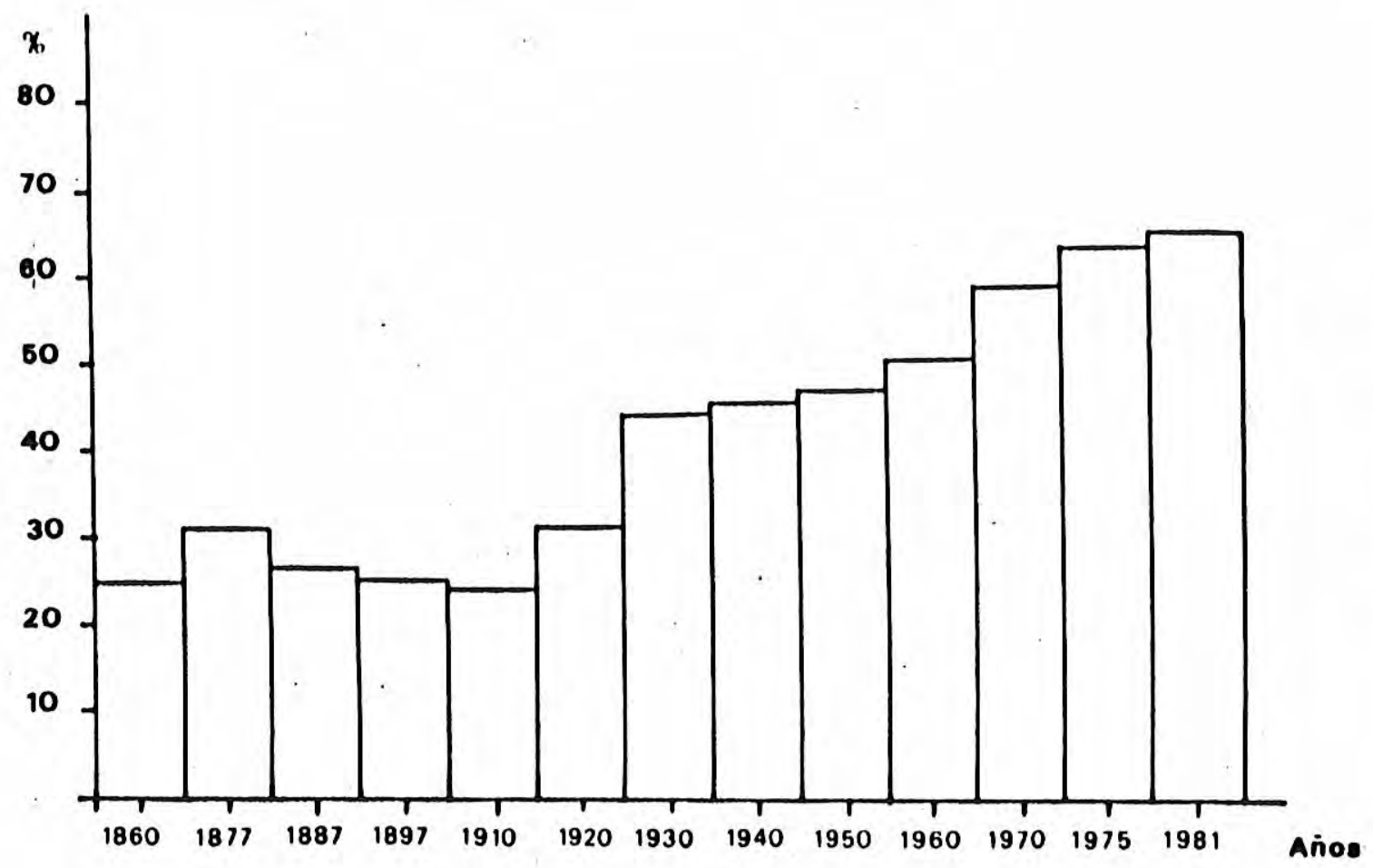

Fig. 23.- La participación de Reinosa en la población totul de la comarca. 1860-1981.

Todo este proceso de concentración de la poblactón se enmarca dentro de otro de mayores dimensiones, que representa el cambio de las estructuras sociales y económicas en toda $l_{a}$ comarca. El envejecimiento, el desfase de las rentas agrarias frente a las industriales, la consolidación de un tipo de actividad complejo -la agricultura a tiempo parcial-, el abandono de numerosas explotaciones marginales y la concentración de las que subsisten, en busca de una mayor rentabilidad de la que no es ajena la reciente e intensa mecanización, son causa $y$ consecuencia, a la vez, de un proceso de cambio complejo, en el que los hechos aparecen imbricados para dar lugar a una sustan cial transformación del espacio agrario, y por ende del pairaje agrario de la comarca de Campó. 
IV PARTE

UN ESTACIO AGRARIO EN PROCESO DE INTENSA TRANSFORMACIUN 
E1 paso de una economla de subsistencia a una economfa de signo más moderno, basada en la explotación ganadera ha si do lento, y como hemos apuntado, plagado de dificultades, hag ta un punto tal que, el citado cambio aparece contenido duran te bastantes décadas, prácticamente hasta 1960.

Ni siquiera la consolidación de Reinosa como centro industrial fue capaz de acelerar estos cambios, que, hasta la mital del presente siglo sólo aparecen esbozados. Para que co miencen a dejarse sentir, para que el espacio agrario se trang forme y surja un nuevo paisaje agrarto ha sido preciso el con curso de varios hechos, inmersos en la propia dinámica de cam bio de la estructura económica española.

En efecto, la contención del éxodo rural tradicional, de hondas resonancias en la comarca, durante dos décadas consecutivas -1910 y 1920-, apenas fue suficiente para impulaar el cambio. La realidad, como ya hemos apuntado, es que el papel. del éxodo deberla ser puesto en cuestión, puesto que, su parcial eliminación, lejos de inscribirse en una mejora de las condiciones económicas de la comarca, fue más bien el resultado de una incipiente industrialización de Reinosa; por ello, una vez pasados los primeros años de supuesta euforia economica, entrará en crlsis una situación, de hecho insostenible 
para una gran parte del campesinado. La causa se encuentra, sin duda, en que, aquellos que dejaron de incorporarse a la tradicional corriente emigratoria, por via de la ocupación en las primeras industrias de Reinosa, no abandonaron su explotación agraria, por lo que la estructura de la propiedad $y$ de las explotaciones permanecio inalterada.

En cambio, años más tarde, cuando las posibilidades de encontrar empleo fuera de la comarca sean mayores, tras el Plan de Estabilización de 1959, aquellos que hablan permanecido al frente de las pequeñas explotaciones tradicioneles, intcian un éxodo, que, en conjunto adquiere ciertas proporciones; no podia ser de otra forma ante el constante deterio ro de las rentas agrarias frente a las rentas industriales, $y$ obviamente, frente a las de aquellos que, conservando su explotación agraria famlliar, se hablan incorporado al traba jo asalariado en la industria.

Tras esta emigración se abrirán ciertas espectativas de cambio para los que, pese a todo, permanecieron en la comarca. En parte, estos cambios se hicieron realidad porque se pudo incrementar, de modo somero, el tamaho de la explotacion agra ria, bien por medio de la compra o más frecuentemente del arrendamiento de las tierras de los que hablan emigrado; a rala de este incremento se pudo, paulatinamente, proceder a una ra cionalización de la explotación.

Las condiciones en las que se llevó a cabo la moderniza cion de las explotaciones agrarias, se vieron favorecidas por el deterioro de los sistemas de aprovechamiento, en régimen extensivo del terrazgo cultivado; esta decadencia hay que atribuirsela al cambio de significado de las nuevas explotacio nes, que de basarse en la subsistencia, pasarán a tener como fin primordial la explotación ganadera. Por ello, la tradicio nal "competencia" entre la alimentación del ganado y la alimen 
tación humana, se resuelve en favor dela primera; el aprovechamiento del terrazgo no tendrá ya como fin la alimentación humana, sino la alimentación del ganado, del que se obtendrán los mayores y en ocasiones los únicos ingresos.

La mecanización será por ello una respuesta inevitable para aquellos que obtienen sus rentas solo de la explotacion agraria, y para los que a éstas añaden las obtenidas en la in dustria de Reinosa. Los primeros podrán incrementar el volumen de ingresos en metálico y los segundos lograrán, cuando menos, mantener la pequera explotación con una acumulación de trabajo reducida, la que les permite lo que consideran,en todos los casos, su ocupación principals la industria.

No obstante, el lastre del pasado es de una entidad tal, que no todo el espacio comarcal se ha modificado, y cuando lo ha hecho, ha sido sorteando no pocos obstáculos. Uno de ellos es el que presenta la estructura de la propiedad; en ella los cambios han sido tan insignificantes, que se sigue manteniendo la enorme distancia entre una pequeña y una gran propiedad de tipo colectivo, en la que, el sentido y significado del aprovechamiento, han variado sustancialmente. De ella, y de mo do indirecto, partirán algunt de las transformaciones en la orientación economica de la expjotación agraria.

Las restricciones impuestas al aprovechaniento de esta propiedad colectiva, no por parte de sus propieterios - los concejos, ayuntamientos o Hermandades- sino por parte del Ea tado desde principios de siglo, harán completamente inviable el sostenimiento de una ganaderla en regimen extensivo, y en ocasiones, cuando no se poselan tierras, ni medios para arren darlas no se pudo, ni siquiera mantener una explotacion ganadera de signo diferente.

La evolución de este proceso ha sido, empero, desigual; y de esta misma desigualdad arrancan buena parte de las diferen 
cias que todavia hoy son perceptibles en el paisaje agrario de la comarca.

En la base de gran parte de estas transformaciones hay que situar, sin duda, la peculiar e intensa atracción ejercida por el núcleo de Reinosa, una atracción que si bien tiene su origen en un pasado remoto al ser cabeza de la Merindad de Campó primero y del Partido Judicial que lleva su nombre des pués, adquiere ciertas proporciones a causa de su pronta conso lidación como un centro de servicios y lugar de intercambio de los pequeños excedentes agrarios, imprescindibles en la economla de subsistencia tradicional.

Este carácter se ha conservado y acentuado en los ultimos años; se ha diversificado la oferta de servicios, sin dum da como resultado de una intensa concentración de la demanda en el propio núcleo, y ha adquirido por todo ello una serie de rasgos, de atributos urbanos, aunque estos tan sollo estén esbozados.

La incidencia de todo ello ha servido para modificar pro fundamente los modos de vida de una gran parte de la población campurriana, que poco o nada tienen ya que ver con los tradicio nales. También se han modificado los sistemas de aprovechamiento del espacio agrario tradicionales, que exigfan una atención continua y una intensa acumulación de trabajo; la mecanización se ha generalizado, incluso sobrepasando las necesidades reales de una parte de las explotaciones, algunas de las cuales conser van todavía, inercia del pasado, profundos rasgos de arcalsmo, pero éstas son las menos, y frecuentemente no son más que un mero complemento, bien sea a las pensiones de jubilacion o bien a las rentas obtenidas en el desempeño de una profesion, al mar gen de la agricultura, en Reinosa.

La rápida transformación en todos los ordenes, es por ello el rasgo distintivo de las últimas décadas; una transformación que, por lo que respecta al paisaje agrario arranca de la incli- 
nación definitiva por la opción ganadera, no basada ya en una agricultura de subsistencia,al estar todo subordinado a la ex plotación de una ganaderla de rasgos modernos, especializada bien sea en la producción de leche o en la cría de reses con destino al sacrificio, y sin perjuicio de que, on una porcion minúscula se sigan realizando cultivos de subsistencia, desti nados al consumo familiar.

El punto de partida, el condicionante estructural de ma yor arraigo es, sin duda, la estructura de la propiedad; desde ella, y pese a su acusado arcalsmo se han tenido que acometer las recientes transformaciones en la estructura económica de la comarca. 
CAPI'IUIOO XIII

UNA TRANSFORMACION INCONCLUSA: LOS OBSTACULUS INSTITUCIUNALES.

En el momento en que en la comarca se dejan sentir algu nos sintomas de cambio, comienzan a aflorar los obstáculos que, tradicionalmente, se hablan opuesto al mismo. El afán de modificar, para adaptar el espacio agrario a las necesidades de la nueva explotación, tropezará con une estructura de la propiedad arcalca, en la que, un número muy elevado de propietarios se reparten un exiguo terrazgo. Ni las soluciones que tradicio nalmente se hablan adoptado -aprovechamiento colectivo, roturaciones etc...- servirán ahora, porque la nueva explotación agraria nace como resultado de iniciativas individuales y por ende diferenciadas entre si, y porque sus neceridades se avenfan mal con los sistemas colectivos tradicionales de aprovechamiento del espacio agrario.

Pese a todo,las minúsculas explotaciones, lejos de decaer, de desaparecer o de reconvertirse a causa de su escasa rentabilidad, siguen siendo la nota dominante en determinados sectores de la comarca-Campbo de Suso en particular-, dado que 
están concebidas como un nero complemento de otras actividades; no deja de ser significativo que, al menos el 50 por 100 de los 'titulares de ellas tengan otra ocupación que consideran principal.

A este obstáculo de carácter institucional habrla que añadir la enorme resistencia al cambio que ofrecen determinadas prácticas de aprovechamiento colectivo del espacio agrario, pa ra poder comprender el alcance de los cambios recientes en la comarca; unos cambios que hemos de considerar inconclusos, no sólo porque se hayan comenzado a dejar sentir recientemente, sino también porque los obstáculos a superar son muy numerosos $y$, como sucede con la estructura de la propiedad,tienen dificil solución, al menos por el momento.

\section{1.- UNA ESTRUCTURA DE IA PRUPIEDAD ARCAICA.}

La comarca de Campó conserva, sin apenas variación, una estructura de la propiedad tradicional, con fuertas rasgos de arcalsmo, resultado no solo de una configuración compleja en el tiempo, sino también de la extraordinaria pervivencia de unas formas de aprovechamiento del espacio agrario complejas o cuando menos, peculiares.

En principio, podemos afirmar que no existe una gradación, un escalonamiento en los umbrales de propiedad, desdo el mayor al menor o a la inversa; la propiedad se concentra en dos polos opuestos, pero complementarios, al menos en el contexto de la actividad agraria tradicionals una muy pequeña propiedad individual y una gran propiedad comunal que, exclufda de la desamor tización decimonónica ha llegado hasta nuestros dlas práctica- 
mente sin sufrir alteracion alguna. Y esta estructura apenas ha variado desde mediados del siglo XVIII; se puede haber pro ducido alguna concentracion en los tramos inferior o medio de la misma, pero ello no la ha alterado en absoluto. En efecto, en un 70 por 100 sigue siendo propiedad colectiva, y el resto propiedad privada.

La primera, aparece concentrada, mientras que en la segunda predomina la más absoluta dispersión; las propiedades de las Juntas Vecinales y Ayuntamientos -en su mayor parte conformadas por montes y ejidos de tradicional aprovechamiento colectivo, están, por lo general agrupadas, individualizadas entre si, pero ocupando de modo invariable los sectores más elevados de los valles, mientras que la propiedad individual, privada, se localiza en el fondo de los mismos y arranque de las laderas, estando dividida en un sinfín de minúscu las parcelas que dificultan su aprovechamiento, precisamente por su reducidlsimo tamaño - entre 10 y 20 áreas de media- y por los problemas de acceso a las mismas -servidumbres de pa so etc..... Un rasgo de indudable arcalsmo, que no encuentra fácil solución, que no aparece paliado ni siquiera por el recurso al arrendamiento $u$ otros reglmenes de tenoncia, vuesto que sollo el 18 por 100 de la superficie se encuentra arrendada. Ello supone que, numerosas explotaciones están basadas en una mnúscula propidad, siendo por esta causa claramente marqi nales, al menos en las condiciones actuales, porque lo cierto es que, tradicionalmente, han tenido su razon de ser en funcion de las espectativas creadas sobre tierras de propledad comunal; en efecto, en ellas se mantenfa al ganado, especialmente al vacuno de raza autbctona, del que obtenfa una parte sustancial de los ingresos.

Las tierras del fondo de los valles, ya fuesen propias - arrendadas, servian para asegurar la subsistencia, estando 
su aprovechamiento organizado y condicionado por las necesidades de la ganaderia.

\section{CUADRO XXXIV}

IA ESTRUCTURA DE LA PROPIEDAD EN CAMPOO.

\begin{tabular}{|c|c|c|c|c|}
\hline Tipo de propietario & $\begin{array}{l}\text { Número de } \\
\text { Propieterios }\end{array}$ & $\%$ & $\begin{array}{l}\text { Hectáreas } \\
\text { que ocuna }\end{array}$ & $\%$ \\
\hline $\begin{array}{l}0-5 \text { Has. } \\
5-10 " \\
10-15 "\end{array}$ & $\begin{array}{r}4.561 \\
187 \\
30\end{array}$ & $\begin{array}{r}94,04 \\
3,85 \\
0,61\end{array}$ & $\begin{array}{r}4.936,1 \\
1.272,6 \\
341,2\end{array}$ & $\begin{array}{r}13,74 \\
3.54 \\
0,94\end{array}$ \\
\hline Total 0-15 Has ..... & 4,778 & 98,50 & $6.549,9$ & 18,22 \\
\hline $\begin{array}{l}15-20 \text { Has. } \\
20-30 " " \\
30-40 "\end{array}$ & $\begin{array}{l}7 \\
6 \\
3\end{array}$ & $\begin{array}{l}0,14 \\
0,12 \\
0,06\end{array}$ & $\begin{array}{l}130,9 \\
130,1 \\
109,2\end{array}$ & $\begin{array}{l}0,36 \\
0,36 \\
0,30\end{array}$ \\
\hline Total 15-40 Has. .... & 16 & 0,32 & 370,2 & 1,02 \\
\hline $\begin{array}{l}40-50 \text { Has. } \\
50-100 " \\
100-150 "\end{array}$ & $\begin{array}{l}2 \\
7 \\
7\end{array}$ & $\begin{array}{l}0,04 \\
0,14 \\
0,14\end{array}$ & $\begin{array}{r}89,6 \\
517,7 \\
894,4\end{array}$ & $\begin{array}{l}0,24 \\
1,44 \\
2,48\end{array}$ \\
\hline Total 40-150 Has. ... & 16 & 0,32 & $1.501,7$ & 4,16 \\
\hline $\begin{array}{l}150-200 \text { Has. } \\
200-300 " \\
300-500 " \\
500-1000 " \\
\text { Más de } 1000 \text { Has. }\end{array}$ & $\begin{array}{r}1 \\
9 \\
17 \\
11 \\
2\end{array}$ & $\begin{array}{l}0,02 \\
0,18 \\
0,40 \\
0,22 \\
0,04\end{array}$ & $\begin{array}{r}185,5 \\
2,605,7 \\
6.733,5 \\
7.970,6 \\
10.007,2\end{array}$ & $\begin{array}{r}0,51 \\
7,25 \\
18,74 \\
22,18 \\
27,92\end{array}$ \\
\hline Total más de 150 Ha.s.. & 40 & 0,86 & $27.502,5$ & 76,60 \\
\hline TOTAL & 4.850 & 100,00 & $35.924,3$ & 100,00 \\
\hline
\end{tabular}

Obviamente, si se ha mantenido la propiedad invariada, con el mismo carácter ha permanecido el aprovechamiento del espacio agrario hasta que, por causa del cambio de razas intro ducido en el ganado vacuno, se hizo preciso llevar a cabo uno. transformacion en él sobre la base de una propiedad anclada en el pasado; prueba de ello es que, la tajante separación entre ambos tipos de propiedad se mantiene y actúa como obstáculo a cualquier intento de transformación. 
a/ El pequeño propietario: un elemento básico en la sociedad rural.

Atributo de otros sectorea de la montaña Cantábrica, la pequeña propiedad alcanza en Campoo tales dimensiones que, si bien su significado en el contexto de la actividad agraria ac tual es muy limitado, justifica en si misma la atención que le vamos a prestar. No en vano, más del 98 por 100 de los propie tarios tienen menos de 15 Has., y de estos, el 97 por 100 no alcanzaba glquiera las 5 Has.

Pero los hechos no son tan sencillos como a primera vig ta pudiera parecer. En efecto, este elevado contingente de pro pietarios se reparten $\tan$ s $b l o$ el 13,7 por 100 de la superficie del espacio comarcal, lo que acentúa la exiguiedad de este tipo de propiedades.

Tomando como ejemplo uno de los municipios de la comarca, Campbo de Enmedio, se puede tipificar el carácter que presenta esta pequeña propiedad en el conjunto de la misma, en la que, podemos avenzar que $1 \mathrm{Ha}$. se considera como una propiedad "decente" según testimonios recogidos en distintos sectores, y que muchas son las explotaciones que superan en poco tal. superficie o incluso no llegan a ella. No puede por ello sorprender, aunque ciertamente sea sorprendente,que por debajo del umbral de las $5 \mathrm{Has}$. el predominto corresponda a aquellos pro pietarios con menos de media Ha. -el 43,8 por 100-. Cierto es que el Catastro presenta grandes deficiencias, y que su análisis debe ser realizado con numerosas salvedades por causa de su escaslsima adecuación a la realidad, pero es un indicador, el único de que disponemos, próximo, que no fiel, a la realidad. En cambio, lo aue si es real, lo que tiene vigencia son los obstáculos que esta pequeña y fragmentada propiedad interpone en el aprovechamiento racional del espacio agrario. De ahf que sea preciso tenerla en cuenta para comprender el sig 
nificado de la explotación agraria actual.'

\section{CUADRO XXXV}

ESTRUCTURA DE LA PROPIEDAD EN CAMPOO DE LENMEUIO: PRUPIETARIOS CON NENOS DE 5 HECTAREAS.

\begin{tabular}{|c|c|c|c|c|}
\hline Tino de nronietario & $\begin{array}{l}\text { Número de } \\
\text { nropietarios }\end{array}$ & $\begin{array}{l}\% \\
\text { Total }\end{array}$ & $\begin{array}{l}\text { Hectáreas } \\
\text { que ocupn }\end{array}$ & $\begin{array}{c}\% \\
\text { Total }\end{array}$ \\
\hline $\begin{array}{l}\text { Menos de } 0,5 \text { Has.... } \\
0,5-1 \text { Ha. } \\
1-2 \text { Has. } \\
2-3 \text { " } \\
3-4 \text { " } \\
4-5 \text { " }\end{array}$ & $\begin{array}{r}760 \\
355 \\
305 \\
126 \\
72 \\
39\end{array}$ & $\begin{array}{r}43,80 \\
20,46 \\
17,59 \\
7,26 \\
4,15 \\
2,24\end{array}$ & $\begin{array}{l}183,16 \\
240,34 \\
455,99 \\
289,09 \\
246,09 \\
172,85\end{array}$ & $\begin{array}{l}2,39 \\
2,83 \\
5,74 \\
3,77 \\
2,95 \\
3,40\end{array}$ \\
\hline Total 0-5 Has...... & 1.657 & 95,50 & $1.759,52$ & 21,13 \\
\hline
\end{tabular}

Fuente: Catastro de Rúatica.

Idénticos caracteres a los anteriormente apuntados presenta el resto de los municipios. En Campoo de suso, los propie tarios de menos de media Ha. representan el 37 por 100 del total, y en Campoo de Yuso, con concentración parcelaria incluida, este grupo supone un 44 por 100 de los propietarios. Ello puede dar idea suficiente de las dimensiones que alcanza la pe. queña propiedad, aunque como hablamos apuntado se trata en bue na medida de una propiedad ficticia (1).

En contraste con ella apenas existe propiedad de tipo medio; 16 propietarios -el 0,3 por 100- tenfan entre 15 y 40 Hectáreas, y por encima de este umbral se confunden ya propie dades individuales aisladas con la propiedad colectiva.

La importancia dentro del terrazgo de la pequeña propie

( 1 ) En el pormenorizado y laborioso análisis que hemos realizado del Catastro pudimos apreciar que, dispuestas en orden coorelativo, el corespondiente a su ordenación alfabética, ana recian pequeñas propiedades de varios hermanos, vurios de los cuales han emigrado, cediendo sus propiedades a los que se que dan en la comarca a cambio de algún tipo de compensación. 
dad es indudable; el 13,7 por 100 de la superficie de la comar ca está repartido entre propietarios de menos de 5 hectáreas. De ésta, el 1,3 por 100 se distribuye entre los que tienen menos de media Hectárea, que representan el 42,1 por 100 de los propietarios de: la comarca. La media de estas propiedades es de aproximadamente 0,23 hectáreas, un "carro de hierba" en el sistema de medidas tradicional.

Como es logico suponer, y por mucho que se completasen estas propiedades con el aprovechamiento de la propiedad comunal, estas minúsculas heredades no constituyen explotacion; son el resultado de múltiples repartos que tradicionalmente se han ido acumulando hasta configurar la estructura actual. En muchos casos, estas pequefas propiedades se integran, sin más en una unidad mayor cuando pertenecen a la misma familia, parte de cuyos miembros han emigrado, puesto que el cambio de titularidad y los elevados impuestos que hay que satisfacer en concepto de transmisión patrimonial dan lugar a que la estruc tura de la propiedad permanezca inalterada, sea irreal en suma.

Pese a todo no deja de tener significado en la configura ción y estructura del terrazgo por los problemas que de ella se derivan; además de pequeñas, se trata de fincas dispersas, muy alejadar entre si, y con un notable número de servidumbres que dificultan cualquier aprovechamiento de las mismis diferen te al tradicional. All1 donde se conservan éstas intactas o poco modificadas, es donde menos ha cambiado la orientación económica de las explotaciones. En efecto, las derrotas de mie. sea, servidumbres de paso y otras prácticas o limitaciones, impiden llevar a cabo un aprovechamiento individual, desgają do del conjunto, salvo en aquellos casos en los que se ha lle vado a cabo una ordenación planificada, no exenta de dificu]. tades en su puesta en práctica. 
Pero si ni por su extensión ni por su valor económico estas propiedades tienen significado, juegan en cambio un pa pel de enorme importancia en la organización de las explotaciones agrarias en la actualidad. Su enorme parcelación -pro piedades de menos de media hectérea se encuentran divididas hasta en más de 3 o 4 parcelas-, su dispersión dentro del te rrazgo, y su inserción entre propiedades de mayor tamaño supone un serio obstáculo para llevar a cabo una racionalizacion de las explotaciones. Una muestra la ofrece el plano par celario de Monegro que incluímos más adelante (ver figura 24). En ell podemos apreciar, entre otros aspectos como el tortuoso trazado de los caminos "camberas" que comunican las distintas parcelas, y los apretados conjuntos que forman algunas de ellas; no es por ello extrafo que el problema de las servidumbres de paso cree no pocas dificultades a la hora de modernizar las explotaciones tradicionales.

En un orden superior, tienen también cierto significado las propiedades de 5 a 10 hectáreas, tanto porque son relati vamente numerosas, si bien muy lejos de las anteriores, como porque de ellars se pasa, casi sin solución de continuidad a la propiedad colectiva. Representan el 3,9 por lou, y agrupan el 4,5 por 100 de la superficie comarcal (ver cuadro XXXIV).

Adaptadas todas ellas a un regimen de explotación ganade ra en regimen extensivo, precisaban contar con una superficie suficientemente extensa, base o complemento de la misma. Y esta superficie era y es la de la propiedad concejil.

b/ La gran propiedad colectiva: el contrapunto a la exigủedad $\geq$ fragmentación de la pequeira propiedad.

La propiedad colectiva, que en la comarca corresponde, en la práctica totalidad, a la gran propiedad, se encuentra adscrita a entidades concejiles. Su significado economico ha sido 
-lo es menos en la actualidad- nada despreciable, y no sólo , porque su aprovechamiento fuese colectivo, sino también porque las pequeñas parcelas que los concejos poselan dentro del terrazgo, repartidas entre los vecinos $y$ aprovechadas en forma individual permitieron sobrevivir a no pocos de ellos hasta de optaron por la emigracion. Esta propiedad, representa algo más del 6 por 100 del terrazgo.

Desconocemos, por falta de documentación suficiente, el porqué estas tierras propiedad de los concejos salieron airo sas del proceso desamortizador. Los expedientes posteriores a 1855 muestran que, en efecto, el número de fincas vendidas fue realmente insignificante. Wuiza la causa se encuentre en que se trataba, en numerosos casos, de tierras marginales, localiza das en forma dispersa en el arranque de las laderas, en secto res poco accesibles y sometidas por ello a no pocas servidumbres. Podian resultar atractivas para los nequeños campesinos, pero éstos, probablemente no dispusiesen de medios para adquirirlas; para los mayores propietarios y burguesla reinosanos no eran atractivas por su enorme dispersión, amén de por la escasa calidad de las mismas, muchas de ellas resultado de las tradicionales roturaciones del monte.

En la actualidad, prácticamente todas las junters vecina les tienen propiedades de este tipo, que arriendan a los vecí nos para su aprovechamiento, porque sabido es que, abandonadas durante un cierto tiempo son presa fácil del matorral a partir del que, muy lentamente se reconstruiria el monte.

Por ser suficientemente expresiva de este tipo de propiedad, reproducimos la estructura que presenta la propiedad de la Junta vecinal de Celada-Marlantes; en ella se puede apre olar como, la inmensa mayorla de ésta está constitulda por monte alto y bajo -el 93,3 por 100-correspondiendo el resto a los prados, tierras y eriales a pastos; esta superficie se encuentra sumamente fragmentada, no siendo por ello muy difenen 
te su estructura a la de la pequeña propiedad.

\section{CUADRO XXXVI}

IA ESTRUCTURA DE LA GRAN PROPIEDAD COMUNAL EN CAMPOO: EL EJEMPLO DE CELADA-MARLANTES.

Erial Monte alto Monte bajo Tierras Prados

Has. Parc. Has. Parc. Has. Parc. Has. Parc. Has. Parc. TUTAL 60,1
5,5
87,8
5,3
0,3
1,1
$100 \%$

Fuente: Catastro de Rústica. Cédula de propiedad de la Junta Vecinal de Celada-Marlantes.

Por esta causa, el valor de la propiedad colectiva, va més allá del simple aprovechamiento en común de los pastos de los montes; es un elemento más dentro del terrazgo, de sig nificado notable por la distorsión que introduce en el mismo.

\section{2.- LOS CAMBIOS EN EL TAMAÑOY_ESTRUCTURA DE LAS EXPLOTACIUNES: UN PROCESO COMPLEJO.}

Si de profundo arcaísmo hemos tachado la estructura que presenta la propiedad en la comarca, un calificativo no menor merece la que presentan las explotaciones agrarias, a poco que se reflexione sobre el elevado porcentaje $-97,7$ por 100- de aquellas que no sobrepasan las 20 has., umbral éste que, todas las fuentes consultadas coinciden en señalar como adecuado para obtener un beneficio aceptable de las mismas. Y es que, si desde el punto de vista de la propiedad Campoo, era una sociedad de pequeños propietarios, los mismos caracteres se repro- 
ducen en las explotaciones; es, en efecto, una sociedad de pe queñas empresas de carácter familiar, cuyo significado en la estructura agraria de la comarca es evidente. Su número, lejos de reducirse, se ha incrementado, al menos hasta donde las fuentes estadisticas, más o menos homogeneas nos permiten alcanzar, hasta el año 1972.

CUADRO XXXVII

NUMERO DE EXPLOTACIUNES SEGUN SU SUPERFICIE EN HECTAREAS

\begin{tabular}{|c|c|c|c|c|c|}
\hline & \multicolumn{2}{|c|}{1962} & \multicolumn{2}{|c|}{1472} \\
\hline & & Número & $\%$ & Número & $\%$ \\
\hline 0-5 Has. & $\cdots$ & 1.432 & 77,5 & 1839 & 79,5 \\
\hline $5-10 "$ & .... & 318 & 17,1 & 344 & 14,7 \\
\hline $10-20$ & $\cdots$ & 51 & 2,7 & 78 & 3,5 \\
\hline $20-30$ & •.. & 2 & 0,1 & 9 & 0,3 \\
\hline $30-50$ & ... & 2 & 0,1 & 2 & 0,1 \\
\hline $50-100$ & $\cdots$ & 5 & 0,2 & 6 & 0,2 \\
\hline $100-200$ & ... & 11 & 0,5 & 4 & 0,1 \\
\hline $200-300$ & .... & 5 & 0,2 & 11 & 0,4 \\
\hline $300-500$ & $\cdots$ & 19 & 1,0 & 19 & 0,8 \\
\hline $500-1000$ & $\ldots$ & 11 & 0,6 & y & 0,3 \\
\hline más de 100 & 0 & 3 & 0,1 & 4 & 0,1 \\
\hline TOTAL...... & ... & 1.859 & 100,0 & 2.325 & 100,0 \\
\hline
\end{tabular}

Fuente: Censos Agrarios de 1 y62 y 1972 .

Pero, dentro de este grupo de menos de 20 has., el predominio $-y$ aqui tampoco existen diferencias respecto a la estructura de la propiedad-corresponde a aquellas de dimensiones minúsculas; inferiores a 5 hectáreas habla en 1972 en la comar ca 1839 explotaciones, que representaban el 79,5 por 100 del to tal. No es extraño por ello que una gran mayorla de las explo- 
taciones, acordes con una extension superficial reducida cuen ten con un rebaño de vecuno sensiblemente inferior a las 10 cabezas. Incluso on el sector más evolucionado por causa de la concentración parcelaria y el abandono de un gran numero de explotaciones marginales como consecuencia de la emigración, con una media de 9,2 hectáreas por explotación entre las que eatán orlentadas a la producción de leche, el número medio de cabezar de ganado vacuno no oxoodo do 20. lin ol ebmputo globul, aquellos que poseen un rebano numeroso y una explotación moderna en general, quedan diluidos entre la masa de minúsculas explotaciones con rebaños de subsistencia, es decir, variados en especies y parcos en número.

Pero si expresiva es esta situación que presentan las ex plotaciones no 10 es menos el que, lejos de mejorar la situación, haya empeorado. En efecto, en contra de jo que serla 16 gico esperar, es decir, que se redujese el número de explotaciones tras la emigración, se produce un incremento de las mig mas entre 1962 y 1972, afros en $10 s$ que el número de emigrantes en la comarca fue muy elevado. Este incremento se produce casi exclusivamente en los tramos inferiores, por debajo de las 5 hectáreas, y sin duda obedece a la consolidación de un tipo de actividad complejo, basado en la puesta en explotación de pequeñas empresas familiares, abandonadas cuando alguno de sus miembros -generalmente el Cabeza de familie- se empleb como obrero industrial en Reinosa. Los pequeños ahorros asf conseguidos -recordemos que el nivel de autoconsumo era y lo es aún muy elevado- fueron invertidos en mejorar y hacer mas llevedero el trabajo en la explotación, toda vez que a ella se le po dla dedicar menos tiempo.

Otra cusa que sin duda puede explicar este incremento del número de explotaciónes a lo largo de la década de 1960 se encuentra en aquellas personas de edad que, una vez jubilados, y para completar la pequeña pensión compran algunas vacas -pocas-, 
para "matar el rato" y obtener unos ingresos suplementarios de los que, por la parquedad de las citadas pensiones, tan necesitados están. Su número en la comarca era elevado, hecho 16 gico of tenemos en cuenta las dimensiones que alcanza el en vejecimiento de la población, como lo demuestra el hecho de que, en 1972 más de un 40 por 100 de los empresarios titulares de explotaciones tuviese más de 65 años. Igualmente corro bora 10 anteriormente indicado el que mas del 53 por 100 declara tener, en el mismo año de 1972 , otra ocupación principal, no agraria.

\section{CUADRO XXXVIII}

ES'TRUCTURA DE IAS EXPLOTACIONES: EDAD VEL TITULAR Y GRADO DE DEDICACION.

GRUPOS DE EDAD

UCUPACIUN DRINCIPAL

\begin{tabular}{|c|c|c|c|c|c|c|}
\hline & $\begin{array}{l}\text { Hasta } 34 \\
\text { años }\end{array}$ & $\begin{array}{l}\text { Entre } \\
35 \text { y } 54\end{array}$ & $\begin{array}{l}\text { Entre } \\
55 \text { y } 64\end{array}$ & $\begin{array}{c}\text { Más de } 65 \\
\text { años }\end{array}$ & Agreria & No agraria \\
\hline C. de Suso & 35 & 296 & 201 & 478 & 441 & 569 \\
\hline C. Enmedio & 17 & 301 & 257 & 312 & 402 & 485 \\
\hline C. de Yuso & 14 & 124 & 78 & 93 & 174 & 135 \\
\hline TOTAL.... & 66 & 721 & 536 & 883 & 1.017 & 1.189 \\
\hline$\%$ & 2,9 & 32,6 & 24,2 & 40 & 46,1 & 53,8 \\
\hline
\end{tabular}

Fuentes Censo Agrarto 1972. No se incluye aquellos empresarios que tienen otra condición al margen de las reseriadas.

E1 trabajo en estas explotaciones marginales, no es $\tan$ sa crificado como lo era tradicionalmente, porque tampoco es preciso mantener una variedad de especies dentro del rebaño, lo que evita la dispersión de esfuerzos que, otrora exiglan las explotaciones. Por otra parte, las condiciones de comercialización de los excedentes -cuando los hay-, es menos complicada, y más segura que en el pasado, lo que ha fucilitado la 
vuelta a la actividad de muchas de ellas. Su rentabilidad e in oluso su propia orientación esdeficiente por causa de la escasa capitalización que en ellas se puede realizar, aunque tampoco son desconocidas inversiones desproporcionadas al tamaño y destino que a éstas se les va a dar. Conocemos casos de adquisicion de una ordeñadora mecanica, para liberar el trabajo de ordeño manual de 2 o tres vacas; se trata sin duda de los que podemos denominar en alguna medida "explotaciones de ocio", de tiempo libre, y no tienen por ello más significado que el meramente anecd́tico, a no ser por el obstáculo que representan para aquellas que tienen una mayor entidad.

Próximas a ellas, en tamax́o y en significado, se encuentran las explotaciones que mantienen invariada la composición del rebaño, es decir, las que mantienen una cierta variedad de especies -vacuno, equino, ovino, caprino etc...- y en las que pre domina el ganado vacuno autóctono; se trata de explotaciones de tamaño reducido, causa por la cual se ven obligadas a mantener el sistema tradicional de àprovechamiento extensivo de los pasta comunales. Este hecho explicarla por otra parte su alto grado de permanencia en sectores -Campoo de Suso- en los que la extensión de los montes y: ejidos comunales tiene una mayor entidad.

En general, para que las explotaciones ganaderas proporcio nen unos beneficios suficientes, un producto final bruto elevado, son precisas unas dimensiones que pocas alcanzan en la comarca; se explota, en efecto, una superficie reducida, al menos en relación al total disponible, por las condiciones estructurales que hemos ido apuntando, y sobre ella se acumula un trabajo intenso, pero con una escasa productividad por causa de la enorme dispersión de las fincas y su minúsculo tamaño. No es extraño por ello que el tamaño medio del rebaño no sunere apenas las 10 cabezas. 


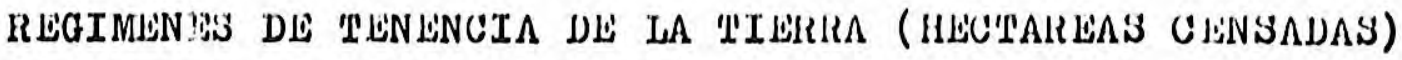

1962

HAS. $\%$

Propiedad.

Arrendamiento.

Aparcerla.....

Otros.

TOTAL.

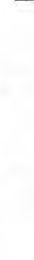

33.183

86,05

2.197

5,69

49

0,12

3,141

8,14

38.570

100,00

$\begin{array}{r} \\ \hline \text { HAS. } \\ \hline 30.119 \\ 2.355 \\ 23 \\ 4.583 \\ \hline 37.583\end{array}$

1972

Fuente: Censo:s Agrarios.

El arrendamiento, que podía ser la solución a esta deficiente estructura de las explotaciones, no es un sistema muy extendido como lo prueba el hecho de que tan solo el 6 por 100 de la superficie censada estuviese arrendada, y sin apenas variación entre 1962 y 1972.

Por esta causa sólo mediante un cambio radical de esta estructura, e incluso de la mentalidad que la mantiene y justifica, puede lograrse una sustancial mejora de los sistemas de explotación; y esto es precisamente lo que se ha llevado a cabo en uno de los sectores de la comarcas Campoo de Yuso.

3.- UN EJEMPLO DE TRANSFORIMACIUN PLANIFICADA: LA CUNCENTIRACIUN PARCELARIA EN CAMPOU DE YUSO.

Quizá uno de los sectores de la comarca que presenta los rasgos más modernos en la explotación ganadera sea el Campóo de Yuso. En él, la cabtica situación que presentaba la estructura de la propiedad, se vio agravada por una serie de circus- 


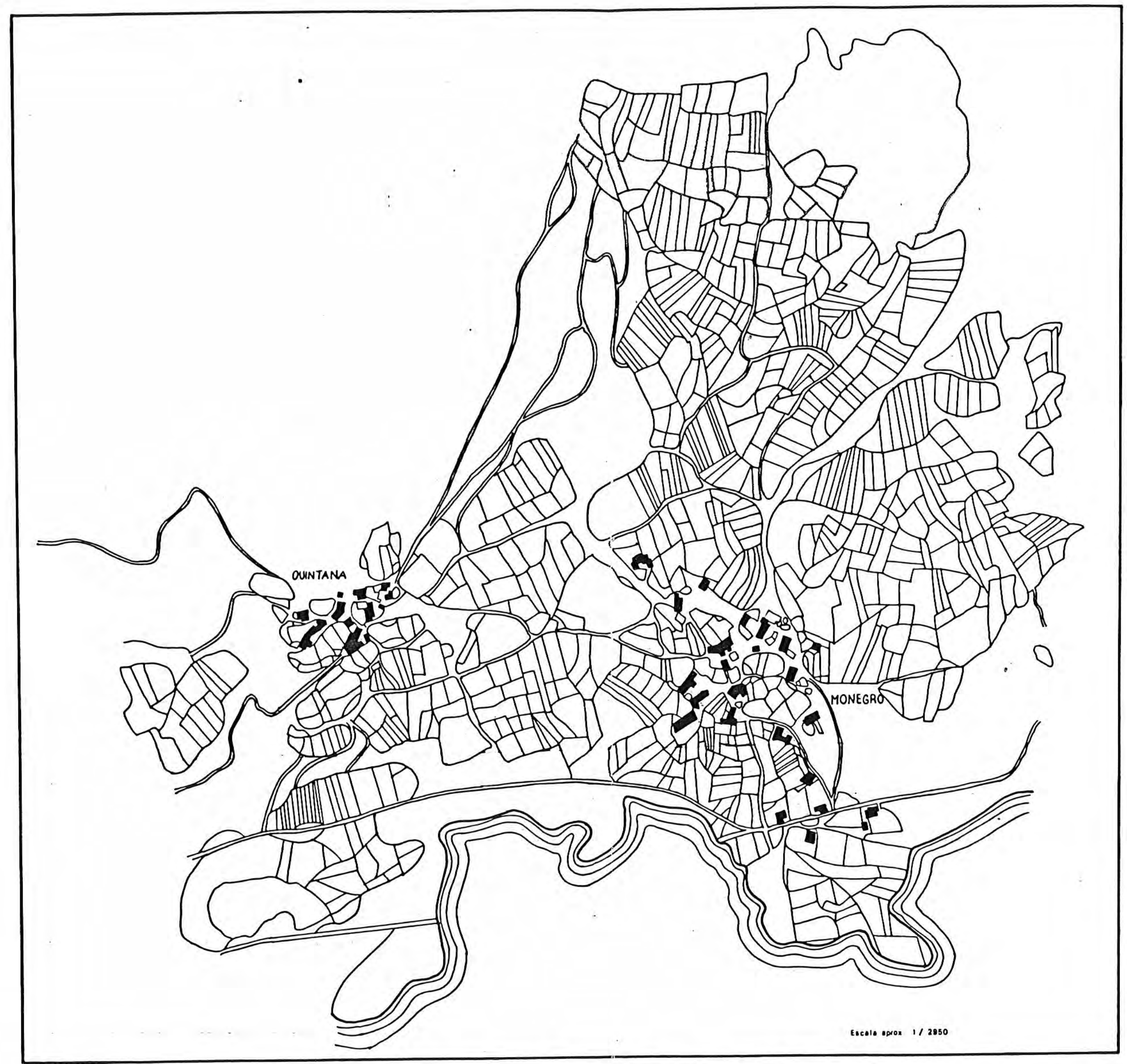

Fig. 24-La fragmentacion del terrazgo de Monegro antes de la concentracion parcelaria. 
tancias adversas que dieron al traste con el sistema de vida tradicional. La terminación de las obras del embalse del rlo 'Ebro en 1947 provocó la desaparición de más de 2000 hectáreas, expropiadas a cambio de unas cantidadas irrisorias, con la par ticularidad de que eran las mejores tierras de todo el valle. Años más tarde, en 1960, el Gobierno decretó la repoblación forestal de otras 1250 hectáreas, con lo que la situación se hizo insostenible para un buen número de vecinos, que se verán obligados a emigrar.

Perdidos además parte de los montes en los que tradicionalmente se habla mantenido el ganado autóctono en regimen ex tensivo, se procederá a la sustitución de estas por razas más productivas -frisonas y mixtas-, toda vez que éste era el único modo de no ver mermados los ingresos por causa de la re ducción del ganado vacuno en cada explotación.

Al perderse los pastos comunales, el ganadero se ve obli gado a estabular y alimentar en su exigua explotación a todo el rebaño, por lo que se verá obligado a reducir en primer lu gar su número y a sustituir el ganado vacuno autóctono -tudan co- por razas mejor adaptadas a la nueva situación y obviamen te más productivas, con el fin de lograr, por via de la productividad lo que antes lograba en forma extensiva.

Cuando es preciso acometer estos cambios comienzan a aflo rar todas las deficiencias que la estructura de la propiedad tradicional presentaba; en efecto, una superficie muy reducida -1808 hectáreas de praderas y tierras de labor- se encontraba fragmentada en 9221 parcelas, sin tener en cuenta las fincas propiedad de las juntas vecinales, lo cual supone un promedio de 0,20 hectáreas por parcela. Incluyendo todas ellas, habfa en 1962 un total de y275 parcelas, de las que 8350, es decir, el 90,0l por 100 no llegaba siquiera a la media hecté rea.

En estas condiciones, la mayor parte de las explotaciones 
eran poco rentables; cada propietario tenla sus tierras sumamente dispersas, haciendo inviable cualquier modernización en ellas. Pero no era la fragmentación el único inconveniente, la exiguedad de la propiedad era, como en el resto de la comar ca el rasgo más sobresaliente, exigüedad que no era paliada ni siquiera por el arrendamiento que, como hemos visto tenla muy poca entidad. Incluso aquellas explotaciones en las que las tierras arrendadas fuesen numerosas adolectan del mismo incon veniente: la fragmentación.

A todo ello habrla que añadir otro obstáculo adicional, en este caso de Indole jurfdica; la mayor parte de las parcelas en que se fragtaban las 1336 hectáreas de praderas natura les y que oscilaban entre las 10 y 20 áreas, carecian de acceso propio, estando éste reconocido por la ley de servidumbres nada más que para recoger el primer fruto y administrar la fin ca. Esto limitaba considerablemente el aprovechamiento de las mismas, y si bien no era inconveniente cuando el único destino que se les daba era la producción de heno para almacenar de cara al invierno, con el fin de alimentar el rebaño de ganado Tudanco que bajaba de los puertos altos, reducido éste y sustituído por razas más productivas, pero tambiên más exigentes en alimentación, tales restricciones juridicas impiden extraer un rendimiento mayor de las fincas. Los ganaderos se vefan obligados a destinar estas parcelas sometidas a servidumbres de paso al "corte en verde" y a adquirir hierba y paja para el in vierno, lo que les llevaba a contraer fuertes dcudas, dado que su disponibilidad de capital era más bien escasa, por no decir nula.

Para poner remedio a todos estas adversidades se decidí́ solicitar la concentración parcelaria en 1963, terminándose ésta 11 años más tarde. El grado de eficacia logrado ha sido muy bajo, como lo demuestra el hecho de que la relación entre la superficie y las parcelas siga siendo insuficiente; subsis- 
ten, en efecto, propiedades muy pequeñas y con un alto grado de fragmentación. No se puede olvidar pese a todo que el nú'mero de parcelas se ha reducido en más de un 50 por 100 y ello ha supuesto un progreso notable para la mayor parte de las explotaciones, que han podido asf acometer la modernización.

Una vez concluida la concentración, las 9275 parcelas quedaron reducidas a 3851, con una media de 2 hectáreas por parcela si contabilizamos toda la superficie; la realidad es muy otra, porque si de las 7861 hectáreas restamos las 4361 , propiedad de las juntas vecinales, concentradas en 54 parcelas, restan 3797 hectáreas de propiedad privada fragmentadas en 3797 parcelas, 10 que supone una media de 0,y2 hectáreas por parcela.

En gran medida,las dificultades para llevar a cabo la con centración procedlan del elevado número de propietarios a los que...habla que respetar y la disparidad de calidades de tierra -hasta siete- . Se piensa incluso que cuando desaparezcan las explotaciones en las que el titutar tiene una edad avanzada -en 1972 más del 50 por 1 Co de los mismos tenla más de 55 años-, serla casi necesario volver a concentrar lo concentrado.

Las transformaciones en el paisaje agrario han sido notables; del paisaje tradicional en el que la parcelación e irregular trazado de cada una de las fincas era la nota dominante, se ha pasado a una distribución más regular, pero sobre parcelas de tamaño no mucho mayor. (Ver figura 25 ).

Por ello los cambios has de ser observados con cautela; si la estructura de la propiedad permanece prácticamente inal terada, si se han abierto mayores posibilidades para llevar a cabo una racionalización de las explotaciones. Gran parte de ellas se han mecanizado, se han orientado definitivamente a la producción de leche, y los resultados han sido, en ceneral bastante satisfactorios. 


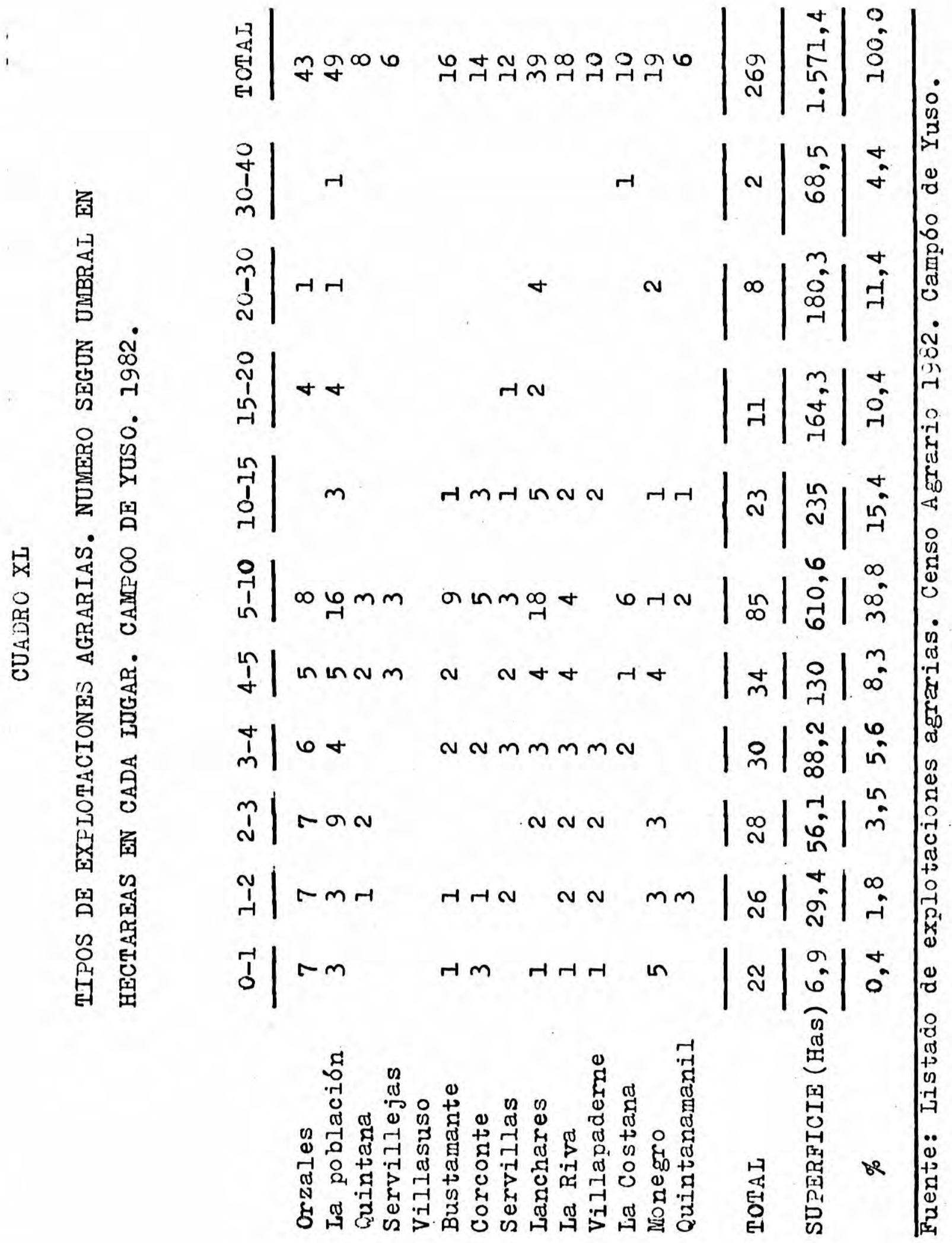


Prueba de que la estructura de las explotaciónes conserva ' fuertes rasgos de arcaismo es el hecho de que todavia en el año presente -1982- mas del 58 por 100 de las explotaciones tienen menos de 10 hectáreas. En el cuadro XI, se aprecian tales caracteres de la estructura reciente en Campoo de Yuso; los mayores Indices de concentración corresponden a los tramos in termedios, entre las 5 y las 20 hectáreas. 
CAPITUIO XIV

IA PROGRESIVA CONSULIDACIUN DE IAA OPCIUN GANADLRA :UN PRUCEISO RECIENTE.

Pese a que persisten todavía, como hemos visto, ciertos obstaculos de Indole institucional que dificultan el proceso de cambio en la comarca, tales como, la pequería propiedad,un elevado número de pequeñas explotaciones e incluso en algún caso la pervivencia de unos tipos y sistema de cultivo poco acordes con la nueva orientación economica en la que se ha per dido el carácter de subsistencia, podemos afirmar que, en los últimos años se ha entrado en una etapa completomente nueva.

Los rasgos que definen este nuevo periodo, todavia recien te, tienen como fundamento las transformaciones realizadas en el aprovechamiento del espacio agrario, transformaciones que podemos sintetizar en el retroceso del espacio cultivado, a costa de una expansión de las praderas. Este incremento no es evidentemente casual; obedece al parcial abandono de una gana derla extensiva, adaptada a un aprovechamiento colectivo del 
terrazgo como elemento imprescindible de una economla de sub sistencia, y es al mismo tiempo resultado do la modernización progresiva de las explotaciones agrarias, a la que el campesi no se ve muchas veces obligado por múltiples causas y a costa de un fuerte endeudamiento.

Se pierde, o se cambia en cierto modo e] tradicional apro vechamiento dej. monte, tanto porque su concurso será cada vez menos necesario, como por las limitaciones impuestas a princi pios de siglo al declararse de Utilidad Pública.

pero, con todo, el retroceso del espacio cultivado es el hecho más sobresaliente de los úlimos años, en relación sin duda con un cambio en el significado que, la explotación gana dera,tiene en la comarca. 'Todo, en la actualidad aparece subordinado a la ganaderla y el aprovechamiento del espacio agrario no podla ser una excepción; podrlamos incluso afirmar que es la base de la misma.

1.- EI, CARACTER MARGINAI DEI ESPACIO GUITIVADU.

En un terrazgo que, al igual que a mediados del siglo XVIII, y pese a las roturaciones de los últimos años del siglo XIX y principios del siglo XX, sigue siendo reducido, la superficie cultivada ha ido perdiendo paulatinamente importancia, y sobre todo ha cambiado de significado ( 2 ). Las prade

( 2 ) Sin duda este hecho resta importancia, como ya apuntamos a la intensidad del proceso roturador de principios de sirilo en la comarca. En efecto, ante la demanda de productos ganaderos impulsada por el desarrollo urbano, la respuesta de la comarca no fue la roturación, más o menos generalizada, de los monte: comunales; y no lo pudo ser porque la ganaderla se siguib explotando en régimen extensivo y porıue la especialización en la producción de leche tardará bastante tiempo en generalizarse. Cuando esto suceda-década de 1960- se procedera a cambiar el sentido del aprovechamiento del terrazgo más que a ampliarlo. por esta causa hoy éste se encuentra totalmente subordinado a la explotación ganadera, incluso en los sectores cultivados aún. 
se han enseñoreado en la comarca, ocupando una proporción nada despreciable de la superficie de la misma, muy superior por supuesto a la que ocupaban a mediados del siglo XVIII. Frente a ella, la superficie cultivada -en su mayor parte hoy subordinada a la explotación ganadera, y no al autoconsumo co mo lo estaba tradicionalmente- se ha ido reduciendo progresivamente hasta representar en la actualidad poco más del 3 por 100 de la superficie comarcal. Una muestra de la intensidad y de la rapidez con la que se acomete este proceso puede ser el enorme desfase existente entre la superficie catastrada como "labrantla y la que realmente se destina a este fin. Con independencia incluso de la muy probable insuficiencia de las fuentes estadisticas, la superficie labrada es siempre muy in ferior a la que, en el catastro aparece con tal destino.

En Campóo de Yuso tan sठlo el 32,4 por 100 de la superfí cie catastrada se cultiva realmente y en los otros municipios aunque el porcentaje es mas elevado, las diferencia siguen siendo notorias.

\section{CUADRO XLI}

RELACION ENTRE LA SUPERFICIE CATAS'TRADA COMO I,ABRAN'PIA Y JiA REALMENTE LABRADA. 1979.

\begin{tabular}{|c|c|c|c|}
\hline & $\begin{array}{l}\text { Hectáreas } \\
\text { catastradas }\end{array}$ & $\begin{array}{l}\text { Hectáreas } \\
\text { labradas }\end{array}$ & $\%$ \\
\hline Campóo de & & & \\
\hline $\begin{array}{l}\text { Yuso } \\
\text { Campó de }\end{array}$ & 314 & 102 & 32,4 \\
\hline $\begin{array}{l}\text { Enmedio } \\
\text { Campoo de }\end{array}$ & 901 & 647 & 71,8 \\
\hline Suso & 1.189 & 618 & 51,9 \\
\hline TOTAL ...... & 2.4 .04 & 1.367 & 56,8 \\
\hline
\end{tabular}




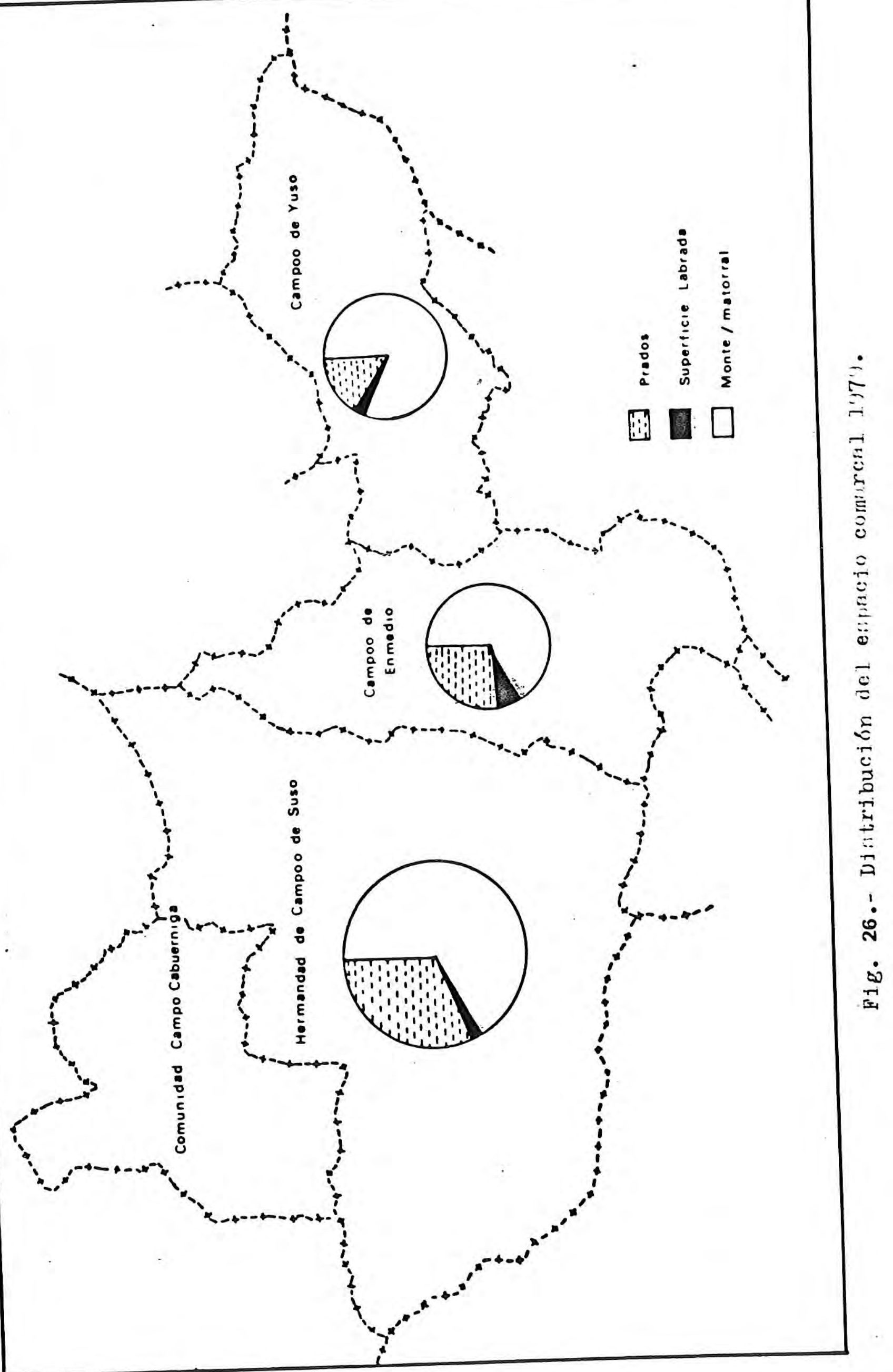


En cierto modo por lo tanto existe una situación de hecho anomala, que refleja un cambio de orientación en el aprovechamiento del terrazgo. En efecto, buena parte de las tierras de labor se abandonan para destinarlas a praderas artificiales, con el fin de hacer frente a una ganaderla,explotada en regimen intensivo, $y$ con mayores exigencias alimentación que las razas de vacuno autßctono. Resulta sumamente expresivo este proceso en todos los municipios, pero sin duda donde adquiere mayores proporciones es en Campoo de Yuso. Aqui se ha product do, desde 1950, una brusca disminución del terrazgo cultivado, que de ocupar un 32,4 por 1(10 en 1950, en la actualidad -1981tan solo representa un 5,5 por 100, una muestra más del cambio que anteriormente apuntábamos.

CUADRO XLII

DISTRIBUCION DEL ESTACIO AGRARIO EN CAMTUU DL YU:SU $1950-1981$

\begin{tabular}{|c|c|c|c|c|c|c|}
\hline & \multicolumn{2}{|c|}{1950} & \multicolumn{2}{|c|}{1960} & \multicolumn{2}{|c|}{1981} \\
\hline & Has. & $\%$ & Has. & $\%$ & Has. & $\%$ \\
\hline $\begin{array}{l}\text { Praderas perma } \\
\text { nentes. }\end{array}$ & 1.228 & 67,6 & 1.228 & 74,8 & 1.682 & 94,5 \\
\hline Cereales & 215 & 11,7 & 109 & 6,5 & 2 & U, I \\
\hline Habas & 24 & 1,3 & 16 & 0,9 & -- & $\ldots$ \\
\hline Guisantes & 5 & 0,2 & 5 & 0,3 & -- & $-\infty$ \\
\hline Yeros & 4 & 0,2 & -- & -- & -- & $-\ldots$ \\
\hline Patatas & 283 & 16,1 & 227 & $1.4,3$ & 10 & 0,5 \\
\hline Alfalfa & 15 & 0,8 & 15 & $u, y$ & 85 & $4, y$ \\
\hline Hortalizas & 13 & 0,7 & 13 & 0,7 & -- & -- \\
\hline Barbecho & 27 & 1,4 & 27 & 1,6 & - & $-\cdots$ \\
\hline TUTAL & 1.814 & 100,0 & 1.640 & 100,0 & 1.779 & 100,0 \\
\hline
\end{tabular}

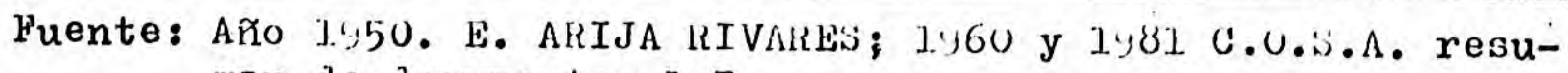
man de documentos 1-T.

Como se puede comprobar, no sólo se ha reducido la superficie cultivada, sino cue la que permanece con tal carácter ha cambiado totellmente de significado. De estar orientada a proporcionar la subsistencia de la población, ha pasado a ser un com- 
plemento más de la alimentación del ganado y ante la imposibi lidad de hacer frente con la hierba que se podla obtener en los prados a la alimentación del ganado, no sólo desde el pun to de vista cuantitativo, sino también cualitativo. La dieta seca que proporciona la hierba durante el. invierno se aviene mal con una abundante producción de leche, por lo que se hace necesario completarla. Ello explica la extensión que alcanzan las praderas artificiales -praderas de polifitas, trébol, balli co etc...-, y la superficie destinada al cultivo de plantas fo rrajeras, en espectal de la alfalfa.

No es extraño que, los alfalfales y las praderas artificiales constituyen una parte sustancial del terrazgo, el 96,2 por 100 en Campóo de Enmedio, el 97 por 100 en Campठo de Yuso, y un porcentaje mucho menor en Campoo de Suso, el 20,9 por 100., por causas complejas, reflejo de la pervivencia aún de una ganaderfa extensiva de cierta entidad; este hecho justifi ca, en parte, la pervivencia de sistemas tradicionales de apro vechamiento del terrazgo cultivado, ante la imposibilidad material de estabular un ganado numeroso durante el invierno y de proporcionarle una dieta continuada de hierba, dado que se reservaba para los ganados estabul.ados en regimen permanente.

No hay que olvidar que la permanencia de una ganaderfa extensiva y por lo tanto del aprovechamiento del terrazgo del modo tradicional, es muy reducida. Pero si cualquier generali zacion es abusiva, en este caso puede serlo en extremo; las diferencias entre los tres municipios de la comarca son sustanciales. En Campoo de Suso, la patata de siembra, de la que se obtienen en la comarca rendimientos elevados $-12.000 \mathrm{Kg}$ por hectárea- ha reemplazado a una parte de las tierras de "pan llevar", que todavia ocupan el 24 por 100 de la superficie cultivada, mientras que las praderas artificiales y las forra jeras tienen una importancia menor. En Campoo de Enmedio la 


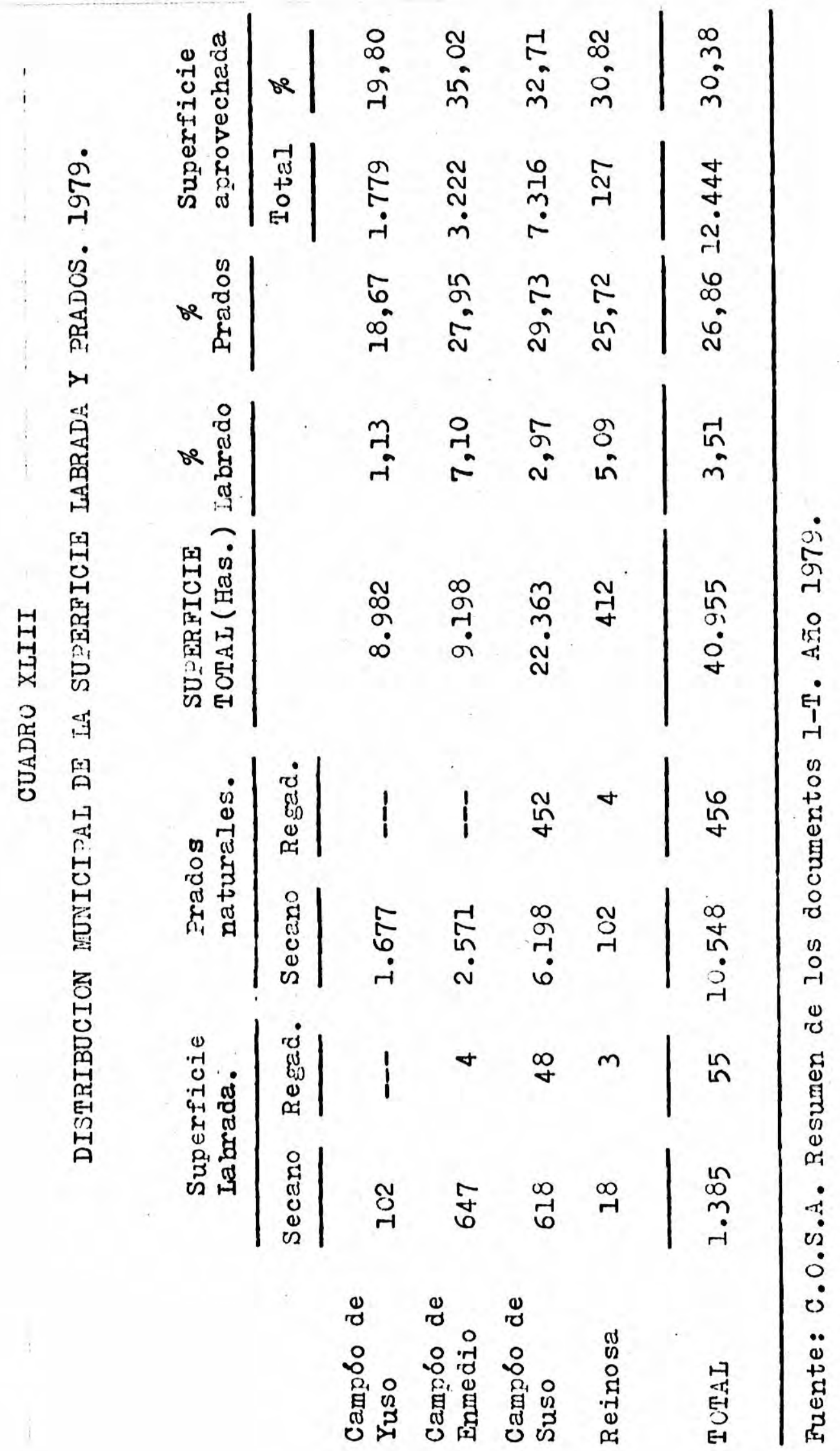


evolución ha sido mucho más rápida hacia una especialización ganadera orientada hacia la producción de leche; las razas autóctonas son ya marginales en el contexto de la explotación, $y$ ello ha estimulado la transformación del terrazgo cultivado, ocupado en su práctica totalidad por la alfalfa $-40,3$ por 100y las praderas de polifitas $-55,9$ por 100-. Por último, y gra cias a la eliminactón de uni parto do los obatículos tradicle nales, Campoo de Yuso presenta una mayor integración en una economla moderna, si bien persisten clerto número de explota ciones residuales, próximas a desaparecer por causa de la ele vada edad de sus titulares; en este sector la superficie ocupa da por la patata de siembra se ha reducido considerablemente en favor de la extensión de las praderas artificiales, que jun to a 10 s prados naturales representan el. 26,8 de la superficie total y más del 90 por 100 de la superficie aprovechada ( 3 ).

El paisaje agrario actual en Campóo aparece completamen te dominado por los prados y praderas artificiales; se trata en efecto de un paisaje de praderas, abandonada ya la dualidad prados-tierras de labor que caracterizo a la agricultura tradicional; $y$ en esto no difiere sustancialmente de otros sectores de la montaña Cantábrica, salvo en e.l tiempo invertido en el proceso de cambio, que en la comarca ha sido muy dilatado ( 4 ). En la base de este cambio se encuentran sin duda los progresos realizados en la modernización de la composición del rebaño en general $\mathrm{y} /$ del de ganado vacuno en particular.

(3) En los Ultimos años - todavia es una experiencia muy re ciente en la comarca- se han puesto en práctica sistemas más evolucionados, mediante la sustitución de cultivos poco rentables por otros más evolucionados y mejor adaptados a las condi ciones ecologicas. El sistema consiste en una rotación que permite obtener rendimientos muy elevados con los que poder soste ner un rebaño cada vez más numeroso. El malz forrajero, del que se obtiene una producción media de $40.000 \mathrm{Kg} . / \mathrm{Ha}$. y la AvenaVeza ( $\left.30.000 \mathrm{Kg} . / \mathrm{Ha}_{.}\right)$son alguno de los cultivos que permiten un más intenso aprovechamiento. En efecto, el malz termina su ciclo vegetativo a primeros de octubre y la Veza-Avena a últimos de mayo, con lo que se pueden obtener por hectárea y año unos $70.000 \mathrm{~kg}$. de amisas especies. ( 4 ) J. GARCIA FERNANDLZ.- Organización Op. cit. p. 49. 
2.- HACIA UNA SIMPJ,IFICACION EN IA EISTRUCTURA DE LA EXPLUTACION GANADERA.

En la misma linea de progreso que en el aprovechamiento del espacio agrario -reducción de tierras de labor en general $y$ pan llevar en particular con el fin de incrementar la produccion de plantas forrajeras, as 1 como extensión de las prederas artificiales-, hay que inscribir la evolución seguida por tamaño y sobre todo por la composición del rebaño campurriano.

Las transformaciones han sido importantes, y a eljas no son ajenas, como vimos, los cambios operadoss en la explotacion tradicional, pero en una apresurada sintesis introductoria con viene apuntar que en el fondo de aquellas se encuentra la sus titución de una ganaderla explotada en regimen extensivo por otra, que, al demandar mayores exigencias en alimentación obligó a realizar una explotación en regimen intensivo.

pero, asimismo conviene apuntar que, al menos en un prin cipio estos cambios no significaron en absoluto progreso, ni para la comarca ni para la explotación ganadera en terminosge nerales. El cambio se comenzo a realizar para, aj menos en una gran parte de los casos adaptar la actividad agraria a los tiempos que corrlan, sin preocuparse, y obviamente sin poder llevar a cabo una transformación radical del sistema. En efec to,pese a que la"presion" del ganado sobre la superficie alro vechable era y es aún muy baja - aproximadamente 0,9 hectáreas por cada cabeza de ganado vacuno-, el rebaño, y especialmente el rebaño de vacuno ha estado y está deficientemente alimenta do, tanto cuantitativamente como cualitetivamente; la causa se encuentra en la enorme complejidad de la composición del citado rebaño en cada explotación. Por esta causa, ell ganado vacuno, al que deberla estar orientada la comarca, se ve obligado a "competir", en una superficie reducida, con otras especies, en ocasiones muy voraces, de las que el propietario no puede aún 
presoindir, for wer fuente de sbtencisn de ingressos, o por destinarse al consumo familiar.

for ello, si bien es cierto que se ha abandonado una agricultura de subsistencia, podemos afirmar que durante bastante tiempo se conserva una ganaderla con el mismo carácter : la subsistencia, al menos en determinados sectores de la comarca.

Tan sólo en los años más recientes se ha modificado esta estructura en favor del ganado vacuno, más que por un incremen to del mismo, por el retroceso de otras especies. pero, sin du. da el punto de partida de estos cambios hay que situarlo en el declive paulatino del aprovechamiento ganadero en régimen extensivo.

\section{a) EI retroceso de l.a ganader fa extensiva}

El proceso de sustitución recientemente operado en la composición del rebaño campurriano no ha sido progresivo des de que, a principios de siglo se introdujeran los primeros ejemplares de ganado de mayor productividad. Muy al contrario, y aprovechando favorables coyunturas del mercado nacional, se va a producir un auje de las razas autoctonas, en especial la raza Tudanca, puesto que las otras dos variedades -campurria na y lebaniega- estaban ya a mediados del. presente siglo prác ticamente absorbidas por ella ( 5 ).

Las dificuj.tades aparecidas en el. transporte y labores agrfcolas por la carencia de combustibles durante la posguerra provocaron una fuerte demanda de ganado tudanco, foméntándose nuevamente, en un ganadero indeciso ante el cambio, la crla del citado ganado, que junto al campurriano habla formado par te del rebaño tradicional.

( 5 ) A. DE MIGUEL PALOMINO. - Dasado y lresente de las razas vacunas santanderinas de montaña. Selección de textos y comentarios, Anales del. Instituto de estudios I gropecuarios. Diputación jrovincial de Sentander. 1977-1978. p. 12-63. 
La imperiosa necesidad de disponer de pasto de montafa para mantener un ganado de diffcil estabulación por causa del elevado número de cabezas que cada ganadero posela, obligb́ a buscar pastos de forma desesperada, sin respetar las ordenanzas de los distintos lugares, que pronto cayeron en desuso. Se comenzo a reducir la superficie de tierras de "pan llevar", que, de ser supertor a la superficie ocupada por los prados en el siglo XVIII, a mediados del presente siglo prácticamen te ocupaban ya la misma superficie. Pero, pese a todo, por falta de pastos se Irá reduciendo también el tamaño del rebaño de vacuno de raza autóctona, modificándose por ello el régimen de explotación.

Tradicionalmente la vigilancia, el cuidado del ganado, e日 taba encomendado a un pastor y dos ayudantes, el sarrujan y el becerrero, o bien a un pastor y un vecino por el sistema de ve cerla. As1 custodiado, el rebaño comenzaba a pastar en las pro ximidades de los pueblos a partir del dla de San José -19 de Marzo-, recogiéndose durante la noche en las cuadras; cuando el tiempo lo permitia, se subla a los puertos de primavera, pa $r a$, el dia 16 de Junio subir a los "puertos altos", en los que permanecla durante todo el verano.

Para poder acceder a estos puertos el ganado "forastero" tenla que pagar un cánon -actualmente de 800 pesetas- por cada cabeza de ganado mayor -vacuno o equino-, mientras que los ve cinos del lugar propietario de los puertos tenfan que pagar, - mejor, pagan actualmente 150 pesetas. Hermanecen en estos puertos hasta el dia 29 de Septiembre, fecha en la que, lenta mente inician el regreso en busca de los pastos del fondo de los valles, en "cabaña" o, donde se conserva el sistema, "en derrota".

Pese a estar en declive este sistema, se mantienan intac tos parte de los rasgos que le caracterizaron, es decir, una dimensión del rebaño de vacuno autóctono muy superior al de 
otras razas, resultando, pese a todo, insuficiente ( 6 ).

Pero el que haya remitido en intensidad no significa en ábsoluto que no se siga practicando. En efecto, la preeminen cla del ganado vacuno de raza tudanca y mixto en Campóo de $\underline{\mathrm{u}}$ so justifica el aprovechamiento de los pastos de montana de este seotor de la comarca, slguiendo el ritmo anteriormente apuntado sin apenas variacion por lo tanto sobre el sistema tradicional. El total de ganado "marcado para pastar en los puertos altos" sigue siendo elevado en cada año, si bien, sen siblemente inferior al que lo hacla en el siglo XVIII y XIX, tanto en la Hermandad de Campoo de Suso como el de Las Asturias de Santillana.

\section{CUADRO XIJIV}

E], APROVECHAMTENTO DE LOS PASTOS DE JOS PULRTOS ALTOS DE LA HERMANDAD DE CAMPOO DE SUSO.

\begin{tabular}{|c|c|c|c|c|c|c|}
\hline & \multicolumn{2}{|c|}{1975} & \multicolumn{2}{|c|}{1976} & \multicolumn{2}{|c|}{1977} \\
\hline & Vacuno & Equino & Vacuno & Equino & Vacuno & Equino \\
\hline $\begin{array}{l}\text { Ganado de las Astu } \\
\text { rias de Santillana }\end{array}$ & 719 & 12 & 786 & 15 & 910 & 89 \\
\hline $\begin{array}{l}\text { Ganado de la Hmdad. } \\
\text { de Campठo de Suso }\end{array}$ & 2.435 & 605 & 1.957 & 697 & 2.029 & 762 \\
\hline & 3.154 & 617 & 2.743 & 712 & 2.939 & 851 \\
\hline
\end{tabular}

Fuente.: Archivo de la Hermandad de Campóo de Susor Espinilla.

Aún siendo numeroso, este ganado no ocupa ya el lugar que tradicionalmente tenla dentro de la explotación, pero también es clerto que salvo la reserva que el ganadero ha de hacer de hierba y paja para el invierno, tampoco le proporciona demasia dos quebrantos, máxdme si tenemos en cuenta que alguno de estos (6) A. DE MIGUEL PALOMINO.- Pasado ... Op. cit. pág 49 
"puertos altos" se han cercado recientemente. Quizá por ello se pueda explicar la estructura, poco evolucionada, que presen ta el aprovechamiento del terrazgo, y el que ciertos sistemas tradicionales -derrota de mieses etc...- continúen estando vigentes actualmente. Pese a todo, este sistema, la derrota de mieses, prohibida desde 1853 salvo autorización expresa del Gobernador Civil, se encuentra francamente en retroceso en el resto de la comarca, donde el ganado autóctono tan sólo repre senta como vimos una proporción poco menos que simbólica. En cam bio, la generalización de otras razas de ganado vacuno ha sido muy rápida e intensa.

b/ La ambivalencia del rebaf̃o campurriano: ganado de leche y de aptitud mixta.

No sin habex, y estar aún atravesando pocas dificultades, los tres minicipios campurrianos -exclulmos Reinosa, porque su participacion en el conjunto es insignificantes-aparecen definitivamente orientados hacia la producción lechera. Cierto es que un número de explotaciones continúan siendo margina les, que a ellas no ha llegado la mecanizacion en forma suficiente y que siguen manteniendo una gran variedad de especies que dificulta su especialización, pero pese a todo las razas vacunas de aptitud lechera han pasado a ser muy superio res al resto.

La sustitución no ha sido posible realizarla de ralz, tan to por las dificultades económicas, Ioficas por otra parte, como por la necesidad de contar con un ganado de aptitud mixta, es decir,que proporcionase, además del trabajo alguna renta por vla de la producción de leche, en sustitución de la tradi cional "pareja" de bueyes o de Tudancas. Se pretendla con ello disponer de un ganado sin los inconvenientes, pero con las ven 
tajas del autóctono -el trabajo-. Pero si el cambio se intció con la introducción del ganado de aptitud mixta, se generalizará y consolidará con la introducción del ganado frisón -la pinta holandesa- del que se obtienen mayures rendimientos. No obstante, los resultados de este proceso no han sido similares en todos los sectores de la comarce. En efecto, ni el volumen, ni la estructura del rebaño presentan caracteres homogeneos, lo que indica la exsatenola de un tipo de trunsforma ción diferencial en la comarca $(7)$.

En Campoo de Suso, la presencia de la raza tudanca, por su significado económico, es todavia muy notoria; representa más del 20 por 100 del total, pero adeńás, la sustitución de razas realizada no ha estado orientada al logro de una mayor producción de leche, como lo demuestra el que las razas frisona y Parda Alpina -402 y 50 ejemplares en 1978 respectiva mente-apenas alcancen el 8 por 100 del ganado vacuno en todo el valle. Aqui ocupan un lugar destacado las razas mixtas -el 70,7 por 100- por su mejor adaptacion y menores exigencias en alimentación, todo ello con el fin de no restar posi bilidades al rebano de los puertos, estabujado durante el in vierno. Por otra parte, la propia estructura del terrazgo ex plica la, hasta ahora escasa vocación lechera de Campoo de $\mathrm{S} \underline{\mathrm{u}}$ so; para un elevado número de ganado vacuno y caballar, tan sollo dispone de una superficle de 76 hectáreas de praderas ax tificiales, mientras que son más de 6000 las hectáreas ocupa das por prados naturales, una parte de los cuales no son de propiedad particular, sino colectiva.

Todo ello explica la preservación de una estructura pro xima a la tradicional, o al menos con pocos cambios, pero es que, además han intervenido otros hechos, capaces por si mig mos de justificar, o al menos alentar la continuidad de los sistemas tradicionales; una propiedad insignificante, y la (7) J. A. QUIJANO DE IA COLINA. - Del campo montañés. Santender 1950. Recopilación de articulos publicados en la Hoja Agri-
cola del Diar1o montañes. 


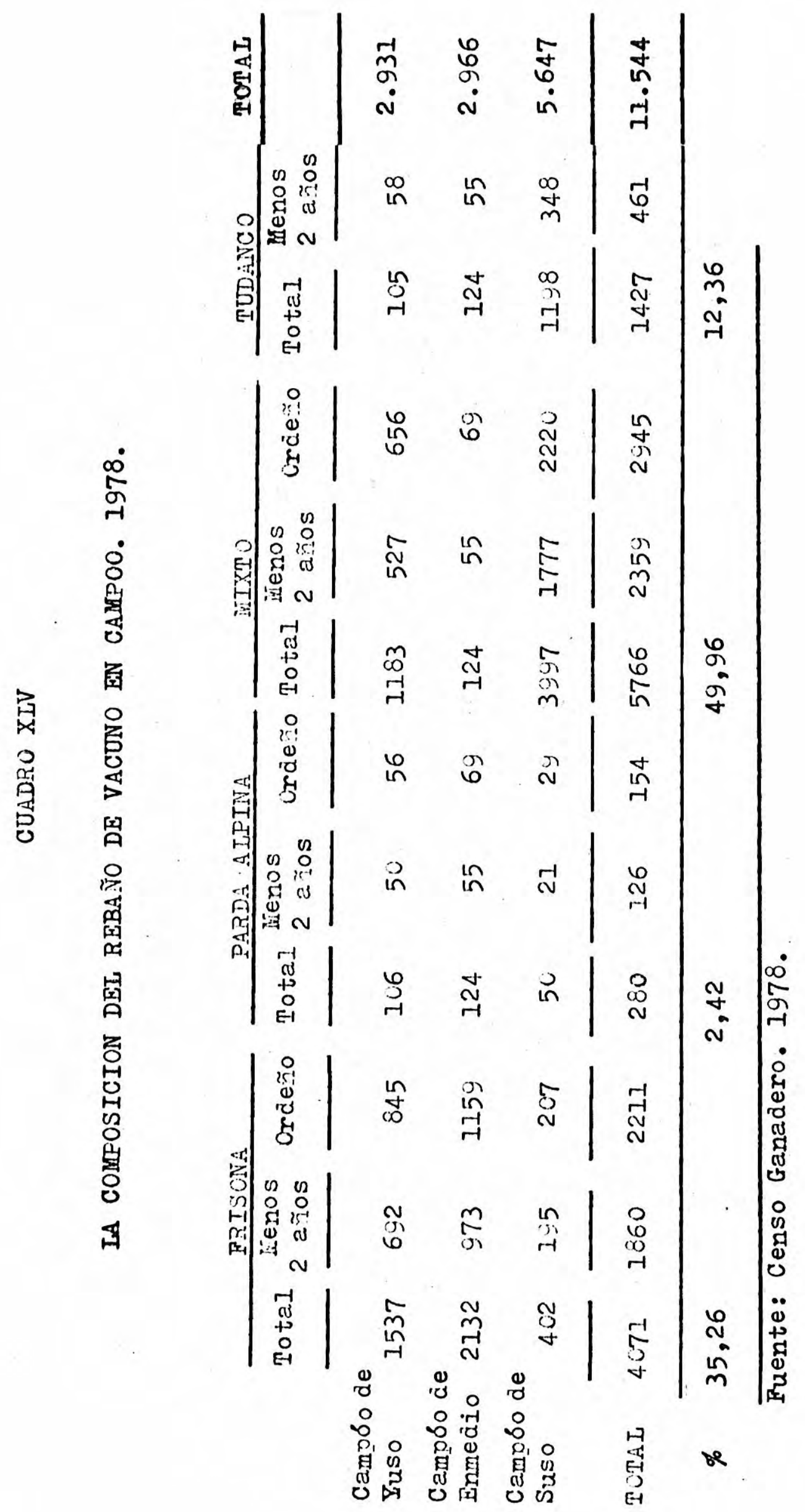


segura obtención de rentas al margen de la ganaderia han re trasado, al menos es este sector, la modernización de la ex plotación ganadera en general. Lo mas sencillo, y esto es lo que se ha hecho en la mayor parte de los casos, ha sido conservar aquél ganado que pudiese proporcionar alguna renta a cambio de una escasa atención, condiciones que cumplla el ga nado vacuno autóctono.

Mejor lograda, pero también incompleta, aparece la trang formacion de la explotación ganadera en Campठo de Yuso; en es te sector las razas autoctonas apenas están representadas, mientras que la Frisona y las mixtas representan -52 y 40 por 100 respectivamente- la mayor parte del ganado vacuno del municipio. La mayor parte de las explotaciones son bastante ren tables, todas ellas orientadas a la producción de leche, pero persisten aún explotaciones marginales que conservan una estrauctura no del todo satisfactoria; de hecho asf parece indicarlo la destacada presencia de razas mixtas, gran parte de las cuales corresponden, en información recogida en el propio municipio, a aquellas explotaciones no mecanizadas, cuyo titu lar tiene una edad avanzada, y de las que se obtienen unos ren dimientos bajos, pero suficientes si se tiene en cuenta que no son más que un mero complemento.

En su conjunto el municipio presenta una superficie apro vechable con fuertes rasgos de modernidad; las praderas artifi ciales ocupan una porción importante del terrazgo, contrastan do con la práctica eliminación de cultivos de subsistencia tra dicionales e incluso con la reducción de la superficie destina da al cultivo de la patata de siembra, que a mediados de siglo llego a adquirir una fuerte expansión.

Campóo de Enmedio es, sin duda el sector de la comarca en el que más intensa ha sido la transformación; las praderas artificiales y el cultivo de forrajeras, en especial la alfal 
fa, ocupan una parte sustancial del terrazgo cul tivado -más del 95 por 100-, y en consonancta con esta evolución, la es pecialización en la producción de leche es más acusada como lo demuestra el hecho de que, más del 70 por 100 del ganado vacuno sea de raza frisona.

En síntesis, podemos afirmar que la especialización, la definitiva inolinación por la opción lechera constituye en la comarca un proceso inacabado e incompleto; prueba de ello es hecho de que ten sollo el 37,6 por 100 del rebaño de ganado vacuno presenta esta aptitud, mientras que en el resto de la comarca el porcentaje es del 87,5 por 100

\section{CUADRO XLVI}

COMPOSICION DEL REBAÑO VACUNO DE APDITUN LECHERA EN CAMIOO Y EN IAA PROVINCIA DE SANTANDER. 1978.

CAMPOO

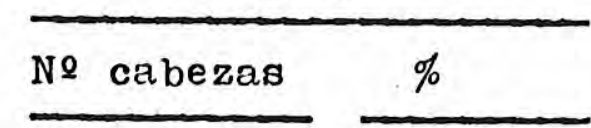

Frisona..........4.071

Frisona (hembras de

más" de 2 años) ...... 2.193

Pardo Alpina...... 280

Pardo Alpina(inem-

bras más de 2 años) 148

Total vacuno apti-

tud lechera........4.351
PROVINCIA

\begin{tabular}{|c|c|}
\hline № cabezas & $\%$ \\
\hline 290.206 & 84 \\
\hline $\begin{array}{r}157.319 \\
9.311\end{array}$ & $\begin{array}{r}45,9 \\
2,7\end{array}$ \\
\hline 5.000 & 1,4 \\
\hline 299.517 & 87,5 \\
\hline
\end{tabular}

Fuente: Censo Ganadero 1978.

La producción media de leche, teniendo en cuenta todas las razas en ligeramente superior a los 1000 litros anuales, si bien es cierto que esta cifra se incremente notablemente en algunos sectores de la comarca como resultado del predomi nio de razas especializadas. Es por ejemplo lo que sucede en Campठo de Yuso, donde, causas complejas como hemos visto, im pulsaron al ganadero a una especialización en la producción 
de leche. La media de leche producida por cada cabeza de vacuno de más de 2 años, destinada exclusivamente a este fin es de aproximadamente 11 litros dia, es decir algo más de 4000 litros anuales. Gran parte de las explotaciones están mecanizadas y la composición del rebaño, es más racional que en otros sectores de la comarca.

\section{CUADRO XLVII}

ESTRUCTURA DE LA EXPLOTACION LECHERA EN CAMPOO DE YUSO.

Litros Producción de \% explotaciones

Hectáreas $\frac{\text { Ganado Vacuno }}{10} \frac{\text { Ordeño Recria }}{12,5} \frac{\text { leche diaria }}{6,9} \frac{\text { Total Entrega }}{69} \frac{12}{52}$
mecantzadas

Fuente: Reglamento estructural de la producción lechera.

Las razas de aptitud mixta y la crla del ganado con destino al sacrificio, son un capltulo esencial en la comarca, pero hasta en Gste son notables las diferencias; gran parte de la carne producida procede del ganado de desecho, de vacas que ya han cumplido su misión económica dentro de la ex plotación -producción de leche o el trabajo-, asl como del ganado no especializado en la producción de leche. La venta de terneros recien destetados, con un peso aproximado de 85 a $90 \mathrm{Kg}$. canal, es 'btro componente esencial de este apartado, pese a que tal venta se realiza al margen de las disposiciones legales, que exigen un peso superior, por causa del apre cio de su carne. En efecto, estos terneros, criados desde su nacimiento con leche materna, sufren una considerable deprecia ción en el momento del destete, razón por la cual el ganadero prefiere venderlos aun por debajo del peso permitido, $120 \mathrm{Kg}$. canal ( 7 ). 


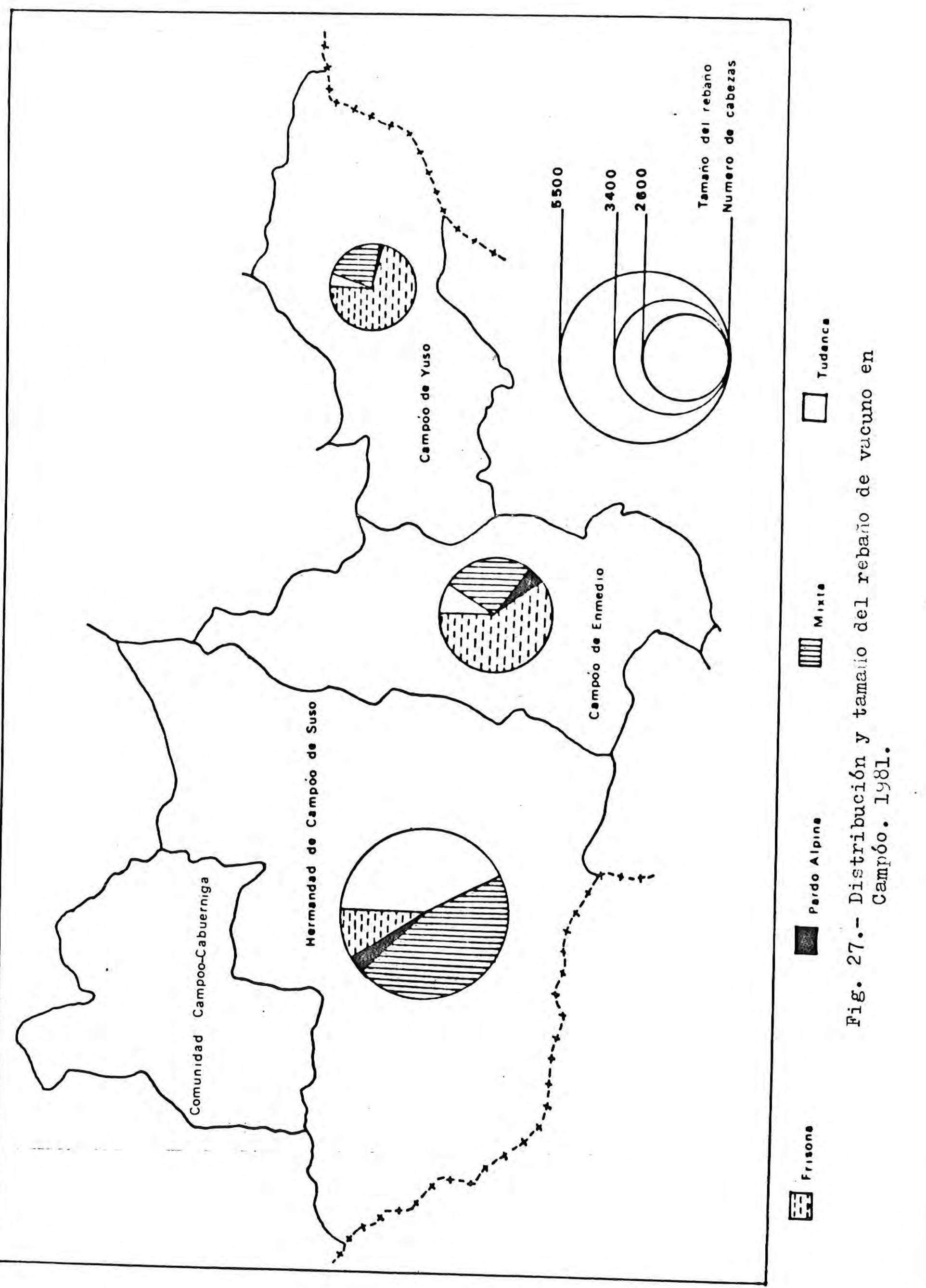


En 1981, la composición del rebaño de vacuno no se ha mo difioado subtanoialmente reapeoto a la existente en 1978. S1 se aprecia un incremento de ganado especializado en la produc ción de carne en Campóo de Suso. Existen ya en efecto algunos e jemplares -106- de raza Charolesa y de Aberden-Angus, prueba de que, si no en la producción de leche, al menos existen indicios de modernización en la producción de carne en este sec tor.

Persiaten no obstente las diferenclas entre los distintos municipios, en cuanto a la composición del rebaño de vacuno, $d \underline{\underline{I}}$ ferencias que se mantienen, aunque aqui la reduccion ha sido general, en la composición del ganado equino y menor.

\section{o/ El carácter subsidiario del ganado equino y menor}

Dentro del inacabado tránsito entre una economla de sub sistencia y una economla abierta, es donde habrla que situar el significado que tiene la presencia, cuantitativamente menos notable que en el pasado, del ganado menor.

Corresponde todavia al fuerte arraigo que numerosos sectores de la población campesina mantienen por un tipo de explotación en la que lo fundamental no es sino proveerse de to do lo necesario para la subsistencia, evitando detraer de los ingresos obtenidos la mayor cantidad de dinero posible; y esto se logra, evidentemente, produciendo la mayor parte de 10 que se precisa consumir. Eil carácter eminentemente doméstico de este ganado - ovejas, cabras, cerdos, gallinas etc...- se he de enmarcar por lo tanto, en el contexto de una explotacion poco racionalizada, como un mero complemento. Su número no es importante, es incluso mucho más bajo que en el próximo pasado, pero en cambio su significado econbmico es fundamental 
en el contexto de la economla doméstica, máxime cuando su manutención no supone más que un pequeño esfuerzo adiccional, atrviendo en cambio como complemento a la dieta alimenticia familiar.

\section{CUADRO XIJIII}

El. GANADO EQUINO Y MENOR EN CAMHOO. 1981.

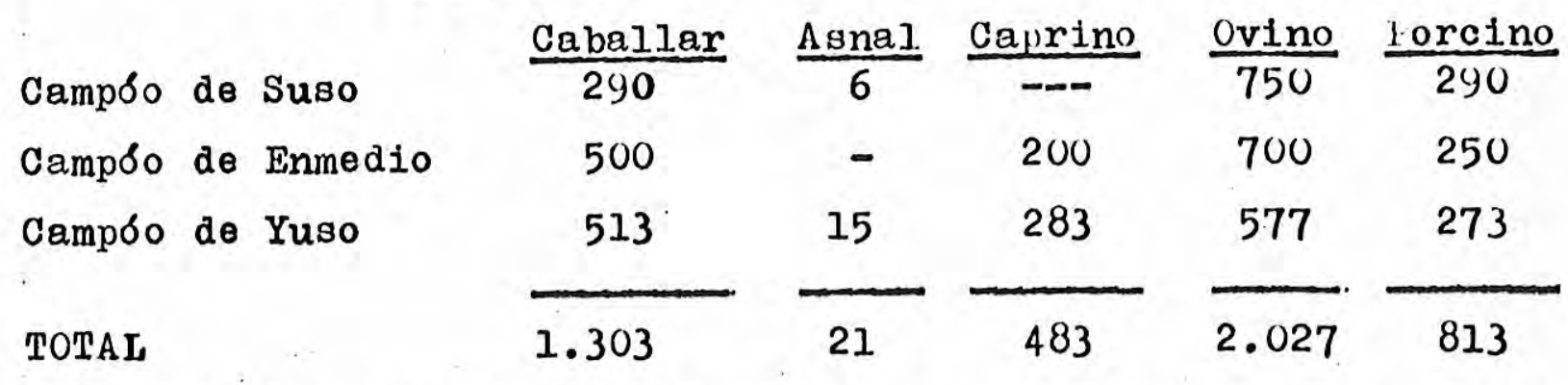

Fuente: Censo ganadero 1981.

Mayor carácter residual posee sin embargo el ganado equino, otrora importante dentro de la explotación agraria. Orientado tradicionalmente hacia la producción de mulos con destino a regiones de fuerte demanda -Castilla fundamentalmente-, en la actualidad apenas tiene significado en el contexto de la explotación moderna. Los ejemplares que existen son, sin embargo, muy apreciados, lo que ha hecho que sus propietarios se hayan decidido a no prescindir de ellos. La venta de este ganado constituye incluso un cap1tulo destacado en las ferias de Reinosa, en espectal la del 21 de Septiembre -San Mateo-, a Ia que acuden compradores de varias regiones, aunque una parte sustancial la constituyen "tratantes" franceses, pals en el que la carne de equino es más apreciada que en España (8).

En suma, la explotación ganadera actual en Campóo, presenta rasgos de modernidad en la composición del rebaño,modernidad a la que no escapan otros aspectos y en especial la mecanizacion.

(8) Crónicas de la Provincia. En Alerta, diario de Santander 23 de Septiembre 1976, pág. 21. 
3.- LA MECANIZACION: UNA CONSTANTE EN LA NUEVA EXPLOTACION GANADERA.

En la explotación ganadera actual, y a un ritmo que, sin poder evaluar tenemos constancia de que ha sido muy intenso, se ha llevado a cabo una intensa mecanización, tanto las gran. des como en las pequeñas, pero en especial en las primeras, porque el laboreo de un número de tierras cada vez mayor, demandaba el empleo de ella a pesar de las dificultades que, pa ra su amortizacion, el campesino tenfa. Tampoco han sido ajenas a este proceso las explotaciones pequenas; y no lo han sido porque en la mecanización encontraron la solución al escaso tiempo que, ocupados sus titulares en otra actividad, le podlan dedicar.

El proceso ha sido muy rápldo e intenso como lo demuestra el hecho de que, los tractores, ordeñadoras y motosegadoras prácticamente inexistentes a principios de la década de 1970 se encuentren generalizados, si no los tres, al menos uno de ellos en las explotaciones actuales. Baste indicar como ejem plo que, an Campbo de Yuso más del 60 por 100 de las explota ciones disponfan de ordeño mecónico en 1982, cuando en 1973 este porcentaje no alcanzaba siquiera el 10 por 100.(i).

Pese a todo la mecantzación y motorización no se ha lle vado a cabo de forma racional. Coexisten ejemplos de acusada infrautilización, como los que afectan a las pequeñas explotaciones, con casos en los que todavia serla preciso llevar a cabo una mecanización mayor. Pero es sin duda en la motort zación donde con mayor intensidad se aprecian las contradiccio

(9) En el presente año -1982-, sobre 102 explotaciones, que representan el 40 por 100 del total, declararon tener ordeño mecanico 65, es decir el 63,7 por 100. Datos obtenidos del Directorio de explotaciones agrarias del censo de 1982 y del Reglamento estructural de la producción lechera del mismo año. Camara Agraria de Campoo de Yuso. 
nes de este proceso reciente de modernización de la explotactón agrarta.

El número de tractores existentes en la comarca en 1980 era de 212 , cantidad relativamente baja on rellación al total de explotaciones; la mayor parte de ellos están infrautiliza dos, al emplearse de modo casi exclusivo en el traslado de la hierba $y$ abono, siendo por ello muy reducido el equipo mecá nico de los mismos ( 10 ); cierto es que la mayor parte de ellos son de potencia bajay de coste reducido, por lo que su adquisición no ha presentado mayores dificultades para el cam pesino, hablendole liberado en cambio de un buen número de ser vidumbres,

En cambio otras labores agricolas que podlan ser mecantzadas, se han seguldo realizando hasta fechas muy recientes de modo manuel, especialmente el ordeno mecánico y la siega de la hierba, Ambos trabajos, pero especialmente el segundo se siguen realizando de modo manual, y ello pese al relativamente bajo precio de las motosegadoras. En Campdo de Suso la media de hectáreas que corresponde a cada motosegadora es de 95,8, algo menos en Campó de Enmedio 70,9 hectáreas, y menos aún en Campó de Yuso, 61,1 hectáreas. Ello implica que parte de este trabajo ae realiza por el procedimiento de arrendar la máquina o contratar la slega con el propletario de la misma, lo que para éste ha representado en muchos casos una rápida amortización de la citada máquina. Esta práctica ha sido muy frecuente hasta hace bien pocos años, pero en la actualidad todas las explotaciones de cierta entidad y dedicación exclusiva cuentan con ella (11).

(10) En Campó de Enmedio, para 57 tractores habia en 1980 13 arados de discos, 8 sembradoras y 7 abonadoras. En Campoo de Suso los 95 tractores se completaban con tan sólo 28 arados y 12 gradas. C.0.S.A. Resumen de documentos 2-T. ( 11 ) El tipo de motosegadora más extendido en la comarca es de la marca AGRIA, de $12 \mathrm{Cv}$. y un precio medio de 65.000 a 70.000 pesetas. Hay también un número elevado de motosegadoras de la marca BEDOGNI, de $14 \mathrm{cv}$. y un precio que oscila entre las 83.000 y las 85.000 pesetas. Delegación de Agricultura. SAN tander. expedientes individuales. 
Los Indioes de motorización, oalculados aobre la potenola de 10 s tractores y motosegadoras, y según los $\mathrm{CV} / \mathrm{Ha}$. de super Piole labrada y de prados, son muy dispares entre los distintos municipios; en Campo de Enmedio la media es de 0,6 cv/ Ha. en Campoo de Enmedio de l,l Cv/Ha. y en Campóo de Yuso de 2 $\mathrm{Cv} / \mathrm{Ha}$. Estos Indices serlan mucho más elevados si el cálculo se realizase exclusivamente sobre la superficie labrada, cuya proporoión es poco menos que insignifioante en relación a la superficie total.

GUADRO XLIX

IAA MOTORIZACION EN CAMPOO. POTENCIA FOR HECTAREA

\begin{tabular}{|c|c|c|c|c|}
\hline & & $\begin{array}{l}\text { Potencia total } \\
\text { en Cv. }\end{array}$ & $\begin{array}{l}\text { Labrantfo y } \\
\text { prados (Has.) }\end{array}$ & $\mathrm{Cv} / \mathrm{Ha}$. \\
\hline $\mathrm{C}_{\mathrm{amp} \delta \mathrm{o}} \mathrm{d}$ & e Suso & 4.386 & 6.816 & 0,6 \\
\hline Campdo de & Y Yuso & 3.731 & 1.777 & 2 \\
\hline Campdo de & e Enmed 10 & 3.758 & 3.218 & 1,1 \\
\hline
\end{tabular}

Fuente: Ministerio de Agricul.tura. Santander. Expedientes de mecanización. Fichas individuales.

Pese a que la mayor parte de los tractores corresponden al tramo de las potenclas medias, entre 25 y $59 \mathrm{Cv}$., su infra utilización es manifiesta si tenemos en cuenta la gran disper sión de las parcelas de cada explotación y el exiguo tamaño de las mismas ( 12 ). Su :número, pese a $s \in r$ reducido como apuntábamos puede parecer suficiente si lo relacionamos con la superficie cultivada y la ocupada por los prados; en efecto, en Campoo de Suso el número de hectáreas por tractor es de

(12) La concentración parcelaria realizada en Campoo de Yuso ha paliado en parte este problema, por lo cual la motorización es mucho más racional. En efecto, el número de tractores en relación a las explotaciones totales es mucho más elevado que en el resto de la comarca. más de un 25 por 100 disponen de él en la actualidad, mientras que en los otros municipios las explotaciones que disponen de tractor no llega al 10 por 100. 
71,7, en Campठo de Yuso de 20,6 y en Campठo de Inmedio de 56,4. Esta media, inferior a la macional -aproximadamente 100 hectá reas- puede resultar engañosa sl no tenemos en cuenta que la superficie realmente aprovechada es muy redicida en toda la co marca, lo que reduce considerablemente el número de hectáreas por cada tractor; por ello, y porque, como hemos indicado la mayor parte de los tractores son de potencia reducida, es mas expresiva la relación potencia/hectárea. que anteriormente hemos apuntado.

Pero, además de infrautilizada es una motortzación que, en general ha estado mal orientada; en efecto, las ordenadoras y motosegadoras, que permiten redimir una gran cantidad de tra bajo mediante una cantidad de dinero asequible a las pequeñas economlas familiares, no se han generalizado hasta fecha bien tardla, y cuando ha tenido lugar no ha sido del todo racional.

En la mecanización el campeaino ha tratado de encontrar la panacea a las insuficiencias tradicionales de las explotaciones agrarias, y ello ha dado lugar a que se haya llevado a cabo por debajo de umbrales que podfan hacerla rentable. La causa de este despilfarro se encuentra en que ha sido concebi da más bien como un recurso para mantener la pequeña explotación familiar a flote, que para hacerla realmente productiva; prueba de ello es el hecho de que, invariada la composición del rebaño, se adquiere algún tipo de maquinarta, como por ejemplo las ordeñadora, para realizar un trabajo que no alcan za más que a una parte del mismo -3 o 4 vacas de leche-, perdi das entre caballos, ovejas, cabras etc...

Pese a todo ha representado un progreso indudable; hoy gran parte de las labores manuales tradicionales ya no se rea Iizan, cuando todavia en 1972 apareclan censados en uno de $10 s$ municipios 150 arados romanos, 145 guadañadores y 120 trillos de pedernal. Y no es más que un ejemplo (13).

( 13 ) C.0.S.A. Censo de liaquinaria en Uso. Doc. 1-T Campoo de Yuso 1972. 
Se trata, en suma de una mecanización que, en la mayor parte de los casos no está orientada a lograr una mejora de ' los rendimientos por via de mejorar las labores agricolas, sino a realizar una sustitución del trabajo, no tanto por comodidad como porque el titular de la explotación no podia realizarlo; en efecto, la mecanización ha permitido subsistir a un gran numero de explotaciones a tiempo parcial, en las que el titular considera, y asf lo hemos constatado en una reciente encuesta, prioritario en su atención el trabajo rea lizado en Reinosa. Sólo de este modo podemos exilicarnos 10 que en apariencia es una gran paradoja: que se encuentren mecanizadas explotaciónes desde umbrales muy bajos (14).

Todas las transformaciones que la actividad agraria ha experimentado en los últimos años han supuesto una muptura con los modos de vida y organización del espacio agrario tradicio nal; y una ruptura, a la que no es ajena la pórdida de significado, en parte inevitable, por causas ajenas a la comarca, del aprovechamiento del monte.

4.- UNA ACTIVIDAD EN RETROCENO: EL APROVECHAMIENTO DE], MONTE

El monte, cuyo concurso era esenctial en la economia tradi cional ha visto perdida paulatinamente su importancia en los últimos decenios, porque una de las actividades que en ell se desarrollaba, el aprovechamiento de la madera para elaborar aperos de labranza y otos articulos ha caido en desuso al no

(14) Del total de explotaciones mecanizadas en $\mathrm{V}_{a m p \delta o}$ de Yusq 84, más del 10 por 100 no alcanzaban ni siquiera las $6 \mathrm{hec}-$ táreas. Los mayores niveles de mecanización correspondan al tramo de las 6 a la 10 hectáreas, que representan el 42 por 100. En cualquier caso, todas ellas tenlan una proporción relativamente importante de tierras arrendadas. Cámara Agraria de Campóo de Yuso.1981. 
existir prácticamente demanda para los mismos, ni en la comar ca ni fuera de ella.

Además de las restricciones tradicionales impuestas por las ordenanzas, hay que añadir las derivadas de su actual cla sificación como montes de utilidad pública, que limita en ellos la extracoión de madera, salvo petición expresa al I.C.U.N.A. Por esta causa, y porque el precio de la madera no hace atrac tiva su explotación, los aprovechamientios forestales son muy reducidos y se realizan con irregularidad en la comarca ( 15).

Es pese a todo una forma más de obtención de ingresos pa ra sus propietarios, st bien su cuantla no es elevada, y los montes susceptibles de aprovechamiento se encuentran agrupados en unas pocas Juntas Vecinales. En conjunto, la comarca posee un potencial forestal notable -3.833 hectáreas produc tivas-. De acuerdo con la Ley de Regimen Local, el importe de los rendimientos del monte corresponde a sus propietarios-en Campó las Juntas Vecinales- con la excepción del 15 por 100 que se destina a la inversión en trabajos de mejora del mis-mo; por otra parte, la Ley de Montes reconoce, con ciertas $1 \underline{i}$ mitaciones a los vecinos de las localidades propietarios de los montes, los aprovechamientos de pastos y lería para el consumo de sus hogarea, que no proporcionan ingreso alguno por renunciar las Juntas Vecinales al cobro del cánon por estos aprovechamientos. ( 16).

Per, con todo, estas restricciones son, al menos a nivel individual, innecesarias; la población de la comarca no depen de del monte, tan estrechamente como en el pasado, para encontrar el complemento de su subsistencia. La explotación agra-

(15) En un periodo de 10 años se extraen aproximadamente 6.000 metros cubicos de roble y unos 21.500 metros cúbicos de haya, siendo su destino bien la elaboración de duela, tabla y traviesa en el haya, y tabla rasa en el roble, con destino a industrias de transformación -fábricas de muebles o se rrerfas de Torrelavega y Burgos, y en una pequeña proporción de Reinosa. I.C.O.N.A. Memoria forestal de la Comarca de Reinosa. 1981:

( 16 ) A. DIAZ de PAZ.- los montes... 0p. cit. pág 81 


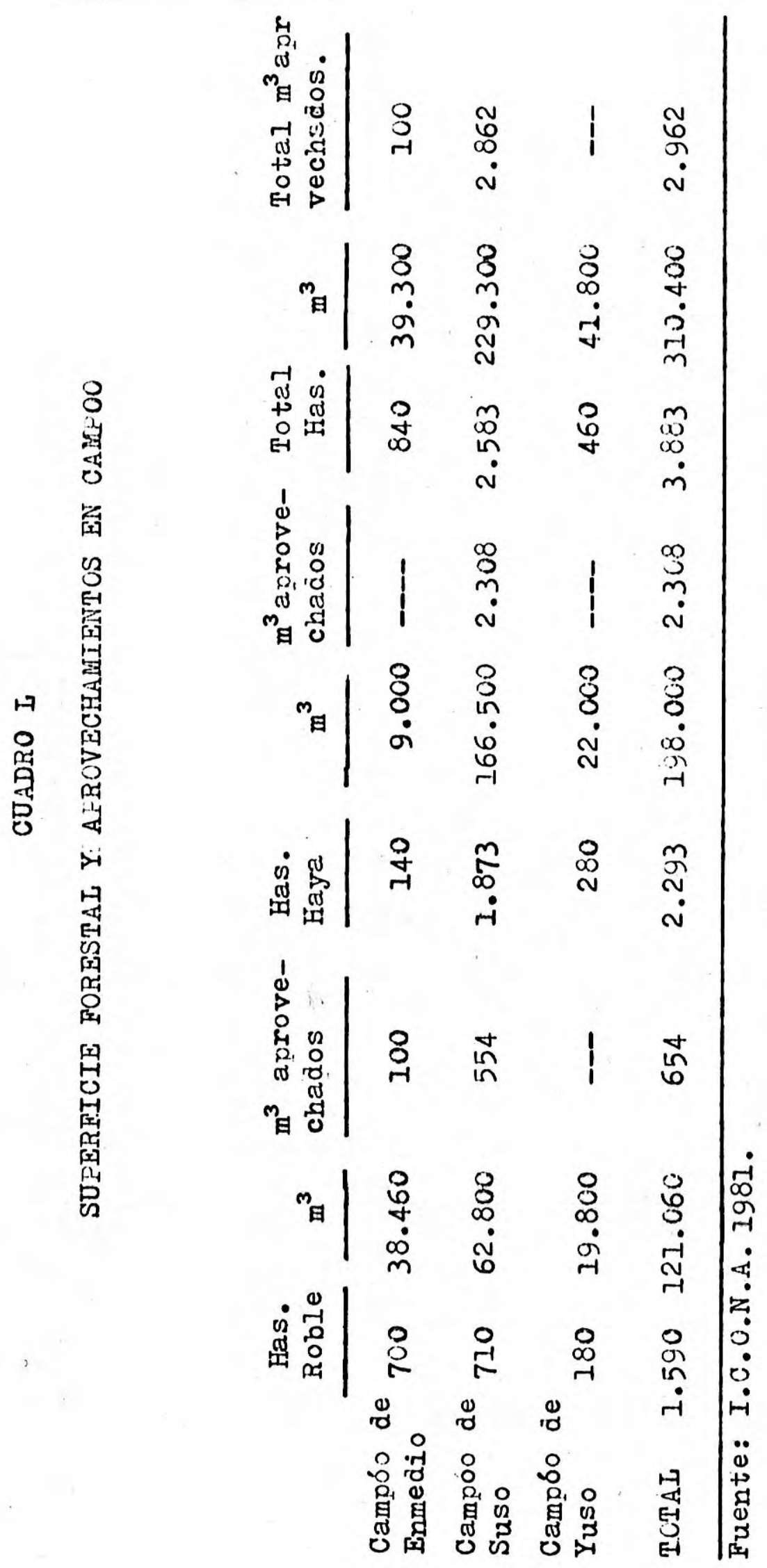


ria cumple hoy, en muchos oasos esta functón de complemento, que no de subsistencia, cuando el labrador ha encontrado-y es muy frecuente- trabajo en la industria de Reinosa. Este nú cleo ha sido el verdadero impulsor de todas las recientes trang formaciones, a las que no escapa, obviamente, él mismo. 
CAPITULO XV

LA REGIENTE EXPANSION DE REINOSA: UN PEQUEÑO NUCLEO INDUSTRIAL, CENTRO COMARCAL DE SERVICIOS.

Pese a la indudable importancia que tiene la industria en toda la comarca, y en el núcleo de Reinosa en particular, en la práctica, ésta ha sido incapaz de contener, una vez supera dos los momentos de euforia iniciales, el éxodo rural que con intensidad se defa sentir desde 1960. Nd siquiera ha servido para absorber el crecimiento demográfico de Reinosa, que por esta causa mantiene una población prácticamente estancada deg de 1950, carácter que también presenta la propia industria. En efecto, el número de actividades industriales, y la población o cupada en ellas es prácticamente la misma que hace 30 años. Es por ello por lo que, si ha habido alguna transformación, ésta se ha debido sin duda a la notable transformación del sector terciario, cuyo significado, en evidente conexion con un reforzamiento del protagonismo del núcleo urbano de Re nosa dentro de la comarca, merece una consideración más dete- 
nida. Meroed a ella el núcleo urbano de Relnosa experimenta un crecimiento de cierta entidad, menor de lo que cabria esperar, puesto que una parte sustancial de 61 se deriva hacia 10s pueblos próximos $y$ en especial hacia Nestares $y$ Matamoro sa; ambos vieron ya incrementado su caserio entre 1960 y 1970, el primero en un 15 por $100 \mathrm{y}$ el segundo on un 63 por 100 , sien do prácticamente los únicos que crecieron, al menos sustancialmente. Pero, a partir de 1970 tal crecimiento ha sido mu cho más espectacular, habiéndose producido un cambio total en el caserio, dotadio ya en ambos casos de cierto aspecto urbano, mayor cuanto más próximo a Reinosa.

Todo este proceso ha tenido lugar en un contexto de atonia de la actividad industrial, que sigue manteniendo, con po cas variaciones, la misma estructura y los mismos niveles de ocupación, contrastando con una notable expansión, en cantidad y calidad del comercio y servicios de núcleo de Reinosa, consolidando y aun incrementando su funcion tradicional de cen tro comarcal de servicios.

No se trata, en absoluto, de un fenómeno anómalo; está perfectamente tipificado en otras regiones y en otros núcleos urbanos similares. En ellos, como en Reinosa, la actividad Industrial está concentrada en una empresa de grandes dimensiones que ocupa a un porcentaje elevado de la población activa industrial -entre el $70 \mathrm{y}$ el 90 por 100; 1gualmente, tras un periodo inicial de fuerte crecimiento, se asiste a un cierto estancamiento, para dar paso a una notable expansión del sector servictos, sin que por ello se llegue a superar el volumen de ocupación de la mano de obra industrial.

Asimismo, dado el escaso efecto multiplicador de la industria dominante, la oferta de empleo está prácticamente monopolizada por ella, y depende de su capacidad de producción; en estos casos, y Reinosa es un magnifico ejemplo, la oferta y la demanda de empleo tienden a equilibrarse con rapidez por la intensa afluencia de una mano de obra poco conflictiva, no 
cualificada de origen rural. Será la propia empresa la que se 'haga cargo de su cualificación mediante las escuelas de apren dices $u$ otros sistemas similares (17).

Cuando la industria cubre sus necesidades de mano de obra, el mercado de empleo se desequilibro/con rapidez, siendo preciso que el sector terciario absorba los excedentes, hecho que sólo sucede cuando esté suficientemente desarrollado; no ha sido date, al menos hasta 1975 el caso de Reinosa, razon por la cual el saldo migratorlo ha s1do, desde 1950, cong tantemente negativo. En camblo, a partir de 1975 -de modo apro ximado- comercio y serviolos crecen en número y diverateloan su oferta, adquiriedo cierta capacidad para absorber los exoe dentes de mano de obra de origen rural, y del propto núcleo de Reinosa, mejorando temporalmente la situación del mercado de trabajo.

En parte, la causa del exodo, que, pese a todo no desapg rece en ou totalidad se encuentra en el hecho de que la oferta de empleo no es cualitativamente diversificada; predomina en general, tanto en 10 s comienzos de la industrialización como posteriormente, la oferta de empleo no cualificado, puestoque el equilibrio entre oferta y demenda de empleo cualificado se logra con rapidez, hecho que hace poco atractivo para parte de la población joven de Reinosa el acceso a aquellos puestos de trabajo, que serán rápidamente ocupados por inmigrantes de ori gen rural, o por la población de la comarca que no abandona su explotación agraria y pasa por ello a engrosar los desplazamientos diarios entre el lugar de residencia y de trabajo.

Se trata de una forma más de migración pendular, en este caso lejana en sus caracteres a la que tiene lugar en las gran des aglomeraciones urbanas.

( 17 ) J. P. LABOIRE - Industializatión et croissance démographique des petites villes en milieu rural: $1^{2}$ exemple de Midipyrénées. Revue Géographique des Pyrénées et dù Sud-Ouest. Tome 45. Avril 1974 no 2 p. 109-131. Sobre estos mismos aspectos ver también G. JALABERT.- Un exemple d'implantatión industrielle en mijieu rural: I'usine aéronautique Ratier-Figeac. Ibid. tome 38 Mars $1967 \mathrm{n}^{2}$ 1, p. 47-67. 
Es por lo tanto, directa o indirectamente, la industria la responsable de los cambios en el modo de vida tradicional de la comarca, pero su importancia debe ser, cuando menos, ma tizada

1.- LA YREEMINENCIA DE LA INDUSTRIA SIDERURGICA: UNA ACTIVIDAD CON ESCASO EFECTO MULTII IICADOR EN LIA DOMARCA.

La Industria de Reinosa no ha pasado de ser una actividad en cierto modo embrionaria, poco diversificada, y ello a pesar de que el volumen de empleo generado fue, en algún momento, su ficiente para reactivar y reconvertir la estructura económica de la comarca. En efecto, como hemos venido apuntando, las ren tas industriales han sido un componente sustencial en la moder nización de la actividad agraria, a la vez que han permitido, gractas a los cada vez más elevados niveles de consumo, una ex pansión del sector servicios sin precedentes.

Todo ello ha sido posible gracias a una industria que, sus tancialmente conserva los mismos rasgos que en el momento de su Instalación, salvo pequeñas modernizaciones o cambios en la estrategla empresarial que se llevaron a cabo al ser absorbida la fábrica de construcción de motores eléctricos -CENEMESA- por la multinacional Westinghouse, y al integrarse la Sociedad Española de Construcción Naval en el grupo de Astilleros Españolies S.A.; tales cambios no se tradujeron en un crecimiento de la oferta de empleo, razón por la cual podemos afirmar que se trata de una actividad estancada. Un ejemplo de este práctico estancamiento lo ofrece la evolución de la mano de obra ocupa 
en la industria sin duda alguna de mayor entidad de las existentes en Reinosa: la siderurgta. El número de trabajadores en ella empleados apenas ha variado desde 1930 (18).

\section{CUADRO II}

EVOLUCION DEL NUMERO DE TRABAJADORES EMPLEADUS EN A.E.S.A 1940-1981.

$\begin{array}{lccc}\text { AÑo } & \text { Ne de trabajadores } & \text { AÑo } & \text { Ne de trabajadores } \\ 1930 & 2.000 & 1974 & 2.600 \\ 1940 & 1.524 & 1975 & 2.592 \\ 1950 & 1.993 & 1976 & 2.548 \\ 1960 & 2.098 & 1977 & 2.521 \\ 1969 & 1.959 & 1978 & 2.442 \\ 1970 & 2.188 & 1979 & 2.372 \\ 1971 & 2.170 & 1980 & 2.360 \\ 1972 & 2.301 & 1981 & \\ 1973 & 2.361 & & \end{array}$

Fuentes A.E.S.A. Departamento de personal. Efectivos por talleres y secciones.

Por ello, y salvo la industria siderurgica, que por otra parte define el carácter del nucleo, apenas existen otras actividades industriales de importancia, razon por la cual, la entidad de esta actividad en conjunto debe ser contemplada con olerta prevención, puesto que ol no se puede negar su importan cia, no es menos cierto que la Industria reinosana carece de dimensiones suficientes y sobre todo de la capacidad para impulsar el desarrollo de actividades paralelas. Su efecto multiplicador, precario en los comienzos de la actividad, es, en una valoración global, muy reducldo. Gran parte de las peque-

(18) Además de la industria siderúrgica y la construcción de motores eléctricos - Westinghouse- apenas existen industrias de importancia. Algunas, consideradas "fábricas de muebles", que en realidad no pasan de ser "carpinterfas"de ciertas dimensiones, pequeñas industrias de alimentación de carácter semiartesanal, y la fábrica de galletas Cuétara, ésta de cierta entidad -250 trabajadores/as-, se instals en 1951 es la única que cuen ta con clerta tradición - en nivejes por supuestos mucho más reducidos- en la comarca; en efecto la fabricación de galletas $y$ dulces en general arranca del siglo XIX, en relación con el tráfico de las harinas con destino al puerto de Santander. 
గas "industrias" de Relnosa tienen un carácter semiartesanal, estando orientadas, casi de modo exclusivo, a satisfacer una 'demanda exclusivamente local o a lo sumo comarcal; tal es 10 que sucede con las fábrioas de muebles, de bebidas o de alimen tación en general. Tanto su origen -un crecimiento de la demanda local- como la falta de mercados ajenos a la comarca, invalida, en mi opinión, la propia denominación de actividad Industrial, máximo al tonemos on cuenta que aponas oxiste manipulación, transformación, de los productos que serán puestos posteriormente a la venta, y que la mayor parte de ellas no tienen siquiera 5 trabajadores empleados (19).

Tan solo cuatro industrias-A.E.S.A, Westinghoue, forjas de Reinosa y Cuétara- tienen un carácter plenamente industrial y a ellas dobe Reinosa el primer estimulo a su exjansion, y decimos el primero, porque el reclutamiento de mano de obra, desde su instalación se ha limitado a mantener un nivel de em pleo invartado, de tal modo que las salidas de actividad son compensadas simplemente por un número de entradas similar (20 ). En estas condioiones, y dado que, obviamente, el oreolmiento vegetativo de la población de Reinosa y de la comarca ha sido hasta el momento de signo positivo, no es extraño que la emigración sea una constante en ambos casos, y que cuando ésta se ha reducido, lo haya hecho casi exclusivamente por causa del dinamismo reciente del comercio y servicios del núcleo de Reinosa.

(19) Este dato es muy génerico, resultado de encuestas reaIfzadas en algunas de ellas. Invariablemente, la demanda de cualquier tipo de información me ha sido negada, al menos en los términos que pretendla. Por ello tan sólo me ha sido po-atble disponer de valoraciones cualitativas, que, no obstante creo tienen cierto valor, por reflejar unos hechos por otra parte evidentes en la observación directa. ( 20 ) Además de A.E.S.A., cuyo nivel de empleo ya hemos comentado las otras trés industrias también se caracterizan por el mismo hecho, es decir, el estancamiento de la oferta de puestos de trabajo. Forjas de Reinosa mantiene unos 80 trabajadores desde su creación 1954, Westinghouse,-antes CENEMESA- aproximadamente 450-500,1.0s mismos con los que inicio sus actividades en 1930. Idéntica situación caracteriza, por último a la fábrica de galletas Cuétara. 
2.- LA CONSOLIDACION DE REINOSA COMO CENTRO COMARCAI DE SERVICIOS.

Sin duda por efecto del propio dinamismo de Reinosa, pero también por causa del incremento del nivel de vida, de ua mayor información y de una notable tendencia al consumo entre la población campesina, en los ultimos axos se ha producido una expansión del comercio y semvicios, prolongando, aunque con un alcance y significado diferente la función que tradicional mente habla venido desempeñando.

Ha sido por lo tanto una mayor presión de la demanda la que ha estimulado esta expansion reciente, ouyo origen hay que situar en el contexto de las transformaciones que en toda la comarca seirán sumando a lo largo de la década de 1970. Pero no se ha producido solo un incremento cuantitativo; junto a 61 se aprecia una diversificación de los servicios ofrecidos y una cada vez mayor calidad en los mismos, tanto de los de uso diario como en los de mayor duración y precio. Y en esto, como en otros aspectos, Reinosa ha actuado como un gran centro aglutinador; la inmensa mayoria del comercio y servicios se concentra en Reinosa, estando el resto de la comarca desprovisto de ellos o reducidos a los de consumo inmediatos la pe queña tienda-taberna de ámbito exclusivamente local. Su oferta de productos ha quedado ampliamente superada por una demanda en expanaion, que permite al mismo tilempo explicar alguno de los caracteres del sector terciario del núcleo de Reinosa

En ell coexdsten servicios y comercio tradicionales, cu-ya oferta ha permanecido más o menos invariada, con otros de nuevo cuño, adaptados tanto a satisfacer las nuevas necesidades de la población rural, coms a atender a una clientela nue va, constitufda por aquellos que, merced al trabajo en Reino- 
sa han logrado un mayor nivel de vida, manteniendo activa su explotación agraria, y por los que trabajan en algunos servi cios de reciente creación y cierta cualificacion -asesorlas agencias de seguros, bancos etc....-.

En respuesta a las necesidades de unos y otros se han de sarrollado servicios especificos que contrastan con aquellos que conservan inalteradas sus caracterfsticas tradicionales En efecto, con una imagen de gran almacén o "bazar" tradicio nal, en el que se pueden encontrar los artlculos más variados, desde piensos para el ganado y aperos de labranza, hasta comes tibles y prendas de vestir, todavia existen varios comercios en Reinosa, con una clientela fiel, asidua, especialmente en los dias de ferias o mercado, y procedente de toda la comarca. Tal clientela acude a ellos por costumbre, o porque su nivel de exigencia no ha variado, siendo por ello todavia importante.; aqui es, en efecto, donde el campesino puede encontrar algunos instrumentos de labranza que ningún otro comercio tiene ya a la venta -rastrillos, horcas, dalles, cebillas para el ganado, campanos, carretillos etc...-, aprovechando también para hacer otras compras en el mismo comercio, para lo que tamblen éste está preparado. Son sin duda una reliquia de aquellos almacenes decimonónicos en los que se combinaba la venta de articulos producidos en la comarca, con productos ultramarinos.

Para esta misma clientela, pero en otro orden de necesidades, se han ido instalando varios centros de venta y repara ción de maquinaria agrfcola, cuya penetración y generalización on la comarca es relativamente reciente -d6cada de 1970-. A1mu cenes de piensos y fertilizantes completan este tipo de oferta de bienes, especlfica en sus caracteres y en su destino final.

La decadencia lógica en el correr de los tiempos, de cier tas actividades tradicionales, que servian para abastecer a cada explotación de una serie de productos imprescindibles, uni- 
da a la Industrialización de Reinosa desde ol. primer terolo del presente siglo, hizo necesarto aumentar y diversificar la ofer ta en el comercio y servicios; y esta tendencia, lejos de remitir en intensidad ha sufrido un nuevo impulso por causa de las nuevas y cada vez mayores exigencias de la población campesina. La mecanización y motorización de las labores agrícolas, la rea lización de reformas en el interior de las casas -frecuentes en los Ultimos años-, y el deseo de procurar un mayor nivel de equipamiento a sus hógares, ha dado lugar a quo proliferen comercios y servicios destinados a tales fines.

CUADRO LII

IA OPERTA DE SERVICIOS DE REINOSA.1975 y 1981

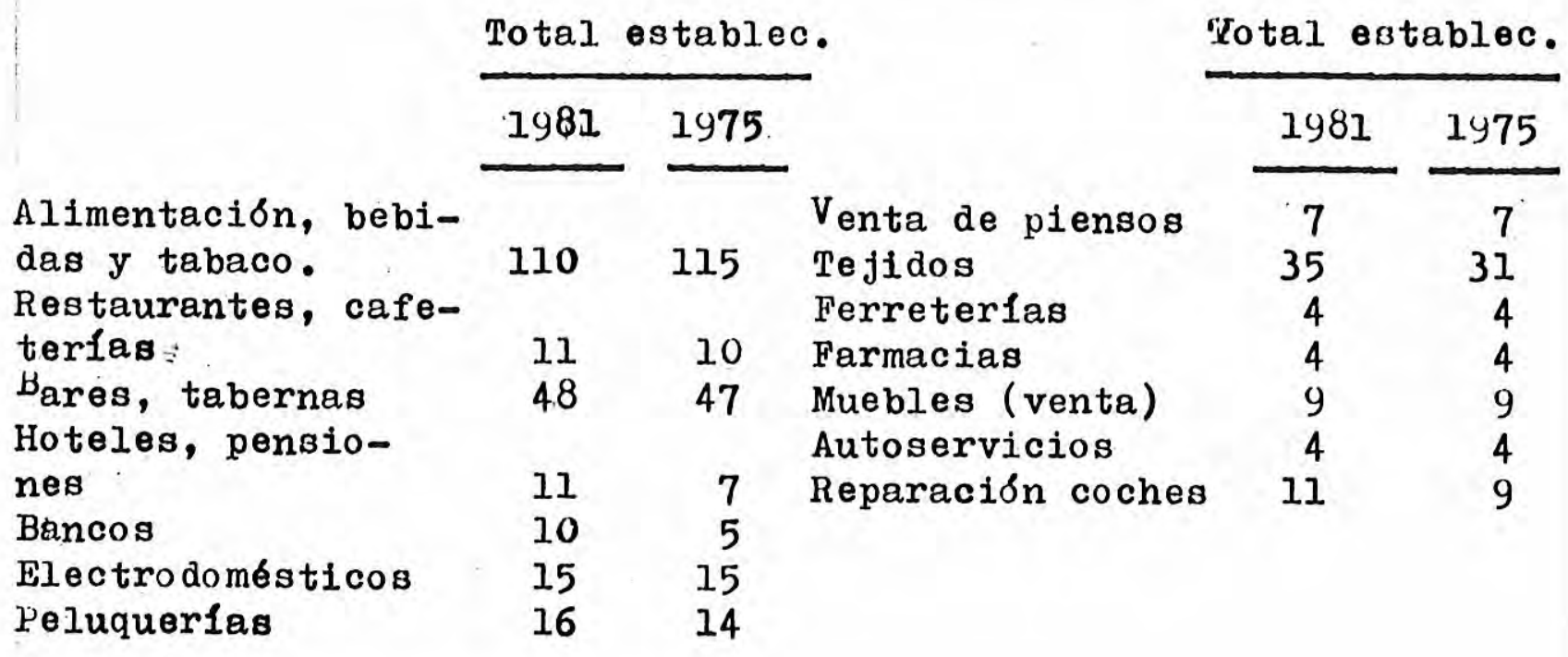

Fuentes Licencia fiscal. Aros 1975 y 1981.

Junto a la demanda de los citados servicios, cuyo origen_ es en buena medida rural, hay que anadir aquellos, que, por es tar la comarca fuertemente polarizada en un solo núcleo, llegan a adquirir cierta importancia; se trata de servicios sanitarios, financieros, enseñanza y servicios profesionales en ge neral -legales, administrativos, jurldicos etc..... No hay que olvidar, por ultimo el significado de otro tipo de servicios, los relacionados con el ocio, puesto que la concentración de 10s mismos en Reínosa es prácticamente absoluta, en competen- 
cla con los que ofrece el núcleo de Aguilar de Campbo, en el Norte de Palencla y del que le separan poco más de $30 \mathrm{~km}$. Pero no son sblo los servicios de ocio los que se encuen tran concentrados en Reinosa; el comercio local de los pequeกоร núcleos de población se encuentra en franca regresión, no s6lo por la constante pérdida de población, sino también por el alto nivel de insatisfacción que su oferta, incapaz de renovarse,genera. El problema queda paliado porque Reinosa, con una irradiación espacial mayor, concentra la mayor parte del comercio, otrora disperso por su área de influencia.

En cualquier caso, el desarrollo del comercio ni es casual ni responde exclusivamente a una cada vez más intensa demanda de origen rural; una importancia aún mayor que ésta, tiene, is gicamente, la propia demanda interna, que constituye in duda la causa fundamental del tamaño, diversidad, y sobre todo calidad de los servicios. Se trata, en efecto, de una demanda cuantitativa y cualitativamente superior a la rural; cuantita tivamente porque la población de Reinosa representa más del 60 por 100 del total comarcal, y cualitativa porque los niveles de renta del núcleo urbano son superiores en conjunto a los de la población rural.

Gracias a ésta se puede explicar el número de determinados comercios -restaurantes, cafeterfas, pub, tiendas de confeccion etc...- y servicios personales y de esparcimiento. La localización de la mayor parte de este comercio y servicios dentro del núcleo urbano se sigue ajustando a la tradicional. Ocupan ambos lados de la actual carretera Nacional 611 -anteriormente conocida como Camino Real de Reinosa-, via obligada de paso para los carreteros en su trayecto hacia Santander, a ambos lados de la cual se ubicaban los almacenes de trigo harina y productos coloniales. Toda la actividad comercial de Reinosa gravita en torno a este eje; aqu1 se encuentra la prác tica totalidad del comercio de cierta calidad, mayor cuanto más 


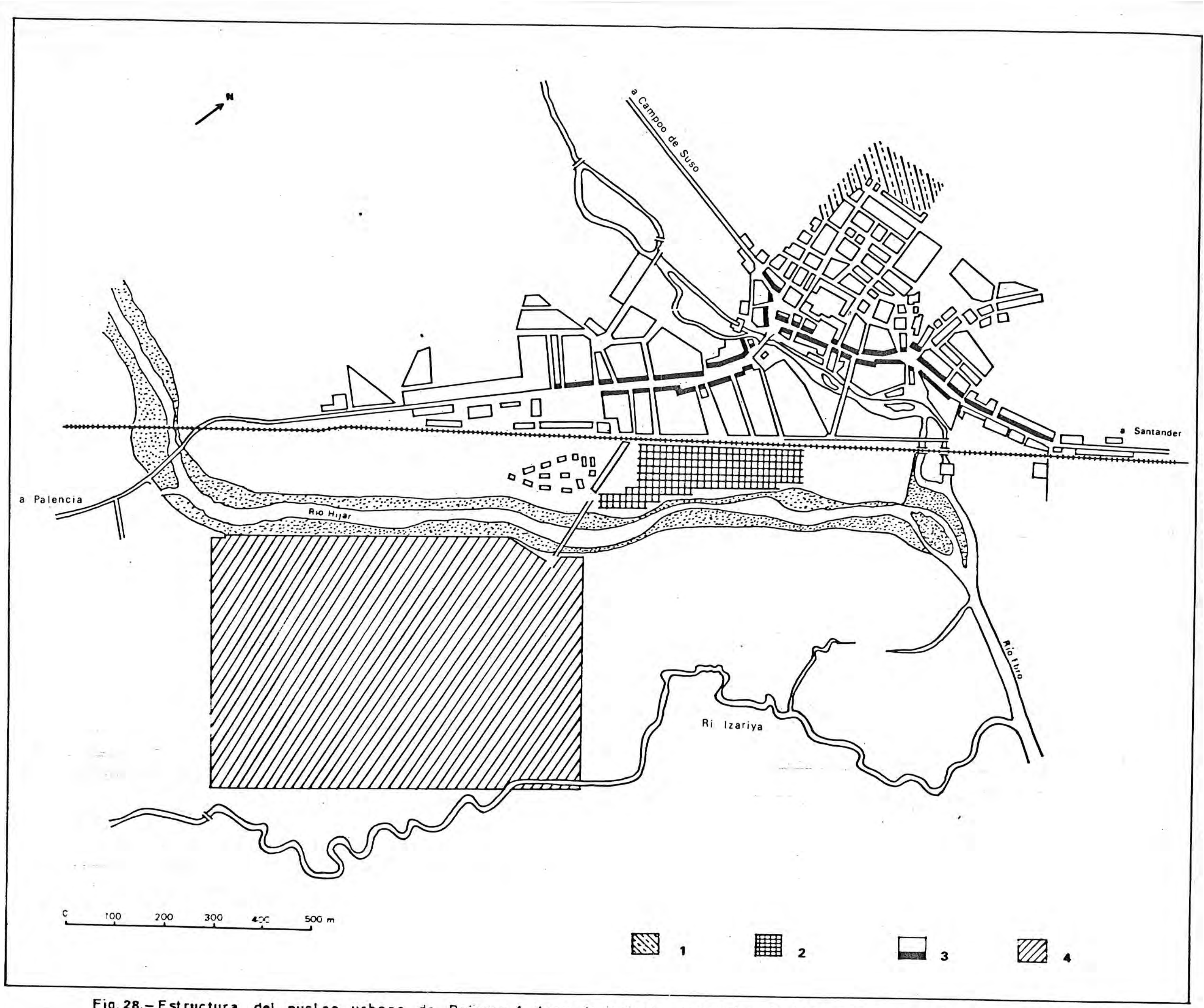

Fig. 28.-Estructura del nucleo urbano de Reinosa. 1- Area de reciente expansion. 2-Area residencial clases trabajadoras 3.-Localizacion del comercio 4.- Area industrial. 
proximo está a lo que podrfamos considerar oomo centro de una estructura desequilibrada: la Plaza Mayor, y la plaza Diez V1 cario (ver figura 28 ). Al márgen de este eje, el comercio es menos variado, y se limita a las pequeñas tiendas destinadas al consumo diario.

Pero con todo, con el significado que tiene el sector ter clario dentro del núcleo, y pese a la reciente expansión, que no podemos cunntificar a la espera de los ultimos resultados censales, es diflotl que Reinosa haya defado de ser, atendién do solo al volumen de mano de obra ocupada, un oentro industrial.

\section{CUADKO LIII}

POBLACION ACIPIVA Y POBJ,ACION DEPENDIENTE EN RLINOSA.1960

\begin{tabular}{|c|c|c|c|c|}
\hline & $\begin{array}{l}\text { loblación } \\
\text { activa }\end{array}$ & $\%$ & $\begin{array}{l}\text { Poblacion } \\
\text { dependiente }\end{array}$ & $\%$ \\
\hline Agricultura.Minas & 64 & 1,9 & 106 & 1,6 \\
\hline Industria & 1.965 & 56,6 & 4.071 & 65,2 \\
\hline Construccion & 81 & 2,4 & 127 & 2 \\
\hline Comercio, transporte & 619 & 18,3 & 990 & 15,7 \\
\hline $\begin{array}{l}\text { Servicios personales } \\
\text { y oftcieles }\end{array}$ & 487 & 14,4 & 539 & 8,5 \\
\hline \multirow[t]{2}{*}{ Otros } & 216 & 6,4 & 442 & 7 \\
\hline & 3.432 & 100,0 & 6.27 .5 & 100,0 \\
\hline
\end{tabular}

Fuente: Censo poblacion 1960.

En 1960, la poblacion activa owupada en la industria representaba más del 56 por 100, y la población de ella dependiente era superior al 65 por 100 del total. Todavia en este momento, Reinosa podla ser definida como un núcleo monofuncio nal, industrial, con una población ocupada en el sector servicios reducida e indudablemente gravitando en torno al elevado 
volumen de mano de obra industrial. Más adelante, cuando a la demanda interna se afrada la procedente de la comarca, la relacion entre el elevado, en volumen, sector secundario y el conJunto de los servicios se irá equilibrando por el crecimiento del último,al reafirmarse la tradicional función de centro de servicios pese a todo, en 1975 todavia el desequilibrto era favorable a la población ocupada en la industria.

3.- IA INTENSIDAD DE IAAS RECIENTES TRANSFORMACIUNES EN EL NUCLEO URBANO DE REINOSA.

El rápido crecimiento de la población de Reinosa desde 1900 - un 346 por 100- se ha visto reflejado en una expansion superficial de considerables dimensiones. Tal ampliación de la superficie ocupada por el núcleo urbano no se ha ljovado a o日 bo de forma continuada, sino de modo esencialmente discontinuo desde el punto de vista temporal, y contradictorio en el orden espacial.

Superada la euforia económica del primer tercio del siglo pasado, la población de Reinosa entrará en una fase de estancamiento, tanto demográfico como económico, del que no saldrá hasta los últimos años de la segunda década del presen te siglo. En este momento se produce un hecho que cambiará el rumbo de un pequeño núcleo de poblacion, tradicional centro de servicios y esencialmente atonico; en efecto, el inicio de las obras de construcción de la factorla que en Reinosa instalará la Sociedad Española de Construcción Naval atraerá un elevado número de trabajadores, incrementándose la población del núcleo en un 42 por 100, lo que supone un principio de ruptura 
de la atonla mantenida desde la segunda mitad del siglo XIX; prueba de ello es el hecho de que, durante los primeros 18 'años del presente siglo tan sólo se construyeron 84 viviendas, 1o que significa que, la actividad de la que hemos denominado "primera generacion" industrial de la comarca, apenas sirvib para contener la depresión que sucedis al ooaso de la carreteria.

Desde el año 1918, el saldo migratorio en cambio comienza a ser positivo; llegan, en efecto, a Reinosa más de 1.000 Inmigrantes; siendo este número mucho mayor al término de la década de 1920. Entre 1919 y 1936 se construyen 590 nuevas vâ viendas para hacer frente a una demanda mucho mayor de 10 que el nucleo podla acoger; estas viviendas, localizadas en forma más o menos dispersa por todo 6l, se concentran de modo parti cular detrás de la Plaza Mayor, constituyendo un sector residencial de clases modestas bastante definido, tanto por sucon tenido social como por su morfologla. Se trata, en efecto, en su mayor parte de viviendas de reducido tamaño $50-60 \mathrm{~m}^{2}$, en edificios de tres o cuatro alturas y construldos con materia les muy pobres, nada diferentes, en suma a las que, para estas clases sociales se construyen antes de la Guerra Civil (21)

La década de 1930 constituye una etapa de estancamiento en la actividad constructiva, al compás de la recesión economica que acompańo a la crlsis mundial, los inorementoa do población decenales son ahora muy pequeños e incluso negativos, y con esta tónica se mantiene el núcleo hasta la década de 1950 ( 22 ). Desde el Intcio de la Guerra Civil y hasta 1950 se construirán 150 viviendas, para atender sin duda a

(21) H. CAPEL.- Capitalismo y morfologla urbana en España. Libros de Cordel. Barcelona 1977, pág, 55 y sig. ( 22 ) El saldo migratorio de la década de 1930 fue negativo. Reinosa perdio 652 habitantes; en cambio, en la década de 1940 cuando menos se contuvo la emigración-cierto es que las condiciones para emigrar no eran las idoneas en el conjunto del palssiendo el saldo positivo - lUl.inmigrantes-. Censos de población y registros civiles. Años citados. 
la demanda aparecida tras la Instalación de la Constructora Nacional de Maquinaria Eléctrica -CENEMESA- en 1930.

\section{CUADRO LIV}

EVOLUCION DEL NUMERO DE VIVIENDAS DE REINOSA DESDE 1900.

\begin{tabular}{|c|c|c|}
\hline & $\begin{array}{l}\text { Viviendas } \\
\text { construldas }\end{array}$ & Total \\
\hline Hasta 1900 & 1.236 & $-\infty-\infty$ \\
\hline $1900-1917$ & 84 & 1.320 \\
\hline $1918-1936$ & 590 & 1.910 \\
\hline $1937-1940$ & 28 & 1.938 \\
\hline $1941-1945$ & 28 & 1.966 \\
\hline $1946-1950$ & 114 & 2.080 \\
\hline $1951-1960$ & 452 & 2.532 \\
\hline $1961-1970$ & 552 & 3.084 \\
\hline
\end{tabular}

Fuentes Nomenclator.

Entre 1950 y 1970 se asiste a una expansión de la actividad constructiva, en unos años en los que, paradógicamente, la emigracion alcanza los valores már elevados del siglo. Cabe su poner que en estos años se hace frente a una demanda contenida durante los anos inmediatamente posteriores a la Guerra Civil. Se construyen 1.004 viviendas, parte de las cuales -312- se deben a la iniciativa oficial -Obra Sindical del Hogar- y Sin dicatos, en terrenos cedidos por el ayuntamiento próximos al polfgono industrial, conformando otro de los conjuntos de residencia obrera del núcleo.

La actividad constructiva, y el desarrollo económico en general durante la década de 1970, dan lugar a que Reinosa ad quiera ciertos caracteres urbanos, insuficientes, pese a todo, para desdibujar la imagen de tradicional centro de servicios. En efecto, se ha productio una renovacion parcial y puntual de su caserfo; nuevos edificios de porte urbano reemplazan a una parte de su decimonónico caserfo, surgen nuevos y diversifica dos comercios, nuevos servicios, y en suma, una nueva población 
que demanda mayores servicios, y una mayor calidad en la cong trucción. Esta no se desplegará ya en las proximidades de la industria, sino alejada de ella, en el Norte y Noroeste del núcleo urbano. Pero este fenómeno es muy reciente; gran parte de estas actuaciones inmoviliarias son posteriores a 1975.

La extensión a lo largo del eje longitudinal que constituye la carretera Palencia-Santander, y la muy baja densidad de ocupacion del espacio siguen siendo las notas dominantes en la estructura del núcleo urbano de Reinosa. 
CAPITUIOO XVI

SIGNIFICADO DE JOS CAMBIOS RECIENTES EN IAA ECONOMIA Y Y ORGANIZACION DEI, ESLACIO.

No es exagerado afirmar que una gran parte de las trang formaciones habidas en la comarca han sido inducidas por el crecimiento en todos los órdenes del núcleo de Reinosa. En cierto modo éste ha actuado como polarizador de todas las ne cesidades e inquietudes que, a trav6s de 61 han enoontrado, por lo general, respuesta.

El desarrollo de los servicios, su mayor número y diver oldad, ha sido causa y a la vez efecto, de una intensa y cong tantemente insatisfecha demanda. Pero es que además, en el tra bajo allf desarroliado por una parte sustancial de la población campesina es de donde proceden sin duda las rentas que han permitido acometer la siempre diffcil empresa de moderni zar la explotación agraria; en efecto, buena parte de las que 1o han hecho, aun a partir de una infraestructura deficiente, 
han contado con unas rentas, més o menos elevadas, ajenas a la explotación agraria.

Pero no ha sido sblo este el impacto de la expensión in dustrial de Reinosa; en el contexto una mejora general del ni vel de rentas se han podido también introducir pequeñas refor mas en el caserfo tradicional, tanto en su interior como en su exterfor. Se ha disociado en muchos casos el recinto destinado a establos de la vivienda, con lo que ha mejorado la higiene y las mismas condiciones de atención a la ganaderla. El nivel de vida es evidentemente mucho más elevado que hace tan solo 10 ○ 15 años; prácticamente todas las casas disponen de los electrodomésticos comunes, se han construldo cuartos de bafio, tambion hasta hace pocos aíos escasos. Pero las transformacio nes no han pasado de ahf; se ha mejorado a nivel individual, y ello ha hecho resaltar aún más las deficiencias del número, todavla elevado, de explotaciones marginales que, a rafa de estos hechos o bien se abandonan, o bien se incorporan al rit mo de modernización de las restantes.

En cambio poco se ha hecho a nivel colectivo; los nacleos de población ofrecen una imagen próxima a la tradicional, en la que tan sólo son novedad pequehos retoques en el caserio y la construcción de algunas naves para establo o garaje-almacén de aperos de labranza y maquinarla agricola. Pese a todo, apenas modifican una estructura con un alto grado de permanenola.

1.- EI RESULTADO DE LAS RECIENTES TRANSFORMACIONES: UN NUEVO PAISAJE AGRARIO.

La consolidación del cambio apuntado en los sistemas de explotación del espacio agrario tradicional, junto con el de sarrollo de nuevas formas de actividad, va a impulsar una mo- 
dificación sustanoial en el paisaje agraria. Este no estará ya condicionado, como lo estaba tradicionalmente por aujec'ciones de tipo colectivo; su organización responde a las ne cesidades de una nueva explotación agraria que, transformada de ralz, demasadaba un orden nuevo, una nueva estructura en el aprovechamiento $d \in I$ espacio agrario; y esta no se hizo esperár pese a 103 numerosos condicionantes de tipo estructural, y pese a la lógica resistencia de una población que vele quebrarse su sistema de vida y que por ello se mog traba reacia a cualquier transformaoion.

En este cambio de mentalidad intervinieron decisivamente aquelios que, gracias a un ahorro posibilitado por las rentas obtenidas de su trabajo en Reinosa, fueron pioneros en el cam bio de las estructuras. Otros muchos siguteron su ejemplo, y no es estrafio por ello que, en el conjunto de las explotacio nes agrarias más evolucionadas, su concurso sea fundamental.

\section{a) El Impacto de Reinosa: el desarrollo de una agricul- tura a tiempo parciel.}

Si todo el espacio comarcal ae ha visto sometido a la in fluencia del núcleo de Reinosa, es en la modernización, en el cambio de orientación de la actividad agraria donde el impacto se ha dejado sentir con más intensidad; por ello, el indirecto concurso de Reinosa es fundamental a la hora de compren der el alcance de todos los cambios habidos en el espacio agra rio.

Comenzaron estos, paradbjicamente, con el renacer de una actividad agraria en decadencia, incapaz de competis y de retener a la población ante las rentas seguras que proporcionaba el empleo asalariado en Reinosa. Desde esta decadente acti 
vidad, incluso desde unos supuestos estructurales invariados en el tiempa, se va a proceder a una transformación del 'paisaje agxario, por via de la modernización de las explota clones, durante la cual se borran gran parte de los vestigios de una actividad que, realizada durante largo tiempo de modo similar, habla dejado una profunda huella en 61.

Todo ello se logrará, no como en otros sectores, median te una concentración de las explotaciones, sino mediante un aumento de las mismas -gran paradoja de la reciente evolución-, por una puesta en funcionamiento de pequeña, y hasta ese momento poco rentables, empresas familiares. En esta reactivaoibn intervinieron de modo deciaivo las rentas obtenidas, al margen de la actividad agraria; gracias a ellas se pudo moder nizar la explotación, completar e incrementar los ingresos y acceder a unos niveles de vida hasta hacfa poco inalcanzables para la mayor parte de la población campesina.

La explotación ganadera a tiempo parcial ha pasado a ser una de las actividades más extendidas en la comarca; gran par te de ellas están mecanizadas y motorizadas, tienen un rebaño racional, moderno, en el que el vacuno de producción de leche predomina sobre otras especies, que muchas veces han desaparecido en su totalidad.

Su número es muy variable en los distintos municipios e incluso su significado, pero sin duda donde se encuentra más generalizada es en Campbo de Enmedio, por causa de la mayor proximidad al núcleo de Reinosa; pero la distancia no ha sido en absoluto obstáculo para el desarrollo de tal actividad. En efectio, con independencia de ella aparecen explotaciones a tiempo parcial en las que lo único que varfa es el sentido, la orientación general de la misma, y obviamente el grado de modernidad. En base a ello se pueden diferenciar con claridad dos tipos o modelos; el primero corresponde a los que, traba jando on Reinosa apenas han procedido a modernizar la infraestructura de la explotación -establos, maquinaria, abonos...., 
y poco han hecho tambien en modificar la composición del rebaño. En estos casos, la actividad agraria es, sin ningún gê nero de dudas, un mero complemento; muchas de ellas ni siquie ra han variado el regimen de explotación del ganado, es deotr, lo siguen haciendo en forma extensiva, y a partir de razas va cunas autbctonas. El número de las que observan esta estructura parece ser todavia importante en Campó de Suso, puesto que en el resto de los municipios, como en su momento vimos, apenas existen razas autbctonas dentro del ganado vacuno, pero, la gran disponibilidad de pastos en 108 puertos altos de la Hermandad de Campठo de Suso habrla permitido conservar elsig tema de explotacion tradicional; al menos asl parece indicar10 el número de cabezas de ganado vacuno y equino que pastan en los puertos altos durante el verano, y las impresiones recogidas "in situ" entre los ganaderos. Ya indicamos también que este sector era el último reducto, en la comarca, para el ganado de raza Tudanca, y uno de los pocos que restan en el conjunto de la provincia.

Se explica, por todo lo apuntado, que en estas explotacio nes el grado de transformación sea reducido, puesto que la rea lidad es que tampoco era necesario; en efecto, la atención que a ellas se le dedica es bastante limitada, al menos no es con tinua a lo largo del año, están liberadas de la diaria servidumbre del ordeño, y la comercialización de los excedentes es batante segura por la estima que alcanza entre los compradores el ganado tudanco. Pero con todo las rentas obtenidas son relativamente inseguras, menos que en ol pasado porque on el caso de que la hierba almacenada en 108 pajares no sea suficieñ te para todo el invierno, el campesino dispone de medios para proceder a la adquisición de algún "camión " de paja y piensos; y sobre todo son unas rentas meramente complementarias. 
El segundo tfipo de transformación llevado a cabo a partir de las rentas obtenidas en la industria o comercio reinosanos, es decir, el segundo tipo de ganaderia a tiempo parcial corresponde a aquellos que han llevado a cabo una modificación tal on su explotación que, aunque en su propia opinion sigan considerando como fundamental el trabajo el Reinosa, las rentas que obtienen de la misma son tan elevadas y en ocasiones mucho más altas que las logradas mediante el empleo asalariado. Muchas de ellas son ademas explotaciones "modelicas", es decir, están mecanizadas y motorizadas, tienen una composición en el rebaño francamente moderna, predominando las "pintas holandesas", la raza frisona, de las que obtienen una media men sual superior a los 500 litros de leche. Pero no es sólo la composición rasgo sobresaliente, puesto que la mayor parte de ellas además mantiene un rebaño numeroso, de más de 15 ejempla res como media, siendo muy frecuente que se posean más de 20 vacas. En conjunto estas explotaciones, en Campbo de Enmedio representan aproximadamente el 48 por 100, no siendo muy diferente el porcentaje en Campóo de Yuso (23).

En ellas, el grueso del trabajo corresponde a la mujer -más del 80 por 100 de los casos-y en un porcentaje menor a los padres $y / 0$ hijos. Bien es cierto que tal trabajo no tiene ya los caracteres tradicionales, como lo demuestra el que más

(23) La evaluación o cuantificación de las dimensiones que alcanza esta actividad es muy dificil de realizar, y no solo por razones fiscales, puesto que el titular de la explo tación sólo. hace la declaración de la renta que obtiene en su trabajo asalariado, y no por las rentas obtenidas de su explotación. El padrón no proporciona información más que de una actividad, y la mujer, que es la que lleva el "peso" de la misma, declara invariablemete dedicarse a "sus Labores". Otra de las fuentes que nos permiten una aproximacion cuantitativa y cualitativa a la par es la domiciliación de los trabajadores en las empresas, pero su valoración es muy irregular por dos causas; en primer lugar porque no se indica que se realice otra actividad, y porque las empresas, aconsejan la domiciliación en Reinosa para no pagar el "plus" de transporte. POr último la e cuesta realizada en el municipio en el que mayor población trabaja en Reinosa Campóo de linmedio, ofrceo unos resujtados que pueden ser tomadosaa modo de pequerío esbozo de una probable estructura. El tamaño de la muestra es pequeño - 41 explotaciones-, algo menos del 10 por 100 , pero está realizada 
del 70 por 100 de las explotaciones a tiempo parcial dispongan de ordeño mecánico. Para la realización de otras labores 'agrlcolas, el titular hace colncidir sus vacaciones con los periodos de máxima actividad enla explotación, especialmente con la recogida de la hierba en el mes de Julio, mientras que otros trabajos no ajustados a un ritmo estaciónal tan acusado se realizan en el tiempo libre diario o festivo.

Se logran de este modo, y a costa de no pocos esfuerzos unos Ingresos elevados, mayores cuanto más moderna es la explotación, y 6sta, en buena parte de los casos lo es. Parale lamente tales explotaciones han ido perdiendo los rasgos de arcalsmo que hablan pervivido casi hasta la decada de 1970, fruto de una cada vez mayor mecanización y racionalización en la alimentación del ganado; éste, en más de un 50 por 100 de las explotaciones, según la encuesta realizada, está destinado exclusivamente a la producción de leche, con unos rendimientos medios superiores a los 4000 litros anuales, mientras que tan s6lo uni 15 por 100 de las explotaciones a tiempo parcial conservan exclusivamente ganado de producción cárnica, pero a base de razas especializadas en buena parte de los ca รоร.

Por todo ello bien podemos afirmar que la tendencia seguida en la modernización de la actividad agrarla consiste on la consolidación de una explotación orientada hacia la produccion de leche.

b/ La explotación ganadera moderna: una inacabada espec1ajizacion en la producción de leche.

La explotación orientada hacia la producción de leche es en Campoo una muestra de la adaptación a nuevas condiciones de mercado, as 1 como del intento de extraer una mayor rentabilidad ante el declive de los sistemas de aprovechamiento tradicionales. 
Su número es todavía reducido en relación al total de explotaciones, pero su sientficado económico es de mucha ma yor entidad. Prueba de ello es que su número se incrementa de año en año. En 1977 había en la comarca -sin incluir Camp6o de Yuso- 575 explotaciones, mientras que un año más tarde, en 1978 exan ya 636 las que estaban censadas, lo que represen ta un inoremento de más del 10 por 100 ( 24).

En relación con las explotaciones censadas on 1.972, su número representa el 31 por 100, muestra de la importancia que está llegando a tener essta orientacion en la comarca.

\section{CUADRO IJV}

EXPINTACIONES DE GANADO VACUNO DE PROHUCOION DE LECHE 1977-1978.

1977

ne de ex-
plotaciones

Campóo de

Suso

Campoo de

Enmedio

Reino 8a

Total otal vacur

no de leche

325

237

13 no de leche

2,706

1.852

184

1978

№ de explotacio nes en 1978

366

explotac.

8,3

7,8

14,1

257

13

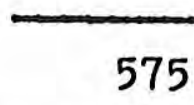

575

4.742

8,2

636

Fuente: Censo de explotaciones agrarias de "ganado vacuno de producción de leche". Cámara Agraria Enmedio, Reinosa, Campoo de Suso.

Gran parte de ellas son de dimensiones modestas; la media de cabezas de ganado vacuno es ligeramente superior a 10 cabezas, número que se reduce si consideramos tan sblo aquellas deg

(24). Censo de Explotaciones Agrarias de "ganado vacuno de producción de leche. Cámaras agrarias de Campoo de Suso, Enmedio y Reinosa. 1977 y 1978. 
tinadas a la producción de leche, hasta 8,2 cabezas. No obstante, los rendimientos no son todavia muy elevados, como resultado, sin duda, del predominio, en algunos sectores de razes mixtas sobre aquelias más especializadas -frisona y par do Alpina-; también tiene una importancia considerable la die ta, prioritariamente seca, que se proporciona a este ganado, aunque en esto, como en otros aspectos, las diferencias entre los distrintos municipios son considerables, como pudimos ver en el análisis de la distribución del terrazgo; en efecto, Campbo de Yuso aparece como el sector más evolucionado, frente a Camp6o de suso, en donde todavia ocupaban una porción impor tante del mismo las tierras de "pan llevar", muy por encima de la destinada al cultivo de forrajeras y a las praderas de poli P1tas.

Pero, al margen de los valores medios, cuya excesiva con sideración nos puede llevar a una distorsión notable de los hechos, el análisis pormenorizado de la estructura de las 725 explotaciones de las que tenemos informacion, y que se corres ponden a la práctica totalidad de las que a la producción de leche están orientadas en toda la comaron, podemos extraer una serie de concusiones que demuestran que, la pretendida modernización es incompleta, que subsisten todavía un sinfin de explotaciones, que hemos de considerar marginales, por cuanto ni el tamaño del rebaño, ni el grado de mecanización, ni por supuesto la producción final ofrecen rasgos de progreso( 25 ).

En efecto, entre explotaciones con una composición del rebaño y con una estructura adecuadas, se incluyen otras cuya producción no va más alld del consumo familiar, es decir, aquelias que tienen destinadas a la produccion de leche una

(25) El grado de fiabilidad de la fuente es, en opinión de los secretarios de las cámaras agrarias muy elevado, logico si tenemos en cuenta que el censo se hizo para conceder una subvención cifrada en 1060 pesetas por cada cabeza, para mejorar la infraestructura de la explotación. La mayor parte de ellas declaran precisar la subvenciban para introducir mejoras en los establos o cerrar fincas. 
o dos vacas, no siendo mucho mayor el resto del rebairo de va cuno.

Frente a ellas se encuentran las que como mínimo tienen un número de "hembras" en producción de leche o secas superior a 10. Estas esplotaciones representan el 29 por 100 en Campbo de Suso, y un porcentaje similar en Campbo de Enmedio, si bien en este municipio.son, en proprocion mayores las que superan las 20 cabezas en el rebaño de cada explotación.

Mayores raggos de progreso muestra en cambio el Campbo de Yúro; aqui la proporción de rebaños con más de 10 hembras de producción de leche es más elevada, aloanzando el 35 por 100 en el conjunto de explotaciones, si bien es cierto que de ellas se pasa casi sin solución de continuidad a rebaños que podemos denominar de "subsistencia", es decir aquelios que no tie nen más que algunas vacas -pocas-, generalmente de raza mixta cuya producción destinan al consumo propio, o, cuando son pocos en la familia, a la venta de algunos litros diarios. Pese a todo, la media de cabezas de vacuno por explotación es supe rior a 15, lo que indica, obviamente que el numero de las que sobrepasan tal tamaño es también muy elevado en el conjunto del municipio. Existen on efecto explotacioner con una entrega de leche superior a 108500 Iitros diarios, y un rebaño su perior a las 30 hembras en plena produccion

Con todo, y pese a que el proceso de camblo es logioamen te bastante lento, la incidenoia que tiene en el paisajo agra rio es Indudablo; esto muestra sintomas inoquivocos de trang formación, es un palaaje de praderas, eliminadas ya las tierras de labor tradicionales que le habian caracterizado hasta hace tan s6lo unos años. La subordinación del mismo a la explotación ganadera es evidente, distinta a la tradicional, puesto que no en vano han caldo en desuso todas las sujecciones colectivas que le dieron forma en el pasado. 
of Un paisaje agrario nuevo y totalmente subordinado a Ia explotación ganadera.

En el contexto de las transformaciones anteriormente apuntadas dentro de la economla rural, representados por el cam bio de razas en el ganado vacuno, y la reducción, cuando no de aparición del rebaño de subsistencia, tendrá lugar un oamblo tambión profundo en el. paisaje agrario. En 6ste, los cultiros tradicionales se han ido austituyendo progresivamente por pra deras artificiales y parcelas, más o menos extensas destinadas al cultivo de forrajeras, especialmente a la alfalfa; igualmen te, los prados naturales, acrecentados en un proceso secular a costa del monte y efidos comunales, son hoy la nota dominante en la mayor parte de las laderas, otrora ocupadas por el mato rral.

Pero las transformaciones van más allá de la simple susti tución de cultivos o de la pequena ampliación del terrazgo. Se ha operado un cambio en todo el sistema de aprovechamiento tra dicional del mismo, que de estar subordinado a una ganaderia extensiva, con fuertes sujecciones de tipo comunal, lo está ahora a una ganaderla explotada en regimen de estabulación y con notables exigencias en alimentación. A causa de ello, y de saparecidas, o al menos reducidas a la minima expresión las de rrotas de mieses, el campesino ha podido proceder al cercado de sus prados, en los que proporciona al ganado una alimentación verde, bien sea mediante el corte, o bien mediante la pacción directa del ganado en ellos. Generalmente estos pre dos, cuando están cercados admiten al menos dos cortes anuales que no se henifican, y alternando entre ambos pasta el ganado en forma más o menos continua, hecho que viene facilitado por otro elemento de reciente cristalización dentro del terrazgo: 
Los cercados de espino.

En la actualidad el paisaje agrario no es solo ya un pai saje de praderas, es ademés un paisaje de praderas cercadas, ouya extensión ha alcanzado dimensiones considerables, llegan do incluso a aquellos prados naturales localizados en sectores en apariencia poco favorables para admitir un aprovechamiento intensivo: las laderas. No obstante su cercado no es gratufto, sino que se persigue una doble finalidad, por una parte apro vechar tales parcelas una vez recogida la hierba por el ganado de cada propietario, en lugar de "en derrota", y por otra abonar someramente estos prados; al mismo tiempo el campesino puede relajar la otrora constante atención al rebaño, dado que dispone de menos tiempo -especiajmente cuando trabaja en Reinosa-.

Salvo en Campoo de Suso, donde aún las tierras de "pan llevar" ecupan una clerta y nada despreciable proporción del terrazgo cultivado -más de 140 hectáreas, que representan el 22 por 100-, siendo un rasgo de Indudable arcalsmo en una eco nomla de signo más abierto y en la que merced a los ingresos obtentdos en la venta de leche o ganado con destino al sacri ficto, el campesino puede resolver el problema de la alimenta ción, en el resto de la comarca, las praderas artificiales, los cultivos de forrajeras y los prados completan casl de mo do exclustivo el aprovechamiento del terrazgo, sin olvidar el significado que tienen 10 s tradicionales cultivos horticolas reducidos al pequeño huerto familiar.

Todos estos elementos, praderas artificiales, prados naturales y huertos aparecen dispuestos en el terrazgo de forma más o menos regular; en efecto, intercalados entre el caserio se encuentran los huertos, de dimensiones reducidas -10 a 20 áreas-, cuyo carácter y significado apenas ha variado con el paso del tilempo. En algunos casos no obstante hemos podido comprobar como los cultivos horticolas, destinados al consu-- 
mo familiar han sido reemplazados por alfalfa o más frecuente mente por polifitas destinadas a su siega en verde o al aprovechamiento "a diente" por el ganado, que permanece en ellos largos periodos de tiempo.

Rodeando a los dispersos o agrupados en paqueños barrios, núcleos de población, las antiguas mieses y eras se han conver tido en praderas cercadas on las que el aprovechamiento es muy intensivo, y a continuacion de ellas se encuentran 10 s prados naturales, remontando las laderas y sin solución de continuidad con el Ifmite del monte; conforme más próximos se encuentran a 61 su calldad disminuye, la hierba obtenta se reduce considerablemente, lo que les hace poco atractivos, hecho que se comprueba cuando su propietario abandona la explotación. En estos casos es muy frecuente que no se recoja en ellos la hierba, reconstruyénsose el matorral con estraordinaria facilidad.

En sintesis, se ha pasado de un paisaje en el que las tie rras cultivadas, y en particular las de "pan llevar" consti-tulan la nota dominante en él, a otro en el que la pradera ocupa la mayor parte del terrazgo, estando cercada en un número elevado de casos al decaer el slstema de aprovechamiento co leotivo on el que se basaba buena parte de la aotividad agraria tradicional, $y$ en la que los terrazgos cultivados domina ban sobre 10s terrazgos ganaderos. Actualmente estos se extienden, bien en forma abierta o cerrados, por la mayor parte de la superficie de la comarca, sin que por ello dejen de tener una importancia secundaria en relación a los espacios in cultos.

Si el paisaje agrario en general ha sufrido un conjunto de transformaciones de sierta entidad, el poblamiento se man tiene, en contraste, prácticamente inalterado. Escasas y aisladas modificaciones salpican una estructura en la que el as pecto más sobresaliente es la permanencia. 
2.- IA ESCASA RENOVACION DEI, POBLAMILNTO IRADICIUNAL: UN MERO RETOQUE A UNA ESTRUCTURA HEREDADA.

El poblamiento del valle de Campó no presenta rasgos originales dentro del conjunto de la montaña cantábrica; se ca racteriza por un elevado grado de permanencia, advirtiendose en $61 \tan$ sollo pequeños cambios inducidos por la necesidad de adaptarlo a la condiciones de la nueva explotación ganadera. Pero estos cambios no desdibujan en absoluto la trama general del mismo en la comarca.

En lo esencial se trata de un poblamiento heredado, de una estructura estable en el tiempo, cuyes únices modificaciones hay que situarlas en la baja edad media, en el siglo XVII y XIX. En el primer caso quedan destertas "yermas" una serie de unidades aisladas, más bien pequeños barrios o anexos de enti dades mayores, hasta un número de ocho ( 26 ). En el siglo XVII no tenemos constancia de la desaparición de unidades completas, pero si son frecuentes referencias a casas abandonadas y arruinadas, junto a la descripcion de las miserias de sus propietarios ( 27 ). En cambio, fruto de la expansión demográ fica de la primera mitad de siglo XIX vuelven a aparecer en sectores diversos de la comarca pequeñas unidades o ampliaciones del caser1o, comenzéndose a concentrar, en un fenómeno que no se ha interrumpido hasta el presente, en Reinosa.

(26) En el Becerro de las Behetrias aparecen documentados en Campo los siguiontes despoblados: Ucieda (termino de Camino) Valvas (têr. de Argüeso) Riañio (Tér. de Entrambasaguas) Regulanes (ter de Ia población Suso) Campo (ter. Celada Calderones) Pozana (tér. de Camino) Quintanilia de Cervatos (tér. de Cervatos) Quintanilla de Enmedio (tér. de Retortillo).

( 27 ) Censo de los Ayuntamientos deI lartido Judicial de Reinosa. 1654. Archivo Historico de Santander, C.E,M. 6-19. 
En su estructura, este poblamiento ha de ser interpretado dentro del contexsto general de un tipo de actividad agraria 'secular, a la que invariablemente aparece asociado; y aquella, bastante similar a la de otros sectores de la montaña cantébrí ca, está constituído por unidades de pequeño tamaño, minúsculas en algún caso, agrupadas en su origen, al menos en Campbo en torno a una casa solariega. Esta unidades ocupan el fondo de los valles, sin que existan entre ellas grandes distancias. $\mathrm{Su}$ caserfo no es muy numeroso, habitualmente de no más de 50 edificaciones, dispuestas en el espacio de forma bastante extendida; el caserio se encuentra aislado entre si e individualizado no por calles, sino por los anexos de la propia vivienda, tales como huertos corrales etc...

Todo ello da al conjunto un aspecto abierto, carente ade más de cualquier linea directriz, tales como calles, o de elementos aglutinantes, como plazas etc.. Se trata por lo tanto de un poblamiento concentrado pero no compacto, laxo pero no disperso.

En el la renovación ha sido muy limitada, salvo en Reino sa, cuyo caso ya hemos analizado, y los núcleos próximos en especial Nestares y Matamorosa, que merced a un notable incre mento de su poblacion han visto transformarse su caserio hasta un punto tal que ha llegado a adquirir cierto aspecto urbano.

a) Un poblamiento concentrado, constituido por pequeñas unidades agrupadas en el fondo de los valles.

Tanto en su población como en las edificaciones, el po blamiento de Campbo destaca por su reducido tamaño. El. 40 por 100 de los núcleos no liegan a los 30 edificios, y 3610 dos, Reinosa y Matamorosa, superaban los 200.

Pese a todo, el grueso de los núcleos, atendiendo a las 


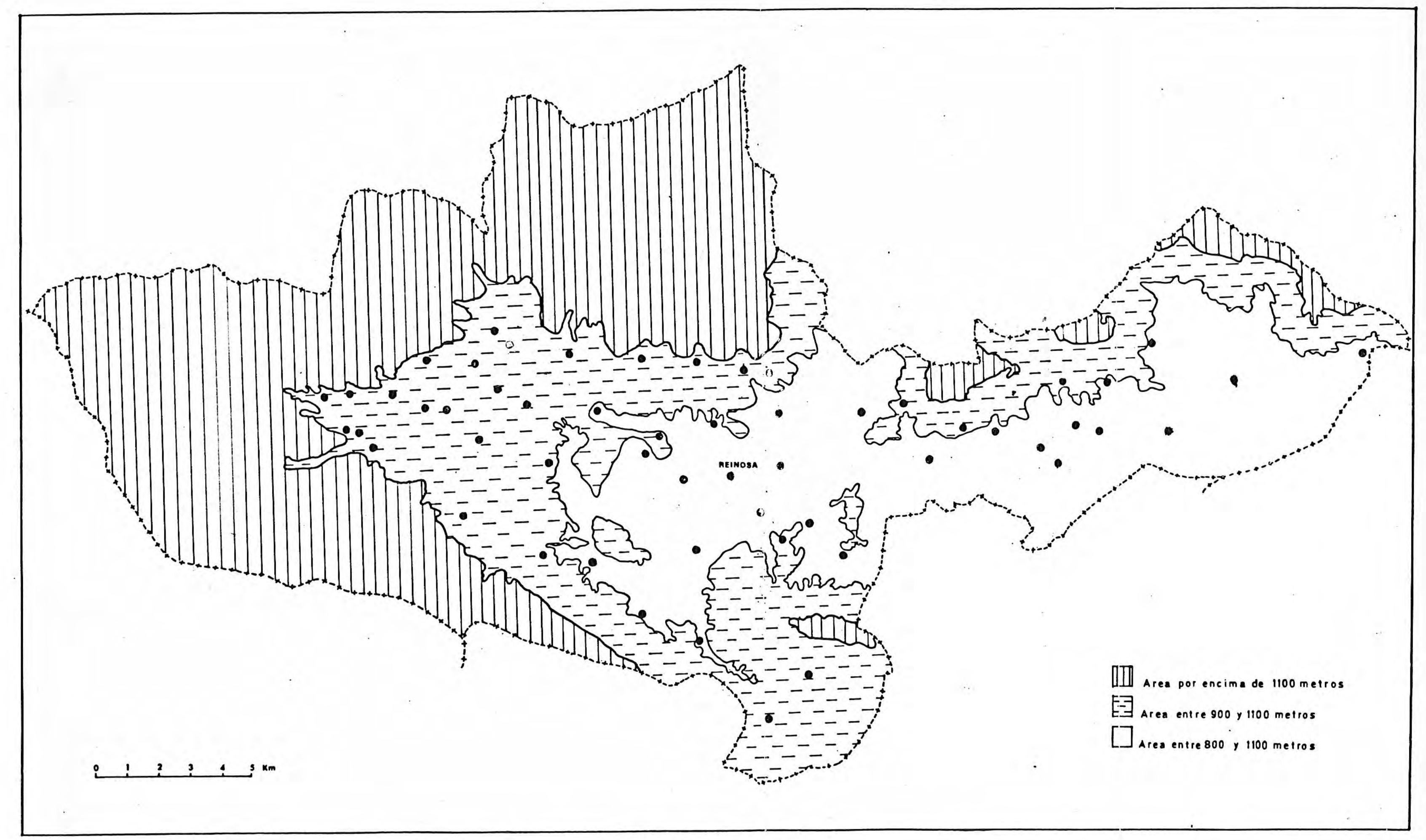

Fig. 29. El poblamiento en Campóo 
dimensiones de su caserio no desciende por debajo de las 15 , pero tampoco rebasa las 45 edificaciones; bien es clerto que, én la práctica cada edificio corresponde a una casa habitada - susceptible de serlo, puesto que en ellos están inmersas todas las dependencias precisas -habitación, cuadra, pajares etc...-, siendo poco frecuente la exlstencia de edificaciones aisladar al margen de la principal; si bien, recientemente se ha Iniciado el proceso de disociación de vivienda y establopajar mediante la construcción exenta de estos últimos.

Todas las unidades o entidades de población se encuentran además agrupadas en el fondo de los valles en forma escalonada entre los 800 y 1000 metros, sobrepasando esta altitud varios núcleos, pero sin sobrepasar en ningún caso los 1.100 metros. Se trata por ello de un poblamiento situado a una consi. derable altura, hecho que condiciona notablemente la estructú ra $d \in 1$ caserio.

Obviamente éste, reducido en gran parte de los núcleos, alberga a una población escasa, menor incluso de lo que por el número de edificios cabría esperar; y este hecho, que ha sido habitual en el pasado, adquiere en la actualidad unas dimensio nes sobresalientes a causa de la intensidad del proceso migratorio reciente, y particularmente de la concentración de la po blación en los núcleos de mayores dimensiones, Reinosa, Matamo rosa y Reinosa. En 1970 más de la mitad de los núcleos de población campurriana no contaba siquiera con 100 habitantes; en el extremo opuesto, y sin solucion de continuidad en el grupo de 500 a 1000 habitantes, $\tan s \delta 102$ núcleos, Keinosa y Matamo rosa superaban esta última cifra, si bien con evidentes diferencias entre ellos, porque si el primero superaba en la misma fecha los 10.000 habitantes, el segundo no llegaba a 1051.500 .

Nada sabemos sobre cual pudo ser el origen de este tipo de poblamiento, pero desde el momento en que tenemos noticias 


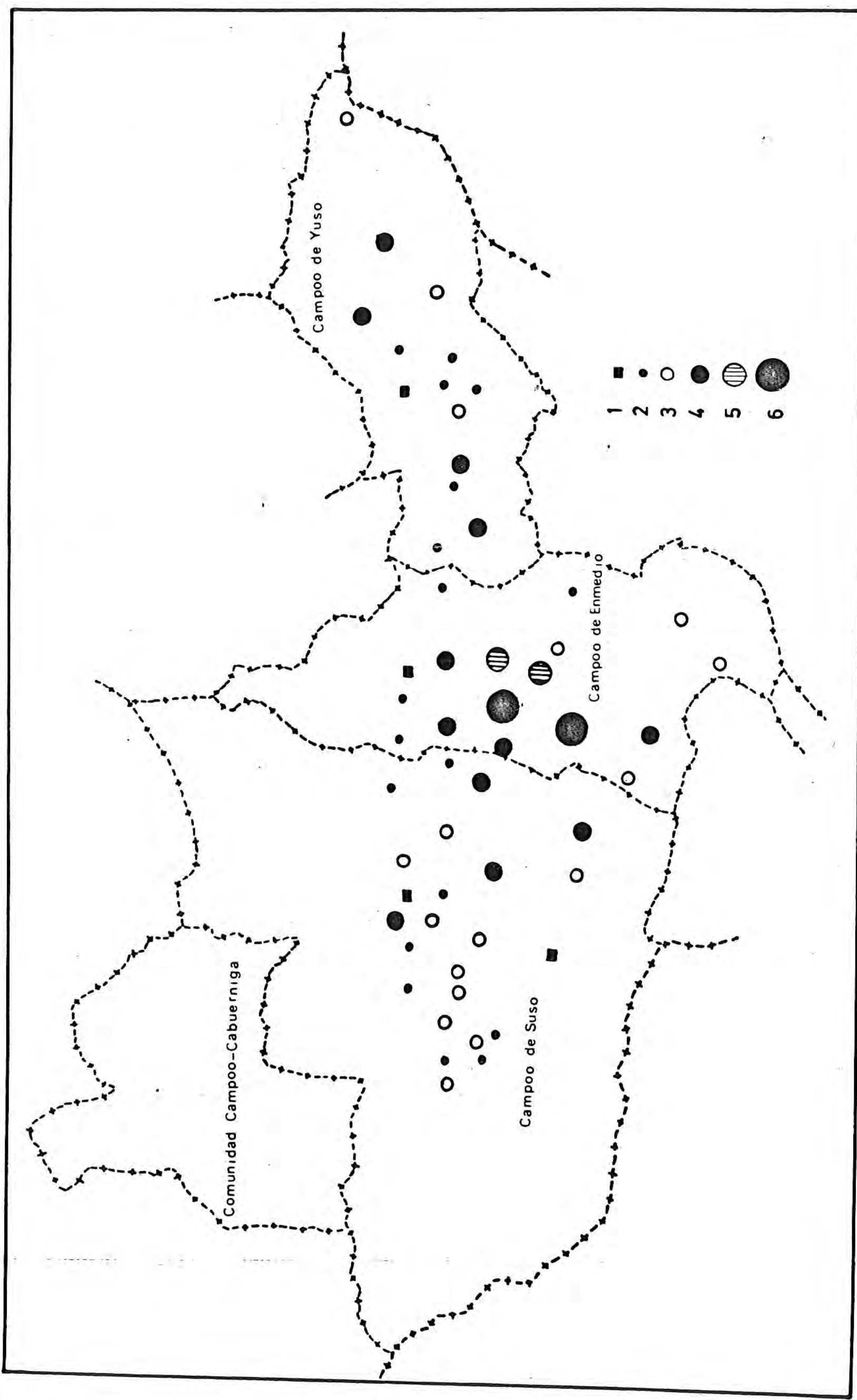

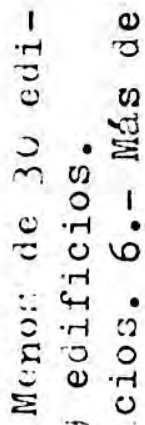

1 ड़

- ना त

त) 0

हิ

तु

¿ ค

ॠ

c

ป

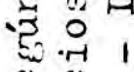

0. 0 ن

4
0.4

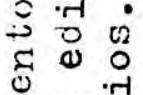

इ खू गु

है

데 0

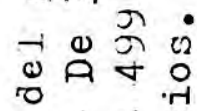

- 1 ा 00

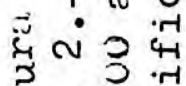
+ . ० 020 ว क्ष 0 ค ? ज蜹 $\dot{1}$ 1
0
0
0
0
0
01 
parece ser que su carácter autónomo, diferenciado entre si es Ia nota dominante, aunque algunos de ellos, surgidos como ane'xos o agregados -barrios- estuviesen integrados en una unidad mayor, el concejo.

\section{CUADRO LVI}

ESTRUCTURA DEL POBLAMIENTO EN CAMPOO SEGUN ELIIFICACION

Tipo de enti-

dades.

1960

\begin{tabular}{|c|c|c|c|c|}
\hline & NGmero & $\%$ & Número & $\%$ \\
\hline De 1 a 14 edif. & 5 & 9,09 & 4 & 7,27 \\
\hline De 15 a 29 & 18 & 32,72 & 18 & 32,72 \\
\hline De 30 a 49 & 14 & 25,49 & 15 & 27,27 \\
\hline De 50 a 99 & 13 & 23,63 & 14 & 25,49 \\
\hline De 100 a 199 & 3 & 5,45 & 2 & 3,63 \\
\hline \multirow[t]{2}{*}{ Más de 200} & 2 & 3,62 & 2 & 3,62 \\
\hline & 55 & 100,00 & 55 & 100,00 \\
\hline
\end{tabular}

Fuente: Nomenolator. Afros 1960 y 1970.

En cualquier caso, el aprovechamiento colectivo del terrazgo y aún de toda la superficie es probable que sea la base de este tipo de poblamiento, sin perjuicio de que el espacio cong trufdo sea relativamente extenso y de que las edificaciones se encuentren en ocasiones a cierta distancia; tal separación está acentuada por la disposición que adquiere el conjunto de anejos de la edificación -corral, huerto etc...- frecuentemente cercado. Este es otro rasgo más de singularidad que, junto a los caracteres que presenta la vivienda, ofrece el poblamien to campurriano.

b/ Un tipo de vivienda esencialmente funcional: la casa bloque de yiedra.

Con pequeñas diferencias de matiz, la casa campurriana pre 
senta una uniformidad que procede sin duda del empleo de un material similar, de su carácter cerrado, con pocos vanos y ádemás pequeños, y de la acusada funcionalidad que, sin exclu sión caracteriza a todas ellas. Con ser importante la identi ficación y descripción tipologica y arquitectónica, creo que tiene interés su análisis en el contexto de acentuada simbiosis que la casa presenta con el espacio comarcal y en particu lar con el terrazgo. Es aqui donde se puede realmente compren der el alcance y significado de los restantes elementos que, desde el punto de vista morfologico caracterizan a la casa cam purriana.

La casa de Campó -y en esto no ofrece ninguna originali dad-, responde al prototipo de casa-bloque, es decir, un edi ficio en el que se integran la vivienda familiar, el establo, el pajar y otras dependencias esenciales dentro de la explota ción. Esta estructura obedece a la necesidad de poder atender a la explotación en las condiciones extremas, frecuentes en los inviernos de Campóo, durante los que la nieve es un elemen to habitual y de larga permanencia en el suelo. La disposición de estas dependencias dentro del edificio sigue un esquema funcional, lógico por otra parte; los relacionados con la ex plotación-cuadras, bodegas etc...- se encuentran en la planta baja, salvo el pajar, que se encuentra en la primera planta, abierto al exterior mediante una ventana en el lateral de la casa; ocupa éste una parte sustancial de lo que en esencia co rresponden a la habitación humana. Igualmente, en la planta baja se encuentra la cocina y otras dependencias, hoy en desu so como la hornera. En el primer piso se encuentra la llamada salona, es decir, una estancia de grandes dimensiones de la que en muchos casos salen las habitaciones. Finalmente en un tercer piso, llamado "tercero" se encuentra el desván, que en ocasiones puede llegar a acoger alguna habitación suplementaria. 
El mismo carácter autárquico presenta la casa, consideran do no sólo el edfficio, sino el espacio inmediato a ella. En efecto, frente a ella o en un lateral se encuentra el corral, de ciertas dimensiones, y rodeado de una tapia de piedras colo cados sin mortero ni argamasa y de unos 70 centimetros de altú ra. Por último, en la fachada trasera se encuentra la pequeña huerta familiar, orientada habitualmente al Norte ( ).

Responde sin duda esta concepción y distribución de la ca sa campurriana a buena parte de los caracteres y sobre todo de las servidumbrea que presenta el quehacer tradictonal sobre el terrazgo, pero, paradojicamente, y por oposición a las numero sas sufecciones colectiva, su disposición en el terrazgo ofre ce rasgos de acusado Individualismo, reforzado éste por una cerca que alsla todo el conjunto. No es, por supuesto,el único tipo de vivienda; además de ell se encuentra la casa rectan gular, alargada, con dos pequeña fachadas, la principal y la trasera, estando adosada lateralmente a otras y por lo tanto carece de los elementos de la anterior.

\section{3.- HACIA IA CUNSECUCION DE UN NIVEI, DE VIDA MAS EJEVADO}

Gan parte de los tradicionales modos de vida han sufrido, con el lógico paso del tiempo, un deterioro, hasta al punto de no conservarse más que en la memoria de las personas de más edad. Nuevas costumbres, nuevas inquietudes y necesidades han determinado un rápido envejecimiento, incluso un rápido envejecimiento de la propia organización interior del hábitat, adap tado hoy, en Ja mayor parte de los casos, a un ritmo de vida diferente.

La cocina, que era la dependencia de mayor significado, don (28) G. DE COSSIO AGUIRRE.- La casa popular en el valie de Campob, Santander. Publicaciones de]. instituto de etnografía y folklore "Hoyos Sainz" Vol X. Diputación Provincial, Santander 1979-1980. Págs. 7-71. 
de, y entorno al fuego, se consumfan las largas horas del invierno campurriano, ha perdido este carácter, en favor de otras habitaciones. Asimismo, gran parte de los elementos que la integraban han desaparecido, siendo sustituldas por otros más modernas y funcionales; en efecto la cocina tradicional, rematada por una gran campana, alrededor de la cual se disponfan sendos tablones de roble o haya, ha sido reemplazada por el moderno "fogón", en el que junto a la cocina de carbón, cuya función ha quedado reducida a calentar la estancia, se encuentra la cocina de butano. No faltan tampoco electrodomésticos cuya presencia refleja un mayor Indice de bienestar, to les como la lavadora automática, frigorf́ficos etc... Dependen cias de nuevo cuño, como el "cuarto de baño" se han generaliza do en los últimos años, siendo rara la casa que no cuenta con 6́l. Del mismo modo se ha procedido a una remodelación de otras dependencias, remodelación que va desde la ampliación de los pequeños vanos de la fachada principal, la construcción de galerfas cerradas en sustitución del tradicional balcón abierto, hasta la sustitución de parte del mobiliario por otro más moderno y funcional.

Pero no todo el panorama ea tan halagüeño; dentro de Je po blacion rural, la tradicional oposición entre los pocos hecen dados y la inmense mayorla de pequerios propletarios se conser va en la actualidad, pero cun otro significado. En efecto, a los primeros, que por 10 general han modernizado su explotacion, se les han ariadido los que han logrado mejorarla merced a las rentas obtenidas en el trabajo en Reinosa. Este grupo goza de unas rentas relativamente elevadas, frente a aquellos cuyas explotaciones son marginales, con la particularidad de que tambien son un complemento, por 10 general a las entecas pensiones de la seguridad Social. Y este grupo tiene una importancia numérica nada despreciable, por causa del grado de envejecimiento de la población rural. En 1972, y cabe suponer 
que la situación no se ha modificado en lo suutancial, el. 40 por 100 de $10 s$ titulares de explotaciones tenla más de 65 años, 10 que proporciona una idea suficiente del carácter de las mismas. Pero tampoco son lás únicas que tienen tal signi ficado; existen otras, cuyo número es diffcil de precisar, que corresponden a los que trabajan, contínua o esporádicamente co mo transportistas autónomos; llama, en efecto la atención el elevado número de camiones consados en jos distintos munted.pios, 38 en Campóo de Yuso, 92 en Campóo de linmedio y 48 en Campóo de Suso. La mayor parte de ellos se dedican al transporte de piensos, paja y ganado, y, hasta donde for iropia experiencia conocemos, esta actividad se suele hacer compati ble con una pequeña explotación de ganado vacuno, y que en lar te prolonga, con distinto carácter una vocación tradicional de la comarca (28).

Gracias a todo ello, las diferencias, que hata hace pocos años eran notables entre la población rural y la población de Reinosa, en el. nivel de consumo y costumbres suciales se han reducido sustancialmente. Prácticamente todos los hogares po seen television, hoy muchos de ellos en color, lo que indica, que duda cabe, unos ntveles de consumo bastante olevados, que el propio medio de comunicación contribuye a difundir.

El automóvil y el telefono son otros indicadores del nivel de consumo y bienestar. El primero se encuentra muy difundido; la inmensa mayorla de los agricultores, al menos de los más jô venes, cuentan con el, estando más generalizado entre los que trabajan en Reinosa. In cambio, el teléfono se encuentra menos difundido; si bien gran parte de los pueblos poseen un telófono público, a nivel individual, y salvo en Reinosa, Matamorosa', y Nestares, prácticamente es desconociảo.

Pero si individualmente se han alcanzado algunas metas, po co o nada se ha hecho colectivamente; la estructura del pobla miento no se ha modificado en absoluto; las calles, más bien 
Ios caminos entre cada casa, se convierten en auténticos barri zales durante el largo invierno, el alumbrado público es prác 'ticamente inexistente, y si bien hoy/ todos los núcleos de población disponen de agua corriente, dejan mucho que desear on la dotación de determinados servicios. Salvo la pequeña tienda de comestibles y la taberna, que a veces se encuentran en un mismo establecimiento, al que se añade una carniceria en determinados pueblos, la carencia de los mismon es abisoluta, puesto que la concentración en Reinosa, y la relativa proximidad de los pueblos a este núcleo, hace innecesaria su existiencia. Los servicios sanitarios, de esparcimiento, educación y obviamente otros más especializados se localizan en Reinosa. Tan solo algunos núcleos de mayor entidad cuentan con alguno de estos servicios, si bien, como en el caso de la asistencia sanitaria, no de forma permanente.

En Campbo de Suso, y al amparo de la coyuntural presencia de practicántes de los llamados "deportes blacos", se han abier to en los últimos años algunos restaurantes, hoteles y fondas, que ni por su número, cinco, dos y una respectivamente, ni por su entidad merecen una consideración más detenida.

Pese a todo, el nivel de vida de la población del núcleo urbano de Reinosa, sino más elevado, si al menos refleja un orden diferente de prioridades. En efecto, el ganadero-empresario ha de atender no sollo a Jas necesidades familiares y per sonales, sino que tiene que prestar atención a lo que constituye su fuente de ingresos, a su explotación agraria; por ello ha de ser necesariamente cauto a la hora de gastar el dinero, puesto que cualquier contratiempo -un año muy seco, una enfer medad del ganado, a el simple mantenimiento de la maquinaria agrlcola- puede obligarle a realizar un gasto inprevisto, razón por la cual precisa restringir notablemente sus gastos. En sintesis, Campoo muestra hoy rasgos inequívocos de mo- 
dernidad, y si bien la mayor parte de los núcleos rurales su fren aún altos niveles de carencia, ésta representa un incon venierte menor por causa de la relativa proximidad al núcleo urbano de Reinosa, suficientemente dotado del. comercio y ser vicios imprescindibles para atender a la población de la comarca. 


\section{CONCLUSIONES}

No puede ser esta recapitulación final un catálogo de resultados, de transformaciones definitivas en un espacio agrario que mantiene inoblumes gran parte de las estructuras que le dieron forma, y sobre las que se ha acometido la ardue empresa de ou modernización. Una modernización que se nos muestra evidente por doquier, pero que se asienta en un frágil e inestable equilibrio entre las necesidades del presente y la herenola del pasado.

Es precisamente on el siempre inconoluso dílogo entre ambas realidades - un pasado no por lejano menos presente $y$ un presente lastrado por la herencia del pasado-, en el que asienta la actual realidad geográfica de la comarca campurria na.

$Y$ esta realidad es muy diferente a la que durante un proceso secular ha imperado en la organización de un espacio, sujeto por sus propios caracteres flatcos a no pocos condicio nantes. A Gstos se fueron afradiendo otros, de Indole instituclonal y de enorme arraigo, perfilando los raggos esenciales de un paisaje agrarto que tan s6lo ahora muestra signos inequivocos de transformacion. Y es que si la sociedad rural tra diotonal apenas evoluciono en sus caracteres, on su organtzaolon, el espacio agrarto tampoco lo hizos ha permanecido inal terado hasta que una nueva estructura se sobreimponga a las ya existentes en la comarca, en suma, hasta que el proceso de in dustrializaoion se consolide, modificando de ralz parte de los valores propios del sistema: de vida tradicional.

Tal cambio, empero, no ha sido fácil de realizar porque 
aquellos valores ostaban firmemente arralgados, eran fruto do una dilatada ocupación del espacio durante la cual b́ste se aprovecho, se organizo del mejor modo posibles coleotivamente. S6lo asl se pudieron paliar parte de los serios inconvententes estructurales que la comarca presentaba. Tal organización colectiva de inquietudes e intereses individuales habla de te ner una proyecoion espacial como de hecho la ha tenido hasta nuestros dias.

El paisaje agrario tradicional apareoe como resultado de un elevado número de oujecciones comunales, cuyo fin no era otro que hacer viable una economla ganadera basada en una agrioultura de subsistencia. Esta organización se mantendna aln grades cambios hasta fechas muy recientes, comenzando su decadenoia en la segunda mitad del presente siglo. En este pe riodo vienen a coincidir una serio de ciroustancias que darán lugar a la crisis de los sistemas tradicionales de organización del espacio, y desde esta crlais surgirá un nuevo tipo de paisaje agrario.

Este proceso se ha llevado a cabo no obstante con unos costos sociales muy elevados; no en vano buena parte de 61 tuvo asiento sobre un éxodo rural, de clerta entidad en algunas décadas $y$ sరlo contenido coyunturalmente por la intensa afluenola de mano de obra a la industria instalada en Reinosa, entre 108 afos 1920 y 1930. Por ello la consolidación de Reino sa como núcleo industrial de cierta entidad es sin duda el eje sobre el que se vertebran gxan parte de los cambios experimen tados por la comarca.

Pero el papel de Relnosa en este proceso de modernizacion ha sido, cuando menos, contradictorio; apenas ha servido para contener el éxodo rural y ello es una muestra evidente del escaso dinamismo que, como ya hemos apuntado caracteriza a la industria alle instalada. La comarca ha seguido perdiendo 
población, hasta un punto tal que alguno de sus municipios tie nen hoy menos habitantes que al comenzar el siglo; es lo que sucede en Campoo de Suso, que ha perdido desde 1900 un 44,7 por 100 de su poblacion, y en Campoo de Yuso, que ha visto mer mados aus efectivos on un 41,6 por 100. Cierto es que parte de esa población no ha dejado la comarca, sino que ha sido absor bida por Reinosa, núcleo que ha experimentado un enorme crecimdiento $-343,6$ por 100-, pero este hecho no empequenece las dimensiones del éxodo hacla otras regiones, constante desde 1960, y en el que participa también la población de Reinosa aportando una elevada proporción del mismo.

En cambio, ai el desarrollo de Reinosa no ha servido pa ra contener el éxodo rural, si ha abierto mayores posibilidades a la población que permanece aún en la comarca. En efecto con las rentas obtenidas en el trabajo realizado en la industria reinosana pudo acometer un proceso de cambio, de moderni zación de la explotación agraria, proceso que sin duda, y en porción nada despreciable arranca de la posibilidad de aumentar el tamano de la superficie de la misma, arrendando las tierras de aquellos que hablan emigrado. Gracias a todo ello, pero no sin una Improba acumulación de trabajo, estas explota taciones, de las que el titular sólo se ocupa parcialmente,son en su mayor parte rentables; poseen un nivel de mecanizacion aceptable, e invariablemente han procedido a una sustitucion de las razas de ganado vacuno autóctonas por ganado frison, o mixto en el peor de los casos, del que obtienen unos rendimien tos elevados que comercializan a través de las centrales leche ras de mayor implantacion dentro de la comarca, Nestle, Morais y Granja la Luz, ubicadas en Santa María de Cayón, Arenas de I guña y Palencia, respectivamente.

Como consecuencia del trabajo en la industria o en 108 servicios de Reinosa, y del trabajo en la propia explotación ganadera se obtienen unas rentas relativamente elevadas con 
las que se ha procedido a una renovacion total o parcial del caserfo; se ha incrementado la construcción de establos,sepa rados ya del edificio destinado a vivienda, se han automatiza do gran parte de las labores del hogar, lo cual permite, o al menos facilita el trabajo de la mujer en la explotacion, libe rado este ya de alguna de las servidumbres tradiotonales -or dero manual, slega etc......

El impacto en el palsaje agrarlo de las transformaciones llevadas a cabo en 6́tas, y en otras explotaciones exclualvamente ganaderas, ha sido muy acusado. Han desaparecido las tierras de "pan llevar", o en el peor de los casos, se ha reducido considerablemente su extension; se ha reducido también el cultivo de la patata, que en la década de 1960 tuvo cierto auge, para dar paso a un paisaje enteramente nuevo,y dominado por la omnipresencia de los prados. Estos son actual mente el componente más sobresaliente del paisaje agrario cam purriano, junto a las praderas artificiales localizadas en los sectores más bajos de los valles, en las proximidades de los núcleos de población. Gran parte de ellas están cercadas, lo que añade otro rasgo distintivo al paisaje: la cerca. En efec to, la pradera cercada, de aprovechamiento intensivo, ha reempla zado a las tierras de labor tradicionales, e incluso a parte de los prados, trás la desaparición de las sujecciones colectivas.

Coexisten estas praderas con sectores cultivados, pero no orientados ya a asegurar la alimentación humana, sino des tinadas a la alimentación del ganado; las forrajeras, y en es pecial la alfalfa, han reemplazado a las leguminosas que tradicionalmente cumplian el mismo fin. Hoy, en la organización del espacio agrario, no se refleja ya la tradicional competen cia entre la alimentación humana y animal. Todo se encuentra subordinado a esta última. 
Pero no en todos los sectores las transformaciones han ostado orientadas on la misma dirección; el aprovechamiento unfvoco y en forma extensiva, de los pastos de los llamados "puertos altos"ha condicionado el ritmo y aun el sentido de las mismas. La especialización en la producción de carne no ha sido similar a la que se ha producido en la producción de leche; baficamente se lleva a oabo a partir del ganado vacuno autóctono, espeolalmente de raza Tudanoa, quo al bien pro porciona una carne de calidad, muy apreciada, no produce ele vados ingresos a causa del escaso peso con que se venden los terneros. Estos viven completamente dependientes de la madre hasta el "destete", es deolr, no se ceban, causa por la oual, y dado el escaso peso que alcanzan el el momento dol nacimien to -entre 20 y $22 \mathrm{Kg}$ - es muy difloll quo aloancen al final del otono el peso mInimo estipulado para su venta $-120 \mathrm{Kg}$. canal-, siendo frecuente que esta se realice al margen de la legalidad vigentio.

Por todo ello, y porque la introducción de razas que ofrezcan mejores resultados ha sido hasta el momento bastante redueida, son muchas las expliotaciones que han abandonado el ganado destinado al sacrificio, para orientarse hacia la producoión de leche. Ia consecuenoia ha sido la reducoión del ganado tudanco -56 por 100 entre $1970 \mathrm{y}$ 1980- on la denominada comarca Reinosa-los Valles, que abarca el extremo meridional de la provincia de Santander, asi como la concentración del mismo, al menos dentro de Camp6o, en lo que bien podemos considerar su último reducto: la Hermandad de Campóo de Suso. Habitualmente se sigue explotando en forma extensiva, sin apenas variación respecto a como tradicionalmente se habla he cho, es deolr, pasando de la estabulación total durante el Invierno a una estabulación parcial en la Primavera, y a un régimen de absoluta libertad en Verano, aprovechando los pag tos comunales de los "puertos altos". En cambio, y frente a 
Ia sensible reduoción de este ganado, en el mismo periodo, la década de 1970, se duplica practicamente el ganado vacuno de raza frisona; una muestra más del proceso de sustitución y de transformación que anteriormente apuntabamos.

Las bases, 108 fundamentos de todos estos cambios siguen siendo, paradóficamentie, similares a las tradicionales. Ira es tructura de la propiedad continua dominada por el binomio gran propledad-minifundio; la primera, de tipo coleotivo controla el mayor volumen de tierras, mientras que la segunda no sblo ocupa una superficie reducida del espacio comarcal, sino que se encuentra sumamente fragmentada en pequefas parcelas. Ya a puntamos en su momento que esta microproptiedad es, al menos on apariencia, más ficticia que real, a causa de los diversos tipos de agrupación de heredades diepersas que existen al mar gen de la ley. Viene a confirmar este hecho la reducida exten sión de las tierras arrendadas; en efecto, el arrendamiento como régimen de tenencia no está tan generalizado como cabrla esperar tras el abandono de numerosas explotaciones, precisa mente las de aquellos que paulatinamente se han incorporado a la tradicional corriente migratoria de la comarca. Entre 1962 y 1972 apenas se habla incrementado la superficie arrendada, y esta misma tónica parece apuntarse en los primeros resulta dos del Censo Agrario de 1982 que hamos podido consultar.

Por todo ello, la importancia de este obstáculo -la pro piedad- debe ser puesta en duda, al menos "a priori", porque parece ser que no ha representado un serio obstáculo para lle var a cabo las transformaciones que en la explotación agraria se han sucedido on los últimos anos, transformaciones que son, con mayor o menor intensidad comunes a toda la comarca, y a. las que no ha sido ajeno el núcleo urbano de Reinosa. En él, $y$ en un contexto de atonla demográfica - los incrementos dece nales de población son entecos- han tenido lugar profundos 
cambios, cuya importancia hay que valorar no de modo aislado, sino en relación con la etapa de modernización general en to'da la comarca. Sólo as 1 se puede comprender el incremento de determinados servicios como educación, sanidad etc... y la di versidad y especialización de otros, reflejo sin duda de un! mayor nivel de vida, del disfrute de rentas más elevadas por parte de sectores más amplios de la sociedad rural.

Como consecuencia el nucleo de Reinosa ha acentuado su capacidad de atracción; monopoliza la oferta comeroial y de servicios de toda la comarca, y aun de sectores próximos, sien do además el contrapunto al despoblamiento de gran parte de los núcleos rurales. Pero la influencia ejercida por Reinosa, ha tenido y tiene sus Ifmites en la propia insuficiencia de las funciones que ejerce. La industria toco pronto techo en su capacidad para absorber las excedentes de mano de obra del conjunto de la comarca; y es que se trata de un tipo de activi dad poco divereificada, con escaso efecto multiplicador. La oferta de puestos de trabajo tiene hoy la finalidad casi exclusiva de mantener un nivel de empleo invariado, y buena prueba de ello es la clausura de la escuela de aprendices que otrora nutriera de especialistas ans talleres.

Los servicios, a los que como ya hemos apuntado debe Re1 nosa gran parte de su dinamismo, están sumamente condicionados por una demanda muy limitada, que, si en un principio fue muy elevada,al partir de altos niveles de carencia, y en contró pronta atisfacción en la oferta de Reinosa, hoy en cambio es una demanda en parte insatisfecha. Son cada vez más frecuentes los desplazamientos hacia centros de rango superior -Torrelavega y especialmente Santander- para hacer determinadas compras y en demanda de cierto tipo de servicios especializados.

Pero con todo, hoy Reinosa es un núcleo con indudables, 
pero limitados caracteres urbanos; ha recuperado $\theta$ incluso ha acentuado su tradicional función de centro comarcal de servicios, sin duda como respuesta a las necesidades de una población rural que disfruta de niveles de renta más elevados que tan soblo hace unos años.

Empero, el reemplazo de las obsoletas estructuras agrarias aún no se ha consumado. En ello se afana una poblactón cada vez más dinámica, on cuyo haber hay que incluir la trang formacion, todavia inconclusa, de un espacto mural, hoy moder no en sus rasgos esenciales. 


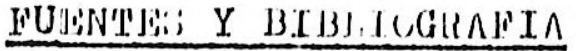


'FUENTES

I.- ARCHIVO GENERAY DE SIMANCAS.

1.- Sección de Expedientes de Hacienda.

Averigunciones para el. encabezamiento de A tenbnius Año 1561; leg. 70 Exp. 2. Relación de lugarea: Abia da, Carieda, Hormas, Bspinilla, Paracuellea, Nnveda, Celada Marlante:3, Suano, Matiamorosa, La Lostana, ijer villas-Servilleja.., Poblacion de Yuso, Bolmir, Retor tillo, Reinosa, Nestares, Salces, Aldueso, Aradillos, Camino, La miña, Morancas, Fresno, Quintanamanil, Fon techa, Celada de los (jalderonen, Soto, Bustamante, Fontibre, Fombelitida, La șerna, Monegro y quintana.

Año 1597; $\operatorname{leg} 70$, exp. 3. Relación de lugares: Lancha res, Quintanamanil, Bustamante, Villasuiso, (uintana $\bar{y}$ Monegro, urzales y Villapaderne, La Costana, Rejnosa, La Riva, población de Yuso, Viljacantid, Pontibre, Sal ces, la Miña, Suano, Camino, Soto, laracuelles, Hormas̄, Proaño, Abiada, Naveda, Celada de los Calderones, Espinilla, Izara, Población de Suso.

2.- Sección de la dirección General de Renta.

a/ Catastiro del Marqués de Ja Ensenada. Respuestas Ge nerates. Itbros 626-634, nubon Inolunjve.

b/ Libro del Mayor Hacendado. Libroa 635 639, ambor inclusive.

3.- Secretarfa de Marina.

a/ Ordenanza de Monte:3, airo 1738. Jeg. 577.

b/ Estado de los árboles de 10:s tres devartamentos de Marina. Año 1748. Leg 575.

c/ Santiago Binar de Reinosa. Asunto, Montes. Airo 1767. Leg. 564 .

4.- Diversos de Castilla.

-Relación de la vecindad que tienen la villa de lieino sa y lugares de su Partido, asi realengo y eximidos como de seĭorlo y abadengo. Sin fecha (hacia 1646). lieg. 23, Fol. 1 .

5.- TOMAS GONZALEZ - - Censo de población de las urovincias Y partidos de la corona de Castilla en el siglo XVI. Con varios apéndices... Madrid 1829. 
II.- ARCHIVO HISTORICO PROVINCIAT, DL SANIIANDER.

1.- Sección Catastro de Ensenada. Respuestas particula res. Argüeso Sig. E. 64. Naveda sig. E. 541. Barrio Sig. E. 104 .

2.- Centro de Estudios Montañeses.

a/ Vecindario del Bastón de cuatro villas de Peñas a Castilla. Año 1743. Leg. 19 no 8 y aîio 1778, Leg. $29 \mathrm{n}=1.1$ a.

b/ Merindad de Campóo. Vecindario. Mío 1645. ijie. 6-19.

3.- Protocolos. Sección padrones y vecindarios.

a/ Reinosa. Año 1681. Leg. 4379.

b/ Reinosa. Aĩo 1768. Leg. 4033.

4.- Diputacion.

a) Ayuntamiento de Campóo de Yuso, año 1845. Leg. 232

b/ Reinosa, aiĭo 1845. Leg 232.

c/ Marquesado de Argüeso. Ar̃o 1845. Leg 232.

d/ Ayuntamiento de Campóo de Enmedio. Año 1845. leg. 232.

e/ Marquesado de Argüeso. Año 1824. legg. 1.631.

III.- BIBLIOTLCA MENEDEZ PELAYO. FONLOS ANTIGUU Y Y MODLRNON.

1.- Vecindario General de España. (Campoflorido) Año. 1717. M./5488.

2.- Campoo de Suso.Año 1551. Ms. 8-6-2y.

3.- Papeles manuscritos referentes a varios pueblos de la provincia de iantander. Colección pedraja. Ms. 8-7-11.

4.- Documentos para la Historia de la provincia de santan der reunidos por Gervasio Eguaras Fernández. Coleccion Pedraja. Ms. 888.

5.- Camp8o. Ms. 156, 167, 274, 124.

6.- Reinosa. Ms. 513.

7.- Urdenanza de Matamorosa. Ms. 452.

8.- Ordenanzas de varios ayuntamientos y concejos de la provincia de Santander. Ma. 432, Doc. 485. Celoda Marlantes pag. 66; Cerbatos, píg. 83; Fombellida, píks. 1.36; liresno, pág. 147; La Miña, pág. 206; Requejo, pág. 341.

IV.- ARCHIVO DE LA DELEGACION FROVINCIAL DE HACIENDA DE SANTANDER .

1.- Censos y foros pertenecientes al Estado y procedentes de los bienes del Estado, del Clero, de propios, de Beneficencia de instrucción pública y de secuestros. Santander. 1 Julio 1855. Registro. 669.

2-- Fincas rústicas procedentes de los bienes del estado, 
del olero, de propton, de benefioencin y de secuestros. Santander 18 de Jul10 de 1955. Reglstro 667.

\section{V.- ARCHIVOS MUNIOIPALES.}

Archivo Ayuntamiento de la Hermandad de Campbo de Suso (Espinilla).

1.- Inventarios y datos estadisticos.

a) Recuento general de ganadería correspondiente a los años 1978-1979.

b/ Cartilla de evaluación, osean, gastos y productoss de las tierras de regadio y secano que se conocen en el término jurisaiccional de este ayuntamiento según sus calidades y cultivos, comprensiva además de los rendimientos y utilidades de todos los gana dos existentes en el mismo. Ayuntamiento del Marque sado de Argueso., años 1850, 1851, 1881,1893.

c/ Copias de los varios antecedentes del camino de ter cer orden desde Saja a Reinosa. 1860.

d/ Memoria sobre el derecho que la antigua Hermandad de Campbo de Suso, hoy ayuntamiento del mismo nom bre, y Ma quesado de Argüeso, tienen al goce exclu sivo de los puertos secos llamados Palombera, Saja y Sejos.

e/ Copia de unas ordenanzas de la Hermandad de Campoo de Suso. 1551.

2.- Conventos y Concordias. Anos 1651-1893.

a/ Año de 1651. Contrata otorgada en Espinilla el. 27 de Septiembre de 1561 entre la Hermandad de Campoo de Suso y los pueblos de Ybio, mazcuerras, Periedo Ontoria, Santibaíez etc... Dicha contrata comienza en el folio 117 de este cuaderno.

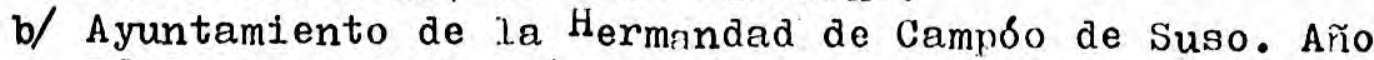
1893. Expediente de los pueblos que tienen derecho por virtud de contrata a veranear con sus ganados vacunos en lins puertos de la palombera, Saja, wuen tes, Tronquilio y lodar, a cuyas reses se les ha impuesto 50 céntimos de peseta a cada una para gas tos de policla rural y sanitaria.

3.- Excepciones de venta de terrenos de la desamortizacion 1865-1898.

a) Ayuntamiento de las Hermandades de Campóo de Susso 1893. Montes y predios rústicos que pertenecen a oste nyuntrintento, mancomunidon con los do liuonto, Los Tojos y Valle de Cabuerniga y particulareis del. 
mismo y cada uno de los pueblos que le componen. $\mathrm{b} / \mathrm{Re} \mathrm{I}_{\mathrm{a}} \mathrm{ci \delta}$ comprensiva de los bienes comunales existentes en este término municipal. Año 1931.

4.- Reglamento de la asociación y Comunidad Campóo-Cabuér niga. Santander 1903.

5.- Relación del ganado propiedad de vecinos de los pueblos marcado para pastar en el puerto de fuentes. Años 1975, 1976 y 1977.

6.- Relación del ganado forastero marcado para pastar. Años 1976 y 1977.

7. - Inventario de edificios públicos y bienes inmuebles del ayuntamiento de la Hermandad de Campbo de Suso. Año 1881.

8.- Recuento general de ganader1a. 1978 y 1979.

9.- Registro Civil. Libros de matrimonios, nacimientos y defunciones. 1871-1980.

10.- Catastro de rústica. Cédulas de propiedad. 10 vol.

11.- Padron municipal de habitantes. 1975 y 1981.

B. Archivo del ayuntamiento de Campó de Enmedio.

1.- Registro Civil. Libros de matrimonios, nacimientos y defunciones. Años 1871-1980.

2.- Catastro de rústica. Cédulas de propiedad. 8 vol.

3.- Recuento General de ganaderí. 1977-1979.

4.- Padrón municipal de habitantes. Años 1975 y 1981.

c. Archivo de] ayuntamiento de Campbo de Yuso.

1.- Registro Civil. libros de matrimonios, nacimientos $y$ defunciones. 1877-1980.

2.- Listado de contribuyentes de Rústica y tecuaria. 1981.

3.- Padrón municipal de habitantes. Años J.975 y 1981.

D. Ayuntamiento de Reinosa

1.- Padron municipal de habitantes. 1450,1960 y 1975.

2.- Licencia Fiscal. Aío 1976.

3.- Memoria del Exmo. Ayuntamiento de Reinosa. Año 1975 
VI.- ARCHIVOS ECLESIA:ITICUS

Archivo Diocesano de Santillana del Mar (Santander).

1.- Libros de Tazm1as. Abiada y Hoz de Abiada, años 17551837, sig. 3.584, fols. 1-221. Entrambasaguas, aйos 1690-1843, sig. 3.633, fols. 1-150. Proaño, años 17801837, sig. 891, fols. 1-119. La Lomba, años 1711-1764, sig. 3.669, fols. 1-47. Villacantid, aíos. 1752-1836, sig. 1.081, fols. 1-21. Villacantid (San Pedro) 17071837, sig. 1065, fols. 1-1.79. Fontibre, airos 1788.1841, s16. 903, fols. 1-.107. Fresno, aiïos 1778 1837, sig. 3.684 , fols. 1-86. Requejo, aî́os $1.792-1836$, sig. 5.252 , fols 1-79. Matamorosa (siglo XVIII, ho jas sueltas) aig. 5.722 .

2.- Libros de bautizado:;. Reinosa, a ios 1594 a 18883 , sig. 1.840 a 1857 ambas inclusive. Ormas, años 3.66 y a 1852 , sig. $5.622,5.623$ y 5.624 . Bspinilla, años 1632 a 1852 , sig. 4.237 y 4.238 .

3.- Libros de finados. Keinosa, aĭoss 1642-1886, sig. 1.840 $1.841,1963,1864,1865,1866,1867,1868$, y 1869. Ormas, años $1670-1851$, sig. $5.622,5.623$ y 5.625. Espinilla, años, 1633-1851, sig. 4.237 y 4.238 .

VII.- ORGANISMOS OFICIAJES PROVINCIALES.

1.- Delegación provincial de estadistica. - Censos de la población de España 1860-1981.

2. - Cámara oficial de Comercio, Industria y Navegación de Santander. Resumen de las principales actividades y trabajos de la cámara durante 1977.

3.- I.C.O.N.A. Memoria forestal de la comarca de Reinosa 1980.

4.- Delegación provincial de Hacienda de Santander, Impueg to industrial 1980.

5.- Delegación provincial del ministerio de Agricultura.

a/ Mecanización. Expedientes individuales.

b/ Censo Ganadero 1981.

6. - Cámara agraria de Campઠo de Suso.

a/ Documentos 1--T sobre distribución de superficies. Años 1977, 1978.

b/ Documentos 2-T sobre maqujnaria en uso. Año 1979.

c/ Explotaciones de ganado vacuno de aptitud lechera. Años 1977 y 1978.

7.- Cámara agraria de Campbo de Enmedio y Reinosa.

a) Documentos 1-T sobre distribución de superficies, ainos 1977, 1978.

b/ Documentos 2-T sobre maquinaria en uso. Añoss 2977 , 1978. 
c/ Relación de ganaderos pertenectentes a la cámara Agraria local de Enmedio y Reinosa que han entre gado en las oficinas de la misma las declaraciones de ganado vacuno, para acogerse al apoyo eco nómico de explotaciones ganaderas modestas. Años $1977,1978$.

8. - Cámara Agraria de Yuso.

a/ Reglamento estructural de la producción lechera. Registro provisional de explotaciones, impreso R-I Ministerio de Agricultura y pesca. Dirección gene ral de la producción agraria. 1982.

b/ Documentos 1-T sobre distribución de superficies, años 1971 a 1980 .

c/ Documentos 2-T sobre maquinaria en uso, años 1971 a 1980.

d/ Instituto Nacional de Estad1stica. Censo Agrario de 1982. Directorio de explotaciones, Diciembre de 1981.

\section{VIII.- OTROS ORGANISMUS OFICIALES.}

1.- Instituto Nacional de Estadistica.

a) Primer Censo Agrario de España 1962 Santander. Cuaderno 39. Madrid 1964.

b/ Censo Agrario de Espaiña de 197a, series A y B. Santander 1972. Cuaderno 39.

2.- Centro Metereológico del Ebro. Zaragoza.

a) Temperaturas. Reinosa, años 1941-1970. Espinilla, años 1969-1976. Arija, años 1956, 1970.

b/ Precipitaciones. Reinosa, años 1941-1970. Espinillla, aйos 1955-1973. Arija, año: 1955-1980.

3.- Ministerio de Agricultura. Caracterización agroclimática de la provincia de Santander. Madrid 1980.

4.- Instituto Nacional de Estadistica. Movimiento Natural de la población española. Aiños 1975, 1976 y 1977.

IX.- FUENTES CARTOGRAFICAS.

1. Mapa topográfico Nacional. Escala $1 / 50.000$. Hojas $n^{2}$ 82 (Tudanca), 83 (Reinosa), 107 (Barruelo de Santullán) 108 (Las Rozas).

2.- Mapa Geológico y Minero de España. Escala I/ 200.000 Hoja ne 11 (Reinosa). Escala 1/ 50.000, hojas 83 (Reinosa) y 108 ( Las Rozas).

3.- Fotografía aerea. Vuelo de 1957; Cobertura completa de las hojas no 82, 83, 107. 108 del Mapa Topográfico Nacional Escala I/ 50.000 . 
BIBI,IOGRAFIA

1.- G. ANES AJVAREZ: Las crisis agrarias en la España Moder na. Ed. Taurus. Madrid, 1970. 517 págs.

2.- -..--, Las fluctuaciones de los urecios del trigo, ce bada y aceite en Espaía: un contraste regional. Moneda y Crédito. 1966, ne 97, págs. 69-150.

3.- -.-.-, Los pósitos en la España del siglo XVIII. Mone da y Orédito. 1968, ne 105 págs. 39-69.

4.- S. ANGIJADA, E. BALCELIS: La vida rural en Ja montana es pafiola. orientaciones para su estudio. Monografias del Instituto de Estudios Pirenaicos. Jaca, 1980. 112 págă.

5.- F. ARCE GARCIA: Ias careterfas en el siglo XVIII. EI gremio de carreteros de Santander. Li Campo, 1981. $n^{2} 84$ págs. 104-106.

6.- F. ARCHE HERMOSA: Apuntes sobre la influencia del puerto en la vida economica de Santander. Santander. 1944. 82 págs.

7.- F. ARIAS CASTRILLO, R. GIMENEZ ORTIZ: Evanoraciones po tenciales y balances de agua en Espeña. Madrid, 1965. 293 págs.

8.- E. ARIJA RIVARES: La miner1a montainesa en el siglo XVIII. Economfa Montañea. 1955, $\mathrm{n}^{2}$ 63. págs. 34-36.

9.- -...-, Campbo de Yuso. Estudio geográfico y sociologico del valle del Fantano del Ebro. Consejo Económico Sindical Provincial. Santander, 1963. 46 págs.

10.- E. ARNAIZ DE PAZ: El hogar solariego montañés; evocacio nes. Madrid, 1935. 160 págs.

11.- F. BARREDA: Comercio mar1timo entre los Estados Unidos y Santander. 1778-1829. Santander, 1950. 99 págs.

12.- E. BAUER MANDERSCHEID: Los montes de España en la Histo ria. Madrid, 1980. 610 págs.

13.- D. BAYON: La empresa ganadera del Norte de España. Agrí cultura $1972, n^{9} 2$. Págs. 711-716. 
14.- J. BENI'TO ARRANZ: El. Canal de Casti1la. Colección Academia Nueva. Valladolid, 1957. 91 pága,

'15.- G. BERTRAND.- Morphostructures cantabriques: Picos de Eu Fopa, Montaná de león et Palencia (Éspagne du nord-ouest.). Revue géographique des Pyrénées et du Sud-Cuest. 'T. 42, Fasc. 2. Enera 1971. Págs. 49-70.

16.- --.---, Les estructures naturelles de l'espace gégraphique. L'exemple des Montagnes Cantabriques centroles nord-ouest de $I^{\prime}$ Espagne). Revue Gógraphique des Pyr6nées et du Sud-cruest. T. 43, 1972. Págs. 175-206.

17. - F. BUSTELO GARCIA DEl, REAIs La población espainola en la segunda mitad del sig.lo XVIIr. Moneda y Crédito 1972, ${ }^{9}$ 123, págs 53-105.

18.- J. CALDERON ESCALADA: Camp6o, panorama historico y etnográfico de un valle. Institución cultural de Cantabria. Diputacion Provincial de Santander. Santander,1971. 226 págs.

19.- -----, Por los caminos de ayer y hoy. Fontibre, 1957 ne 17. Pág. 1 .

20.- H. CAPEL: Capitalismo y moxfologia urbana en Espana. L1bros del Cordel. Barcelona 1977. 142 págs,

21.- J. CARO BAROJA: Los arados españoles: sus tipos y reparticiones. Revista de dialectologia y tradiciones populares. Tomo V. Madrid,1949.

22.- -...-- Los pueblos del Norte de la Peninsula Iberica. Ed. Txertoa. San Sebastian, 1973. 303 pags.

23.- J.L. CASADO: Cantabria a través de su historia: la crísis del siglo XVI. Santander, 1979. 256 Págs.

24.- F. COELLO: Atias de España $y$ sus pesesiones de Ul tramar. Provincia de Santander. Madrid 1868.

25.- CONFEDERACION ESLANOIA DE CAJAS DE AHURRU: Situación actual y verspectivas de desarrollo de Santander. 4 Tomos. Madrid, 1972.

26.- COTEGIO OFICIAX DE INGENIEROS TECNICOS AGRICUTIAS DE SANTANDER: Informe sobre el campo montaics. Aula de cultura de la Caja de Ahorros de Santander y Cantabria. 1980.

27.- G. DE COSiIU AGUIRRE: La casa popular en el valle de cam póo. Publicaciones del instituto de Etnografla y Fol.klo re "Hoyos Sainz". Vol. X. Diputación provincial de Santander. Santander 1979-1980. Págs. 7-71. 
28.- R. CIRY: Etude géologique d'une partje des urovinces de Burgos, Palencia, León et Santander. Bulletin de la societé d'Historie Naturelle de Toulouse, tome 74. Toulouse 1939, 528 pags * XIII lám.

29.- J. DANTIN CERECEDA: Resumen fistográfico de la Jenínsula Iberice. Consejo Superior de Investigaciones Cientificas. Madrid, 1948. 303 págs.

30.- -- - - Las I1neas ixóxeras de España según los Indices termopluviometricos. Avance al estudio de la aridez en España. Estudios Geográficiss. 1941, pags. 35-91.

31.- A. DIAZ DE JAZ: Los montes de Utilidad pública en Cantabria y la ley de Montes. El Campo 1981, ne 84. Páfra. 81-89

32.- M. DOASO OLASATEGUI: Las industrias lecheras en la provin cla de Santander. Tierras del Norte $1953 \mathrm{n}^{2}$ 7-8.

33.- D. DUQUE Y MERINO: Del nacimiento del Ebro: geografla, hi drografla, historia. Boletín de la Real Sociedad Geográfi ca. Madrid, 1881. Tomo XI pég. 309.

34.- M. ESCAGEDO SALMON.: Costumbres pastoriles cántabro-monta ñesas. Santander,1921. 202 pégs.

35.- M. FERRER REGAIES: La ganader 1a bovina en Jea región asturcántabra. Instituto de Estudios $\Lambda$ sturianos. Uviedo, 1963. 112 págs.

36.- ---.-, La Industria en la España Cantábrica. Ed. More-ton. Bilibao, 1968. 192 págs.

37.- -..--., Concentración y dispersión de la industria en la Esparia Cantábrica. XX Congreso Geográfico Internacional. 1966. Págs. 159-178.

38.- A. GARCIA BARBANCHO: Las migraciones interiores españolas. Estudio cuantitativo desde 1900 . Estudtos del Instituto de Desarrolio Económico. Madrid, 1967. 128 págs.

39.- J. GARCIA FERNANDEZ: Organización del espacio y economfa rural en la España Atlántica. Ed, S. XXI. Madrid, 1975 332 págs.

40,- - - - Sociedad y organización tradicional del espacio en Asturias. Diputación provincial. de oviedo. Patronato J.Ma Cuadrado. Oviedo, 1976. 198 pags,

41.- - - - , Los grandes conjuntos climáticos de Esparia. Valla dolid 1968. Multicopiado. 53 págs.

42.- A. GARCIA GOMEZ: Praderas del Norte. Agricultura, n 507 1974. Págs. 483-486. 
43.- J. GARCIA DE JAA PUENTE. Reinosa y el valie de Campoo. San tander 1916, 131 págs,

44.- J. GONZAIEZ ECHEGARAY: Sobre la geografía humana de Canta bria. Santander, 1959. 69 pága.

45.- -...-., Aportactón al estudto de1 carro chillon on Canta bria. Iublicaciones del Instituto de Linograf'la y Folklore. Vol I. Santander, 1969. légs. 47-80.

46.- MgC. GONZAIEZ ECHEGARAY: Aportacion al estudio de las fe rrerlas montañesas. Publicaciónes del Instituto de Etnografia y Folklore "Hoyos Sainz" Santander, 1973. Vol V, págs. 129-212.

47.- G. MORENO MORAL: Notas preliminares para una climatologfa de Cantabria. Anales del Instituto de Estudios Agropecuarios, Vol IV, Santander 1979-1980. Págs. 61-79.

48.- A. GUERRA DELGADO: Mapa de suelos de España E. 1/1.000000. Descripción de las asociaciones y tipos principales de. suelos. Consejo Superior de Investigaciones Cientificas. Madrid, 1968.

49.- E. GUINEA IJOPEZ: Geograf1a botánica de Santander. Publica ciones de la Excelentísima Diputación Provincial de Santander, 1953. 408 págs.

50.- J.A. GUTIERREZ DE ROZAS YNCERA: La ganaderfa montaî̀esa. Anales del Instituto de Estudios Agropecuarios. Diputacion lrovincial Santander,1979-1980. lágs. 109-153.

51.- M. GUTIERREZ ARAGON: La raza bovina tudanca; uresente y porvenir. Tierras del Norte, $\mathrm{n}^{2} 27$. Santander 1960.

52.- J.F. HERNANDEZ: La climatología en Reinosa. Fontibre,1959 n 37, págs. 3-4.

53.- F. HERNANDEZ FACHECO.- Fisiograf1a, geolog1a y glaciaris mo cuaternario de las montainas de Reinosa. Memoria de la Real Academia de Ciencias Exactas, flateas y naturales. Tomo X. Madrid, 1944. 190 págs.

54.- N. DE HOYO SANCHO.- La casa en Camuóo. Fontibre, Iy60 no 41. Págs. 3-4.

55.- G. JAIABERT: Un exemple d'imnlantation industrielle en milieu rural: I'usine aéronautique Ratier-l'igeac. Revue Géographique des fyrénées et du sud-Ouest. T. 38. Marzo 1967. N2 1. Págs. 47-67.

56.- P. DE JUSUE: Nota.s sobre geografía histórica. los foramon tanos, Malacoria y la Cordillera Cantábrica. Altamira, 1957 ne 1 y 3. Pág. 27.

57.- E. KAISER: Situacion agraria santanderina. El Campo, 1972 n² 64. Pág. 20-22. 


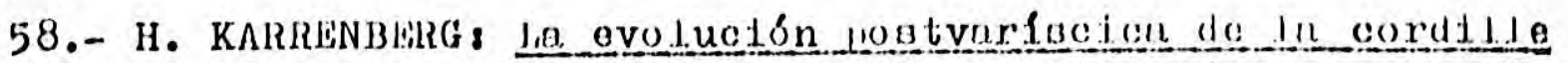
ra cántabro-astúrica. Publicaciones extranjeras sobre Geo logla de Espana, Conse jo ijuperior de Investigacionew Cien t1ficas. Madrid, 1946. Iégas. 105 221.

59.- J.P. JABOIRE: Industrialisation et croisance demográuhinue de vettites vilites; en milieu rural: I, exemnle de Midi-Jyré nées. Revue Géographique des fyrénées et du Sud-Ouest. To me 45, no 2 Abril 1974, pág. 109-174.

60.- E. LARRUGA: Memorias noliticas y económicas sobre Jos fru tos fábricas y minas de kspaña, con incjusión de los reales decretos, ordenes, collules, aranceles exjedidos para su go bierno y fomento. 12 tomos en 6 volúmenes. Madrid 1788-89.

61.- A. JAVIN MARAliA: B1 ganado vacuno en la montalia, bage de la explotación agrlcola. Primer Congreso Nacional de Inge nieria Agrnómica. Tomo III pág. 232-250.

62.- R. IION VALDERRABANU:- La cría caballar en Santander. Ing titución Cultural de Cantabria. Diputación l'rovincial de Santander, 1972. 1.52 págs.

63.- M. LURENZO YARDO. El pantano del Ebro. Zaragoza, 1918. 283. Págs.

64.- E. LORIENTE EICALLADA: Los hayedos del bossoue de ijaja. Publicaciones del Instituto de Etnografla y Folklore "Hoyos Sainz" Vol V. 1973, pága 243-256.

65.- B. MADARIAGA DE JAA CAMPA: Bosquejo histórico sobre el. de sarrollo del ganado bovino en la montaina. Él Lampo, 1981 ñ 84. Fágs. 47-50.

66.- P. MAINOZ: Diccionarto Geográfico- Batad1atico de kisuaina y sus poseasiones de U. tramar. Madrid, 1845. 16 Volúmener.

67.- $A$. MAESTRE.- Descrinción flstea y geolobgica de la Provincia de Santander. Junta General de bistedilstica. Madrid 1868. 120 págs.

68.- G. MARTINEZ DIEZ: Libro Becerro de las Behetrías. 3 Tomos León, 1981.

69.- J. MARTINEZ GONZALEZ: Monólogos y estampas de costumbres campurriano-montaíesas. Santander, 1969. 344 págs.

70.- A. MARTINEZ ROIZ: Pasado, presente y futuro de la razavacuna tudanca.

71.- T. MARTINEZ VARA: Estado de las fábricas, comercio, indus tria y agricul.tura en las montaías de jantander (siglo XVIII) Ed. Librerla Estudio. Santander,1979. 304 págs. 
72.- J. MATARUBIA RIOS: Urografía del Alto Campóo. Fontibre, 1958, ne 23. Pág. 9.

73.- A. DE MIGUEL PAIOMINO: pasado y presente de las razas va cunas santanderinas de montaña. Anales del Instituto de Estudios agropecuarios, Vol.III. Institución cuiltural de Cantabria. Santander 1977-1978. L'ágs, 9-65.

74.- P. MONSERRAT RECORDER, F. FILIAT: La ganader 1a extensiva y las culturas rurales montañesas. Anajes del Instituto de Estudios Agropecuarios, vol III. Institución Cultural. de Cantabria. Santander 1977-1978. 1'ágs. 84-120.

75.- J. NADAl: La población espaínola (\$i GJos XVI al XX). Lid. Arlel, Barcelona, 1973. 286 págu.

76.- J. NASARRE: La agricul tura en la cornisa cantábrica. E1 Campo, 1977, ne 64. Págs. 3-16.

77.- F. NUSSBAUM, F. GIGAX: la glaciacisn cuaternaria en la Cordillera Cantábrica. Estudios Geográficos no 50,1953 pága. 261-27u.

78.- J. OR'PEGA VAlCARCLil: La transformación de un espacio rural. lias Montañas de Burgos. Universidad de Valladolid, Departamento de Geografla, 1974. 531 págs.

79.- V. PAJACIO ATARD: El comercio de Casitilla y el puerto de Santander en el siglo XVIII. Consejp superior de Investi gaciones Cient1ficas, Madrid, 1960. 206 págs.

80:- V. PEREZ MOREDA: Las crlsis de mortalidad en la España Interior. Siglos XVI-XIX. Ed, Siglo XXI, Madrid, 1980 526 págs.

81.- M. DEJ, POZO IBANEZ: Notas para la pruenación del pastoreo en praderas de tipo atléntico. Madrid 1963. 50 págs.

82.- J.A. QUIJANO DE LA COLINA: Del campo montañés. Jantander 1950, 451 págs.

83.- J. RAMIREZ DEJ, POZO, Ma.J. AGUILAR: Consideractones sed1 mentologicas en las facies Puberck y Weald de la cubeta de Santander-Burgos. Estudios Geológicos, vol XXVIII, $n^{9}$ 2-3. 1972,págs. 173-193.

84.- REINOSA. THE MANUFACIURE OF ITPEEL, FORGING:S ANI CASTINGS : en The Motor Ship: This is Astilleros Españoles S.A., June 1974, A special Survey, Pags 73-75.

85.- J. REMON ERAiO: Panorama forrajero en Cantabria. El Campo, 1981, ne 84, págs. 25-34.

86.- V. RENERO: Formas dialectales y toponimicas en Cantabria. Altamira 1974, ne 1-3. Págs. 109.

87.- PRESIDENCIA DEJ, GOBIERNO: Reseña estad1stica de la provin cia de Santander. Madrid, 1965.

88.- D. RINGROSE: Los transportes y ell estancamiento económice de España(1750-1850) Éd. Tecnos, Madrid 1972. 222 págs. 
89.- J.Ma. RION, A. AIMEIA, J. GARRIDO: Contribución al conocimiento de la Geologla cantábrica. Un estudio de parte de las provincias de Burgos; Vizcaya y Santander. Boletin del Instituto Geológico y Minero. Tomo LVIII, págs 47-228. Madrid 1945.

90.- A. DE LOS RIOS Y RIOS: Memoria sobre las Antiguas y moder nas comunidades de pastos entre los valles de Campóo de Suso, Cabuérniga y otros de la provincia de Santander. San tander 1878, 80 págs.

91.- -..--., Sobre el origen del cultivo de la patata en Cam p8o. Fontibre 1958, ne 18 pág. 9

92.- R. RODRIGUEZ CANTON: los orlgenes de la industria moderna en Campóo. Fontibre 1459, n 33, pág 9 .

93.- A. RODRIGUEZ FERNANDEZ: Los Carabeos; historia, economia $y$ sociedad en un concejo rural de la Merindad de Campoo. Centro de Estudios Montafíses. Diputación Provincial. San tander, 1979. 449 págs,

94.- J. SAINZ DE OMEIIACA Nota previa bobro el modio godimente rio en la cuenca triásica cantábrica. Boletín de la Real Sociedad Española de Historia Natural. Tomo 72 ne 1-4. Madrid 1974. Págs 191-201.

95.- L. SAN MIGUEL: Notas para un estudio siociológico-jur1di. co de la "derrota". Boletín del Instituto de L'studios A turianos, $n^{2} 55,1965$. Págs. 3-28.

96.- C. SIli IO CORREA: El balneario de Corconte. Santander 1980, 130 págas.

97.- F. SIMON SEGURA: La desamortización esspañola de] siglo XIX. Madrid 1973. 328 págs,

98.- F. SUJU Y LNMBA: 1aseo toronimico por Cantabria. Bojetín de la Real Sociedad Geográfica. Madrid 1951. Tomo 87, pággs. 569-607.

99.- E. DE SUTO Y VANCEN: Caracter1sticas especiales de las en tidades locales y juntas vecinales en la Móntaña. Altamira 1952, ne 2-3 págs. 149 .

100.- M. DE TERAN: Santander, puerto de embarque para las harinas de Castilla. Estudios Geográficos 1947, no 29, págs 746-758.

101.- -....., Programa para el estudio del hábitat. Estudios Goegráficoss. 1947, no 27, págs. 418-426.

1U2. - F. TOMAS Y VAJIENTE: Recientes Investigaciones sobre la desamortización. Intento de síntesis. Moneda y Crédito, 1974, no 131. Págs. 95-161. 103.- 
104.- F. WAIS SAN MARTIN: Historia de los ferrocarrile:s espa-ñoles. Madrid, 1974. 728 págs. 
$-349-$

INDICES 
INDICE DE CUADROS

I. Precipitaciones mensuales medias en mms. y dias de lluvia, nieve y granizo por mes............ 31

II. Dtistribución de las precipotaciones anuales..... 33

III. Lluvia máxima en un día en cada mes ......... 37

IV. Freouencia de la nieve en Campó ........... 42

v. Temperaturas medias mensuales............. 43

VI. Temperaturas minimas medias y minimas absolutas.. 46

VII. Temperaturas máximas medias y máximas absolutas.. 49

VIII. La superficie forestal en Campoo............ 61

IX. Distribución del espacio agrario mediados del si glo XVIII.............................. 78

X. Rendimientos medios del cereal.Relacion simiente producto............................ 94

XI Composición del Rebaño en el valle de Capbo a fi

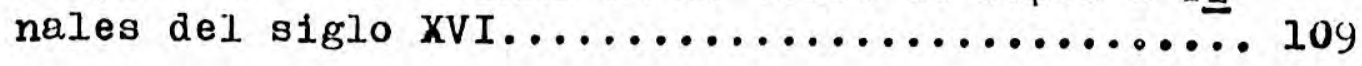

XII. La composición del rebaño en el Marquesedo de Ar güeso a finales del siglo XVIII............... 111

XIII. La importancia cuantitativa del ganado menor en el Marquesado de Argüeso................. 112

XIV. Tamaño medio de la explotación ganadera a media dos del siglo XVIII. Mayores hacendados......... 113

XV. El aprovechamiento de los pastos de los "puertos altos" de Campбo por el rebaño de las Asturias de

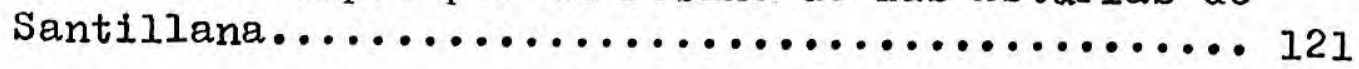

XVI. Estructura de la carretería campurriana a media-

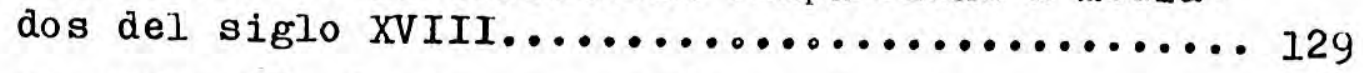

XVII La reducción de la población en Campóo en el si-

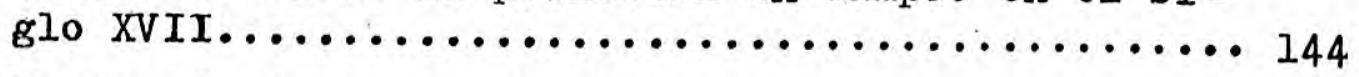

XVIII Evolución de la población de Campóo hasta mediados del siglo XIX........................ 146 
XIX. Estructura de la gran propiedad individual en Cam póo a mediados del siglo XVIII...............

XXX. Estructura soctal en Campóo a mediados del siglo

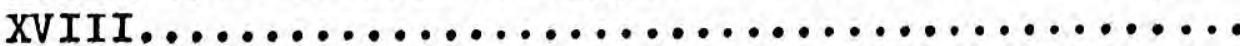

XXI. Superficie municipal desamortizada entre 1855-1881 169

XXII. La escasa entidad de la desamortización eclesiás-

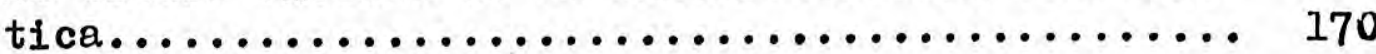

XXIII. Composición del rebaño de vacuno en Campóo en

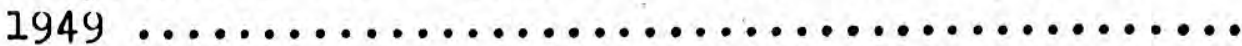

XXIV. Patrimonio familiar medio. Año $1949 \ldots \ldots \ldots \ldots \ldots \ldots . . . .181$

XXV. Número y superficie de las explotaciones en 1.962. 182

XXVI. La propiedad comunal:montes de Utilidad Pública.. 183

XXVII. El desequilibrio en la evolución demográfica de la comarca en ell último tercio del siglo XIX..... 202

XXVIII. Evolución reciente de la población comarcal...... 204 XXIX. Evolución demográfica de Campó. 1877-1970...... 211

XXX. Ia mortalidad infantil en Campóo............. 212

XXXI. Saldo migratorio decenal en Campóo 1887-1970.... 216

XXXII. La participacion relativa de los distintos grupos de edad en Campbo en la segunda mitad del siglo

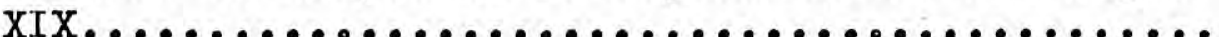

XXXIII. Las dimensiones de envejecimiento reciente en

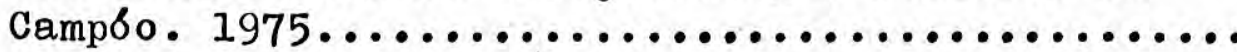

XXXIV. La estructura de la propiedad en Campbo..........

XXXV. Estructura de la propiedid en Campóo de Enmedio: propietarios de menos de 5 hectáreas............

XXXVI. La estructura de la gran propiedad comunal en Cam pbo: el ejemplo de Celada-Marlantes.............

XXXVII. Número de explotaciones según su superficie en

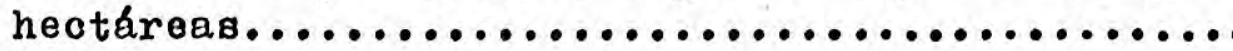

XXXVIII. Estructura de las explotaciones: edad del titular y grado de dedicacion.................... 246

XXXIX. Regimen de tenencia de la tierra (has. censadas). 248 XI. Tipos de explotaciones agrarias. Número según um bral en hectáreas en cada lugar. Campóo de yuso 1982 
XLI. Relación entre la superficie catastrada como la

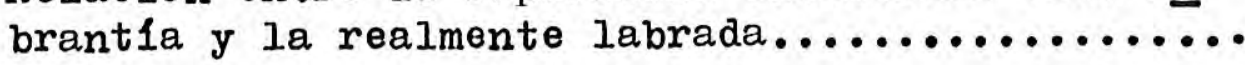

Pág.

258

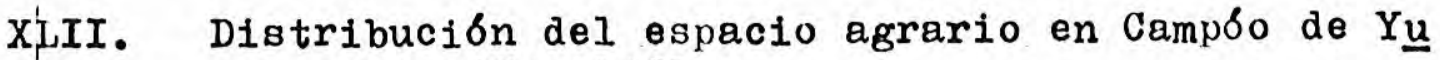

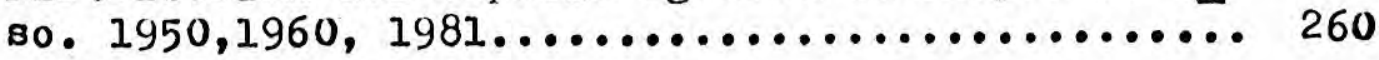

XLIII. Distribución municipal de la superficie labrada $y$ prados. 1979

XIIV. El aprovechamiento de los pastos de los "puertos altos" de la Hermandad de Campbo de Suso. Años 1975, 1976 y $1977 \ldots \ldots \ldots \ldots \ldots \ldots \ldots \ldots \ldots \ldots \ldots \ldots$

XLV. La composición del rebaño de vacuno en Campóo.

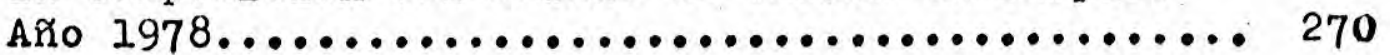

XIVI. Composición del rebaño vacuno de aptitud lechera en Campóo y en la provincia de Santander. 1978..... 272

XIVII. Estructura de la explotación lechera en Campoo de

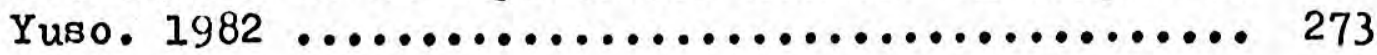

XIVIII. El ganado equino y menor en Campóo. Año 1981.... 276

XIIX. La motorización en Campbo. Poterncia por Ha...... 279

I. Superficie forestal y aprovechamientos en Campoo. 283

LI. Evolución del número de trabajadores empleados en

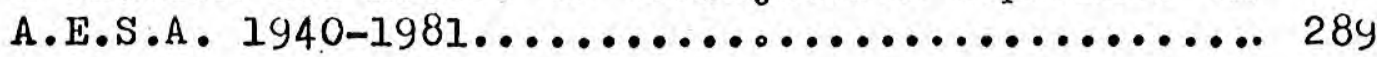

III. La oferta de servicios en Reinosa. 1975-1981.... 293

IIII. Población activa y poblacion dependiente en feino sa. 1960.

LIV. Evolución del número de viviendas de Reinosa desde 1900.

IV. Explotaciones de ganado vacuno de producción de

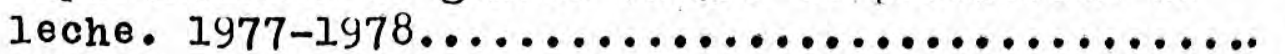
308

LVI. Estructura del poblamiento en Campoo según edifi-

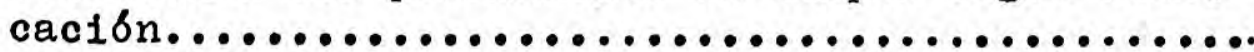


INDICE DE FIGURAS

Página

1.- Localización del espacio comarcal . 2

2.- Diviaion administrativa de la comarca........ 4

3.- Mapa topográfico de Campbo................ 14

4.- Distribución mensual de las precipitaciones

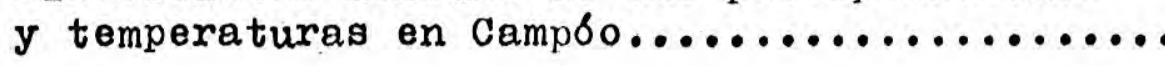

5.- La Irregularidad de las precipitaciones estivales en Reinosa. Variacion interanual on $1.0 s$ meвев de Julto y Agosto..................

6.- Precipitación anual en mms. y temperatura media anual en Reinosa 1940-1970.............

7.- Variación Interanual do las temperaturas medias mensuales en Enero, Abril, Julio y Octubre. Reinosa......................

8.- Localización, tamaño y estructura de los mon-

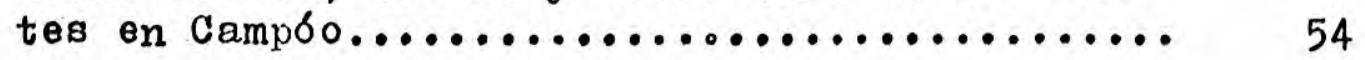

9.- Distribucion de las masas forestales......... 58

10.- Evolución de los diezmos de trigo en Campbo... 92

11.- Evolución de los diezmos de trigo, centeno y cebada en Villacantid (Campóo de Suso)........ y5

12.- Camino del Collado de Somahoz.............. 126

13.- La capacidad de molturación en Campó........ 135

14.- Evolución de la mortalidad-defunciones abso lutas- en la segunda mitad del siglo XVII en Reinosa............................

15.- Evolución de los nacimientos y defunciones en Reinosa, Espinil.la y Ormas................ 145

16.- Evolución de la población en Campóo.1860-1981. 200 
17.- Crecimiento intercensal en Campoo. 1877-1981...... 206

18. - Evolución, en cifras absolutas de los nacimientors $y$ defunctiones en Campoo................... 208

19.- Saldos migratorios decenales en Camp6o. 1877-1970. 215

20.- La población de Campó en 1860 y $1877 \ldots \ldots \ldots \ldots . .219$

21.- La población de Reinosa. 1950 y $1975 \ldots . . \ldots \ldots . .221$

22.- La población de Campbo -salvo Reinosa- en 1975 y

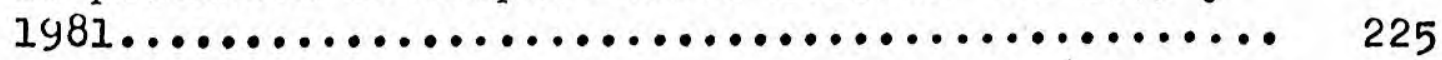

23. - La participación de Reinosa en la población total de la comarca. 1860-1981..................... 227

24.- La fragmentación del terrazgo de Monegro (Campó de Yuso) antes de la concentración parcelaria..... 249

25.- Estructura resultante de la concentración parcelaria en el lugar de Monegro (Campoo de Yuso)...... 252

26.- Distribución del espacio comarcal en 1979........ 259

27. - Distribución y tamaño del rebaño de vacuno en Cam-

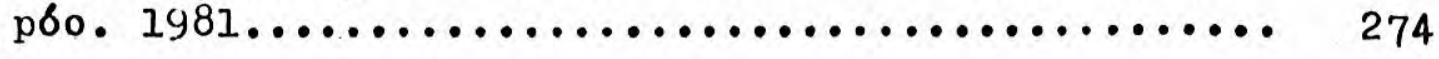

28.- Estructura del núcleo urbano de Reinosa......... 295

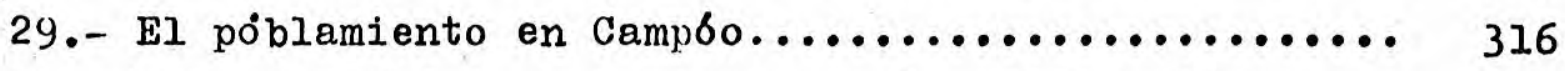

30. - Estructura del. poblamiento según edificación..... 318 
INDICE GENERAL

Página

INTRODUCCION

I PARTE. - LAS CONDICIONES ECOLJOGICAS DEI, VALLE DE CAMPOO

CAPITULO I\& LA ESTRUCTURA MORFOLOGICA

1.- Un sector de la cuenca tríásica cantábrica..

2.- El sinclinal de Abiada: una estructura compleja

3.- La Intensa tectónica de fractura del sector oriental: Campoo de Enmedio y Yuso ..........

4.- El modelado glaciar: un mero retoque ........

5.- Un relieve de montana caracteristico .......

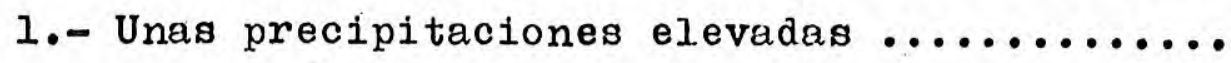

a) Importancia y significado de las precipi-

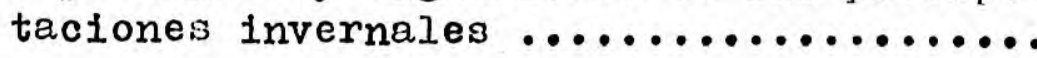

b/ El declive estival de las precipitaciones:

un fenómeno de enorme significado, en par te atenuado por las precipitaciones secun

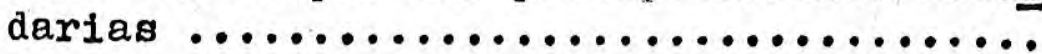

c/ La presencia y regularidad de la nieve en

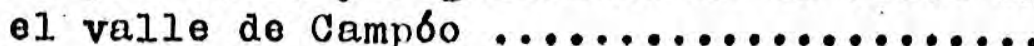

2. Un régimen térmico de montaña

a/ Un invierno frlo y de larga duración ....

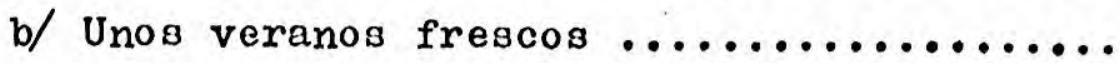

CAPITULO III. - UN PAISAJE VEGETAI, FROFUNUAMENTE TRANSFORMADO.

1.- El carácter residual de las masas foresto,les

2.- El predominio de las formaciones subseriales: un resultado de la práctica destrucción de la climax arborea 
Página

II PARTE. - LA ORGANIZACION TRADICIONAI DEL ESTACIO:

SOCIEDAD Y ECONOMIA DE UN VALLEE DE MON'TANA ......

CAPITULO IV. - UNA ECONOMIA DE SUBSISTENCIA $\ldots \ldots \ldots \ldots \ldots$

1.- La dualidad en el aprovechamiento del espa-

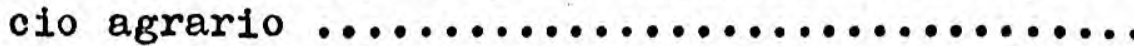

2.- La organización colectiva del terrazgo: una respuesta a las insuficiencia estructurales del valje de Campó

3.- El predominio de las tierras de pan llevar: un aprovechamiento del potencinl ecológico de cara al autoabastecimiento ...............

a/ Unas técnicas y sistemas de cultivo adap tados al medio, pero inadecuados ........ 87

b/ La debilidad e irregularidad de los rendimientos: una constante en la actividad agraria tradicional ................. 93

c/ El carácter subsidiario de los prados .... 97

4.- El aprovechamiento del monte: una actividad complementaria, sometida a numerosas res-

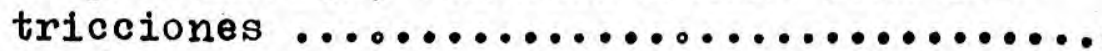

a/ El artesanado de la madera: una actividad tradicional destinada al intercambio .............................. 100

b/ los obstáculos a la explotación del monte

CAPITULO V.- UNA ECONOMIA AGRARIA BASADA EN LA EXIILUTACION GANADERA EXTEN'SIVA

1.- La complejidad de la composición y significado de la explotación ganadera .......... 107

2.- El predominto de sistemas extensivos para el aprovechamionto de los pastos ........... 1.14

a/ Las comunidades de pastos: el aprovecha miento extensivo de los pastos de monta ña

CAPITULO VI. - ILA BUSQUEDA DE UN COMYLEMENTO A INS BAJUS RENDIMIEN'TOS AGRICOIJAS

1.- El carácter tradicional del intercambio con el interior del pals 
Página

2. - El desarrollo de la carretería en el siglo XVIII: una actividad de marcado carácter estacional

a/ La construcción de la carretera de Reino sa: el ocaso del aislamiento tradicional del valle de Campoo

b/ E1 auge de la industria harinera en Reinosa: una consecuencia del tráfico de trigo con destino al puerto de Santander..

CAPITULO VII. - LOS OBSTACULOS Y CONDICIONANTES EN TAA ORGANIZACION TRADICIONAL DEL ESPACIO .......... 140

1.- Una población exigua en un regimen demográfico tradicional.

a/ Ell recurso a ja emigración: una constante en la evolución demográfioa de la comarca

2.- Una sociedad campesina de pequeños propietarios: el escaso significado de la gran propiedad tradicional

CAPITULO VIII.- LA ECONOMIA RURAL TRADICIONAL

1.- Una economía generadora de escasas rentas: la miseria de gran parte de la población campesina

2.- La entidad y significado de las rentas no agrarias

III PARTE.- CAMBIOS Y I ERMANINCIAS EN LA SOCIEDAD Y ECONOMIA TRADICIONALES

CAF ITULO IX. - LA PROGRESIVA TRANSFORMACION DE JAS EITTRUCTURAS AGRARIAS TRADICIONALES: UN , ROCL'SO LEN'LO Y PLAGADO DE DIFICULTADES

1.- Una estructura agraria heredada: el escaso impacto del proceso desamortizador ..........

a/ Los resultados del proceso desamortizador: una estructura de la propiedad inalterada.

b/ La pervivencia del carácter comunal en el aprovechamiento del monte.

2. - La construcción del ferrocarril Alar-Santan der: la crisis de los sistemas de transporte tradicionales. 
rágina.

3.- De una economía autárquica a una economía de intercambio: la progresiva consolidación de la opción ganadere ............... 174

CAPITULO X.- LAS IIFICUJTADES PRESENTES EN El, MUMI'NTO

DEL CAMBIO.

1.- El lastre del pasado: una estructura de la

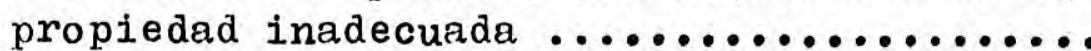

2.- La construcción del limbalse del Ebro: In dislocación de las estructuras tradiciona-

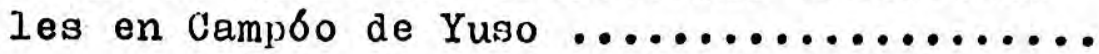

CAFITUL,O XI.- EL CONTRAYUNTO A J,OS :SI.SLEMAS DE VIDA TRA DICIONALES: INS IRIMLROS' INTENIUS INUU,TIRIAJIZA

DORE, DEJ, VAJLE DES CAMPOO ..............

1.- El carácter tradicional. de las primereis industrias de Campbo ...................... 190

2. - El nacimiento de 1a industria moderna: La Sociedad Española de Construcción Naval ....

193

CAPITULO XII.- IA IRREGULAR EVJIUCION DEMUGRAFICA DE

CAMPOO: UI LENTO CRECIMIENTY DE LA JOBLACIUN PU

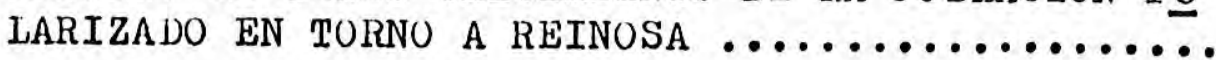

1.- Una población en irregular y débil, pero conatante crecimiento ............... 201

a/ La contención del bxodo rural y el estun camiento de la poblaclón en el últim. tếr clo del siglo XIX .................. 201

b/ De una población estancada a una pobla ciśn en crecimiento: un resultado de la expansion economica de lieinosa ......... 203

c/ Ia vuelta al estancamiento: un fenómeno reciente, de significado contradictorio... 205

2.- Una dinámica demográfica irregular presidida por el éxodo rural.

a/ La desigual trayectoria de la natalidad y mortalidad hacia la consecución de un bajo crecimiento vegetativo

b/ El éxodo rural: una constante en la evolu ción demográfica de la comarca ......... 213 
3.- Un tipo de envejeoimiento complefos dimensiones y contrastes espaciales............

4.- La despoblacion: una consecuencia de la concentración en el núcleo de Reinosa........

TRANSFORMACION

1.- Una estructura de la propiedad arcaica básico en la sociedad rural ..............

b/ La gran propiedad colectiva: el contra punto a la exigüedad y fragmentacion de la pequeña propiedad

2. - Los cambios en el tamaño y estructura de las explotaciones: un proceso complejo ......

3.- Un e jemplo de transformación planificada: Ia conoentración parcelaria en Campóo de Yuso

CAPITULO XIV . - LA PROGRESICA CONSOLIDACIUN DE LA OPCION GANADERA: UN YROCE.JO RECIENTE

1.- El carácter marginal del espacio cultiva do

2.- Hacia una simplificación en la estructura de la explotación ganadera.

264

a) El retroceso de la ganadería extensiva.... 265

b/ La ambivalencia del rebaño campurriano: ganado de leche y de aptitud mixta .......

c/ Bl carácter subsidiario del ganado equino y menor

3.- Ja mecanizacion: una constante en la nueva.

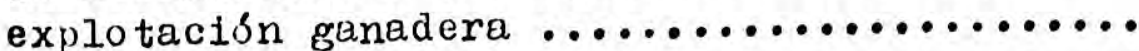

4. - Una actividad en retroceso: el aprovechamiento del monte

CAPITULO XV.- LA RECIENTE EXIPANSION DE REINUSA: UN PEQUEÑO NUCLEO INDUSTRIAL, CENTRO COMARCAL

1.- La preeminencia de la industria siderúrgica: una actividad con escaso efecto multiplicador 
2. Ia consolidación de Reinosa como centro

légina

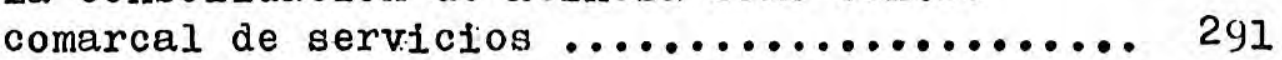

3.- La intensidad de las recientes transfor maciones en el núcleo urbano de Reinosa

CAPITULO XVI.- SIGNIFICADO DE LOS CAMBIOS RECIENTES EN LA ECONOMIA Y ORGANIZACION DEL ENPACIO .........

1.- El resultado de las recientes transforma ciones: un nuevo paisaje agrarto ......... 302

a/ El Impacto de Reinosa: el desarrollo de una agricultura a tiempo parcial ..... 303

b/ Ia explotación ganadera moderna: una inacabada especialización en la produccion de leche.....................

c/ Un paiaje agrario nuevo y totalmente subordinado a la explotación ganadera

2. - La escasa renovación del poblamiento tra dicional: un mero retoque a una estructura heredada.........................

a/ Un poblamiento concentrado, constituido por pequeñas unidades agrupadas en

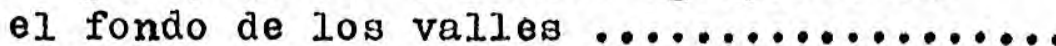

b/ un tipo de vivienda esencialmente funcional: la casa-bloque de piedra ....... 319

3.- Hacia la consecución de un nivel de vida más elevado........................

CONCLUSIONES

FUENTES $\times$ BIBLIOGRAFIA......................... 334

INDICES...................................... 349

-Indice de cuadros...................... 350

-Indice de figuras ...................... 353

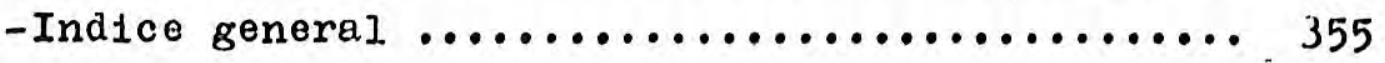

